

Bacillus cereus growth and biofilm formation: the impact of substratum, iron sources, and transcriptional regulator Sigma 54 


\section{Thesis committee}

\section{Promotor}

Prof. Dr Tjakko Abee

Personal chair at the Laboratory of Food Microbiology

Wageningen University \& Research

\section{Co-promotor}

Dr Masja N. Nierop Groot

Senior scientist, Fresh Food \& Chains

Wageningen University \& Research

\section{Other members}

Prof. Dr Remco Kort, VU Amsterdam

Prof. Dr Michiel Kleerebezem, Wageningen University \& Research

Dr Emilia Ghelardi, University of Pisa, Italy

Prof. Dr Ole A.L. Okstad, University of Oslo, Norway

This research was conducted under the auspices of the Graduate School VLAG (Advanced studies in Food Technology, Agrobiotechnology, Nutrition and Health Sciences) 


\title{
Bacillus cereus growth and biofilm formation: the impact of substratum, iron sources, and transcriptional regulator Sigma 54
}

\author{
Hasmik Hayrapetyan
}

\section{Thesis}

submitted in fulfilment of the requirements for the degree of doctor

at Wageningen University

by the authority of the Rector Magnificus,

Prof. Dr A.P.J. Mol,

in the presence of the

Thesis Committee appointed by the Academic Board

to be defended in public

on Tuesday 18 April 2017

at 4 p.m. in the Aula. 
Hasmik Hayrapetyan

Bacillus cereus growth and biofilm formation:

the impact of substratum, iron sources, and transcriptional regulator Sigma 54, 182 pages.

PhD thesis, Wageningen University, Wageningen, the Netherlands (2017)

With references, with summary in English

ISBN: 978-94-6343-119-4

DOI: $10.18174 / 408256$ 


\section{Table of contents}

$\begin{array}{ll}\text { Abstract } & 7\end{array}$

Chapter 1 General introduction and thesis outline 9

Chapter 2 Comparative analysis of biofilm formation by Bacillus 37 cereus reference strains and undomesticated food isolates and the effect of free iron

Chapter 3 Comparative genomics of iron-transporting systems in 57 Bacillus cereus strains and impact of iron sources on growth and biofilm formation

Chapter 4 Sporulation dynamics and spore heat resistance in wet and 85 dry biofilms of Bacillus cereus

Chapter 5 Bacillus cereus ATCC 14579 RpoN (Sigma 54) is a pleiotropic 103 regulator of growth, carbohydrate metabolism, motility, biofilm formation and toxin production

Chapter 6 General discussion

Summary $\quad 175$

Acknowledgements $\quad 177$

$\begin{array}{ll}\text { About the author } & 179\end{array}$

$\begin{array}{ll}\text { List of publications } & 180\end{array}$

Overview of completed training activities 181 



\begin{abstract}
Biofilms are surface-associated communities of microbial cells embedded in a matrix of extracellular polymers. It is generally accepted that the biofilm growth mode represents the most common lifestyle of microorganisms. Next to beneficial biofilms used in biotechnology applications, undesired biofilms can be formed by spoilage and pathogenic microorganisms in food production environments. Bacillus cereus is a foodborne human pathogen able to cause two types of food poisoning, emetic and diarrheal. B. cereus can persist in factory environments in the form of biofilms, which can become a source of food contamination. This thesis adds to the knowledge about (a)biotic factors and conditions that affect $B$. cereus biofilm formation, including the effect of type of substratum such as polystyrene and stainless steel, with the latter supporting the highest biofilm formation for all tested strains including two reference strains and 20 food isolates. The ability of $B$. cereus to use a variety of iron sources was subsequently studied in these 22 strains and linked to the genes encoding iron transport systems present in the respective genomes, revealing significant diversity in the capacity to use complex and non-complex iron sources for growth and biofilm formation. For spore forming Bacilli, biofilm formation and sporulation are two intertwined cellular processes and studies in wet and dry (airexposed) biofilms revealed differences in sporulation rate and efficacy, with biofilmderived spores showing higher heat resistance than their planktonic counterparts. Additionally, comparative phenotype and transcriptome analysis of $B$. cereus wild type and a Sigma 54 deletion mutant provided insight into the pleiotropic role of this transcriptional regulator in $B$. cereus biofilm formation and physiology in general. Taken together, this knowledge improves our understanding of the biofilm lifecycle of this notorious food-borne human pathogen and provides clues which can help to reduce the domestication of this microorganism in production environments.
\end{abstract}



General introduction and thesis outline 



\section{Microbial biofilms}

Biofilms are surface-associated communities of microbial cells embedded in a matrix of extracellular polymers. The biofilm lifestyle of bacteria predominates the planktonic growth mode in virtually all environments, including nature, industrial environments or human host (Geesey et al. 1978, Costerton et al. 1995, Davey and O'Toole 2000). Once formed, biofilms are hard to eradicate and viable biofilm cells are protected from antimicrobials and disinfectants due to the protective effect of the biofilm matrix (Simões et al. 2006). Additionally, resistance to antimicrobials may also result from the generation of variants with reduced growth rate within the biofilm resulting in increased general stress resistance (Lewis 2001, Mah and O'Toole 2001). In the shelter of a biofilm, microbial cells can persist in different environments including the human host and food processing environments and may lead to chronic human infections and cause contamination of food products, respectively.

The first studies about biofilms are dating back to 1940s (Zobell 1943), and although Antonie van Leeuwenhoek described microbes attached to a tooth surface already at the end of the $17^{\text {th }}$ century, the term "biofilm" was initiated in the scientific literature since 1980s (Costerton et al. 1978, Costerton et al. 1987). Since then, the scientific community gained significant insight in the mechanisms underlying a biofilm lifestyle of microorganisms. Despite the improved understanding of how biofilms are formed, its contribution to human infections and industrial losses are still common issues society has to solve (Fux et al. 2005a, Brady et al. 2011, Bridier et al. 2015).

In food production environments, biofilms can be formed on virtually all surfaces in contact with food, such as pasteurizers, filling machines, conveyer belts, storage tanks and even on cleaning and handling tools like plastic gloves and floor mops (Christison et al. 2007, Majed et al. 2016). Biofilms are a possible cause of recontamination in food production and should be considered in development of hazard analysis and critical control point plans (HACCP) (Sharma and Anand 2002, Shi and Zhu 2009). It is generally assumed that (re)contamination originating from biofilms is a major determinant affecting food quality and safety (Faille et al. 2014). Besides the recontamination risk, biofilms are undesired in processing environments since their presence may also cause corrosion and equipment inefficiencies (Kumar and Anand 1998).

Microbial biofilms can be formed in a wide range of conditions varying from nutrient-poor and-rich environments to static and in dynamic flow conditions. Depending on the conditions encountered and physiology of the microorganisms involved, different types of biofilms can be formed and a range of structures and 
morphologies can be encountered (Abee et al. 2011) (Fig. 1). Bacterial biofilm types include air liquid interface biofilms (Fig. 1a) which are formed on surfaces partly submerged in a static liquid culture. Microorganisms forming this type of biofilms include motile species such as Bacillus cereus (Wijman et al. 2007) and Salmonella enterica (Scher et al. 2005). Colony biofilms on agar plates and (floating) pellicle biofilms on liquid surfaces are two other types of static biofilms, both frequently used in B. subtilis biofilm research (Fig. 1c and d) (Branda et al. 2001, McLoon et al. 2011).

Besides air-liquid biofilms, submerged type of biofilms can be formed on the bottom of a standing culture, such as formed by Lactobacillus plantarum (Fig. 1b) or B. subtilis (Fig. 1e). Submerged biofilms can also be formed under constant liquid flow (Fig. 1f) in flow cells (Houry et al. 2010) or in other appliances providing continuous flow (Örnek et al. 2002). Dynamic flow conditions may evoke organised mushroomlike community structures for some species, as shown for Pseudomonas aeruginosa (Crusz et al. 2012)(Fig. 1f).

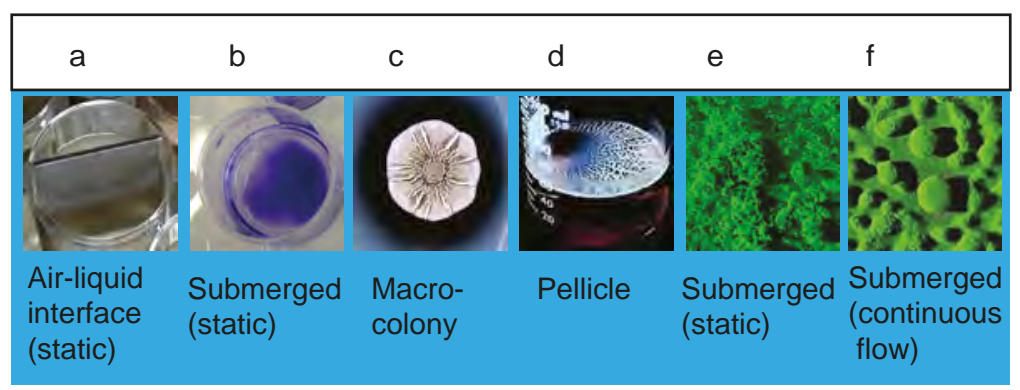

Figure 1. Different types of biofilms formed in laboratory conditions. a) Bacillus cereus air-liquid interface biofilm formed on stainless steel, b) Lactobacillus plantarum static biofilm on the bottom of a polystyrene 12-well plate stained with crystal violet (picture provided by M.D. Fernandez Ramirez), c) Bacillus subtilis colony on the surface of agar and (d) a pellicle in a standing culture (Branda et al. 2001), e) Bacillus subtilis submerged static biofilm formed in a 96-wells plate (Bridier et al. 2013), f) Pseudomonas aeruginosa mushroom-like structures formed in a flow-cell (Crusz et al. 2012). Figures reproduced with permission. 


\section{Bacillus cereus: a cause of spoilage and foodborne illness}

B. cereus is a food spoilage and pathogenic sporeforming species. It belongs to the Bacillus cereus group (Bacillus cereus sensu lato), which includes seven closely related but diverse species, namely B. cereus (sensu stricto), Bacillus mycoides, Bacillus pseudomycoides, Bacillus weihenstephanensis, Bacillus thuringiensis, Bacillus anthracis and Bacillus cytotoxicus (Guinebretière et al. 2008, Ceuppens et al. 2013). These species can be distinguished based on their morphology, physiology and pathogenic potential, such as presence of toxin genes which are often located on plasmids, although $B$. cereus, $B$. anthracis and $B$. thuringiensis are genetically closely related (Helgason et al. 2000, Rasko et al. 2004).

The spores of B. cereus are commonly present in soil (Vilain et al. 2006) and contaminate raw materials used for food products including raw milk, rice, pasta, spices, starch and vegetables (Shinagawa 1990, Christiansson et al. 1999, Guinebretiere et al. 2003).

B. cereus can also reside in the environment of a host. The gut of invertebrates, such as soil dwelling insects or mosquito larvae, is supposedly the natural niche of this bacterium (Jensen et al. 2003). In addition to the invertebrate gut, $B$. cereus has been associated with plant roots (Lecomte et al. 2011, Xu et al. 2014), which is presumably the natural habitat of emetic B. cereus (Ehling-Schulz et al. 2015).

B. cereus is frequently associated with food and foodborne disease (Andersson et al. 1995, Ehling-Schulz et al. 2004, Schoeni and Lee Wong 2005) causing diarrheal and emetic types of illness (Schoeni and Lee Wong 2005, Stenfors Arnesen et al. 2008). The diarrheal type is caused by enterotoxins produced in the small intestine (Senesi and Ghelardi 2010), while the emetic type of poisoning occurs from ingestion of food already containing the emetic toxin cereulide (Stenfors Arnesen et al. 2008). Starch containing food such as pasta and fried rice dishes prepared in advance and stored at ambient temperatures are mainly associated with the emetic syndrome (Ehling-Schulz et al. 2004, Schoeni and Lee Wong 2005, Bennett et al. 2013). The symptoms of gastroenteritis or intoxication caused by B. cereus are generally mild and therefore not easily recognised or reported, resulting in underestimation of the number of cases, especially if it concerns sporadic illnesses rather than outbreaks (Vaillant et al. 2005). A few severe food poisoning cases have been reported leading to liver failure and death (Dierick et al. 2005). In 2013, foodborne outbreaks caused by toxins produced by different Bacillus species in the EU constituted the $5.4 \%$ of all reported outbreaks with a known cause (EFSA et al. 2015). A large number of these outbreaks were reported in France, where $B$. cereus is currently the second most frequently found causative agent of confirmed and suspected food borne outbreaks after Staphylococcus aureus (Glasset et al. 2016). The increase in reported B. cereus- 
induced outbreaks in France in recent years is partly due to the input of national health and food safety authorities in the epidemiological and microbiological investigations of outbreaks leading to improved detection of suspected foodstuff (Glasset et al. 2016). Notably, the prevalence of food products containing detectable levels of $B$. cereus ( $>10^{2} \mathrm{CFU} / \mathrm{g}$ ) on the Dutch market was also $5.4 \%$ in the years 2007 to 2010 (Biesta-Peters et al. 2016). Interestingly, the number of foodborne outbreaks in the EU due to Salmonella has decreased markedly by $38 \%$ in the years from 2008 to 2013 due to measures taken by member states, while the reported number of outbreaks attributed to bacterial toxins produced by Bacillus, Clostridium and Staphylococcus species, has increased by about 59 \% (EFSA et al. 2015). This indicated that, control of contamination with toxin producing human pathogens including $B$. cereus may become even more important in the coming years if this trend continues, especially since this pathogen is known to form biofilms that may act as a contamination source in food production environments.

\section{Bacillus cereus biofilms}

\section{Biofilms in food processing environments}

$B$. cereus is able to form biofilms on different surface materials and in different environmental conditions (Wijman et al. 2007, Karunakaran and Biggs 2011). It is a common contaminant of dairy products and its presence has been associated with persistent biofilms in the production environment (Te Giffel et al. 1996, Flint et al. 1997, Lin et al. 1998, Svensson et al. 2000, Faille et al. 2001). In a commercial dairy plant, biofilm consortia were dominated by the Bacillus genus (37\%), of which $12 \%$ was B. cereus (Sharma and Anand 2002). Bacillus strains have been isolated from various other environments including paperboard production (Kolari et al. 2001), and beer production plants (Storgårds et al. 2006) or in hospitals (Kuroki et al. 2009). Persistence of pathogenic bacteria in industrial environments poses a risk to food safety and can cause economic loss.

The best strategy for the industry to fight against $B$. cereus biofilms is to prevent its formation either by reduction of the spore load in raw materials or by early detection and eradication of the newly developing biofilms (Andersson et al. 1995, Simões et al. 2010). Hygienic design of the equipment and effective cleaning procedures with proper frequency will help to reduce the risk of biofilm formation. However, for elimination of established biofilms, routine cleaning procedures are not always effective (Andersson et al. 1995, Sharma and Anand 2002, Storgårds et al. 2006, Salustiano et al. 2009, Simões et al. 2010). In this case, more effective cleaning 
and disinfection procedures have to be considered along with improved equipment design to prevent biofilm formation. Modification of contact surfaces preventing biofilm formation is another strategy to prevent their establishment (Carlson et al. 2008, Agarwala et al. 2014). The number of publications on B. cereus biofilms grew exponentially over the last 20 years (Majed et al. 2016) indicating an increased interest and the need for knowledge in this area.

\section{A model system for biofilm formation}

Several systems are available for analysis of biofilm formation capacity under laboratory conditions, including static or continuous flow, submerged or air-liquid or air-agar interface biofilms (Branda et al. 2005). A static air-liquid interface biofilm model was previously developed to study B. cereus biofilms (Wijman et al. 2007). A modified version of this model was also applied for Salmonella biofilms (Castelijn et al. 2013). The latter system is composed of a 12-well plate with inserted coupons (Fig. 1a). Wells are half-filled with medium, and coupons are positioned vertically mimicking the partly filled tanks or sights of the processing lines where residual liquid stagnation can occur. By selection of different types of coupons it is possible to study biofilm formation on different materials such as stainless steel, polystyrene or glass. Therefore this model system was selected in the current study to characterise $B$. cereus biofilm formation.

\section{Domesticated strains and food isolates}

Reference strains, also called lab strains or model strains, that have been used in research laboratories for several years may accumulate genetic changes causing a loss of certain phenotypes which are present in their non-domesticated counterparts (Fux et al. 2005b). As a result of domestication for more than a century, the model strain $B$. subtilis 168 lost the ability to form robust and architecturally complex biofilms, which could be restored by reintroduction of functional copies of genes from undomesticated strains that were mutated or lost in the strain 168 (Stanley and Lazazzera 2005, McLoon et al. 2011).

The reference strains of $B$. cereus commonly used in research are $B$. cereus ATCC 14579 and ATCC 10987. ATCC 14579 has been isolated from air in a cow-shed in 1887 (Frankland and Frankland 1887), and ATCC 10987 was isolated from spoiled cheddar cheese in Canada in 1930 (Herron 1930). Both strains have been cultivated in laboratory conditions for an extended period of time and to obtain a more comprehensive characterisation of the species, undomesticated strains are often being studied along with reference strains. Strain diversity is an important factor 
especially since $B$. cereus includes ecologically diverse representatives (Guinebretière et al. 2008). Wijman et al. (2007) studied 56 different $B$. cereus strains of different origin and showed large diversity in their biofilm forming capacities. A large diversity between strains was also demonstrated when the two reference strains were compared with 15 and 20 undomesticated B. cereus food isolates from 4 out of 7 different phylogenetic groups classified according to (Guinebretière et al. 2008), concerning their germination capacity and carbohydrate utilisation, respectively (Warda et al. 2016a, Warda et al. 2016b).

\section{Influence of environmental factors: iron sources and biofilm formation}

Biofilm formation is known to be affected by a large number of environmental factors including nutrient composition, anaerobiosis, high osmolarity, temperature, levels of inorganic molecules, mechanical interactions and surface material (Gotz 2002, Stanley et al. 2003, Karatan and Watnick 2009). Interestingly, the same environmental signal may trigger different responses depending on the species. For instance, nutrient limitation promotes biofilm formation by Salmonella enterica (Gerstel and Römling 2001) and B. subtilis (Stanley et al. 2003), but inhibits it for Vibrio cholera (Yildiz et al. 2004). For B. cereus more strains tend to form biofilm in nutrient poor or sporulation inducing medium compared to a rich medium (Wijman et al. 2007, Hsueh et al. 2008). The environmental conditions which promote or inhibit biofilm formation can be indicative of the natural habitat of the strain in which it should be able to prosper and persist (Stanley and Lazazzera 2004, Karatan and Watnick 2009).

One of the environmental factors reported to affect biofilm formation is iron. For example, high iron availability positively affects biofilm formation by $P$. aeruginosa (Banin et al. 2005, Glick et al. 2010) and Vibrio cholera (Mey et al. 2005) but other species, such as Staphylococcus epidermidis (Deighton and Borland 1993) and Escherichia coli (Brombacher et al. 2006) form more biofilm in iron scarce conditions. Bacteria encounter a variety of nutrients in the food processing environment. Depending on the product being produced and its origin (plant or animal), the iron sources available may vary. In order to thrive in these environments, the microorganisms depend on highly efficient systems to utilise those sources.

Iron sources common in the mammal host and animal based products are heme, haemoglobin, transferrin and ferritin (Wandersman and Delepelaire 2004). Ferritin is the iron storage and transport molecule present not only in mammals but also in almost all living organisms such as insects, plants and bacteria (You and Wang 2005). Lactoferrin is the iron binding molecule in milk and human lymph and 
mucosal secretions (Wandersman and Delepelaire 2004). In the mammal hosts almost all the iron is in a bound form in order to prevent its toxic effects and to render it unavailable for invading microorganisms (Wandersman and Delepelaire 2004, Miethke and Marahiel 2007).

The ability to use complex iron sources correlates with the pathogenic potential of the microorganism (Cendrowski et al. 2004, Abergel et al. 2006). Pathogens developed two main mechanisms to sequester iron from sources present in the host. One of the mechanisms is the production of low molecular weight compounds with high affinity for ferric iron, called siderophores. Siderophores are secreted into the environment and imported by $\mathrm{ABC}$ transporters into the cell upon iron binding (Ratledge and Dover 2000, Wilson et al. 2006, Hotta et al. 2010). B. cereus produces two types of siderophores: petrobactin and bacillibactin (Wilson et al. 2006, Hotta et al. 2010).

The second mechanism of iron transport involves production of specific surface located receptors that directly associate with host iron sources (Brown and Holden 2002, Wandersman and Delepelaire 2004). This type of a surface protein, named IlsA, was recently characterised in B. cereus (Daou et al. 2009, as a part of an Isd system previously described in B. anthracis (Gat et al. 2008) and $S$. aureus (Mazmanian et al. 2003). The IlsA system assists in iron acquisition from heme, haemoglobin and indirectly also from ferritin (Daou et al. 2009, Segond et al. 2014).

Biofilm formation capacity is a prerequisite for the virulence potential for many microorganisms (Rupp et al. 1999, Moreau-Marquis et al. 2009, Burbank et al. 2015). Iron transport is also associated with virulence (Harvie and Ellar 2005, Abergel et al. 2006, Porcheron and Dozois 2015) in some species. In B. cereus, a ferric dicitrate uptake system is required for its virulence in lepidopteran infection model (Harvie and Ellar 2005). In B. anthracis the petrobactin siderophore is necessary for its virulence in a mouse model and growth in macrophages (Cendrowski et al. 2004, Abergel et al. 2006). Knowledge about the capabilities of pathogenic microorganisms to transport and utilise different iron sources will help to predict their growth and virulence potential in different environments including the human host. 


\section{Bacillus cereus spores and the biofilm lifecycle}

\section{Spores as food contaminants}

B. cereus is able to form highly resistant spores. Bacterial spores are notorious because of their high survivability and resistance to treatments generally lethal for vegetative cells, such as heat, desiccation, lysozyme, radiation, extreme $\mathrm{pHs}$, high pressure and many chemicals (Nicholson et al. 2000, Atrih and Foster 2002, Setlow 2006, Setlow 2007). Due to their resistance, the spores are difficult to eliminate from food and food production environments. $B$. cereus spores can survive mild food processing treatments and may contaminate and grow out in processed products, especially chilled products with extended shelf-life, also known as REPFEDs (Refrigerated Processed Foods of Extended Durability) (Choma et al. 2000, Ehling-Schulz et al. 2004). An example of a heat-treated product that is prone to growth of $B$. cereus is pasteurised milk. Psychrotolerant $B$. cereus strains that survive pasteurisation can grow even at refrigeration temperatures below $7^{\circ} \mathrm{C}$ and cause spoilage known as "sweet curdling" or "bitty cream" (Meer et al. 1991, Te Giffel et al. 1997, De Jonghe et al. 2010). Spoilage caused by B. cereus can reduce the shelf-life of the products and cause economic loss.

Contamination of food products with $B$. cereus spores may result directly from their presence in food ingredients. However, the food production environment can also serve as a source of such contamination. Spores or cells of B. cereus may enter food processing lines with the raw materials (Carlin 2011) and attach to surfaces of tanks and pipelines of processing equipment (Lindsay et al. 2006). Attached spores may germinate, grow out and eventually lead to the development of mature biofilms when favourable conditions are encountered (Wijman et al. 2007). Within established biofilms, B. cereus is able to form spores (Lindsay et al. 2006, Wijman et al. 2007, Faille et al. 2014), which forms an additional route of contamination via release of spores from the biofilm and thus close the vicious cycle, as depicted in Fig. 2. Recently, El-Khoury et al. (El-Khoury et al. 2016) analysed sporulation efficacy in $B$. thuringiensis air liquid interface biofilms and presented a model describing spore formation in the biofilm, the impact of mechanical washing and cleaning causing only partial removal of biofilm spores, and the role of residual spores in starting a new biofilm after germination and outgrowth. Since the environment is known to affect the onset and efficiency of sporulation (Driks 2002, Piggot and Hilbert 2004, Abbas et al. 2014), the conditions that biofilm cells encounter in the production environment, such as fluctuations in nutrient availability or air exposure, may affect the amount of spores formed, which in turn will affect the risk related to those biofilms. 


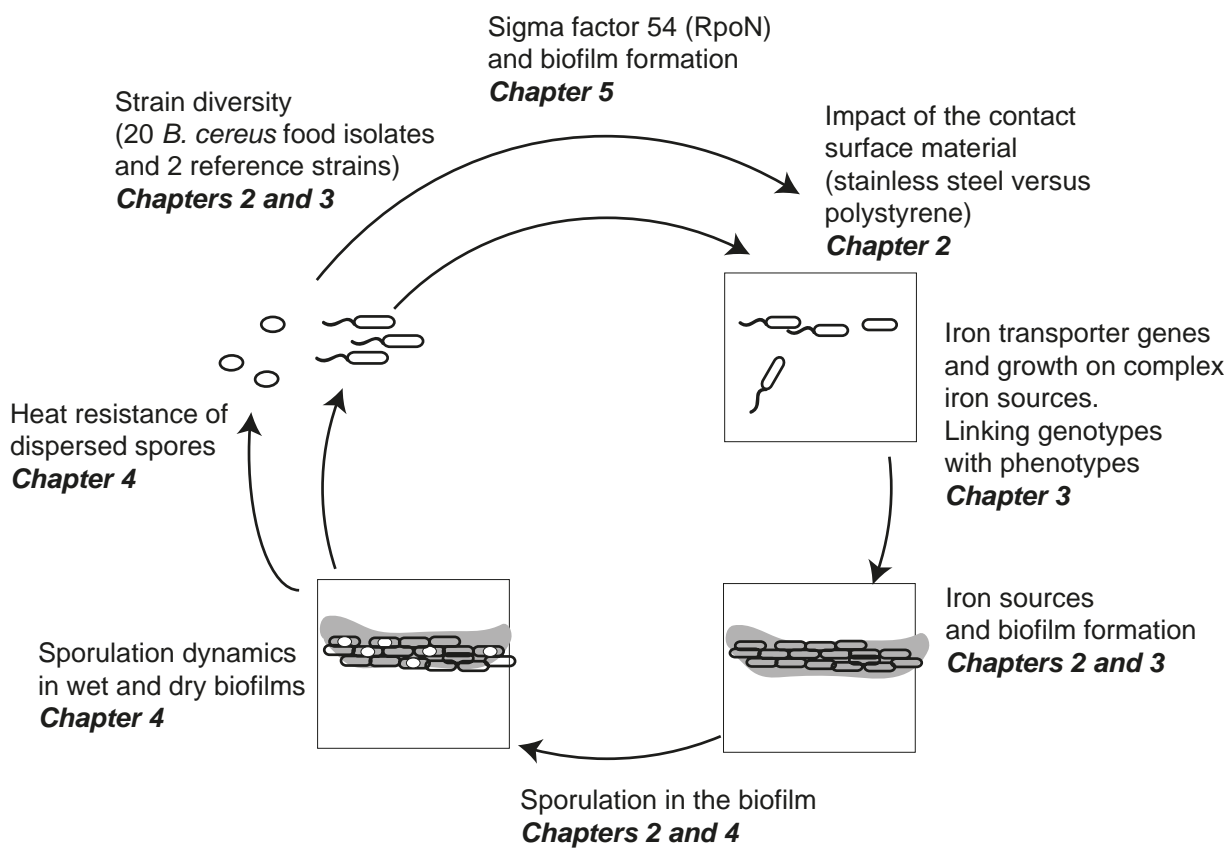

Figure 2. B. cereus biofilm lifecycle and research focus of this thesis.

\section{Factors affecting spore properties}

It is known that in addition to intrinsic strain characteristics, sporulation conditions also affect the properties of formed spores, including their wet heat resistance (Melly et al. 2002, Nguyen Thi Minh et al. 2011, Guizelini et al. 2012, Abbas et al. 2014). Sporulation temperature is a well-studied factor influencing spore heat resistance, with increasing temperatures generally resulting in increased heat resistance (Palop et al. 1999). In B. subtilis, a higher spore heat resistance correlated with a higher degree of muramic acid cross-linking in the cortex and lower core water content (Melly et al. 2002). Lower core water often associates with higher heat resistance and high DPA (dipicolinic acid) content (Setlow 2006). Metal availability in the medium and resulting amount and types of metals accumulated in the spore also affect spore heat resistance. Cations reported to increase heat resistance are calcium, potassium, magnesium and manganese (Cazemier et al. 2001, Oomes and Brul 2004), albeit that effects are species-specific. For example, spore heat resistance of $B$. megaterium increased with manganese content in the spore core (Ghosh et al. 2011) but not of $B$. subtilis spores (Granger et al. 2011). Spore heat resistance seems to be more affected by a combined effect of multiple metals compared to single metals (Cazemier et al. 2001, Oomes and Brul 2004). Spores of B. subtilis formed in the presence of calcium, magnesium, manganese, iron, and potassium were more heat resistant compared 
to spores formed on only manganese containing medium (Oomes and Brul 2004). This effect could be explained by induction of genes encoding for SASPs (Small Acid Soluble Proteins) at an earlier moment during sporulation in the presence of the metal mixture (Oomes and Brul 2004).

In the colony type biofilms of $B$. subtilis, spores are formed preferentially in the elevated wrinkled structures which are formed prior to the onset of sporulation. Perturbations in the regulation of these processes resulting in a faster sporulation caused a decrease in spore heat resistance (Veening et al. 2006). Maturation of released spores in the presence of divalent cations (in particular $\mathrm{Ca}^{2+)}$ is also important for acquiring full heat resistance (Sanchez-Salas et al. 2011), possibly linked to protein crosslinking in the spore outer layer (Abhyankar et al. 2015). The sporulation efficiency of $B$. cereus was reduced in the absence of oxygen, however, the resulting spores were more heat resistant (Abbas et al. 2014).

The biofilm growth mode provides an environment for sporulation which is distinct from free floating planktonic growth conditions in terms of cell local densities, oxygen and nutrient availabilities. This may have an influence on the properties of spores formed within the biofilm. In general, spores formed on an agar surface are more heat resistant compared to spores formed in planktonic state (Veening et al. 2006). Spores obtained from the biofilms of emetic $B$. cereus strains formed on polystyrene surfaces were more heat resistant, larger in size and slower in germination compared to spores formed in planktonic cultures (van der Voort and Abee 2013). Taken together, the heat resistance of spores derived from biofilms can be affected by different environments encountered in a food processing line, including different food contact materials and exposure to wet and dry conditions. Heat resistance of such biofilm spores is relevant since it affects food safety or spoilage risks.

\section{Regulation of biofilm formation}

Biofilm formation and its regulation involve complex multistep processes which have been widely studied in selected model organisms such as the spore-forming species B. subtilis (Vlamakis et al. 2013, Majed et al. 2016). Although some overlap has been noticed, biofilm formation in $B$. cereus involves additional unique factors. Similar to $B$. subtilis, the SinR/SinI biofilm repressor and anti-repressor pair (Pflughoeft et al. 2011, Fagerlund et al. 2014) and the master regulator for sporulation, Spo0A, play a role in B. cereus biofilm formation (Hamon and Lazazzera 2001, Gao et al. 2015). Additional regulators which affect $B$. cereus biofilm formation indirectly or via a yet unknown pathway have been reported (reviewed in (Majed et al. 2016)). 
These include the biofilm repressor AbrB (Fagerlund et al. 2014), SigH, virulence regulator PlcR (Hsueh et al. 2006), necrotrophic regulator NprR (Dubois et al. 2012) and CodY (Hsueh et al. 2008, Lindbäck et al. 2012). CodY is a transcriptional regulator which senses the nutrient status of the cell and mediates stationaryphase adaptations (Hsueh et al. 2008, Frenzel et al. 2012). It activates PlcR and production of virulence factors in stationary phase (Frenzel et al. 2012, Lindbäck et al. 2012). PlcR activates the necrotrophic regulator $n p r R$ at the onset of stationary phase (Dubois et al. 2013), which in turn promotes production of a biosurfactant lipopeptide kurstakin (Gelis-Jeanvoine et al. 2016), shown to promote B. cereus biofilm formation (Dubois et al. 2012). In addition to transcription factor-based biofilm control, the signaling molecule cyclic-di-GMP has been shown to positively affect $B$. cereus biofilm formation (Fagerlund et al. 2016).

The transcriptional regulator Sigma 54 (RpoN) is another regulatory protein which is not a part of the so far described biofilm regulatory pathways, however it is reported to affect biofilm formation in a range of bacterial species (Thompson et al. 2003, Wolfe et al. 2004, Iyer and Hancock 2012, Hao et al. 2013, Francke et al. 2011), although its impact on $B$. cereus growth and biofilm formation has not been addressed. Therefore, the impact of Sigma 54 on cellular processes in B. cereus was studied in this thesis.

\section{Sigma factor 54 transcription regulation}

Bacterial gene expression requires the presence of sigma factors (Helmann and Chamberlin 1988), which are transcriptional regulators that bind to the RNA polymerase (RNAP) core enzyme and direct it to specific promoter sequences to initiate the transcription. Bacteria possess several sigma factors which can be classified in two main families, sigma 70-like which includes all the sigma factors with similar structure and function, and sigma 54, which consists of a single member, the Sigma 54 (Merrick 1993), also known as Sigma L in B. subtilis or RpoN (from the gene name). During the rapid growth phase in nutrient rich environments, the main housekeeping sigma factor (Sigma A) is in charge of general gene regulation, while after this phase the role of other (alternative) sigma factors becomes more important for adaptation to stressful conditions (Jishage and Ishihama 1995, Jishage et al. 1996, Hecker and Völker 2001).

Sigma 54 is an alternative sigma factor, which has a unique structure and mechanism of transcription regulation. Sigma 54 was first described in Salmonella Typhimurium as a regulator of glutamine synthetase expression (Garcia et al. 1977). Nowadays, more is known about the mechanism of action of this sigma factor (Cannon et al. 1993, Buck et al. 2000, Bose et al. 2008, Wigneshweraraj et al. 2008), which is 
schematically represented in Fig. 3. Unlike the other sigma factors that recognise the typical $-35 /-10$ location sites of the promoter, Sigma 54 binds to a $-24 /-12$ conserved motif and forms a stable complex which is unable to spontaneously melt DNA and start transcription. For functioning it requires specific activator molecules called Enhancer Binding Proteins (EBPs), which bind to an upstream DNA region (Buck et al. 2000) and catalyse the transcription start by using the energy from ATP and bending the DNA (Zhang et al. 2002).

\section{Sigma factor 54 function}

The presence and the role of Sigma 54 has been studied in a range of microorganisms. The presence of a Sigma 54-encoding gene and the number of its EBPs generally correlates with the genome size of the microorganism (Francke et al. 2011). Interestingly, Sigma 54 is present in all diderm (Gr-) bacteria which have an outer membrane consisting of lipopolysaccharides (LPS). It is absent in most of endosymbionts or facultative intracellular species which also have a small genome and less versatile habitats. In monoderm (gram positive) bacteria it is present in Firmicutes, mostly in Clostridia and sporulating species of the class Bacilli (Francke et al. 2011).

One of the commonly recognised functions of Sigma 54 is the regulation of nitrogen metabolism (Reitzer and Schneider 2001, Da Silva Neto et al. 2010, Peng et al. 2015). In B. subtilis, Sigma L regulates several nitrogen catabolic reactions such as utilisation of arginine (Belitsky and Sonenshein 1999) or leucine and valine degradation (Debarbouille et al. 1999). Furthermore, the expression of sigL in $B$. subtilis is influenced by the catabolite control protein (CcpA) thus potentially serving as a link between nitrogen and carbon metabolism (Choi and Saier Jr 2005). Both nitrogen and carbon metabolism related processes are under the control of Sigma 54 in B. thuringiensis (Peng et al. 2015).

For some microorganisms, Sigma 54 plays a role in a wide range of functions. For instance in P. fluorescens, Sigma 54 was involved in motility, assimilation of many nutrients, stress tolerance and plant root colonisation (Jones et al. 2007). For others it has a very specific role in a few cellular functions. In Listeria monocytogenes it is mainly involved in carbohydrate metabolism via direct regulation of PTS (phosphotransferase system) activity, pyruvate pool and catabolite regulation (Arous et al. 2004). In L. plantarum only the mannose PTS system is directly regulated by Sigma 54, which also imports glucose in low amounts and influences carbohydrate metabolism (Stevens et al. 2010). 


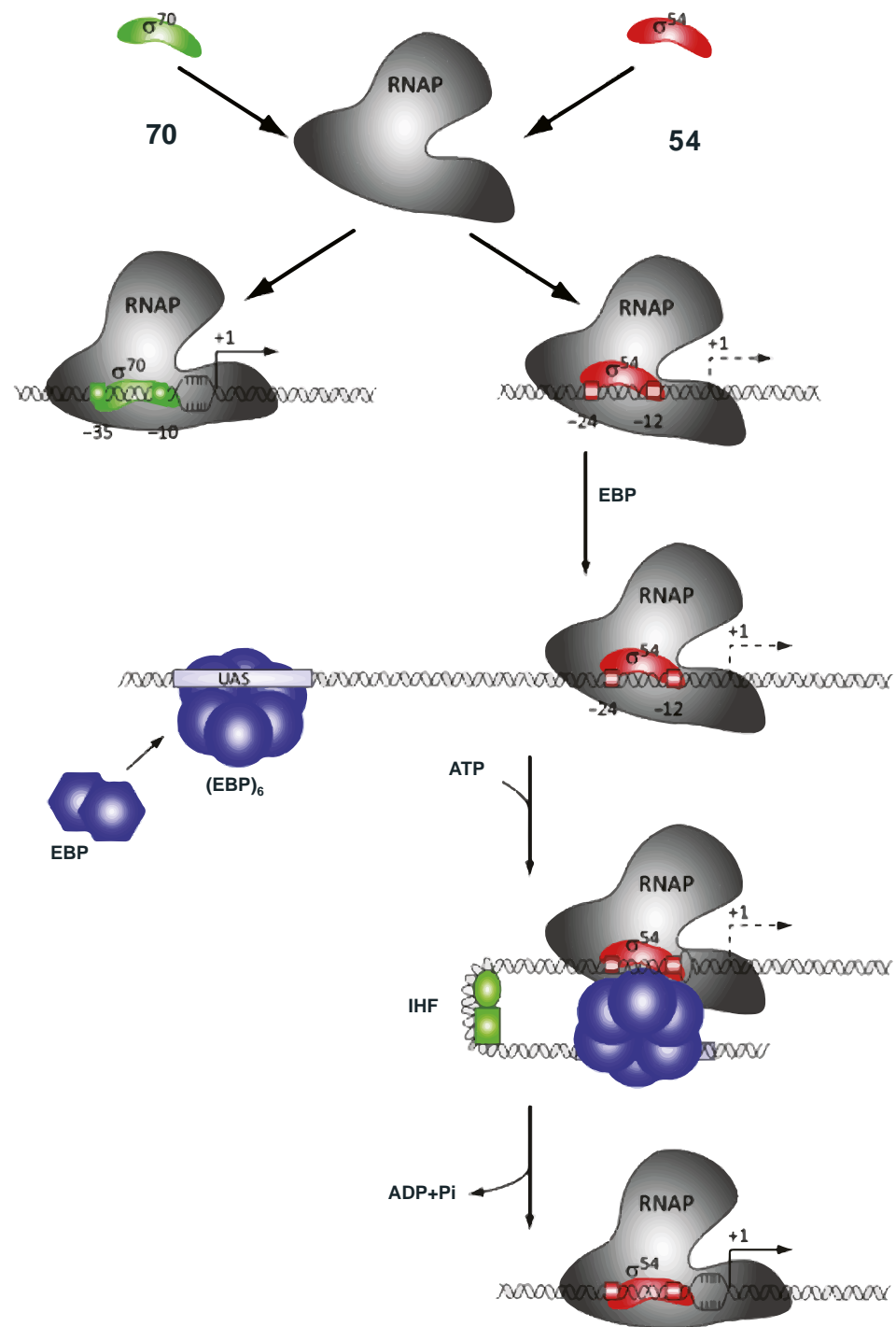

Figure 3. Sigma 54 transcription regulation mechanism. Reproduced with permission (Joly et al. 2010).

Other functionalities reported for Sigma 54 are flagellar biosynthesis and motility (Cases et al. 2003, Jones et al. 2007, Mattila et al. 2012), virulence (Hendrickson et al. 2000, Ancona et al. 2013, Hao et al. 2013), biofilm formation and colonisation (Jones et al. 2007, Iyer and Hancock 2012, Hao et al. 2013), antibiotic resistance (Jones et al. 2007), stress resistance (Hwang et al. 2011) and cold shock adaptation (Wiegeshoff et al. 2006).

The wide range of functionalities affected by Sigma 54 makes it difficult to define a general function for this sigma factor. Francke et al. (2011) made such an attempt 
based on in silico analysis of Sigma 54 binding sites, EBPs and their genomic context in all sequenced prokaryotes. Phylum-dependent distribution of the rpoN suggested a possible evolutionary relationship between Sigma 54 and lipopolysaccharide and flagellar biosynthesis (Francke et al. 2011). The enigmatic Sigma 54 was implicated as a central controller of the bacterial exterior (Francke et al. 2011). This means that it is involved in cellular functions related to the physical interaction of the organism with its environment, including host colonisation and biofilm formation. Some of the related processes are the transport and biosynthesis of exopolysaccharides, flagella, lipopolysaccharides (LPS) and peptidoglycan. The role of this sigma factor in B. cereus has not been yet characterised, which makes it an interesting target to study.

\section{Other factors affecting biofilm formation}

Microbial biofilm formation is also highly dependent on physiological factors such as presence of flagella and cellular motility, cell surface properties and production of extracellular polymeric substances (EPS) (Karatan and Watnick 2009, Abee et al. 2011). Flagella mediated motility in $B$. cereus is important for static biofilm formation in order to reach to the surfaces for attachment, in contrast to continuous flow conditions (Houry et al. 2010). Flagella are also important for adhesion of B. cereus to epithelial cells (Ramarao and Lereclus 2006). Cell surface properties and chemical composition are known to affect biofilm formation and maturation (Auger et al. 2009, Candela et al. 2011, Karunakaran and Biggs 2011, Mukherjee et al. 2012). The initial, reversible, attachment of the cells to the surface is mostly governed by physicochemical interactions and is affected by surface properties such as hydrophobicity and charge (Karunakaran and Biggs 2011). Molecules able to modify the cell surface properties also affect biofilm formation, such as the putative cell wall peptidase (CwpFM) presumably involved in processes, such as peptidoglycan modification, cell wall turnover, separation of daughter cells, motility and adhesion (Tran et al. 2010). Furthermore, during biofilm formation the cell surface properties are being modified. For example, B. cereus biofilm cells were more hydrophilic and had decreased surface charge (Karunakaran and Biggs 2011, Mukherjee et al. 2012) along with increased amounts and modified compositions of cell wall polysaccharides compared to their planktonic counterparts (Mukherjee et al. 2012). Further steps in biofilm formation involve irreversible attachment and EPS production. EPS components mediate cell to cell and cell to surface interactions and provide mechanical stability to the biofilm, along with a range of other functionalities, such as serving as a source of nutrients and a protective shelter for the cells (Flemming and Wingender 2010). EPS includes proteins, polysaccharides, lipids and extracellular DNA , and the composition and relative amounts can vary dependent on the species and/or strains involved (Abee et al. 2011). 


\section{Thesis outline}

In this thesis, different phases of the biofilm lifecycle of $B$. cereus were studied, including initial attachment, biofilm maturation and sporulation, dispersal of biofilm spores, and the role of Sigma 54 in growth and biofilm formation. The topics studied in this thesis are depicted in Fig. 2.

Chapter 2 describes environmental factors promoting or inhibiting biofilm formation using a collection of $B$. cereus food isolates and two model strains, $B$. cereus ATCC14579 and ATCC10987. Findings in this chapter show that B. cereus biofilm formation is highly dependent on the surface material and affected by strain diversity.

In Chapter 3 the effect of different iron sources, including complex sources such as haemoglobin, transferrin and ferritin was studied on growth and biofilm formation of 20 different genome sequenced B. cereus food isolates. Comparative genome analysis of these strains was used to identify putative systems for iron acquisition in B. cereus. The ability of the selected strains to use a range of (complex) iron sources for growth was correlated to the predicted repertoire of genes encoding iron binding proteins and transporters.

In Chapter 4 we determined the sporulation efficiency in B. cereus biofilms grown in liquid medium and during exposure of these biofilms to air. Subsequent heat resistance of biofilm-derived spores was compared to the spores formed in planktonic conditions.

Biofilm formation is a complex multistep process. Regulation of this process in $B$. cereus is partly characterised and in Chapter $\mathbf{5}$ the role of transcriptional regulator Sigma factor 54 was studied. This sigma factor may affect a range of cellular processes including biofilm formation. In Chapter 5 we constructed a deletion mutant of this sigma factor and comparative analysis of the wild type and the mutant showed the pleiotropic role of Sigma 54 in B. cereus affecting a range of functionalities, including motility, biofilm formation, virulence and carbohydrate metabolism.

The final chapter (Chapter 6) provides a general discussion of the main findings, implications for practice and future research perspectives. 


\section{References}

Abbas, A. A., S. Planchon, M. Jobin and P. Schmitt (2014). Absence of oxygen affects the capacity to sporulate and the spore properties of Bacillus cereus. Food Microbiology 42: 122-131.

Abee, T., Á. T. Kovács, O. P. Kuipers and S. van der Veen (2011). Biofilm formation and dispersal in Gram-positive bacteria. Current Opinion in Biotechnology 22(2): 172-179.

Abergel, R. J., M. K. Wilson, J. E. Arceneaux, T. M. Hoette, R. K. Strong, B. R. Byers and K. N. Raymond (2006). Anthrax pathogen evades the mammalian immune system through stealth siderophore production. Proceedings of the National Academy of Sciences of the United States of America 103(49): 18499-18503.

Abhyankar, W., R. Pandey, A. Ter Beek, S. Brul, L. J. de Koning and C. G. de Koster (2015). Reinforcement of Bacillus subtilis spores by cross-linking of outer coat proteins during maturation. Food Microbiology 45, Part A: 54-62.

Agarwala, M., T. Barman, D. Gogoi, B. Choudhury, A. R. Pal and R. N. S. Yadav (2014). Highly effective antibiofilm coating of silver-polymer nanocomposite on polymeric medical devices deposited by one step plasma process. Journal of Biomedical Materials Research - Part B Applied Biomaterials 102(6): 1223-1235.

Ancona, V., W. Li and Y. Zhao (2013). Alternative sigma factor RpoN and its modulation protein YhbH are indispensable for Erwinia amylovora virulence. Molecular Plant Pathology.

Andersson, A., U. Rönner and P. E. Granum (1995). What problems does the food industry have with the spore-forming pathogens Bacillus cereus and Clostridium perfringens? International Journal of Food Microbiology 28(2): 145-155.

Arous, S., C. Buchrieser, P. Folio, P. Glaser, A. Namane, M. Hébraud and Y. Héchard (2004). Global analysis of gene expression in an rpoN mutant of Listeria monocytogenes. Microbiology 150(5): 1581-1590.

Atrih, A. and S. J. Foster (2002). Bacterial endospores the ultimate survivors. International Dairy Journal 12(2-3): 217-223.

Auger, S., N. Ramarao, C. Faille, A. Fouet, S. Aymerich and M. Gohar (2009). Biofilm formation and cell surface properties among pathogenic and nonpathogenic strains of the Bacillus cereus group. Applied and Environmental Microbiology 75(20): 6616-6618.

Banin, E., M. L. Vasil and E. P. Greenberg (2005). Iron and Pseudomonas aeruginosa biofilm formation. Proceedings of the National Academy of Sciences of the United States of America 102(31): 11076-11081.

Belitsky, B. R. and A. L. Sonenshein (1999). An enhancer element located downstream of the major glutamate dehydrogenase gene of Bacillus subtilis. Proceedings of the National Academy of Sciences 96(18): 10290-10295.

Bennett, S. D., K. A. Walsh and L. H. Gould (2013). Foodborne disease outbreaks caused by Bacillus cereus, Clostridium perfringens, and Staphylococcus aureus - United States, 1998-2008. Clinical Infectious Diseases 57(3): 425-433.

Biesta-Peters, E. G., S. Dissel, M. W. Reij, M. H. Zwietering and P. H. in't Veld (2016). Characterization and exposure assessment of emetic Bacillus cereus and Cereulide Production in food products on the Dutch market. Journal of Food Protection 79(2): 230-238.

Bose, D., T. Pape, P. C. Burrows, M. Rappas, S. R. Wigneshweraraj, M. Buck and X. Zhang (2008). Organization of an activator-bound RNA polymerase holoenzyme. Molecular Cell 32(3): 337346.

Brady, R. A., G. A. O'May, J. G. Leid, M. L. Prior, J. W. Costerton and M. E. Shirtliff (2011). Resolution of Staphylococcus aureus biofilm infection using vaccination and antibiotic treatment. Infection and Immunity 79(4): 1797-1803.

Branda, S. S., J. E. González-Pastor, S. Ben-Yehuda, R. Losick and R. Kolter (2001). Fruiting body formation by Bacillus subtilis. Proceedings of the National Academy of Sciences of the United States of America 98(20): 11621-11626. 
Branda, S. S., Å. Vik, L. Friedman and R. Kolter (2005). Biofilms: The matrix revisited. Trends in Microbiology 13(1): 20-26.

Bridier, A., T. Meylheuc and R. Briandet (2013). Realistic representation of Bacillus subtilis biofilms architecture using combined microscopy (CLSM, ESEM and FESEM). Micron 48: 65-69.

Bridier, A., P. Sanchez-Vizuete, M. Guilbaud, J. C. Piard, M. Naïtali and R. Briandet (2015). Biofilm-associated persistence of food-borne pathogens. Food Microbiology 45(PB): 167-178.

Brombacher, E., A. Baratto, C. Dorel and P. Landini (2006). Gene expression regulation by the curli cctivator CsgD protein: modulation of cellulose biosynthesis and control of negative determinants for microbial adhesion. Journal of Bacteriology 188(6): 2027-2037.

Brown, J. S. and D. W. Holden (2002). Iron acquisition by Gram-positive bacterial pathogens. Microbes and Infection 4(11): 1149-1156.

Buck, M., M. T. Gallegos, D. J. Studholme, Y. Guo and J. D. Gralla (2000). The bacterial enhancerdependent $\sigma 54(\sigma(N))$ transcription factor. Journal of Bacteriology 182(15): 4129-4136.

Burbank, L., M. Mohammadi and M. C. Roper (2015). Siderophore-mediated iron acquisition influences motility and is required for full virulence of the xylem-dwelling bacterial phytopathogen Pantoea stewartii subsp. stewartii. Applied and Environmental Microbiology 81(1): 139-148.

Candela, T., E. Maes, E. Garenaux, Y. Rombouts, F. Krzewinski, M. Gohar and Y. Guerardel (2011). Environmental and biofilm-dependent changes in a Bacillus cereus secondary cell wall polysaccharide. Journal of Biological Chemistry 286(36): 31250-31262.

Cannon, W., F. Claverie-Martin, S. Austin and M. Buck (1993). Core RNA polymerase assists binding of the transcription factor $\sigma ; 54$ to promoter DNA. Molecular Microbiology 8(2): 287-298.

Carlin, F. (2011). Origin of bacterial spores contaminating foods. Food Microbiology 28(2): 177-182.

Carlson, R. P., R. Taffs, W. M. Davison and P. S. Stewart (2008). Anti-biofilm properties of chitosancoated surfaces. Journal of Biomaterials Science, Polymer Edition 19(8): 1035-1046.

Cases, I., D. W. Ussery and V. De Lorenzo (2003). The 054 regulon (sigmulon) of Pseudomonas putida. Environmental Microbiology 5(12): 1281-1293.

Castelijn, G. A., J. A. Parabirsing, M. H. Zwietering, R. Moezelaar and T. Abee (2013). Surface behaviour of S. Typhimurium, S. Derby, S. Brandenburg and S. Infantis. Veterinary Microbiology 161(3-4): 305-314.

Cazemier, A. E., S. F. M. Wagenaars and P. F. Ter Steeg (2001). Effect of sporulation and recovery medium on the heat resistance and amount of injury of spores from spoilage Bacilli. Journal of Applied Microbiology 90(5): 761-770.

Cendrowski, S., W. MacArthur and P. Hanna (2004). Bacillus anthracis requires siderophore biosynthesis for growth in macrophages and mouse virulence. 51(2): 407-417.

Ceuppens, S., N. Boon and M. Uyttendaele (2013). Diversity of Bacillus cereus group strains is reflected in their broad range of pathogenicity and diverse ecological lifestyles. FEMS Microbiology Ecology 84(3): 433-450.

Choi, S. K. and M. H. Saier Jr (2005). Regulation of sigL expression by the catabolite control protein CcpA involves a roadblock mechanism in Bacillus subtilis: Potential connection between carbon and nitrogen metabolism. Journal of Bacteriology 187(19): 6856-6861.

Choma, C., M. H. Guinebretière, F. Carlin, P. Schmitt, P. Velge, P. E. Granum and C. Nguyen-The (2000). Prevalence, characterization and growth of Bacillus cereus in commercial cooked chilled foods containing vegetables. Journal of Applied Microbiology 88(4): 617-625.

Christiansson, A., J. Bertilsson and B. Svensson (1999). Bacillus cereus spores in raw milk: Factors affecting the contamination of milk during the grazing period. Journal of Dairy Science 82(2): 305-314.

Christison, C. A., D. Lindsay and A. von Holy (2007). Cleaning and handling implements as potential reservoirs for bacterial contamination of some ready-to-eat foods in retail delicatessen environments. Journal of Food Protection 70(12): 2878-2883. 
Costerton, J. W., K. J. Cheng, G. G. Geesey, T. I. Ladd, J. C. Nickel, M. Dasgupta and T. J. Marrie (1987). Bacterial biofilms in nature and disease. Annual Review of Microbiology 41: 435-464.

Costerton, J. W., G. Geesey and K. Cheng (1978). How bacteria stick. Scientific American(238): 86-95.

Costerton, J. W., Z. Lewandowski, D. E. Caldwell, D. R. Korber and H. M. Lappin-Scott (1995). Microbial biofilms. Annual Review of Microbiology 49: 711-745.

Crusz, S. A., R. Popat, M. T. Rybtke, M. Cámara, M. Givskov, T. Tolker-Nielsen, S. P. Diggle and P. Williams (2012). Bursting the bubble on bacterial biofilms: a flow cell methodology. Biofouling 28(8): 835-842.

Da Silva Neto, J. F., T. Koide, S. L. Gomes and M. V. Marques (2010). Global gene expression under nitrogen starvation in Xylella fastidiosa: Contribution of the o54 regulon. BMC Microbiology 10.

Daou, N., C. Buisson, M. Gohar, J. Vidic, H. Bierne, M. Kallassy, D. Lereclus and C. Nielsen-LeRoux (2009). IlsA, a unique surface protein of Bacillus cereus required for iron acquisition from heme, hemoglobin and ferritin. PLoS Pathogens 5(11).

Davey, M. E. and G. A. O'Toole (2000). Microbial biofilms: From ecology to molecular genetics. Microbiology and Molecular Biology Reviews 64(4): 847-867.

De Jonghe, V., A. Coorevits, J. De Block, E. Van Coillie, K. Grijspeerdt, L. Herman, P. De Vos and M. Heyndrickx (2010). Toxinogenic and spoilage potential of aerobic spore-formers isolated from raw milk. International Journal of Food Microbiology 136(3): 318-325.

Debarbouille, M., R. Gardan, M. Arnaud and G. Rapoport (1999). Role of bkdR, a transcriptional activator of the SigL-dependent isoleucine and valine degradation pathway in Bacillus subtilis. Journal of Bacteriology 181(7): 2059-2066.

Deighton, M. and R. Borland (1993). Regulation of slime production in Staphylococcus epidermidis by iron limitation. Infection and Immunity 61(10): 4473-4479.

Dierick, K., E. Van Coillie, I. Swiecicka, G. Meyfroidt, H. Devlieger, A. Meulemans, G. Hoedemaekers, L. Fourie, M. Heyndrickx and J. Mahillon (2005). Fatal family outbreak of Bacillus cereus-associated food poisoning. Journal of Clinical Microbiology 43(8): 4277-4279.

Driks, A. (2002). Overview: Development in bacteria: spore formation in Bacillus subtilis. Cellular and Molecular Life Sciences 59(3): 389-391.

Dubois, T., K. Faegri, S. Perchat, C. Lemy, C. Buisson, C. Nielsen-LeRoux, M. Gohar, P. Jacques, N. Ramarao, A.-B. Kolstø and D. Lereclus (2012). Necrotrophism is a quorum-sensing-regulated lifestyle in Bacillus thuringiensis. PLoS Pathogens 8(4): e1002629.

Dubois, T., S. Perchat, E. Verplaetse, M. Gominet, C. Lemy, M. Aumont-Nicaise, R. Grenha, S. Nessler and D. Lereclus (2013). Activity of the Bacillus thuringiensis NprR-NprX cell-cell communication system is co-ordinated to the physiological stage through a complex transcriptional regulation. Molecular Microbiology 88(1): 48-63.

EFSA, ECDC, E. F. S. A. and and E. C. f. D. P. a. Control) (2015). The European Union summary report on trends and sources of zoonoses, zoonotic agents and food-borne outbreaks in 2013. EFSA Journal 13(1): 3991-n/a.

Ehling-Schulz, M., E. Frenzel and M. Gohar (2015). Food-bacteria interplay: pathometabolism of emetic Bacillus cereus. Front Microbiol 6: 704.

Ehling-Schulz, M., M. Fricker and S. Scherer (2004). Bacillus cereus, the causative agent of an emetic type of food-borne illness. Molecular Nutrition and Food Research 48(7): 479-487.

El-Khoury, N., R. Majed, S. Perchat, M. Kallassy, D. Lereclus and M. Gohar (2016). Spatio-temporal evolution of sporulation in Bacillus thuringiensis biofilm. Frontiers in Microbiology 7: 1222.

Fagerlund, A., T. Dubois, O. A. Økstad, E. Verplaetse, N. Gilois, I. Bennaceur, S. Perchat, M. Gominet, S. Aymerich, A. B. Kolstø, D. Lereclus and M. Gohar (2014). SinR controls enterotoxin expression in Bacillus thuringiensis biofilms. 9(1).

Fagerlund, A., V. Smith, Å. K. Røhr, T. Lindbäck, M. P. Parmer, K. K. Andersson, L. Reubsaet and O. A. Økstad (2016). Cyclic diguanylate regulation of Bacillus cereus group biofilm formation. Molecular Microbiology 101(3): 471-494. 
Faille, C., T. Bénézech, G. Midelet-Bourdin, Y. Lequette, M. Clarisse, G. Ronse, A. Ronse and C. Slomianny (2014). Sporulation of Bacillus spp. within biofilms: A potential source of contamination in food processing environments. Food Microbiology 40: 64-74.

Faille, C., F. Fontaine and T. Bénézech (2001). Potential occurrence of adhering living Bacillus spores in milk product processing lines. Journal of Applied Microbiology 90(6): 892-900.

Flemming, H.-C. and J. Wingender (2010). The biofilm matrix. Nat Rev Micro 8(9): 623-633.

Flint, S. H., P. J. Bremer and J. D. Brooks (1997). Biofilms in dairy manufacturing plant - Description, current concerns and methods of control. Biofouling 11(1): 81-97.

Francke, C., T. Groot Kormelink, Y. Hagemeijer, L. Overmars, V. Sluijter, R. Moezelaar and R. J. Siezen (2011). Comparative analyses imply that the enigmatic sigma factor 54 is a central controller of the bacterial exterior. BMC Genomics 12 .

Frankland, G. C. and P. F. Frankland (1887). Studies on some new micro-organisms obtained from air. Philosophical Transactions of the Royal Society of London. B 178: 257-287.

Frenzel, E., V. Doll, M. Pauthner, G. Lucking, S. Scherer and M. Ehling-Schulz (2012). CodY orchestrates the expression of virulence determinants in emetic Bacillus cereus by impacting key regulatory circuits. Molecular Microbiology 85(1): 67-88.

Fux, C. A., J. W. Costerton, P. S. Stewart and P. Stoodley (2005a). Survival strategies of infectious biofilms. Trends in Microbiology 13(1): 34-40.

Fux, C. A., M. Shirtliff, P. Stoodley and J. W. Costerton (2005b). Can laboratory reference strains mirror 'real-world' pathogenesis? Trends in Microbiology 13(2): 58-63.

Gao, T., L. Foulston, Y. Chai, Q. Wang and R. Losick (2015). Alternative modes of biofilm formation by plant-associated Bacillus cereus. MicrobiologyOpen.

Garcia, E., S. Bancroft, S. G. Rhee and S. Kustu (1977). The product of a newly identified gene, $\mathrm{gInF}$, is required for synthesis of glutamine synthetase in Salmonella. Proceedings of the National Academy of Sciences 74(4): 1662-1666.

Gat, O., G. Zaide, I. Inbar, H. Grosfeld, T. Chitlaru, H. Levy and A. Shafferman (2008). Characterization of Bacillus anthracis iron-regulated surface determinant (Isd) proteins containing NEAT domains. Molecular Microbiology 70(4): 983-999.

Geesey, G., R. Mutch, J. t. Costerton and R. Green (1978). Sessile bacteria: an important component of the microbial population in small mountain streams. Limnol. Oceanogr 23(6): 1214-1223.

Gelis-Jeanvoine, S., A. Canette, M. Gohar, T. Caradec, C. Lemy, M. Gominet, P. Jacques, D. Lereclus and L. Slamti (2016). Genetic and functional analyses of krs, a locus encoding kurstakin, a lipopeptide produced by Bacillus thuringiensis. Research in Microbiology.

Gerstel, U. and U. Römling (2001). Oxygen tension and nutrient starvation are major signals that regulate $a g f D$ promoter activity and expression of the multicellular morphotype in Salmonella Typhimurium. Environmental Microbiology 3(10): 638-648.

Ghosh, S., A. Ramirez-Peralta, E. Gaidamakova, P. Zhang, Y. Q. Li, M. J. Daly and P. Setlow (2011). Effects of Mn levels on resistance of Bacillus megaterium spores to heat, radiation and hydrogen peroxide. Journal of Applied Microbiology 111(3): 663-670.

Glasset, B., S. Herbin, L. Guillier, S. Cadel-Six, M. L. Vignaud, J. Grout, S. Pairaud, V. Michel, J. A. Hennekinne, N. Ramarao and A. Brisabois (2016). Bacillus cereus-induced food-borne outbreaks in France, 2007 to 2014: epidemiology and genetic characterisation. Euro Surveillance 21(48).

Glick, R., C. Gilmour, J. Tremblay, S. Satanower, O. Avidan, E. Déziel, E. P. Greenberg, K. Poole and E. Banin (2010). Increase in rhamnolipid synthesis under iron-limiting conditions influences surface motility and biofilm formation in Pseudomonas aeruginosa. Journal of Bacteriology 192(12): 2973-2980.

Gotz, F. (2002). Staphylococcus and biofilms. Molecular Microbiology 43(6): 1367-1378. 
Granger, A. C., E. K. Gaidamakova, V. Y. Matrosova, M. J. Daly and P. Setlow (2011). Effects of Mn and Fe levels on Bacillus subtilis spore resistance and effects of Mn2+, other divalent cations, orthophosphate, and dipicolinic acid on protein resistance to ionizing radiation. Applied and Environmental Microbiology 77(1): 32-40.

Guinebretiere, M. H., H. Girardin, C. Dargaignaratz, F. Carlin and C. Nguyen-The (2003). Contamination flows of Bacillus cereus and spore-forming aerobic bacteria in a cooked, pasteurized and chilled zucchini purée processing line. International Journal of Food Microbiology 82(3): 223-232.

Guinebretière, M. H., F. L. Thompson, A. Sorokin, P. Normand, P. Dawyndt, M. Ehling-Schulz, B. Svensson, V. Sanchis, C. Nguyen-The, M. Heyndrickx and P. De Vos (2008). Ecological diversification in the Bacillus cereus Group. Environmental Microbiology 10(4): 851-865.

Guizelini, B. P., L. P. S. Vandenberghe, S. R. B. R. Sella and C. R. Soccol (2012). Study of the influence of sporulation conditions on heat resistance of Geobacillus stearothermophilus used in the development of biological indicators for steam sterilization. Archives of Microbiology 194(12): 991-999.

Hamon, M. A. and B. A. Lazazzera (2001). The sporulation transcription factor Spo0A is required for biofilm development in Bacillus subtilis. Molecular Microbiology 42(5): 1199-1209.

Hao, B., Z. L. Mo, P. Xiao, H. J. Pan, X. Lan and G. Y. Li (2013). Role of alternative sigma factor 54 (RpoN) from Vibrio anguillarum M3 in protease secretion, exopolysaccharide production, biofilm formation, and virulence. Applied Microbiology and Biotechnology 97(6): 2575-2585.

Harvie, D. R. and D. J. Ellar (2005). A ferric dicitrate uptake system is required for the full virulence of Bacillus cereus. Current Microbiology 50(5): 246-250.

Hecker, M. and U. Völker (2001). General stress response of Bacillus subtilis and other bacteria. Advances in Microbial Physiology. 44: 35-91.

Helgason, E., O. A. Økstad, D. A. Caugant, H. A. Johansen, A. Fouet, M. Mock, I. Hegna and A.-B. Kolstø (2000). Bacillus anthracis, Bacillus cereus, and Bacillus thuringiensis-one species on the basis of genetic evidence. Applied and Environmental Microbiology 66(6): 2627-2630.

Helmann, J. D. and M. J. Chamberlin (1988). Structure and function of bacterial sigma factors. Annual Review of Biochemistry 57: 839-872.

Hendrickson, E. L., P. Guevera, A. Peñaloza-Vàzquez, J. Shao, C. Bender and F. M. Ausubel (2000). Virulence of the phytopathogen Pseudomonas syringae pv. maculicola is rpoN dependent. 182(12): 3498-3507.

Herron, W. (1930). Rancidity in cheddar cheese. Master's Thesis, Queen's University, Kingston, Ontario, Canada.

Hotta, K., C. Y. Kim, D. T. Fox and A. T. Koppisch (2010). Siderophore-mediated iron acquisition in Bacillus anthracis and related strains. Microbiology 156(7): 1918-1925.

Houry, A., R. Briandet, S. Aymerlch and M. Gohar (2010). Involvement of motility and flagella in Bacillus cereus biofilm formation. Microbiology 156(4): 1009-1018.

Hsueh, Y.-H., E. B. Somers and A. C. L. Wong (2008). Characterization of the codY gene and its influence on biofilm formation in Bacillus cereus. Archives of Microbiology 189(6): 557-568.

Hsueh, Y. H., E. B. Somers, D. Lereclus and A. C. L. Wong (2006). Biofilm formation by Bacillus cereus is influenced by PlcR, a pleiotropic regulator. Applied and Environmental Microbiology 72(7): 5089-5092.

Hwang, S., B. Jeon, J. Yun and S. Ryu (2011). Roles of RpoN in the resistance of Campylobacter jejuni under various stress conditions. BMC Microbiology 11.

Iyer, V. S. and L. E. Hancock (2012). Deletion of $\sigma 54(r p o N)$ alters the rate of autolysis and biofilm formation in Enterococcus faecalis. Journal of Bacteriology 194(2): 368-375.

Jensen, G. B., B. M. Hansen, J. Eilenberg and J. Mahillon (2003). The hidden lifestyles of Bacillus cereus and relatives. Environmental Microbiology 5(8): 631-640. 
Jishage, M. and A. Ishihama (1995). Regulation of RNA polymerase sigma subunit synthesis in Escherichia coli: intracellular levels of sigma 70 and sigma 38. Journal of Bacteriology 177(23): 6832-6835.

Jishage, M., A. Iwata, S. Ueda and A. Ishihama (1996). Regulation of RNA polymerase sigma subunit synthesis in Escherichia coli: Intracellular levels of four species of sigma subunit under various growth conditions. Journal of Bacteriology 178(18): 5447-5451.

Joly, N., C. Engl, G. Jovanovic, M. Huvet, T. Toni, X. Sheng, M. P. H. Stumpf and M. Buck (2010). Managing membrane stress: the phage shock protein (Psp) response, from molecular mechanisms to physiology. FEMS Microbiology Reviews 34(5): 797-827.

Jones, J., D. J. Studholme, C. G. Knight and G. M. Preston (2007). Integrated bioinformatic and phenotypic analysis of RpoN-dependent traits in the plant growth-promoting bacterium Pseudomonas fluorescens SBW25. Environmental Microbiology 9(12): 3046-3064.

Karatan, E. and P. Watnick (2009). Signals, regulatory networks, and materials that build and break bacterial biofilms. Microbiology and Molecular Biology Reviews 73(2): 310-347.

Karunakaran, E. and C. A. Biggs (2011). Mechanisms of Bacillus cereus biofilm formation: An investigation of the physicochemical characteristics of cell surfaces and extracellular proteins. Applied Microbiology and Biotechnology 89(4): 1161-1175.

Kolari, M., J. Nuutinen and S. M. Salkinoja-Salonen (2001). Mechanisms of biofilm formation in paper machine by Bacillus species: the role of Deinococcus geothermalis. Journal of Industrial Microbiology and Biotechnology 27(6): 343-351.

Kumar, C. G. and S. K. Anand (1998). Significance of microbial biofilms in food industry: A review. International Journal of Food Microbiology 42(1-2): 9-27.

Kuroki, R., K. Kawakami, L. Qin, C. Kaji, K. Watanabe, Y. Kimura, C. Ishiguro, S. Tanimura, Y. Tsuchiya, I. Hamaguchi, M. Sakakura, S. Sakabe, K. Tsuji, M. Inoue and H. Watanabe (2009). Nosocomial bacteremia caused by biofilm-forming Bacillus cereus and Bacillus thuringiensis. Internal Medicine 48(10): 791-796.

Lecomte, J., M. St-Arnaud and M. Hijri (2011). Isolation and identification of soil bacteria growing at the expense of arbuscular mycorrhizal fungi. FEMS Microbiology Letters 317(1): 43-51.

Lewis, K. (2001). Riddle of biofilm resistance. Antimicrobial Agents and Chemotherapy 45(4): 9991007.

Lin, S., H. Schraft, J. A. Odumeru and M. W. Griffiths (1998). Identification of contamination sources of Bacillus cereus in pasteurized milk. International Journal of Food Microbiology 43(3): 159-171.

Lindbäck, T., M. Mols, C. Basset, P. E. Granum, O. P. Kuipers and A. T. Kovács (2012). CodY, a pleiotropic regulator, influences multicellular behaviour and efficient production of virulence factors in Bacillus cereus. Environmental Microbiology 14(8): 2233-2246.

Lindsay, D., V. S. Brözel and A. Von Holy (2006). Biofilm-spore response in Bacillus cereus and Bacillus subtilis during nutrient limitation. Journal of Food Protection 69(5): 1168-1172.

Mah, T.-F. C. and G. A. O'Toole (2001). Mechanisms of biofilm resistance to antimicrobial agents. Trends in Microbiology 9(1): 34-39.

Majed, R., C. Faille, M. Kallassy and M. Gohar (2016). Bacillus cereus biofilms - same, only different. Frontiers in Microbiology 7.

Mattila, M., P. Somervuo, T. Rattei, H. Korkeala, R. Stephan and T. Tasara (2012). Phenotypic and transcriptomic analyses of Sigma L-dependent characteristics in Listeria monocytogenes EGD-e. Food Microbiology 32(1): 152-164.

Mazmanian, S. K., E. P. Skaar, A. H. Gaspar, M. Humayun, P. Gornicki, J. Jelenska, A. Joachmiak, D. M. Missiakas and O. Schneewind (2003). Passage of heme-iron across the envelope of Staphylococcus aureus. Science 299(5608): 906-909.

McLoon, A. L., S. B. Guttenplan, D. B. Kearns, R. Kolter and R. Losick (2011). Tracing the domestication of a biofilm-forming bacterium. Journal of Bacteriology 193(8): 2027-2034. 
Meer, R. R., J. Baker, F. W. Bodyfelt and M. W. Griffiths (1991). Psychrotrophic Bacillus spp. in fluid milk products: a review. Journal of Food Protection 54(12): 969-979.

Melly, E., P. C. Genest, M. E. Gilmore, S. Little, D. L. Popham, A. Driks and P. Setlow (2002). Analysis of the properties of spores of Bacillus subtilis prepared at different temperatures. 92(6): $1105-1115$.

Merrick, M. J. (1993). In a class of its own - The RNA polymerase sigma factor $\sigma 54(\sigma(\mathrm{N}))$. Molecular Microbiology 10(5): 903-909.

Mey, A. R., S. A. Craig and S. M. Payne (2005). Characterization of Vibrio cholerae RyhB: the RyhB Regulon and Role of ryhB in Biofilm Formation. Infection and Immunity 73(9): 5706-5719.

Miethke, M. and M. A. Marahiel (2007). Siderophore-based iron acquisition and pathogen control. Microbiology and Molecular Biology Reviews 71(3): 413-451.

Moreau-Marquis, S., G. A. O'Toole and B. A. Stanton (2009). Tobramycin and FDA-approved iron chelators eliminate Pseudomonas aeruginosa biofilms on cystic fibrosis cells. American Journal of Respiratory Cell and Molecular Biology 41(3): 305-313.

Mukherjee, J., E. Karunakaran and C. A. Biggs (2012). Using a multi-faceted approach to determine the changes in bacterial cell surface properties influenced by a biofilm lifestyle. Biofouling 28(1): $1-14$.

Nguyen Thi Minh, H., A. Durand, P. Loison, J. M. Perrier-Cornet and P. Gervais (2011). Effect of sporulation conditions on the resistance of Bacillus subtilis spores to heat and high pressure. Applied Microbiology and Biotechnology 90(4): 1409-1417.

Nicholson, W. L., N. Munakata, G. Horneck, H. J. Melosh and P. Setlow (2000). Resistance of Bacillus endospores to extreme terrestrial and extraterrestrial environments. Microbiology and Molecular Biology Reviews 64(3): 548-572.

Oomes, S. J. C. M. and S. Brul (2004). The effect of metal ions commonly present in food on gene expression of sporulating Bacillus subtilis cells in relation to spore wet heat resistance. Innovative Food Science \& Emerging Technologies 5(3): 307-316.

Örnek, D., A. Jayaraman, B. Syrett, C. H. Hsu, F. Mansfeld and T. Wood (2002). Pitting corrosion inhibition of aluminum 2024 by Bacillus biofilms secreting polyaspartate or $\gamma$-polyglutamate. Applied Microbiology and Biotechnology 58(5): 651-657.

Palop, A., P. Mañas and S. Condón (1999). Sporulation temperature and heat resistance of Bacillus spores: A review. Journal of Food Safety 19(1): 57-72.

Peng, Q., G. Wang, G. Liu, J. Zhang and F. Song (2015). Identification of metabolism pathways directly regulated by Sigma54 factor in Bacillus thuringiensis. Name: Frontiers in Microbiology 6: 407.

Pflughoeft, K. J., P. Sumby and T. M. Koehler (2011). Bacillus anthracis sin locus and regulation of secreted proteases. Journal of Bacteriology 193(3): 631-639.

Piggot, P. J. and D. W. Hilbert (2004). Sporulation of Bacillus subtilis. Current Opinion in Microbiology 7(6): 579-586.

Porcheron, G. and C. M. Dozois (2015). Interplay between iron homeostasis and virulence: Fur and RyhB as major regulators of bacterial pathogenicity. Veterinary Microbiology 179(1-2): 2-14.

Ramarao, N. and D. Lereclus (2006). Adhesion and cytotoxicity of Bacillus cereus and Bacillus thuringiensis to epithelial cells are FlhA and PlcR dependent, respectively. Microbes and Infection 8(6): 1483-1491.

Rasko, D. A., J. Ravel, O. A. Økstad, E. Helgason, R. Z. Cer, L. Jiang, K. A. Shores, D. E. Fouts, N. J. Tourasse, S. V. Angiuoli, J. Kolonay, W. C. Nelson, A. B. Kolstø, C. M. Fraser, T. D. Read and H. M. Jackson (2004). The genome sequence of Bacillus cereus ATCC 10987 reveals metabolic adaptations and a large plasmid related to Bacillus anthracis pXO1. Nucleic Acids Research 32(3): 977-988.

Ratledge, C. and L. G. Dover (2000). Iron metabolism in pathogenic bacteria. Annual Review of Microbiology. 54: 881-941. 
Reitzer, L. and B. L. Schneider (2001). Metabolic context and possible physiological themes of o54dependent genes in Escherichia coli. Microbiology and Molecular Biology Reviews 65(3): 422444.

Rupp, M. E., J. S. Ulphani, P. D. Fey and D. Mack (1999). Characterization of Staphylococcus epidermidis polysaccharide intercellular adhesin/hemagglutinin in the pathogenesis of intravascular catheterassociated infection in a rat model. Infection and Immunity 67(5): 2656-2659.

Salustiano, V. C., N. J. Andrade, N. F. F. Soares, J. C. Lima, P. C. Bernardes, L. M. P. Luiz and P. E. Fernandes (2009). Contamination of milk with Bacillus cereus by post-pasteurization surface exposure as evaluated by automated ribotyping. Food Control 20(4): 439-442.

Sanchez-Salas, J. L., B. Setlow, P. Zhang, Y. Q. Li and P. Setlow (2011). Maturation of released spores is necessary for acquisition of full spore heat resistance during Bacillus subtilis sporulation. 77(19): 6746-6754.

Scher, K., U. Romling and S. Yaron (2005). Effect of heat, acidification, and chlorination on Salmonella enterica serovar Typhimurium cells in a biofilm formed at the air-liquid interface. Applied and Environmental Microbiology 71(3): 1163-1168.

Schoeni, J. L. and A. C. Lee Wong (2005). Bacillus cereus food poisoning and its toxins. Journal of Food Protection 68(3): 636-648.

Segond, D., E. Abi Khalil, C. Buisson, N. Daou, M. Kallassy, D. Lereclus, P. Arosio, F. Bou-Abdallah and C. Nielsen Le Roux (2014). Iron acquisition in Bacillus cereus: the roles of IlsA and bacillibactin in exogenous ferritin iron mobilization. 10(2).

Senesi, S. and E. Ghelardi (2010). Production, secretion and biological activity of Bacillus cereus enterotoxins. Toxins 2(7): 1690-1703.

Setlow, P. (2006). Spores of Bacillus subtilis: Their resistance to and killing by radiation, heat and chemicals. Journal of Applied Microbiology 101(3): 514-525.

Setlow, P. (2007). I will survive: DNA protection in bacterial spores. Trends in Microbiology 15(4): $172-180$.

Sharma, M. and S. K. Anand (2002). Biofilms evaluation as an essential component of HACCP for food/ dairy processing industry - A case. Food Control 13(6-7): 469-477.

Shi, X. and X. Zhu (2009). Biofilm formation and food safety in food industries. Trends in Food Science and Technology 20(9): 407-413.

Shinagawa, K. (1990). Analytical methods for Bacillus cereus and other Bacillus species. International Journal of Food Microbiology 10(2): 125-141.

Simões, M., L. C. Simões, I. Machado, M. O. Pereira and M. J. Vieira (2006). Control of flowgenerated biofilms with surfactants: Evidence of resistance and recovery. Food and Bioproducts Processing 84(4 C): 338-345.

Simões, M., L. C. Simões and M. J. Vieira (2010). A review of current and emergent biofilm control strategies. LWT - Food Science and Technology 43(4): 573-583.

Stanley, N. R., R. A. Britton, A. D. Grossman and B. A. Lazazzera (2003). Identification of catabolite repression as a physiological regulator of biofilm formation by Bacillus subtilis by use of DNA microarrays. Journal of Bacteriology 185(6): 1951-1957.

Stanley, N. R. and B. A. Lazazzera (2004). Environmental signals and regulatory pathways that influence biofilm formation. Molecular Microbiology 52(4): 917-924.

Stanley, N. R. and B. A. Lazazzera (2005). Defining the genetic differences between wild and domestic strains of Bacillus subtilis that affect poly- $\gamma$-DL-glutamic acid production and biofilm formation. Molecular Microbiology 57(4): 1143-1158.

Stenfors Arnesen, L. P., A. Fagerlund and P. E. Granum (2008). From soil to gut: Bacillus cereus and its food poisoning toxins. FEMS Microbiology Reviews 32(4): 579-606.

Stevens, M. J. A., D. Molenaar, A. De Jong, W. M. De Vos and M. Kleerebezem (2010). o54mediated control of the mannose phosphotransferase sytem in Lactobacillus plantarum impacts on carbohydrate metabolism. Microbiology 156(3): 695-707. 
Storgårds, E., K. Tapani, P. Hartwall, R. Saleva and M. L. Suihko (2006). Microbial attachment and biofilm formation in brewery bottling plants. Journal of the American Society of Brewing Chemists 64(1): 8-15.

Svensson, B., Å. S. A. Eneroth, J. Brendehaug, G. Molin and A. Christiansson (2000). Involvement of a pasteurizer in the contamination of milk by Bacillus cereus in a commercial dairy plant. Journal of Dairy Research 67(3): 455-460.

Te Giffel, M. C., R. R. Beumer, M. H. Bonestroo and P. M. Rombouts (1996). Incidence and characterization of Bacillus cereus in two dairy processing plants. Netherlands Milk and Dairy Journal 50(4): 479-492.

Te Giffel, M. C., R. R. Beumer, P. E. Granum and F. M. Rombouts (1997). Isolation and characterisation of Bacillus cereus from pasteurised milk in household refrigerators in the Netherlands. International Journal of Food Microbiology 34(3): 307-318.

Thompson, L. S., J. S. Webb, S. A. Rice and S. Kjelleberg (2003). The alternative sigma factor RpoN regulates the quorum sensing gene rhlI in Pseudomonas aeruginosa. FEMS Microbiology Letters 220(2): 187-195.

Tran, S.-L., E. Guillemet, M. Gohar, D. Lereclus and N. Ramarao (2010). CwpFM (EntFM) is a Bacillus cereus potential cell wall peptidase implicated in adhesion, biofilm formation, and virulence. Journal of Bacteriology 192(10): 2638-2642.

Vaillant, V., H. De Valk, E. Baron, T. Ancelle, P. Colin, M. C. Delmas, B. Dufour, R. Pouillot, Y. Le Strat, P. Weinbreck, E. Jougla and J. C. Desenclos (2005). Foodborne infections in France. Foodborne Pathogens and Disease 2(3): 221-232.

van der Voort, M. and T. Abee (2013). Sporulation environment of emetic toxin-producing Bacillus cereus strains determines spore size, heat resistance and germination capacity. Journal of Applied Microbiology 114(4): 1201-1210.

Veening, J. W., O. P. Kuipers, S. Brul, K. J. Hellingwerf and R. Kort (2006). Effects of phosphorelay perturbations on architecture, sporulation, and spore resistance in biofilms of Bacillus subtilis. Journal of Bacteriology 188(8): 3099-3109.

Vilain, S., Y. Luo, M. B. Hildreth and V. S. Brözel (2006). Analysis of the life cycle of the soil Saprophyte Bacillus cereus in liquid soil extract and in soil. Applied and Environmental Microbiology 72(7): 4970-4977.

Vlamakis, H., Y. Chai, P. Beauregard, R. Losick and R. Kolter (2013). Sticking together: building a biofilm the Bacillus subtilis way. Nature Reviews Microbiology 11(3): 157-168.

Wandersman, C. and P. Delepelaire (2004). Bacterial iron sources: From siderophores to hemophores. Annual Review of Microbiology. 58: 611-647.

Warda, A. K., R. J. Siezen, J. Boekhorst, M. H. J. Wells-Bennik, A. De Jong, O. P. Kuipers, M. N. Nierop Groot and T. Abee (2016a). Linking Bacillus cereus genotypes and carbohydrate utilization capacity. PloS One 11(6): e0156796.

Warda, A. K., Y. Xiao, J. Boekhorst, M. H. J. Wells-Bennik, M. N. Nierop Groot and T. Abee (2016b). Analysis of germination capacity and inventarisation of germinant receptor (sub) clusters of genome sequenced Bacillus cereus environmental isolates and model strains. Applied and Environmental Microbiology.

Wiegeshoff, F., C. L. Beckering, M. Debarbouille and M. A. Marahiel (2006). Sigma L is important for cold shock adaptation of Bacillus subtilis. Journal of Bacteriology 188(8): 3130-3133.

Wigneshweraraj, S., D. Bose, P. C. Burrows, N. Joly, J. Schumacher, M. Rappas, T. Pape, X. Zhang, P. Stockley, K. Severinov and M. Buck (2008). Modus operandi of the bacterial RNA polymerase containing the 054 promoter-specificity factor. Molecular Microbiology 68(3): 538546.

Wijman, J. G. E., P. P. L. A. De Leeuw, R. Moezelaar, M. H. Zwietering and T. Abee (2007). Airliquid interface biofilms of Bacillus cereus: Formation, sporulation, and dispersion. Applied and Environmental Microbiology 73(5): 1481-1488. 
Wilson, M. K., R. J. Abergel, K. N. Raymond, J. E. Arceneaux and B. R. Byers (2006). Siderophores of Bacillus anthracis, Bacillus cereus, and Bacillus thuringiensis. Biochemical and Biophysical Research Communications 348(1): 320-325.

Wolfe, A. J., D. S. Millikan, J. M. Campbell and K. L. Visick (2004). Vibrio fischeri o54 controls motility, biofilm formation, luminescence and colonization. Applied and Environmental Microbiology 70(4): 2520-2524.

Xu, Y. B., M. Chen, Y. Zhang, M. Wang, Y. Wang, Q. b. Huang, X. Wang and G. Wang (2014). The phosphotransferase system gene ptsI in the endophytic bacterium Bacillus cereus is required for biofilm formation, colonization, and biocontrol against wheat sharp eyespot. FEMS Microbiology Letters 354(2): 142-152.

Yildiz, F. H., X. S. Liu, A. Heydorn and G. K. Schoolnik (2004). Molecular analysis of rugosity in a Vibrio cholerae O1 El Tor phase variant. Molecular Microbiology 53(2): 497-515.

You, S.-A. and Q. Wang (2005). Ferritin in atherosclerosis. Clinica Chimica Acta 357(1): 1-16.

Zhang, X., M. Chaney, S. R. Wigneshweraraj, J. Schumacher, P. Bordes, W. Cannon and M. Buck (2002). Mechanochemical ATPases and transcriptional activation. Molecular Microbiology 45(4): 895-903.

Zobell, C. E. (1943). The effect of solid surfaces upon bacterial activity. Journal of Bacteriology 46(1): 39-56. 



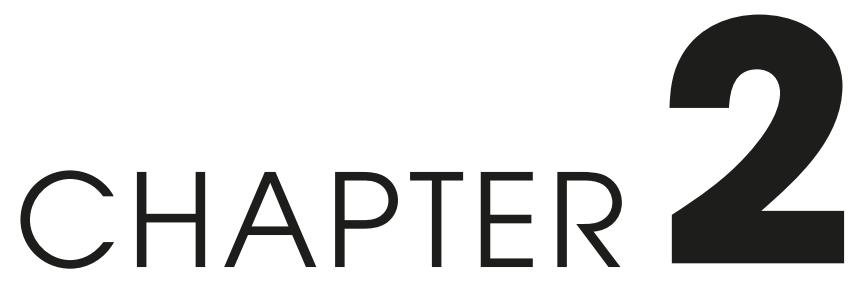

Comparative analysis of biofilm formation by Bacillus cereus reference strains and undomesticated food isolates and the effect of free iron

Hasmik Hayrapetyan

Lisette Muller

Marcel Tempelaars

Tjakko Abee

Masja Nierop Groot 


\section{Abstract}

Biofilm formation of Bacillus cereus reference strains ATCC 14579 and ATCC 10987 and 21 undomesticated food isolates was studied on polystyrene and stainless steel as contact surfaces. For all strains, the biofilm forming capacity was significantly enhanced when in contact with stainless steel (SS) as a surface as compared to polystyrene (PS). For a selection of strains, the total CFU and spore counts in biofilms were determined and showed a good correlation between CFU counts and total biomass of these biofilms. Sporulation was favoured in the biofilm over the planktonic state. To substantiate whether iron availability could affect $B$. cereus biofilm formation, the free iron availability was varied in BHI by either the addition of $\mathrm{FeCl}_{3}$ or by depletion of iron with the scavenger 2,2-Bipyridine. Addition of iron resulted in increased air-liquid interface biofilm on polystyrene but not on SS for strain ATCC 10987, while the presence of Bipyridine reduced biofilm formation for both materials. Biofilm formation was restored when excess $\mathrm{FeCl}_{3}$ was added in combination with the scavenger. Further validation of the iron effect for all 23 strains in microtiter plate showed that fourteen strains (including ATCC10987) formed a biofilm on PS. For eight of these strains biofilm formation was enhanced in the presence of added iron and for eleven strains it was reduced when free iron was scavenged. Our results show that stainless steel as a contact material provides more favourable conditions for $B$. cereus biofilm formation and maturation compared to polystyrene. This effect could possibly be linked to iron availability as we show that free iron availability affects $B$. cereus biofilm formation. 


\section{Introduction}

Most microorganisms have the capacity to adhere to surfaces and reside in surfaceassociated, multicellular communities called biofilms. Within a biofilm, cells are held together in a self-produced extracellular matrix that typically consists of extracellular polysaccharides, proteins and sometimes eDNA (Branda et al. 2005). Embedded in the biofilm, cells are protected from harsh environmental conditions including physical stresses, chemicals, and antimicrobial components because the matrix acts as a protective barrier that limits the penetration of disinfectants into the bulk of the biofilm. This can cause a problem for the food industry (Marchand et al. 2012) as equipment surfaces where biofilms develop can become a source of product recontamination (Flint et al. 1997, Eneroth et al. 2001).The lifecycle of a biofilm is a multistep process involving attachment of planktonic cells to a surface, biofilm development and maturation, and eventually disassembly and release of the cells. The biofilm development process is regulated via multiple regulatory pathways that trigger its formation depending on the environmental conditions (Vlamakis et al. 2013). Attachment is known to be influenced by numerous factors such as physicochemical properties of the substratum surface (Flint et al. 2000), surrounding environment, cell surface characteristics (Vanhaecke et al. 1990) and other factors as reviewed in Palmer et al. (2007) and Goulter et al. (2009). However, the importance of surface characteristics seems to vary between reported studies and it has been suggested that this reflects the existence of different mechanisms of adhesion employed by individual microorganisms (Tresse et al. 2007). Besides the substratum surface characteristics and strain diversity, biofilm formation is also influenced by a multitude of other factors including environmental conditions, nutrient availability, presence of specific organic and inorganic molecules in the environment that can act as signals for biofilm formation (Karatan and Watnick 2009, Petrova and Sauer 2012). One of such molecules is iron, which is also the main component of stainless steel widely used in industrial environments. Iron has been shown to promote biofilm formation by several microorganisms, such as Pseudomonas aeruginosa, Escherichia coli, Staphylococcus aureus and Streptococcus pneumoniae (Banin et al. 2005, Wu and Outten 2009, Trappetti et al. 2011, Lin et al. 2012). On the other hand, iron has also been shown to prevent biofilm formation by Legionella pneumophila (Hindré et al. 2008) and Streptococcus mutans (Berlutti et al. 2004).

Bacillus cereus is a food spoilage and pathogenic sporeformer. Different studies report biofilm formation by $B$. cereus on abiotic surfaces including stainless steel, polystyrene and glass (Auger et al. 2006, Lindsay et al. 2006, Wijman et al. 2007, Houry et al. 2010, Karunakaran and Biggs 2011) but a direct comparison between 
different substrata has not been performed. Within the established biofilms, B. cereus is able to form spores (Lindsay et al. 2006, Wijman et al. 2007, Faille et al. 2014) which may lead to product contamination upon release. The objective of this study was to assess the biofilm forming capacity of $21 \mathrm{~B}$. cereus food isolates and two reference strains, ATCC 14579 and ATCC 10987 on stainless steel and polystyrene and to evaluate the influence of iron. For a selection of strains, these biofilms were characterised in more detail by correlating the total biomass with cell counts. Spore numbers in the biofilms were also determined. The data provided in this study show a large diversity in biofilm forming capacity between the different $B$. cereus isolates and show a preference for stainless steel as contact surface over polystyrene. We also show that the free iron availability may enhance biofilm formation of several B. cereus strains.

\section{Materials and methods}

\section{Strains and culturing conditions}

Twenty-one Bacillus cereus strains previously isolated from food products and supplied by food manufacturers, were used in this study and compared for biofilm formation with the B. cereus reference strains ATCC 10987 and ATCC 14579 (Table 1). The strains were identified as Bacillus cereus based on performance on Bacillus cereus selective media and ribosomal RNA sequencing. Strains were streaked on BHI (Brain Heart Infusion, Becton Dickinson, France) agar plates from stocks stored at $-80{ }^{\circ} \mathrm{C}$ and incubated for $24 \mathrm{~h}$ at $30{ }^{\circ} \mathrm{C}$ to obtain single colonies. A single colony was used to inoculate BHI broth and incubated overnight $(18 \mathrm{~h})$ at $30^{\circ} \mathrm{C}$ without shaking. Preliminary tests using BHI, TSB, LB and a chemically defined minimal medium (Mols et al. 2007) showed that BHI was the optimum medium supporting biofilm formation (data not shown) and was therefore selected for subsequent experiments.

\section{Biofilm formation and quantification}

Biofilm formation by selected B. cereus isolates was tested in 12-well plates (Cellstar, suspension culture plate, Greiner bio-one, Germany) which were half filled with $3 \mathrm{ml}$ broth and inoculated with $1.5 \%$ overnight-grown cultures. Biofilms were allowed to develop on stainless steel (SS, AISI 304, surface finish 2B) or polystyrene (PS) coupons (22 mm wide, $18 \mathrm{~mm}$ height) placed vertically in the wells. Coupons were washed and sterilized prior to use as described by Castelijn et al. (2013). Around half $\left(2 \mathrm{~cm}^{2}\right.$ on each side) of the total surface area of the coupons was submerged into liquid medium. Coupons were only used once and were discarded 
Table 1. B. cereus strain codings used in this study and their source of isolation.

\begin{tabular}{ccl}
\hline $\begin{array}{c}\text { B. cereus strain } \\
\text { designation } \\
\text { used in this study }\end{array}$ & $\begin{array}{c}\text { Strain designation } \\
\text { according }\end{array}$ & Source of isolation \\
\hline BC1 & 4077 & Chilled dessert \\
\hline BC2 & 4078 & Unknown \\
BC3 & 4079 & Canned chocolate beverage \\
BC4 & 4080 & Dried onion \\
BC5 & 4081 & Provolone sauce \\
BC6 & 4082 & Asparagus ham sauce \\
BC7 & 4083 & Tortelini con fungi \\
BC8 & 4084 & Indian rice dish \\
BC9 & 4085 & Asparagus soup \\
BC10 & 4086 & Boiled rice \\
BC11 & 4087 & Pea soup \\
\hline BC12 & 4088 & Dressing \\
BC13 & 4116 & White sauce \\
BC14 & 4117 & Pasteurised milk \\
BC15 & 4118 & Ice cream \\
BC16 & 4120 & Water \\
BC17 & 4147 & Quiche \\
BC18 & 4149 & Cooked ham \\
BC19 & 4153 & Smoothie \\
BC20 & 4155 & Beef salad \\
BC21 & 4158 & Gas packaged, cooked and spiced potatoes \\
\hline ATCC 14579 & Reference strain & Air from a cow shed \\
ATCC 10987 & Reference strain & Spoiled cheese \\
\hline & & \\
\hline
\end{tabular}

after the experiment. Plates were wrapped with parafilm to prevent evaporation during incubation for 24 and $48 \mathrm{~h}$ at $30^{\circ} \mathrm{C}$. Biofilms on the coupons were quantified using the crystal violet (CV) assay for total biofilm formed and plate counting to determine the number of culturable cells in the biofilm.

Total biofilm was visualized and quantified by staining with CV as described previously (Castelijn et al. 2013) with the following modifications: coupons with biofilms were gently washed by dipping 2 times in de-mineralized (demi) water and left in $0.1 \%$ CV (MERCK) for $30 \mathrm{~min}$ to stain. After staining the coupons were washed again 3 times in demi water and subsequently de-stained in $4 \mathrm{ml} 70 \%$ ethanol for 45 min. Two hundred $\mu \mathrm{l}$ of this ethanol with dissolved CV was transferred to a 96-well plate to measure the OD at $595 \mathrm{~nm}$. The obtained OD values served as quantitative measures of the total biofilm biomass. 
In order to determine culturable cells in the biofilm, coupons were washed by dipping 3 times in phosphate-buffered-saline (PBS) and placed in $50 \mathrm{ml}$ tubes filled with $3 \mathrm{ml}$ PBS and $0.5 \mathrm{~g}$ glass beads ( $\mathrm{D}=100 \mu \mathrm{m}$, SIGMA). Tubes were vortexed at maximum speed (VortexGenie2, SI, USA) for $1 \mathrm{~min}$ to detach the cells from the coupon and to obtain individual cells in the sample. Preliminary experiments showed that this methodology effectively separated cells from each other and from the substratum and did not affect cell viability. Serial dilutions were made and spread plated on BHI-agar plates and colony forming units (CFU) were counted after $24 \mathrm{~h}$ incubation at $30{ }^{\circ} \mathrm{C}$. For spore counts, the suspended biofilm was heated at 80 ${ }^{\circ} \mathrm{C}$ for $10 \mathrm{~min}$ to inactivate all vegetative cells prior to plating. Initial attachment of cells to the SS coupons was determined after $2 \mathrm{~h}$ incubation time following the same approach as described above for the biofilm CFU counts.

For Scanning Electron Microscopy (SEM) SS and PS coupons with biofilm were washed 3 times in PBS and the procedure described previously for preparation of the samples was followed (Castelijn et al. 2012).

\section{The role of iron in biofilm formation}

To assess the role of iron, biofilm formation was measured in the following 4 conditions: $\mathrm{BHI}$ as a control; $\mathrm{BHI}$ supplemented with iron $\left(\mathrm{FeCl}_{3}\right)$ to a final concentration of $250 \mu \mathrm{M}$ added $\mathrm{FeCl}_{3}$ (MERCK); BHI supplemented with $450 \mu \mathrm{M}$ 2,2-Bipyridine (MERCK) (BHI+Bip); and BHI supplemented with both $\mathrm{FeCl}_{3}$ and 2,2 Bipyridine $\left(\mathrm{BHI}+\mathrm{Bip}+\mathrm{FeCl}_{3}\right)$. The concentrations used allowed growth of most of the strains and were selected based on pilot studies showing a significant effect on biofilm formation. The filter sterilized (25 and $45 \mathrm{mM}$ for $\mathrm{FeCl}_{3}$ and 2,2 Bipyridine respectively) stocks of these components were added to BHI broth just before inoculation. Biofilms formed on the coupons in 12-wells were measured for the reference strain ATCC 10987.

Screening of all $B$. cereus strains was performed in a microtiter plate assay (Djordjevic et al. 2002) in 96-wells plates filled with $200 \mu \mathrm{l} \mathrm{BHI}$ inoculated with $1.5 \%$ overnight culture of the respective strains with or without $\mathrm{FeCl}_{3}$ and/or Bipyridine supplementation. The amount of biofilm formed was measured after 24 $\mathrm{h}$ with the $\mathrm{CV}$ assay, with the difference that biofilms analyzed were formed on the walls of the wells instead of coupons. Washing, staining and de-staining steps were performed using $250 \mu \mathrm{l}$ of appropriate solutions and the OD measurement at $595 \mathrm{~nm}$ was performed in the same 96-well plate. The biofilm was considered to be affected (promoted or inhibited) if the resulting change between conditions was significant and the optical density measurement from CV staining was at least 0.1 units. 


\section{Statistical analysis}

Indicated values are the average of at least three individual experiments performed on different days with each experiment including 2 or 3 biological replicates. Standard deviations were calculated based on all replicate values. Significance of the differences observed was concluded based on a one-sided t test, assuming equal variances, using a $\mathrm{P}$ value $<0.05$ for statistical significance.

\section{Results}

\section{Biofilm formation by Bacillus cereus reference strains and undomesticated isolates}

In an initial screen to assess the diversity in biofilm forming capacity, $23 \mathrm{~B}$. cereus strains (ATCC 14579 and ATCC 10987 as reference strains and 21 food isolates) were allowed to form biofilms in $\mathrm{BHI}$ at $30{ }^{\circ} \mathrm{C}$ on either polystyrene (PS) or stainless steel (SS) coupons positioned vertically in 12 wells plates as described in the materials and methods. After 24 and $48 \mathrm{~h}$, the biofilm formed was quantified using the crystal violet (CV) assay. The data presented in Fig. 1 show a large diversity in biofilm forming capacity within the tested B. cereus strains. Based on the CV assay, all the strains formed biofilm on SS coupons within $24 \mathrm{~h}$. For some of the strains the biofilm formed within $24 \mathrm{~h}$ on SS was completely (BC2 and 11) or partially (e.g. $\mathrm{BC} 3,7,13)$ released after $48 \mathrm{~h}$, whereas for several others CV staining was increased (e.g. BC15, ATCC 14579 and ATCC 1098) at 48 h. For two strains (BC14 and 21) no change (within 0.1 OD unit) in biofilm formation was observed (Fig. 1). In contrast to SS, the biofilms formed on PS as measured by CV staining were considerably lower. On PS coupons only 8 (BC3, 4, 6, 7, 9, 10, 14, 18) and 9 (BC2, 3, 6, 7, 9, 10, 14, 18, ATCC 10987) out of 23 strains formed a biofilm within 24 and 48h, respectively. The biofilms were formed on the coupons at the air-liquid interphase, with strain BC7 that formed also submerged biofilms as an exception. Comparative SEM analysis using ATCC10987 showed no obvious structural differences between PS and SS biofilm cells and matrix components (Fig. 2), although it cannot be excluded that sample preparation affected the original structure of the biofilm. 

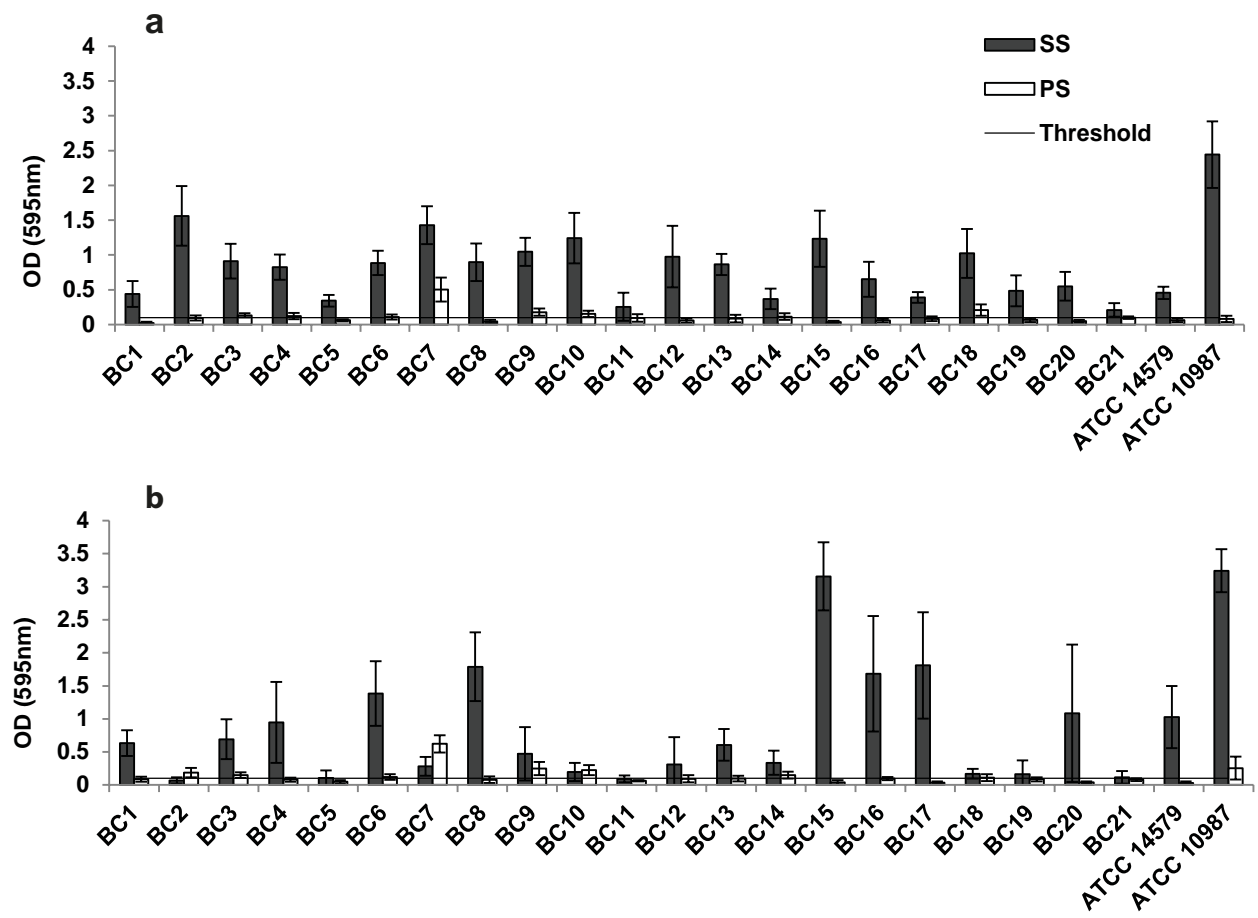

Figure 1. Biofilm formation of Bacillus cereus food isolates and reference strains ATCC 14579 and ATCC 10987 on polystyrene and stainless steel coupons. Biofilms formed in BHI at $30{ }^{\circ} \mathrm{C}$ after $24 \mathrm{~h}$ (a) and 48 $\mathrm{h}$ (b) were measured by the crystal violet assay. The threshold, indicated by a solid line, is equal to the background signal plus three times the standard deviation $(\mathrm{OD}=0.1)$. Values higher than the threshold level were considered positive for biofilm formation. The background was subtracted from presented values.

A subset of seven strains was selected representing both high and low biofilm formers based on the CV quantification (Fig. 1) and the number of viable cells and spores present in the $48 \mathrm{~h}$ biofilm of these strains were determined. This time point was selected since at $48 \mathrm{~h}$ both reference strains formed higher amounts of biofilm (Fig. 1) and more spores were formed in the biofilm compared to $24 \mathrm{~h}$ (not shown). Two subgroups of $B$. cereus isolates could be distinguished (Fig. 3a). One subgroup represents strains forming biofilms with high CFU counts on SS in the range of 7.5-8 $\log$ CFU/coupon (both ATCC 14579 and 10987, BC8 and BC15), however with substantially lower cell counts (in the range of 5-5.7 log CFU/coupon) on PS coupons. This was in good agreement with the total biomass measured with CV, which showed significantly higher biofilm formation on SS compared to PS for these strains (Fig.1). 

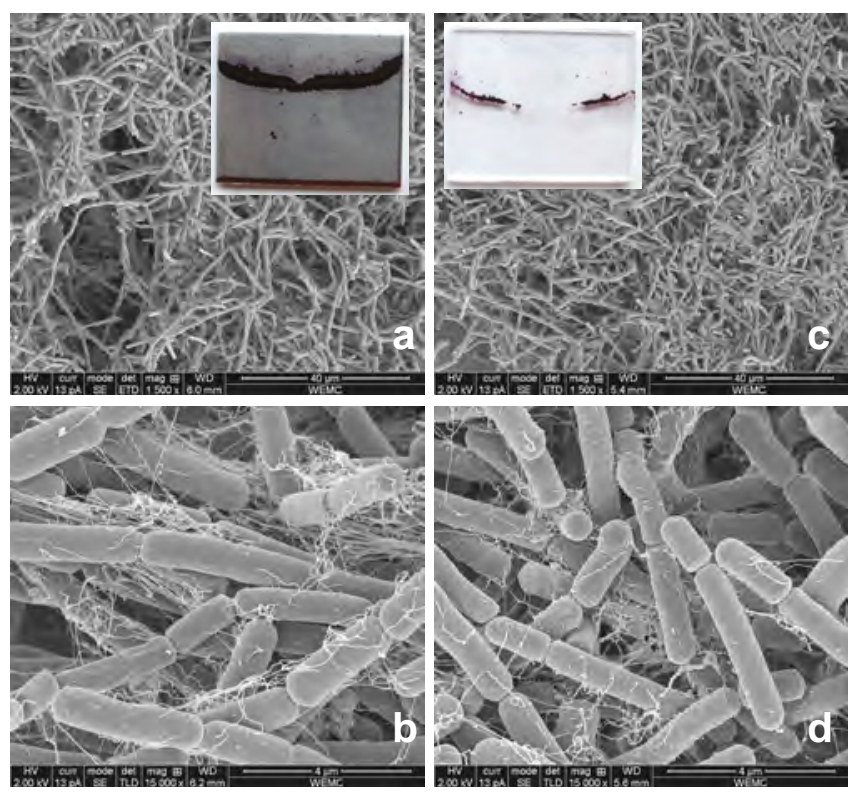

Figure 2. Biofilm of $B$. cereus ATCC 10987 on SS (a, b) and PS (c, d) in BHI at $30{ }^{\circ} \mathrm{C}$ after $48 \mathrm{~h}$. Scanning electron microscope images and a picture of the coupons with CV stained biofilm.

The other subgroup (encompassing strains BC7, 11, and 19), formed biofilms with relatively low CFU counts (5.7-6.6 log CFUs per coupon) on SS (BC7, 11, 19) and PS (BC11 and 19) (Fig. 3a). Combining CV data and number of cells measured in the $48 \mathrm{~h}$ biofilms indicates that a minimum number of around log 6 cells per coupon is required for $\mathrm{CV}$ detection above the background level. In general, there was a good correlation $\left(\mathrm{R}^{2}=0.89\right)$ between $\mathrm{CV}$ quantification and CFU counts for B. cereus biofilms formed both on SS and PS (Fig. 3d). The only exception was strain BC7 for which CFU counts were similar on SS and PS but CV read out was significantly higher on PS compared to SS indicating that total biomass was not proportional to the number of cells on PS (Fig. 3d). This could suggest a different biofilm matrix composition for this strain on PS. CFU numbers for all these seven strains in the planktonic phase were comparable (7.7-8 log CFU/ml) after $48 \mathrm{~h}$ (not shown) and exclude that observed differences in biofilm formation could be merely explained by differences in growth capacity. Although BHI is a rich medium which does not support $B$. cereus sporulation, several strains formed considerable amounts of spores (6.4 - $6.6 \mathrm{log}$ spores/coupon) within the biofilms (Fig. 3b). The sporulation efficiency (defined as number of spores relative to the total number of cells in the population) showed that sporulation was higher on SS (0.08-7.9\%) compared to PS $(0.005-3.8 \%)$. Notably, for both types of biofilms a higher sporulation efficiency was observed compared to that of planktonic cells (0.0002-0.1\%) (Fig. 3c). 
a
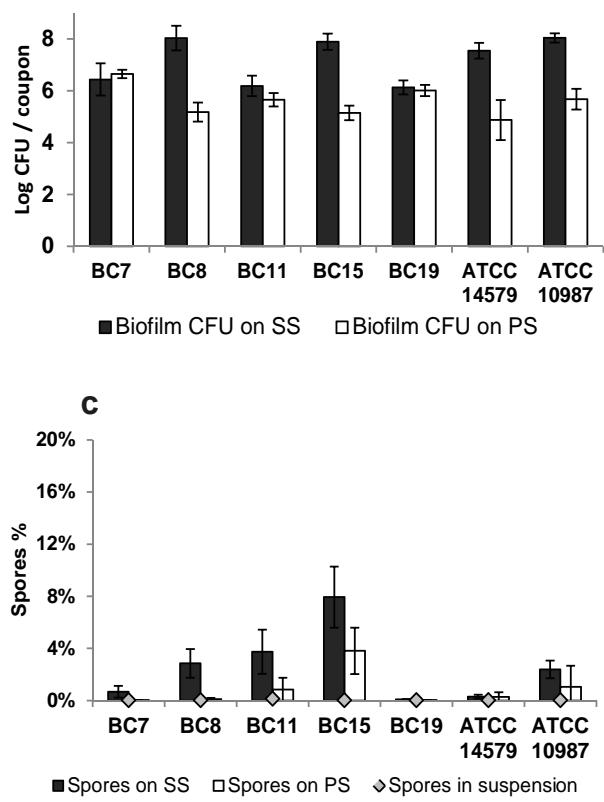

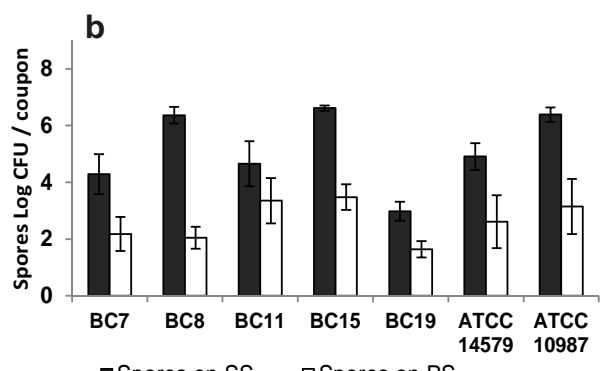

$\square$ Spores on SS $\quad$ Spores on PS

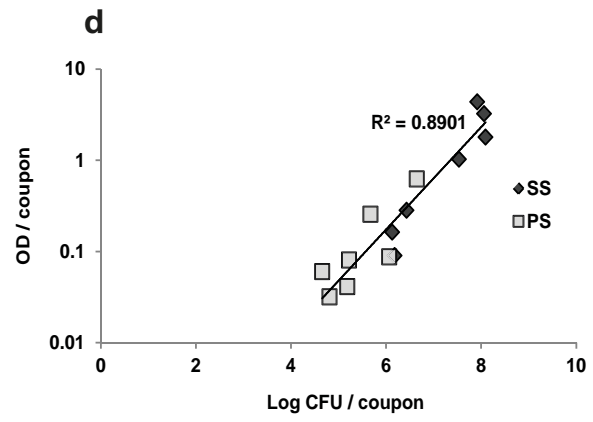

Figure 3. Biofilms of selected B. cereus strains on stainless steel and polystyrene coupons in BHI at 30 ${ }^{\circ} \mathrm{C}$ after $48 \mathrm{~h}$. a) Total CFU counts in the biofilms; b) number of spores in respective biofilms; c) spores relative to total CFU counts in biofilms (columns) and in planktonic phase in the suspension around the biofilm (diamonds), d) correlation between the overall biomass (OD values) and log CFU numbers of the biofilms for the seven selected $B$. cereus strains on the two materials.

\section{Influence of iron availability on biofilm formation of B. cereus ATCC 10987}

The observation that biofilm formation on SS coupons was higher for most B. cereus strains triggered us to study the impact of iron, which is the main component in SS, on biofilm formation. B. cereus ATCC 10987 forms biofilm on both materials and was therefore used for tests with either reduced iron availability or excess of iron. Iron availability was reduced by addition of 2,2-Bipyridine (Bip), which is an efficient scavenger of iron, for iron excess conditions, $250 \mu \mathrm{M} \mathrm{FeCl}_{3}$ was added to the BHI medium.

Scavenging iron with Bip significantly reduced biofilm formation on both PS and SS (Fig.4a). This effect was not observed when Bip was added together with excess iron. Addition of Bip also lowered the final number of planktonic cells in suspension by $0.4 \log \mathrm{CFU} / \mathrm{ml}$ compared to the control (BHI) at $48 \mathrm{~h}$ (not shown). In BHI + Bip the numbers of attached cells within the biofilms were reduced by 1.3 and $1 \log$ on PS and SS, respectively (Fig. 4b). 
Excess of iron promoted biofilm formation on PS but not on SS (Fig. 4a and b), possibly because in the latter case sufficient iron was already available. Supplementation with iron specifically affected biofilm formation since the CFU counts in planktonic stage were not significantly different from that in BHI without iron supplementation (data not shown). Thus, both overall biomass of the biofilm and biofilm cell numbers were affected similarly by the iron availability as reflected in the linear correlation $\left(R^{2}=0.96\right)$ between these two parameters (Fig. 4c).

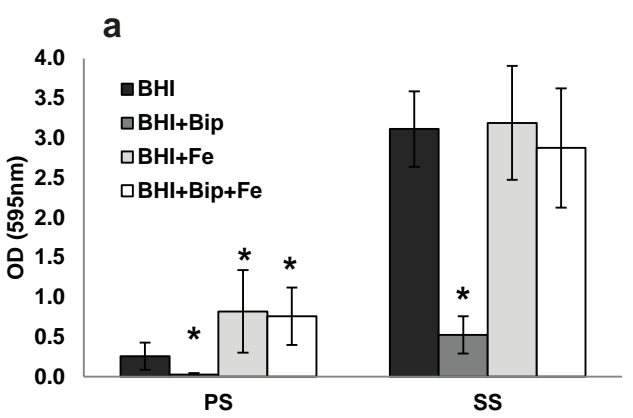

b

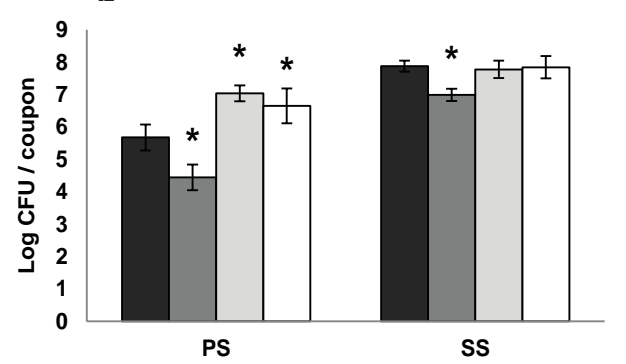

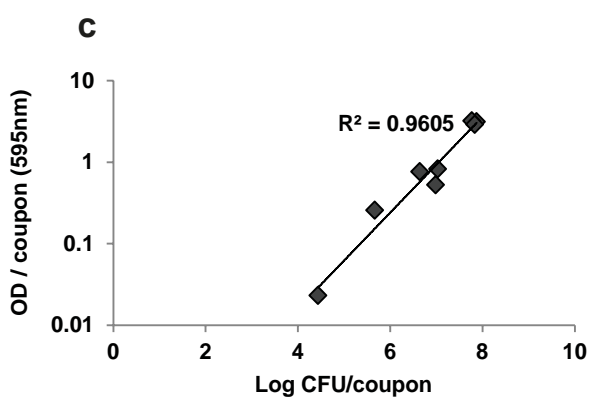

Figure 4. Biofilm formation by B. cereus ATCC 10987 on PS and SS as influenced by iron availability in the following four conditions: BHI; BHI supplemented with $250 \mu \mathrm{M} \mathrm{FeCl}_{3}$ (BHI + Fe); BHI supplemented with 450 $\mu \mathrm{M}$ 2,2-Bipyridine (BHI + Bip); BHI supplemented with 2,2-Bipyridine and $\mathrm{FeCl}_{3}(\mathrm{BHI}+\mathrm{Bip}+\mathrm{Fe})$. a) Biofilm biomass as determined by the crystal violet assay, b) total CFU counts in the biofilms, c) correlation between the OD and log CFUs. Asterisk (*) indicates significant difference $(\mathrm{p}<0.05)$ compared to BHI.

The initial attachment of $B$. cereus 10987 on the two materials was comparable and was not significantly altered when iron was scavenged (Fig. 5). Therefore, the observed effects could not be explained by a reduced initial attachment. Furthermore, addition of extra iron did not promote but significantly reduced the attachment of $B$. cereus cells to both materials (Fig. 5).

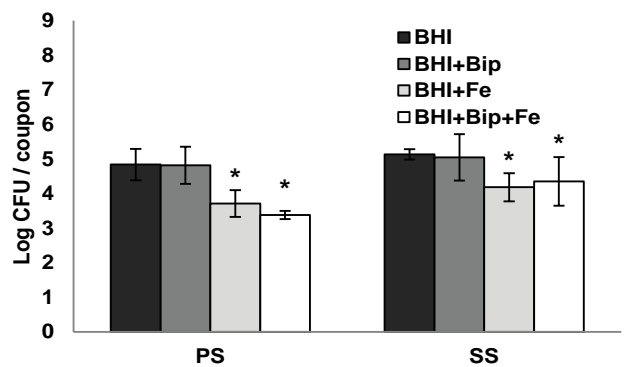

Figure 5. Initial attachment of $B$. cereus ATCC 10987 on PS and SS in BHI measured after $2 \mathrm{~h}$ of inoculation as influenced by iron availability. Asterisk (*) indicates significant difference $(\mathrm{p}<0.05)$ compared to BHI . 


\section{Influence of iron on biofilm formation by other $B$. cereus strains}

The potential role of iron in biofilm formation by B. cereus was further studied for all $23 \mathrm{~B}$. cereus strains. Experiments were performed in a microtiter plate assay using a smaller de-staining volume to increase the sensitivity of the assay and to allow high throughput analysis. Fourteen out of the 23 strains tested, namely BC $1,2,3,7,9,10,11,13,14,18,19,20,21$ and ATCC 10987, formed a biofilm (CV assay) in the microtiter plate in BHI without additives (Fig. 6). Addition of iron promoted the biofilm formation of 7 out of those 14 biofilm forming strains (BC $2,9,10,11,13,19$, ATCC 10987). In addition it promoted the biofilm of BC16, a non-producer in BHI. The biofilm forming capacity was not affected for the other strains (Fig. 6). This effect could not be attributed to the influence on cell counts since iron supplementation did not affect final cell counts measured after $24 \mathrm{~h}$ (data not shown). BC7 showed an opposite effect as addition of iron reduced the amount of biofilm formed, albeit that this could be a result of a loss or breakdown of the biofilm. Removal of iron by addition of Bip either eliminated or reduced the ability to form biofilms for 12 strains (BC 1, 2, 3, 7,9, 10, 11, 13, 14, 18, 19, ATCC 10987), including the above mentioned 7 strains that showed enhanced biofilm formation with added iron. The effect of Bip may in part be explained by an effect on growth as its addition reduced total final cell counts between 0.5-2.3 log CFU/ml (not shown) for a subset of the strains, including those with affected biofilm formation.

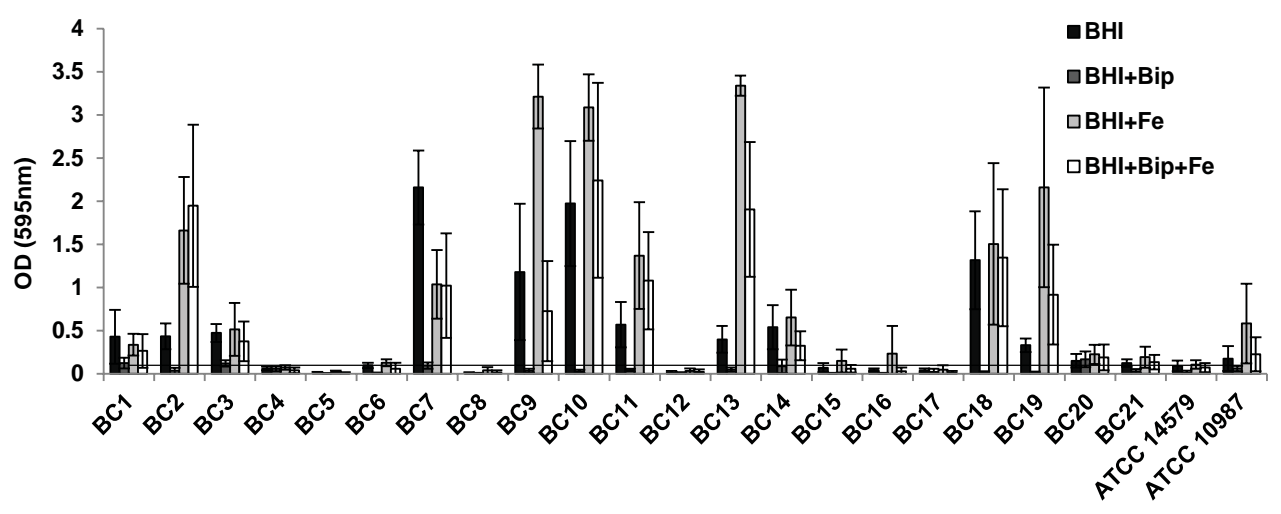

Figure 6. Biofilm formation of Bacillus cereus food isolates and reference ATCC strains in PS 96-wells plate as influenced by iron availability in the following four conditions: BHI; BHI supplemented with $250 \mu \mathrm{M} \mathrm{FeCl} 3$ (BHI + Fe); BHI supplemented with $450 \mu \mathrm{M}$ 2,2-Bipyridine (BHI + Bip); BHI supplemented with 2,2-Bipyridine and $\mathrm{FeCl} 3(\mathrm{BHI}+\mathrm{Bip}+\mathrm{Fe})$. Biofilm was measured after $24 \mathrm{~h}$ at $30{ }^{\circ} \mathrm{C}$ by crystal violet assay. 


\section{Discussion}

In this study, we showed that biofilm formation on stainless steel is a trait widely present in B. cereus. The study included both B. cereus food isolates and the two frequently described reference strains ATCC 14579 (air isolate) and ATCC 10987 (spoiled cheese isolate). Biofilm formation by these strains was higher on stainless steel (SS) compared to polystyrene (PS) and was typically formed at the air-liquid interface, as also reported previously for B. cereus (Wijman et al. 2007, Houry et al. 2010). The data reveal that the biofilm forming capacity of B. cereus is strongly dependent on the surface material. For high throughput studies, polystyrene multiwell plates are often used. However, our findings suggest that for B. cereus, PS is a relatively weak biofilm supporting material compared to SS. Moreover, SS is relevant for food producers as it is typically applied for process equipment.

CV quantification is a commonly applied method to quantify total biomass in biofilm studies. We observed that for several strains biofilm formation on PS coupons was below the selected threshold level based on CV analysis, however CFU's up to 5-6 log units per coupon could still be measured. This could be explained by the detection limit of the CV assay which requires at least $5.5 \log$ units of CFUs for quantification. This implied that below the threshold level of the CV assay, still significant numbers of cells can be present on a surface that could be of relevance in industrial practice. The CV assay appeared to be a good measure for B. cereus biofilm formation as the amount of total biofilm (CV) was proportional to the number of cells in the biofilm (correlation $\mathrm{R}^{2}=0.89$ ) (Fig. 3d). Similar observations have been previously reported for B. cereus 10987 (Auger et al. 2006) and Pseudomonas biofilms (Head and Yu 2004). SEM images of the biofilms formed on SS and PS (Fig. 2) showed no major structural differences and this suggests that differences in CV readings are correlated with cell numbers in the biofilm, though at this stage we cannot exclude the possible presence of other matrix components that are not visualised by SEM or are lost during sample preparations.

B. cereus ATCC 10987, isolated from spoiled cheese, is among the highest biofilm formers of the food isolates indicating that it is a representative strain for $B$. cereus biofilm studies and may be favoured over strain ATCC 14579 with poor biofilm formation on glass or PVC (Auger et al. 2006, Karunakaran and Biggs 2011) and PS (this study). Nevertheless, B. cereus ATCC 14579 can form considerable amounts of biofilm on SS coupons reaching $7.5 \log$ CFUs attached/coupon versus 8 log for strain ATCC 10987.

BHI broth used in our study is a rich medium which did not support effective sporulation of B. cereus in planktonic state, although in biofilms, sporulation efficiency was significantly higher reaching spore percentages on SS coupons up to 3.7 and $7.9 \%$ of 
the total population for strains $\mathrm{BC} 11$ and $\mathrm{BC} 15$, respectively. The higher sporulation efficiency in the biofilm compared to planktonic cells may be explained by several factors including the higher cell density reached in a biofilm, more extensive nutrient limitation (van Gestel et al. 2012), and/or intertwined regulatory pathways between biofilm formation and sporulation as proposed previously for $B$. subtilis (Vlamakis et al. 2013). The latter remains to be elucidated for $B$. cereus. The observed biofilm spore numbers were still lower than those reported for air-liquid interface biofilms of $B$. cereus in nutrient limited media (up to $90 \%$ spores) (Wijman et al. 2007, Faille et al. 2014), suggesting that sporulation is also affected by the type of medium used. For submerged biofilms attached on glass wool, no substantial differences in sporulation efficiency were reported when compared to those obtained in the planktonic phase for B. cereus ( 0.04 and $0.03 \%$, respectively) in a nutrient limited medium, whereas for B. subtilis, $49 \%$ versus $10 \%$ spores respectively were reported (Lindsay et al. 2006).

Once spores are formed in the biofilm they form a risk for recontamination of food products (Faille et al. 2014) > . Several factors, including shear forces and nutritional changes in the environment, can release cells and spores from mature biofilms, or can detach them as a whole. These cells and spores can be a concern for recontamination of food products or fouling of process lines upon settling and outgrowth resulting in generation of new biofilms.

In this study, we established a promoting role for $\mathrm{FeCl}_{3}$ in biofilm formation by $B$. cereus. It could be hypothesized that iron promotes the initial attachment of cells, since we observed higher biofilm on PS in BHI $+\mathrm{Fe}$ after $48 \mathrm{~h}$. However the initial attachment of strain ATCC 10987 after $2 \mathrm{~h}$ in this condition was significantly reduced compared to BHI (Fig. 5). In BHI the CFU counts attached on SS after $2 \mathrm{~h}$ reached 5.1 $\log \mathrm{CFU} /$ coupon (Fig. 5) which is equivalent to $4.5 \log \mathrm{CFU} / \mathrm{cm}^{2}$, similar to attachment of $4.3 \log \mathrm{CFU} / \mathrm{cm}^{2}$ on SS after $6.5 \mathrm{~h}$ in milk previously reported for a B. cereus isolate (Peña et al. 2014). Furthermore, the attachment on PS and SS were comparable, which indicates that a denser biofilm formation on SS cannot be explained by a higher initial attachment. Similar findings were reported previously showing no correlation between the initial attachment by different strains of $B$. subtilis to PS within $1.5 \mathrm{~h}$ and the biofilm formed after $48 \mathrm{~h}$ (Bridier et al. 2011).

Iron is an essential element for many aerobic microorganisms as a principal component in electron transfer and in many other enzyme reactions. In addition, it has been proposed to act as a signalling molecule in biofilm formation (Banin et al. 2005). A positive relation between iron availability and biofilm formation has been described in literature for several microorganisms, such as Pseudomonas aeruginosa (Banin et al. 2005), Escherichia coli (Wu and Outten 2009) and Staphylococcus aureus (Lin et al. 2012), however, to our knowledge not for Bacillus. 
Several mechanisms for a biofilm promoting effect of iron have been proposed for various species (Yang et al. 2007, Patriquin et al. 2008, Cai et al. 2010), but its role in biofilm formation of $B$. cereus remains to be determined. The fact that both under iron excess and iron limited conditions a linear correlation was found between biofilm CFUs and CV stained biomass (Fig. 4c) combined with the fact that initial attachment to the surface was not promoted by iron suggests that a role of iron in surface-associated behaviour such as cell-cell interaction is more likely than a role in cell-substratum interaction or production of matrix components in the biofilm.

Based on their response to iron availability, two overrepresented groups could be observed for the $B$. cereus strains tested. The first group of strains were able to form biofilm on PS in BHI (microtiter plate assay), which was highly affected by the free iron availability in the medium (Fig. 6). The second group included strains such as BC5, 8 and 15, that formed no biofilm on PS, but could form a considerable biofilm on SS coupons. For the second group neither biofilm formation on PS (fig. 6) nor the planktonic growth were significantly affected (not shown) by addition or removal of iron. The distinction between these two groups may be explained by their capacity to use complex sources of iron present in BHI as alternative to free iron. This requires the presence and activity of siderophore-mediated transport systems that could be strain-specific (Daou et al. 2009, Hotta et al. 2010).

It remains to be addressed why biofilm formation on SS was higher compared to PS and a combination of factors may be involved such as substratum physicochemical characteristics, cell envelope composition of $B$. cereus or availability of iron from the SS. Passive release of metals from stainless steel may play a role, especially when the SS surface is deformed or damaged (Herting et al. 2005). In the experimental set-up of this study we measured release of only $0.7 \pm 0.05 \mu \mathrm{M}$ iron (ICP-MS, not shown) after $48 \mathrm{~h}$, which seems of minor importance compared to the amount added in this study $(250 \mu \mathrm{M})$, though it could be still relevant in comparison with the measured total solvable iron content in BHI of $13.5+0.08 \mu \mathrm{M}$ (ICP-MS, not shown). On the other hand active release of iron mediated by corrosion could also take place. Several aerobic biofilm forming bacteria, such as Pseudomonas and Bacillus megaterium, are able to cause local bio corrosion of stainless steel (Rajasekar and Ting 2011 ). B. cereus has also been implicated in corrosive behaviour of different metallic surfaces (Rajasekar and Ting 2010 , Bragadeeswaran et al. 2011). Further experiments are required to test whether this effect could play a role in food processing environments.

To conclude, B. cereus forms considerably higher amounts of biofilm on SS compared to PS in terms of total biomass and the number of attached cells. The efficiency of spore formation was higher in the biofilm, especially on SS, compared to planktonic 
state. This illustrates that microbial behaviour in industrial environments where stainless steel is widely used for process equipment can be very different from that encountered in a laboratory.

Besides its well documented role in different cellular functions, we show that free iron availability is important for effective biofilm formation by several B. cereus food isolates. More insights into the mechanism of this phenomenon may provide new leads to prevent domestication and establishment of this pathogen in factory environments.

\section{Acknowledgements}

The authors would like to thank Tiny Franssen-Verheijen of the Wageningen Electron Microscopy Centre (WEMC) for technical support with the SEM analysis and Peter Nobels

from the Chemical and Biological Laboratory for iron content measurements with ICP-MS.

The project is funded by TI Food and Nutrition, a public-private partnership on precompetitive research in food and nutrition. The public partners are responsible for the study design, data collection and analysis, decision to publish, and preparation of the manuscript. The private partners have contributed to the project through regular discussion. 


\section{References}

Auger, S., E. Krin, S. Aymerich and M. Gohar (2006). Autoinducer 2 affects biofilm formation by Bacillus cereus. Applied and Environmental Microbiology 72(1): 937-941.

Banin, E., M. L. Vasil and E. P. Greenberg (2005). Iron and Pseudomonas aeruginosa biofilm formation. Proceedings of the National Academy of Sciences of the United States of America 102(31): 11076-11081.

Berlutti, F., M. Ajello, P. Bosso, C. Morea, A. Petrucca, G. Antonini and P. Valenti (2004). Both lactoferrin and iron influence aggregation and biofilm formation in Streptococcus mutans. Biometals 17(3): 271-278.

Bragadeeswaran, S., R. Jeevapriya, K. Prabhu, S. S. Rani, S. Priyadharsini and T. Balasubramanian (2011). Exopolysaccharide production by Bacillus cereus GU812900, a fouling marine bacterium. African Journal of Microbiology Research 5(24): 4124-4132.

Branda, S. S., Å. Vik, L. Friedman and R. Kolter (2005). Biofilms: The matrix revisited. Trends in Microbiology 13(1): 20-26.

Bridier, A., D. Le Coq, F. Dubois-Brissonnet, V. Thomas, S. Aymerich and R. Briandet (2011). The spatial architecture of Bacillus subtilis biofilms deciphered using a surface-associated model and in Situ imaging. PloS One 6(1).

Cai, Y., R. Wang, M. M. An and B. B. Liang (2010). Iron-depletion prevents biofilm formation in Pseudomonas aeruginosa through twitching motility and quorum sensing. Brazilian Journal of Microbiology 41(1): 37-41.

Castelijn, G. A., J. A. Parabirsing, M. H. Zwietering, R. Moezelaar and T. Abee (2013). Surface behaviour of S. Typhimurium, S. Derby, S. Brandenburg and S. Infantis. Veterinary Microbiology 161(3-4): 305-314.

Castelijn, G. A. A., S. van der Veen, M. H. Zwietering, R. Moezelaar and T. Abee (2012). Diversity in biofilm formation and production of curli fimbriae and cellulose of Salmonella Typhimurium strains of different origin in high and low nutrient medium. Biofouling 28(1): 51-63.

Daou, N., C. Buisson, M. Gohar, J. Vidic, H. Bierne, M. Kallassy, D. Lereclus and C. Nielsen-LeRoux (2009). IlsA, a unique surface protein of Bacillus cereus required for iron acquisition from heme, hemoglobin and ferritin. PLoS Pathogens 5(11).

Djordjevic, D., M. Wiedmann and L. A. McLandsborough (2002). Microtiter plate assay for assessment of Listeria monocytogenes biofilm formation. Applied and Environmental Microbiology 68(6): 2950-2958.

Eneroth, Å. S. A., B. Svensson, G. Molin and A. Christiansson (2001). Contamination of pasteurized milk by Bacillus cereus in the filling machine. Journal of Dairy Research 68(2): 189-196.

Faille, C., T. Bénézech, G. Midelet-Bourdin, Y. Lequette, M. Clarisse, G. Ronse, A. Ronse and C. Slomianny (2014). Sporulation of Bacillus spp. within biofilms: A potential source of contamination in food processing environments. Food Microbiology 40: 64-74.

Flint, S. H., P. J. Bremer and J. D. Brooks (1997). Biofilms in dairy manufacturing plant - Description, current concerns and methods of control. Biofouling 11(1): 81-97.

Flint, S. H., J. D. Brooks and P. J. Bremer (2000). Properties of the stainless steel substrate, influencing the adhesion of thermo-resistant Streptococci. Journal of Food Engineering 43(4): 235-242.

Goulter, R. M., I. R. Gentle and G. A. Dykes (2009). Issues in determining factors influencing bacterial attachment: A review using the attachment of Escherichia coli to abiotic surfaces as an example. Letters in Applied Microbiology 49(1): 1-7.

Head, N. E. and H. Yu (2004). Cross-sectional analysis of clinical and environmental isolates of Pseudomonas aeruginosa: biofilm formation, virulence, and genome diversity. Infection and Immunity 72(1): 133-144.

Herting, G., I. Odnevall Wallinder and C. Leygraf (2005). A comparison of release rates of $\mathrm{Cr}, \mathrm{Ni}$, and Fe from stainless steel alloys and the pure metals exposed to simulated rain events. Journal of the Electrochemical Society 152(1): B23-B29. 
Hindré, T., H. Brüggemann, C. Buchrieser and Y. Héchard (2008). Transcriptional profiling of Legionella pneumophila biofilm cells and the influence of iron on biofilm formation. Microbiology 154(1): 30-41.

Hotta, K., C. Y. Kim, D. T. Fox and A. T. Koppisch (2010). Siderophore-mediated iron acquisition in Bacillus anthracis and related strains. Microbiology 156(7): 1918-1925.

Houry, A., R. Briandet, S. Aymerlch and M. Gohar (2010). Involvement of motility and flagella in Bacillus cereus biofilm formation. Microbiology 156(4): 1009-1018.

Karatan, E. and P. Watnick (2009). Signals, regulatory networks, and materials that build and break bacterial biofilms. Microbiology and Molecular Biology Reviews 73(2): 310-347.

Karunakaran, E. and C. A. Biggs (2011). Mechanisms of Bacillus cereus biofilm formation: An investigation of the physicochemical characteristics of cell surfaces and extracellular proteins. Applied Microbiology and Biotechnology 89(4): 1161-1175.

Lin, M. H., J. C. Shu, H. Y. Huang and Y. C. Cheng (2012). Involvement of iron in biofilm formation by Staphylococcus aureus. PloS One 7(3).

Lindsay, D., V. S. Brözel and A. Von Holy (2006). Biofilm-spore response in Bacillus cereus and Bacillus subtilis during nutrient limitation. Journal of Food Protection 69(5): 1168-1172.

Marchand, S., J. De Block, V. De Jonghe, A. Coorevits, M. Heyndrickx and L. Herman (2012). Biofilm formation in milk production and processing environments; influence on milk quality and safety. Comprehensive Reviews in Food Science and Food Safety 11(2): 133-147.

Mols, M., M. De Been, M. H. Zwietering, R. Moezelaar and T. Abee (2007). Metabolic capacity of Bacillus cereus strains ATCC 14579 and ATCC 10987 interlinked with comparative genomics. Environmental Microbiology 9(12): 2933-2944.

Palmer, J., S. Flint and J. Brooks (2007). Bacterial cell attachment, the beginning of a biofilm. Journal of Industrial Microbiology and Biotechnology 34(9): 577-588.

Patriquin, G. M., E. Banin, C. Gilmour, R. Tuchman, E. P. Greenberg and K. Poole (2008). Influence of quorum sensing and iron on twitching motility and biofilm formation in Pseudomonas aeruginosa. Journal of Bacteriology 190(2): 662-671.

Peña, W. E. L., N. J. de Andrade, N. F. F. Soares, V. O. Alvarenga, S. Rodrigues Junior, D. Granato, A. D. Giraldo Zuniga and A. de Souza Sant'Ana (2014). Modelling Bacillus cereus adhesion on stainless steel surface as affected by temperature, $\mathrm{pH}$ and time. International Dairy Journal 34(1): 153-158.

Petrova, O. E. and K. Sauer (2012). Sticky situations: Key components that control bacterial surface attachment. Journal of Bacteriology 194(10): 2413-2425.

Rajasekar, A. and Y. P. Ting (2010). Microbial corrosion of aluminum 2024 aeronautical alloy by hydrocarbon degrading bacteria Bacillus cereus ACE4 and Serratia marcescens ACE2. Industrial and Engineering Chemistry Research 49(13): 6054-6061.

Rajasekar, A. and Y. P. Ting (2011). Role of inorganic and organic medium in the corrosion behavior of Bacillus megaterium and Pseudomonas sp. in stainless steel SS 304. Industrial and Engineering Chemistry Research 50(22): 12534-12541.

Trappetti, C., A. J. Potter, A. W. Paton, M. R. Oggioni and J. C. Paton (2011). LuxS mediates irondependent biofilm formation, competence, and fratricide in Streptococcus pneumoniae. Infection and Immunity 79(11): 4550-4558.

Tresse, O., K. Shannon, A. Pinon, P. Malle, M. Vialette and G. Midelet-Bourdin (2007). Variable adhesion of Listeria monocytogenes isolates from food-processing facilities and clinical cases to inert surfaces. Journal of Food Protection 70(7): 1569-1578.

van Gestel, J., M. A. Nowak and C. E. Tarnita (2012). The evolution of cell-to-cell communication in a sporulating bacterium. PLoS Computational Biology 8(12).

Vanhaecke, E., J. P. Remon, M. Moors, F. Raes, D. De Rudder and A. Van Peteghem (1990). Kinetics of Pseudomonas aeruginosa adhesion to 304 and 316-L stainless steel: Role of cell surface hydrophobicity. Applied and Environmental Microbiology 56(3): 788-795. 
Vlamakis, H., Y. Chai, P. Beauregard, R. Losick and R. Kolter (2013). Sticking together: building a biofilm the Bacillus subtilis way. Nature Reviews Microbiology 11(3): 157-168.

Wijman, J. G. E., P. P. L. A. De Leeuw, R. Moezelaar, M. H. Zwietering and T. Abee (2007). Airliquid interface biofilms of Bacillus cereus: Formation, sporulation, and dispersion. Applied and Environmental Microbiology 73(5): 1481-1488.

Wu, Y. and F. W. Outten (2009). IscR controls iron-dependent biofilm formation in Escherichia coli by regulating type I fimbria expression. Journal of Bacteriology 191(4): 1248-1257.

Yang, L., K. B. Barken, M. E. Skindersoe, A. B. Christensen, M. Givskov and T. Tolker-Nielsen (2007). Effects of iron on DNA release and biofilm development by Pseudomonas aeruginosa. Microbiology 153(5): 1318-1328. 



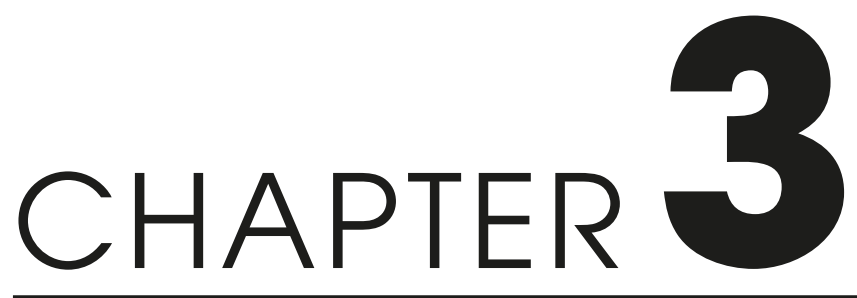

Comparative genomics of iron-transporting systems in Bacillus cereus strains and impact of iron sources on growth and biofilm formation

Hasmik Hayrapetyan

Roland Siezen

Tjakko Abee

Masja Nierop Groot

Published in Frontiers in Microbiology (2016) 7:842 


\begin{abstract}
Iron is an important element for bacterial viability, however it is not readily available in most environments. We studied the ability of 20 undomesticated food isolates of Bacillus cereus and two reference strains for capacity to use different (complex) iron sources for growth and biofilm formation. Studies were performed in media containing the iron scavenger 2,2-Bipyridine. Transcriptome analysis using B. cereus ATCC 10987 indeed showed upregulation of predicted iron transporters in the presence of 2,2-Bipyridine, confirming that iron was depleted upon its addition. Next, the impact of iron sources on growth performance of the 22 strains was assessed and correlations between growth stimulation and presence of putative iron transporter systems in the genome sequences were analysed. All 22 strains effectively used $\mathrm{Fe}$ citrate and $\mathrm{FeCl}_{3}$ for growth, and possessed genes for biosynthesis of the siderophore bacillibactin, whereas 7 strains lacked genes for synthesis of petrobactin. Hemoglobin could be used by all strains with the exception of one strain that lacked functional petrobactin and IlsA systems. Hemin could be used by the majority of the tested strains (19 of 22). Notably, transferrin, ferritin, and lactoferrin were not commonly used by $B$. cereus for growth, as these iron sources could be used by 6,3 , and 2 strains, respectively. Furthermore, biofilm formation was found to be affected by the type of iron source used, including stimulation of biofilms at liquid-air interphase $\left(\mathrm{FeCl}_{3}\right.$ and $\mathrm{Fe}$ citrate) and formation of submerged type biofilms (hemin and lactoferrin). Our results show strain variability in the genome-encoded repertoire of iron-transporting systems and differences in efficacy to use complex iron sources for growth and biofilm formation. These features may affect $B$. cereus survival and persistence in specific niches.
\end{abstract}




\section{Introduction}

Iron is one of the essential elements required for growth and metabolism of the majority of microorganisms. Despite its important role in microbial cells, the availability of free iron in the environment is limited due to oxidation of ferrous iron to ferric ions which precipitate near neutral pH (Ratledge and Dover 2000). Free ferrous iron can be toxic to mammals due to formation of oxygen radicals, consequently the majority of host iron is bound to transport molecules such as hemoglobin (red blood cells), transferrin (serum) and lactoferrin (milk and mucosal secretions), or to ferritin-like proteins for intracellular iron storage (Ratledge and Dover 2000). The storage of iron in complexed form also reduces its availability for invading pathogenic microorganisms. However, many pathogens developed mechanisms to overcome iron scarcity by the expression of scavenging systems specific to complex and non-complex iron sources. Two main scavenging mechanisms for iron have been described. Bacteria may secrete specific molecules with high affinity to iron named siderophores (Ratledge and Dover 2000, Zawadzka et al. 2009) that facilitate iron transport into the microbial cell. These siderophores sequester iron from different sources such as transferrin (Abergel et al. 2008). The second mechanism involves specific ABC-type transporters encompassing highaffinity surface receptors specific for either complex iron compounds or free iron (Brown and Holden 2002, Daou et al. 2009). B. cereus genomes encode several putative $\mathrm{ABC}$ transporters for complexed iron including ferric citrate (Harvie and Ellar 2005, Fukushima et al. 2012) and ferrichrome, and several others of unknown substrate specificity (Hotta et al. 2010). Furthermore, a possible interplay between different molecules has been suggested. For example the heme-binding surface protein IlsA in B. cereus also serves as ferritin receptor and assists in ferritin-iron sequestration by bacillibactin siderophore (Segond et al. 2014). IlsA has also been shown to transfer bound hemin to another surface iron transporting molecule of the IlsA system IsdC (Abi-Khalil et al. 2015).

For B. cereus, two different siderophores, bacillibactin (BB) and petrobactin (PB) (Wilson et al. 2006) have been identified. $\mathrm{PB}$ is the main siderophore for $B$. anthracis (Koppisch et al. 2005) and important for its virulence since it is not recognised by the innate immune system (Abergel et al. 2006). In B. cereus, BB seems to be of higher importance in virulence compared to $\mathrm{PB}$ based on experiments in an insect model (Segond et al. 2014).

B. cereus has been reported to use various iron sources for growth that are typically present in red blood cells such as hemoglobin ( $\mathrm{Hb})$, hemin and other hemoproteins (Sato et al. 1998, Sato et al. 1999a, Sato et al. 1999b). For B. cereus ATCC 14579, the use of ferritin as an iron source has been described (Daou et al. 2009). Concerning the use of transferrin by different $B$. cereus strains, contradictory reports have been 
published that conceivably links to strain variability (Sato et al. 1998, Park et al. 2005, Daou et al. 2009) and pointing to the importance to take strain diversity into account in studies on iron metabolism. Lactoferrin, an iron source typically present in milk, cannot be used by $B$. cereus and inhibits its growth when present in high concentrations (Sato et al. 1999b, Daou et al. 2009). Ferric citrate, an iron source formed from citric acid which is commonly present in milk and citrus fruits, can also be used by B. cereus (Fukushima et al. 2012). These iron sources can be encountered in different environments including soil, food and processing environments, and mammal or insects. The ability to use these sources largely determines the fitness of bacteria and capacity to adapt to specific niches.

Besides its important role as essential element for bacterial growth and virulence (Cendrowski et al. 2004, Harvie et al. 2005, Porcheron and Dozois 2015), iron has also been reported to affect biofilm formation (Porcheron and Dozois 2015). It was recently shown that air-liquid biofilm formation by a selection of $B$. cereus food isolates was stimulated by addition of $\mathrm{FeCl}_{3}$ (Hayrapetyan et al. 2015a). Biofilm formation may serve as survival mechanism in different environments and can be an important factor contributing to host colonisation. To our knowledge, the impact of different (complex) iron sources on biofilm formation capacity and type of biofilms formed including submerged or surface-attached liquid-air biofilms, has not been reported for this species.

In this study we investigated the use of different iron sources by $22 \mathrm{~B}$. cereus strains in relation to their genome content. Expression of the iron transporters in iron deplete and replete conditions was studied in the reference strain ATCC 10987. Since the ability of $B$. cereus to form biofilms contributes to its persistence in environment and free iron availability is important for biofilm formation of B. cereus (Hayrapetyan et al. 2015a), we also studied the effect of iron sources encountered in different environments on biofilm formation.

\section{Materials and Methods}

\section{Strains and culturing conditions}

Twenty Bacillus cereus food isolates from the NIZO culture collection were used in this study (Hayrapetyan et al. 2015a) along with two reference strains B. cereus ATCC 10987 and ATCC 14579. To obtain overnight cultures, a loop full with stock cultures stored at $-80{ }^{\circ} \mathrm{C}$ was inoculated into $10 \mathrm{ml} \mathrm{LB}$ broth (Miller, MERCK), supplemented with $100 \mu \mathrm{M}$ 2,2-Bipyridine (Bip) (MERCK) to induce iron starvation, and incubated for $18 \mathrm{~h}$ at $30{ }^{\circ} \mathrm{C}$ with shaking at $200 \mathrm{rpm}$. 
The twenty $B$. cereus food isolates were sequenced by next-generation whole genome sequencing. For eight strains (B4077, B4078, B4080, B4086, B4087, B4147, B4153, B4158), total DNA isolation and sequencing details are described elsewhere (Krawczyk et al. 2015), for the remaining 12 isolates draft genomes were obtained as described below.

To isolate genomic DNA, B. cereus strains used in this study were grown overnight (18 h) with shaking $(200 \mathrm{rpm})$ in $10 \mathrm{ml}$ of brain heart infusion (BHI) broth (Becton Dickinson) at $30^{\circ} \mathrm{C}$. Two $\mathrm{ml}$ of this culture was centrifuged at $13,000 \mathrm{xg}$ to harvest the cells and the resulting cell pellet was resuspended in 50mM EDTA/pH 8,0. Genomic DNA of the strains was isolated using the Wizard Genomic DNA Purification Kit (Promega, Madison, USA), according to the manufacturer's instructions.

The isolated DNA was sheared to 250-350 bp fragments and paired-end sequenced on an Illumina HiSeq2000 outsourced to BaseClear (Leiden, The Netherlands). CLC genomics workbench (v6.0.1) (http://www.clcbio.com/products/clc-genomicsworkbench), SSPACE (v2.3) (PMID21149342) and GapFiller (v1.1) (PMID 23095524) were used for assembly. The RAST server (PMID18261238) was used to annotate the genomes. This Whole Genome Shotgun project has been deposited at DDBJ/EMBL/ GenBank under the accession numbers: LJJZ00000000 (B4081), LJKA00000000 (B4082), LJKB00000000 (B4083), LJKC00000000 (B4084), LJKD00000000 (B4085), LJKE00000000 (B4088), LJKF00000000 (B4116), LJKG00000000 (B4117, recently re-classified by NCBI as Bacillus mycoides based on ANI typing (Federhen et al. 2016)), LJKH00000000 (B4118), LJKI00000000 (B4120), LJKJ00000000 (B4155), LJIT00000000 (B4079).

\section{Searching for iron-transporting systems in B. cereus genomes}

Orthologous groups (OGs; i.e. gene families) were determined using OrthoMCL (Enright et al. 2002). This program uses all-against-all protein BLAST where it groups proteins with more homology within the species than homology with proteins outside the species. In this way orthologs (genes in different species that evolved from a common ancestral gene by speciation) are separated from paralogs (genes related by duplication within a genome). In addition to the 20 newly sequenced genomes of food isolates (Krawczyk et al., 2015), the circular genomes of the two reference strains B. cereus ATCC 14579 and ATCC 10987 obtained from the NCBI database, were included. Contigs of the 20 newly sequenced genomes were scaffolded into their presumed correct order using the circular reference genomes as templates.

A database (in MS Excel) was built encompassing information about the location and length of orthologous proteins. Multiple sequence alignment files (MSA) were 
made (MUSCLE, version 3.8) (Edgar 2004), where the protein sequences within ortholog groups were aligned, to facilitate identification of pseudogenes (encoding incomplete proteins).

A literature search was performed to find known iron-uptake systems for $B$. cereus (Daou et al. 2009, Zawadzka et al. 2009, Hotta et al. 2010). Orthologous groups (OGs) containing the locus tags of these known genes were searched for in the OG table. Furthermore, a key word search was done to find additional iron uptake and storage systems, by searching in the annotation of all genomes for keywords: iron, ferric, ferrous, ferritin.

For relevant identified OGs containing pseudogenes, which are fragments of genes (i.e. truncated, frame-shifted or at the end of contigs), which had been classified by OrthoMCL into separate OGs adjacent on the chromosome, were combined into single OGs representing all the fragments of a single pseudogene.

The RAST automatic annotation of the encoded proteins was manually improved using InterproScan (http://www.ebi.ac.uk/Tools/pfa/iprscan/), NCBI-BLAST (http:// blast.ncbi.nlm.nih.gov/) and NCBI/Genbank database for the comparison of genes with other species (http://www.ncbi.nlm.nih.gov/).

\section{Growth and biofilm formation}

The growth and biofilm formation on different iron sources was tested in LB (as control), LB supplemented with $600 \mu \mathrm{M} \mathrm{2,2-Bipyridine} \mathrm{(LB+Bip)} \mathrm{as} \mathrm{iron} \mathrm{depleted}$ condition, and in iron-replete conditions using $\mathrm{LB}+\mathrm{Bip}$ with addition of the following iron sources in final concentrations: $\mathrm{FeCl}_{3}(250 \mu \mathrm{M})\left(\mathrm{LB}+\mathrm{Bip}+\mathrm{FeCl}_{3}\right)$, ferric citrate $(250 \mu \mathrm{M}) \quad(\mathrm{LB}+\mathrm{Bip}+\mathrm{Fe}$ citrate), hemoglobin (human, $2.5 \mu \mathrm{M})(\mathrm{LB}+\mathrm{Bip}+\mathrm{Hb})$, hemin (4, 8 and $16.5 \mu \mathrm{M})(\mathrm{LB}+\mathrm{Bip}+\mathrm{Hemin}$ ), ferritin (from equine spleen, $0.9 \mu \mathrm{M})(\mathrm{LB}+\mathrm{Bip}+$ Ferritin), transferrin (human, partially saturated, $1.5 \mu \mathrm{M})$ ( $\mathrm{LB}+\mathrm{Bip}+$ Transferrin), and lactoferrin (bovine milk, $0.7 \mu \mathrm{M})(\mathrm{LB}+\mathrm{Bip}+$ Lactoferrin). 2,2-Bipyridine, $\mathrm{FeCl}_{3}$ and ferric citrate were from MERCK and the remaining iron sources used were obtained from SIGMA. Selected concentrations were adapted from previously reported concentrations used for B. cereus (Daou et al. 2009),(Segond et al. 2014), with some optimization for the culturing conditions and strains of this study.

The strains were grown in a 96-well plate filled with $200 \mu \mathrm{LB}$ with or without supplements inoculated with $1 \%$ overnight culture. The growth was monitored by measuring the OD at $600 \mathrm{~nm}$ in SPECTRAmax (model PLUS384) at $30{ }^{\circ} \mathrm{C}$, with shaking for 60 seconds every 5 minutes. The growth index (GI) for each iron source was calculated as described elsewhere (Daou et al. 2009), by dividing the OD at 600 $\mathrm{nm}$ reached in LB after $10 \mathrm{~h}$ of growth by OD reached when grown with the specific iron source. 
The biofilms formed in 96-wells plates inoculated as described above, were measured after $24 \mathrm{~h}$ of static incubation at $30{ }^{\circ} \mathrm{C}$ using the Crystal Violet (CV) assay as described previously (Hayrapetyan et al. 2015a). Washing, staining and destaining steps were performed using $250 \mu$ of de-mineralized water, $0.1 \%$ crystal violet and $70 \%$ ethanol, respectively. After de-staining the OD was measured at 595 $\mathrm{nm}$. The strain was considered to form a biofilm if in a given condition the OD value was higher than 0.1, a threshold value as defined in (Hayrapetyan et al. 2015a).

\section{Transcriptome analysis to identify iron-responsive genes}

For transcriptome analysis RNA was isolated from static liquid cultures of $B$. cereus ATCC 10987 grown in BHI (control), BHI supplemented with $450 \mu \mathrm{M}$ Bip (BHI + Bip) for iron deplete condition, $\mathrm{BHI}$ supplemented with $250 \mu \mathrm{M} \mathrm{FeCl}_{3}\left(\mathrm{BHI}+\mathrm{FeCl}_{3}\right)$ and $\mathrm{BHI}$ with both $\mathrm{Bip}$ and $\mathrm{FeCl}_{3}\left(\mathrm{BHI}+\mathrm{Bip}+\mathrm{FeCl}_{3}\right)$ for iron replete conditions, and the latter to test whether iron supplementation could restore effects evoked by iron starvation induced by Bip. These conditions were based on a previous study in our laboratory showing the role of free iron in biofilm formation (Hayrapetyan et al. 2015a). The samples were taken at exponential growth phase (5 h). RNA was isolated as previously described (Hayrapetyan et al. 2015b). Labelling and hybridization were performed as described elsewhere (Mols et al. 2013). Two independent biological replicates were hybridized on the arrays, each sample was used three times and was labelled with the swapped dyes Cy3 and Cy5.

Custom-made array design for B. cereus ATCC 10987 developed by Agilent Technologies (GEO accession number GPL7681) (Mols et al. 2010) was used in this study. Microarray scanning and data normalization were performed as previously described (Hayrapetyan et al. 2015b). Genes with more than 2 fold change in expression and $\mathrm{p}<0.05$ were considered significantly affected. The processed and raw microarray data is deposited in GEO database under accession number GSE74045.

\section{Statistical analysis}

Presented values are averages of at least 3 independent experiments with standard deviations. The growth was considered recovered if the growth index of the strain on a specific iron source was significantly different from the growth index of the same strain when grown in LB + Bip without iron supplementation. Significance of the growth differences was concluded based on a two-sided student's t test, assuming equal variances and a $\mathrm{P}$ value $<0.01$. 


\section{Results}

\section{Iron transporting systems presence and expression}

Genomes of 20 food isolates and 2 reference B. cereus strains ATCC 14579 and ATCC 10987 were analysed for genes with predicted function in iron transport (Fig. 1A and Table 1). Genes encoding for synthesis of siderophore BB structural components (dhbACBEF) and transporters were present in all strains, while $\mathrm{PB}$ biosynthesis genes ( $a s b A B C D E F$ ) were absent in 7 of the 22 strains analysed. For 5 strains, PB biosynthesis genes were present but a functional fpuA/fhuB gene cluster necessary for PB uptake was lacking. However, another permease ( $f a t C D$ ) with a redundant function with $f h u B$ (Dixon et al. 2012), was identified in all the strains in a cluster together with ATP- and substrate-binding proteins (BC5103-5106). Interestingly BC4416, a fhuD-like putative iron compound binding protein with unknown specificity (Hotta et al. 2010) was absent in the strains that also lacked PB siderophore biosynthesis genes, which could indicate a role for this protein in PB transport.

The IlsA-system acts as a hemophore, and is encoded by the ilsA gene (BC1331) and an isd-like operon consisting of the ABC-transporter (BC4544-4546), sortase (BC4543), heme degrading monooxygenase (BC4542) and heme transport associated proteins BC4547, BC4548, and BC4549 (IsdC) in B. cereus ATCC 14579 (Daou et al. 2009). Genes encoding the IlsA system are present in all strains. In B4079 the IlsA protein appears to be truncated and non-functional due to a point mutation in the encoding gene that creates a premature stop codon. In B4147 the IlsA also appears to be ineffective due to a large internal deletion identified in the encoding gene (both verified with PCR and sequencing). The transport associated protein (BC4547) was identified as a pseudogene in 8 strains. Interestingly, the other transport associated secreted component of this system BC4548, which may function as a hemophore that captures heme from $\mathrm{Hb}$ and has $98 \%$ identity to isdX1 of $B$. anthracis (Daou et al. 2009), was absent in 11 strains.

Several other known iron ABC-transporters, such as an iron (III) dicitrate-binding complex (fhuD, fecCDE), a ferrichrome-binding complex (feuA/fhuGB), a fepC/ fhuGD complex and a fepBC/fhuGB complex, were present in all strains. The feuA/ fhuGB complex, known to bind ferric citrate in B. cereus (Fukushima et al. 2012), was only absent in strain B4088. The putative iron-binding protein yfiY (BC2208) was identified in all strains. Three additional systems, two of which encode ferrous iron transport FeoB-FeoA proteins (Kim et al. 2012), were identified in all B. cereus strains. Besides iron uptake genes, proteins involved in iron storage in bacteria, as for example the ferritin-like di-iron-binding proteins of the Dps family (DNA 
protection during starvation) (Tu et al. 2012) were considered. Five genes with putative function in iron storage were identified and were present in most strains with a few exceptions (Fig. 1A). The global regulator of iron uptake Fur (Harvie et al. 2005) was also present in all strains.

Transcriptome analysis of ATCC 10987 in iron replete $\left(\mathrm{BHI}+\mathrm{FeCl}_{3} ; \mathrm{BHI}+\mathrm{Bip}+\mathrm{FeCl}_{3}\right)$ and deplete (BHI + Bip) conditions showed significant upregulation of most of the above mentioned genes encoding iron transporters under iron starvation evoked by addition of scavengers (Fig. 1B).

Iron transport genes were upregulated from 8 up to 900 fold (Supplementary Table 1), which was most prominent for the BB biosynthesis genes. Ferritin-like proteins for storage of intracellular iron were not significantly affected. The second ferrous iron transport cluster FeoA/B (BCE4965-4966) was significantly up regulated during iron starvation, indicating that the so called "living fossil" (Hantke 2003) might still be functional in atmospheric conditions. Upon supplementation with $\mathrm{FeCl}_{3}$, none of these genes were significantly affected, with exception of BCE3769. This was the case also in the presence of Bip together with $\mathrm{FeCl}_{3}$ (with BCE2399 as an exception), showing that addition of iron reversed the iron starvation effect of Bip and support a role in iron transport and metabolism for these genes. These results indicate that iron scavenger Bip can be used to assess the efficacy of alternative (complex) iron sources to support growth of the selected 22 strains. 
A. Genotypic clusters

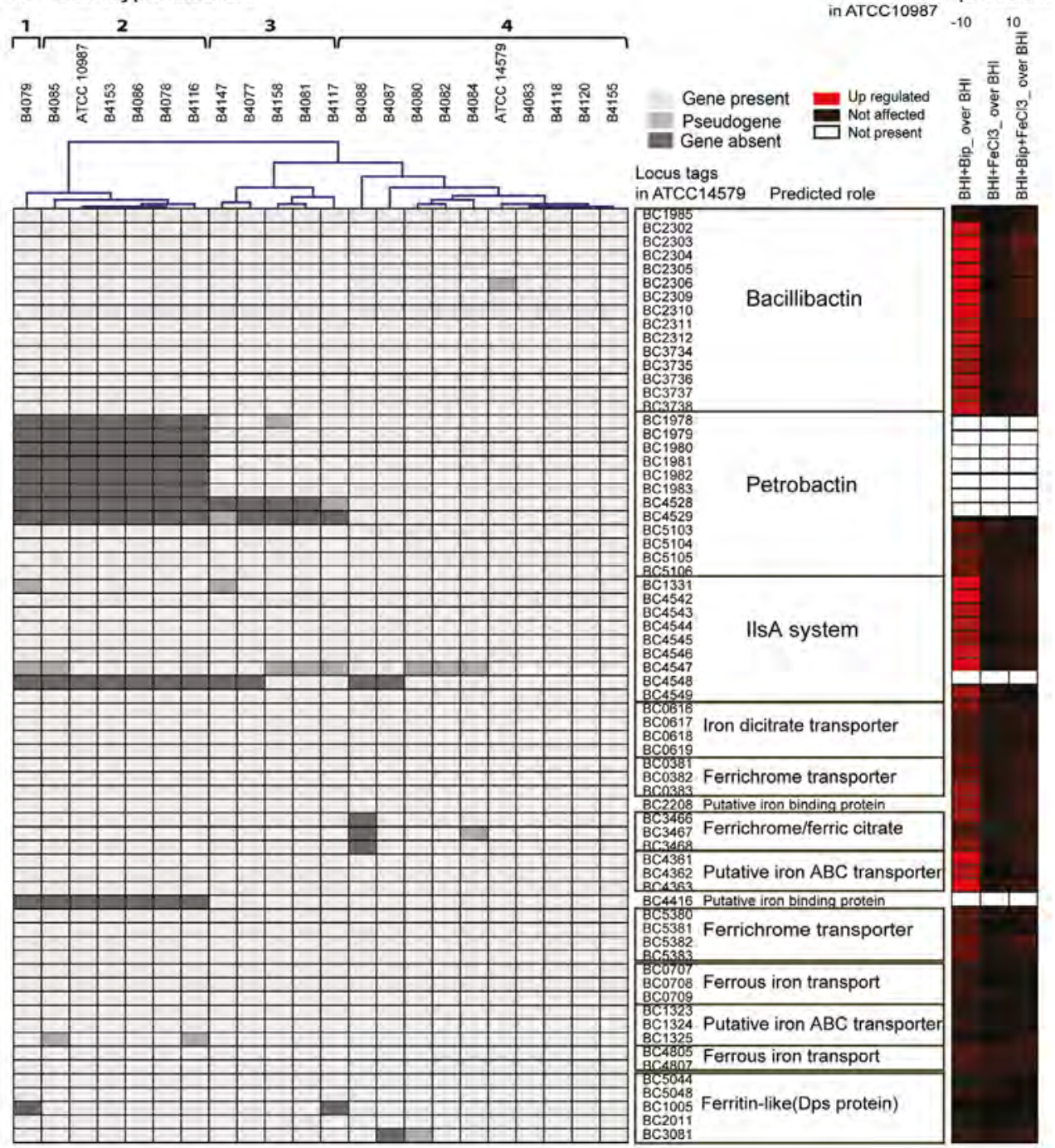

Figure 1. (A) Hierarchical clustering of $22 \mathrm{~B}$. cereus strains based on gene repertoire encoding iron transporters. Clustering was performed using Genesis software (Sturn et al. 2002). (B) Expression of genes encoding iron transporters in B. cereus ATCC 10987 in $\mathrm{BHI}$, $\mathrm{BHI}+\mathrm{Bip}, \mathrm{BHI}+\mathrm{FeCl}_{3}$ and $\mathrm{BHI}+\mathrm{Bip}+\mathrm{FeCl}_{3}$ at exponential growth phase $(t=5 \mathrm{~h})$. Up-regulated genes are presented in red, down-regulated genes in green and unaffected genes in black. The scale -10 to 10 is based on $\log _{2}$ values of expression ratios compared to BHI. 


\section{Iron sources and growth}

The ability of $B$. cereus strains to use different iron sources for growth was tested in LB + Bip medium (Fig. 2, 3 and 4). The capacity to cope with iron starvation varied highly among the different strains (Fig. 3 and 4). Notably, growth of all strains was restored in the presence of either Fe citrate or $\mathrm{FeCl}_{3}$ by $80-135 \%$ according to growth index (GI) values. All strains, except B4079, could grow with $\mathrm{Hb}$ as sole iron source and restored growth to levels ranging from $43 \%$ for strain B4078, up to 90 $\%$ for strain B4117, compared to control conditions (LB medium).

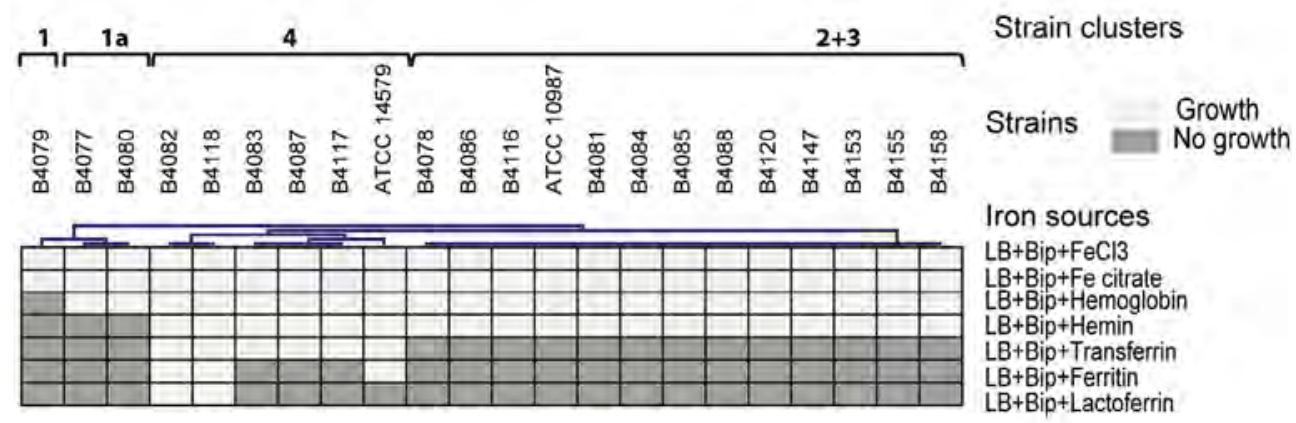

Figure 2. Phenotypic hierarchical clustering of 22 B. cereus strains based on ability to grow on different iron sources. Strains were clustered using the Genesis software (Sturn et al. 2002).

Hemin could be used by all except three strains (B4077, B4079, B4080). Notably, bacteria that use heme as an iron source also have to cope with its toxicity. This is achieved by a tight control of heme transport, biosynthesis and degradation. All strains harboured genes to synthesize protoheme and heme, as well as genes encoding the heme efflux $\mathrm{ABC}$ transporter HrtA-HrtB, and the associated twocomponent system HssS-HssR (Stauff and Skaar 2009)(not shown). Only in strain B4158 the latter gene cluster appeared impaired due to an internal deletion, and this strain was among those most sensitive to hemin, along with B4118 and B4147 that were inhibited at higher hemin concentrations (Fig. 5). 

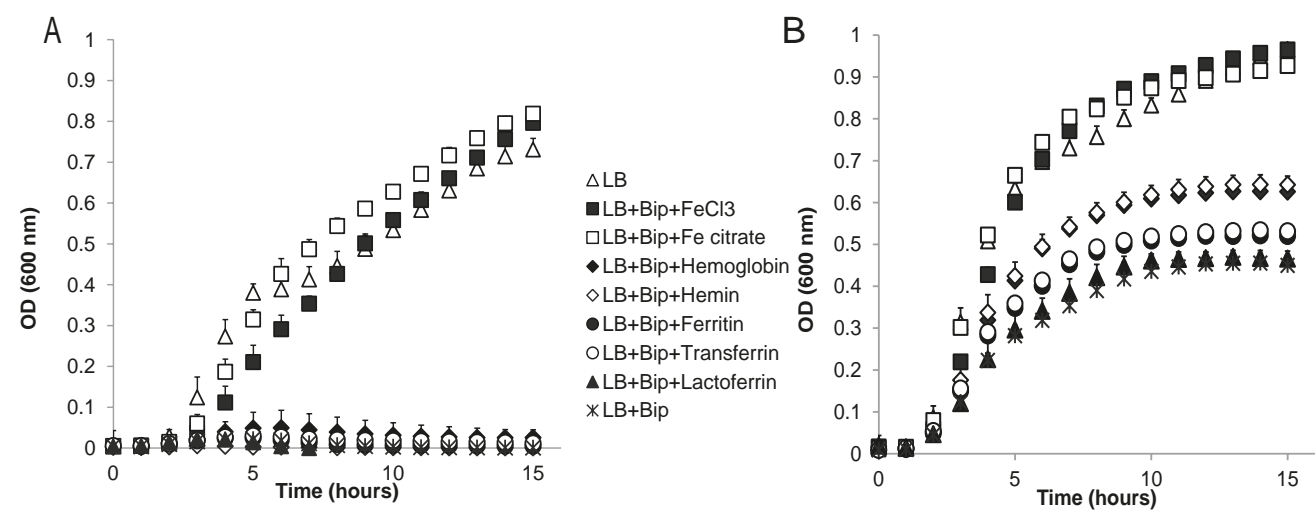

Figure 3. Growth of strains B4079 (A) and ATCC 14579 (B) in LB and LB supplemented with iron scavenger ( $L B+B i p)$ with and without addition of different iron sources. Presented values are averages of 3 independent experiments with standard deviation. Data points for LB for both strains are very close to $\mathrm{FeCl}_{3}$ and $\mathrm{Fe}$ citrate. For B4079 (A) data points of $\mathrm{LB}+\mathrm{Bip}$ are very close to $\mathrm{LB}+\mathrm{Bip}+\mathrm{Lactoferrin}$, $\mathrm{LB}+\mathrm{Bip}+$ Transferrin, $\mathrm{LB}+\mathrm{Bip}+$ Ferritin and LB + Bip + Hemin. For ATCC 14579 (B) LB + Bip data points are very close to $\mathrm{LB}+\mathrm{Bip}+$ Lactoferrin; $\mathrm{LB}+\mathrm{Bip}+$ Ferritin is close to $\mathrm{LB}+\mathrm{Bip}+$ Transferrin; $\mathrm{LB}+\mathrm{Bip}+\mathrm{Hb}$ is close to $\mathrm{LB}+\mathrm{Bip}+$ Hemin.

Transferrin and ferritin could be used by 6 and 3 strains, respectively (Fig. 2), and both compounds restored growth to a maximum of $60 \%$ of the control. Lactoferrin was a poor iron source for most strains and could only be used by strains B4082 and B4118 (Fig. 2) albeit that growth was restored to a maximum of $47 \%$ of the controls (not shown).

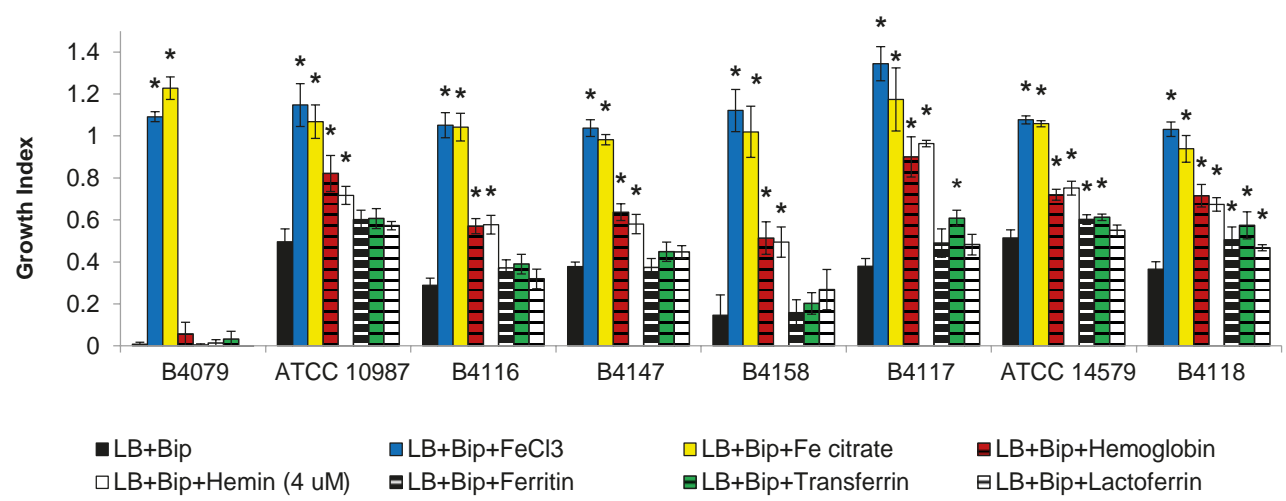

Figure 4. Growth indexes for selected strains in LB, LB supplemented with iron scavenger (LB + Bip) with and without supplementation with different iron sources. Growth indexes represent the ratio of $\mathrm{OD}(600 \mathrm{~nm})$ reached after $10 \mathrm{~h}$ of growth with the corresponding iron source relative to the OD reached in LB. Asterix (*) indicates significant difference $(\mathrm{p}<0.01)$ from iron depleted condition (LB + Bip) for each strain, indicating that the strain could grow with the supplemented iron source. 


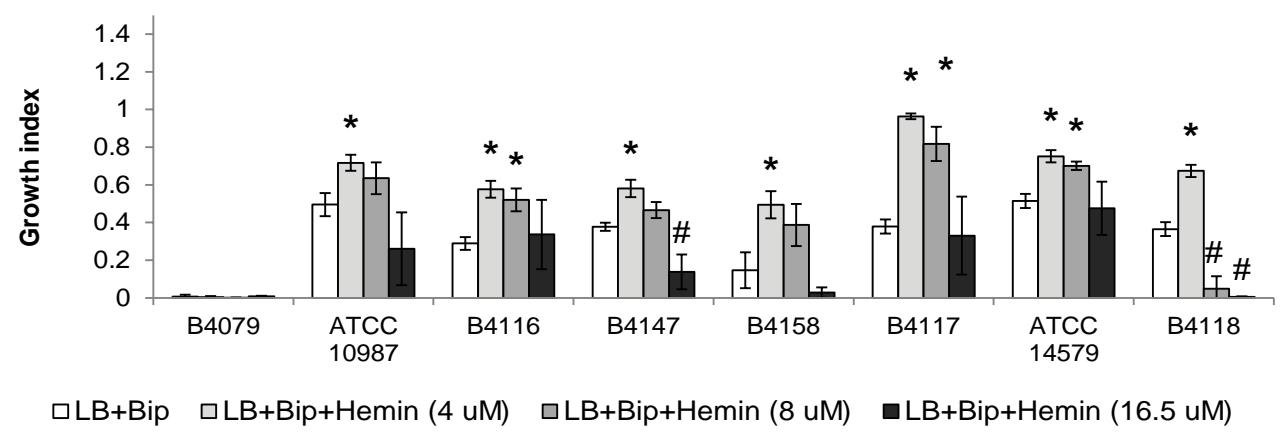

Figure 5. Growth of selected B. cereus strains on different concentrations of hemin. Growth is expressed as the growth indexes. Asterix $(*)$ indicates significant difference $(\mathrm{p}<0.01)$ from growth index in LB + Bip for each strain showing that the strain could grow on the specified concentration of hemin, while the hash (\#) shows that the growth was significantly inhibited. For all of the presented strains, 4 uM hemin was the optimal concentration for growth, with the exception of strain B4079which did not grow on this iron source with any concentration.

\section{Linking genotypes with growth phenotypes}

The growth performance data on different iron sources and genome contents were clustered (Fig. 2 and 1A). Four main clusters could be distinguished but phenotypes did not match fully with predicted capacity based on gene content. B4079 showed poorest growth in iron-depleted condition and with complex iron sources. In line with this observation, B4079 lacks most functional transporters. B4079 clusters separately from the other strains (cluster 1, Fig. 1 a and b) and based on gene content it is most similar to the subgroup of strains lacking PB encoding genes (cluster 2, Fig. 1A). The strains of cluster 2 (Fig. 1A), along with the strains missing $f p u A / f h u B$ genes for PB import (cluster 3, Fig. 1A), belong to one large phenotypic cluster (cluster $2+3$, Fig. 2) of strains which can use $\mathrm{FeCl}_{3}$, Fe citrate, $\mathrm{Hb}$ and hemin, but not transferrin, ferritin or lactoferrin. The exceptions are B4077 (no growth on hemin) and B4117 (can use transferrin) which fall out of the phenotypic cluster $2+3$. The other five strains that could use more than three of the above mentioned complex iron sources group together based on phenotypes (cluster 4, Fig. 2) and they harbour all or most iron transporter genes considered (genotypic cluster 4, Fig. 1A). Notably, the other five strains with all the genes present did not match the expected use of complex iron sources. On the other hand, the feuA/fhuGB complex is lacking in strain B4088 which nevertheless can grow on Fe citrate. Overall, the phenotypes for 15 out of 22 strains (70\%) corresponded to that predicted based on genome content. 


\section{Iron sources and biofilm formation}

The ability of the different strains to form biofilms with different types of iron sources was tested on polystyrene microtiter plates. Ten out of 22 tested strains formed a biofilm in LB medium without supplementation (control) (Table 2). Removal of free iron with Bip eliminated the biofilm forming capacity of 9 of these strains, leaving only strain B4155 positive for biofilm formation. For two strains (B4080 and B4120), biofilm formation was promoted under iron deplete condition (Table 2), even though the growth was reduced. Supplementation with Fe citrate and $\mathrm{FeCl}_{3}$ not only restored but even increased biofilm forming capacity of the above mentioned 10 strains, and additionally triggered biofilm formation by B4087 (Table 2). Hb allowed biofilm formation by 16 strains, among them 6 strains that did not form biofilm in the control condition, albeit the amount of formed biofilm was lower than that formed in presence of $\mathrm{FeCl}_{3}$ or $\mathrm{Fe}$ citrate for most of the strains. In the presence of hemin, 6 strains were able to form biofilm, similar to lactoferrin. These biofilms were completely submerged on the bottom of the well, in contrast to the air-liquid interface biofilm formed in $\mathrm{LB}, \mathrm{LB}+\mathrm{Bip}+\mathrm{FeCl}_{3}$ and $\mathrm{LB}+\mathrm{Bip}+\mathrm{Fe}$ citrate (Fig. 6).

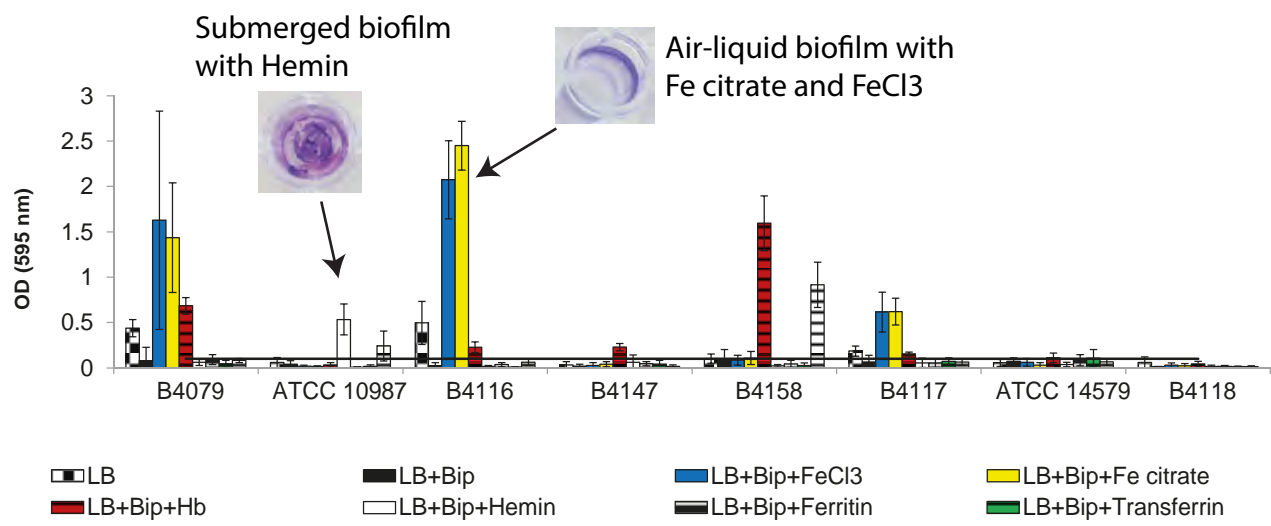

Figure 6. Biofilm formation for selected B. cereus strains. The biofilm was formed in polystyrene 96-well plate in LB and LB supplemented with Bip, with or without addition of different iron sources. The biofilm was measured with the CV assay after $24 \mathrm{~h}$ incubation at $30{ }^{\circ} \mathrm{C}$. 


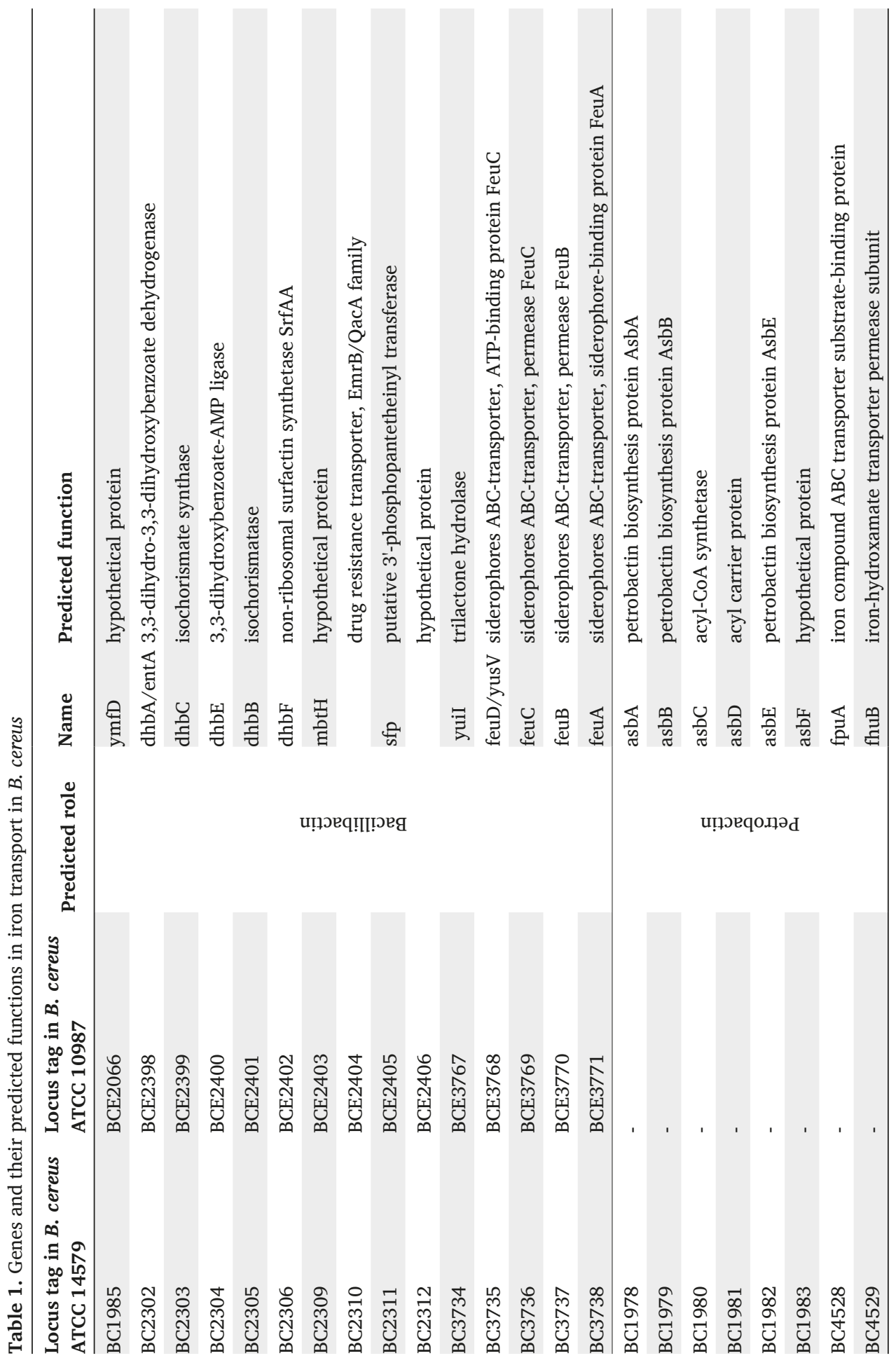




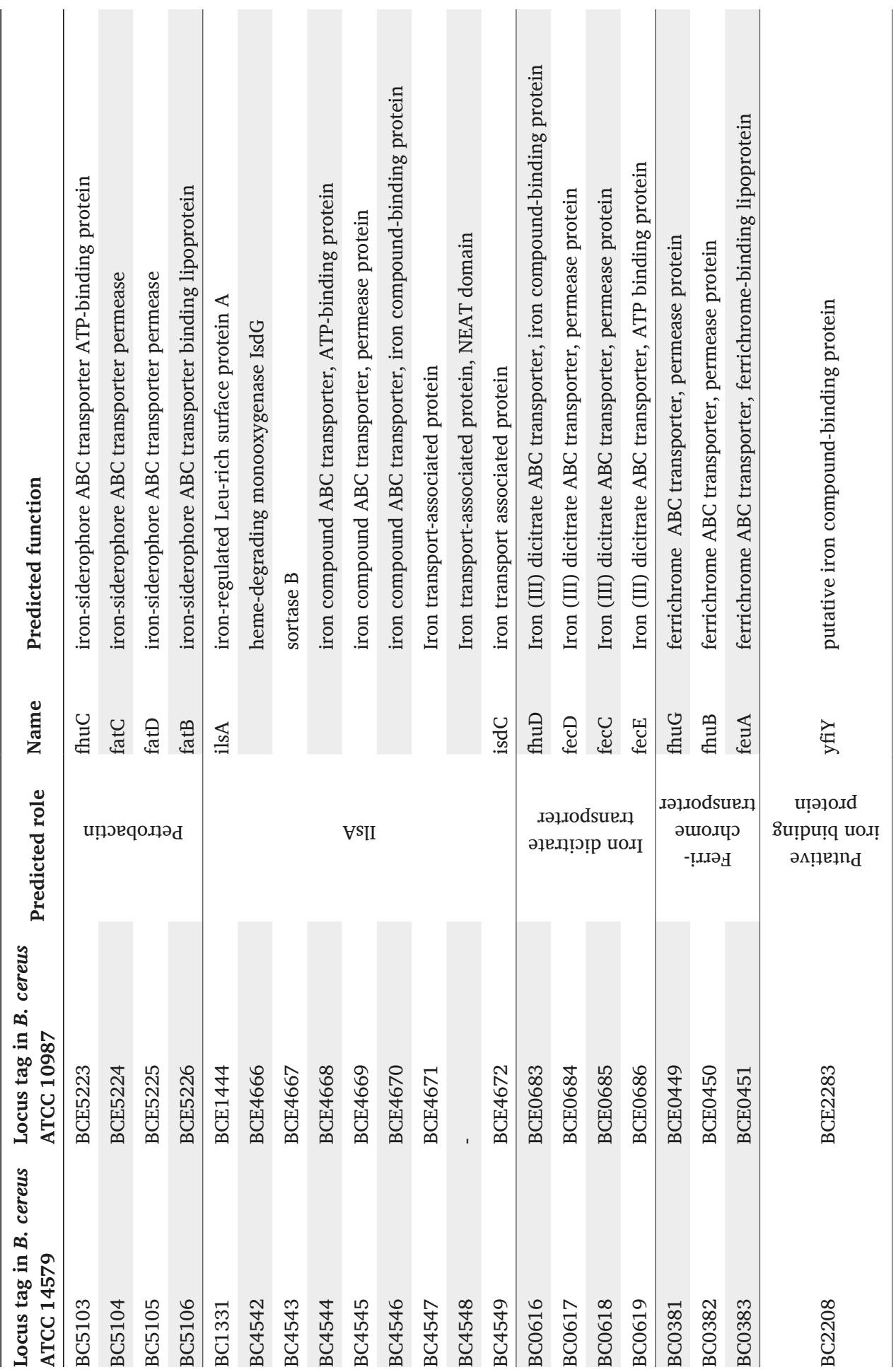




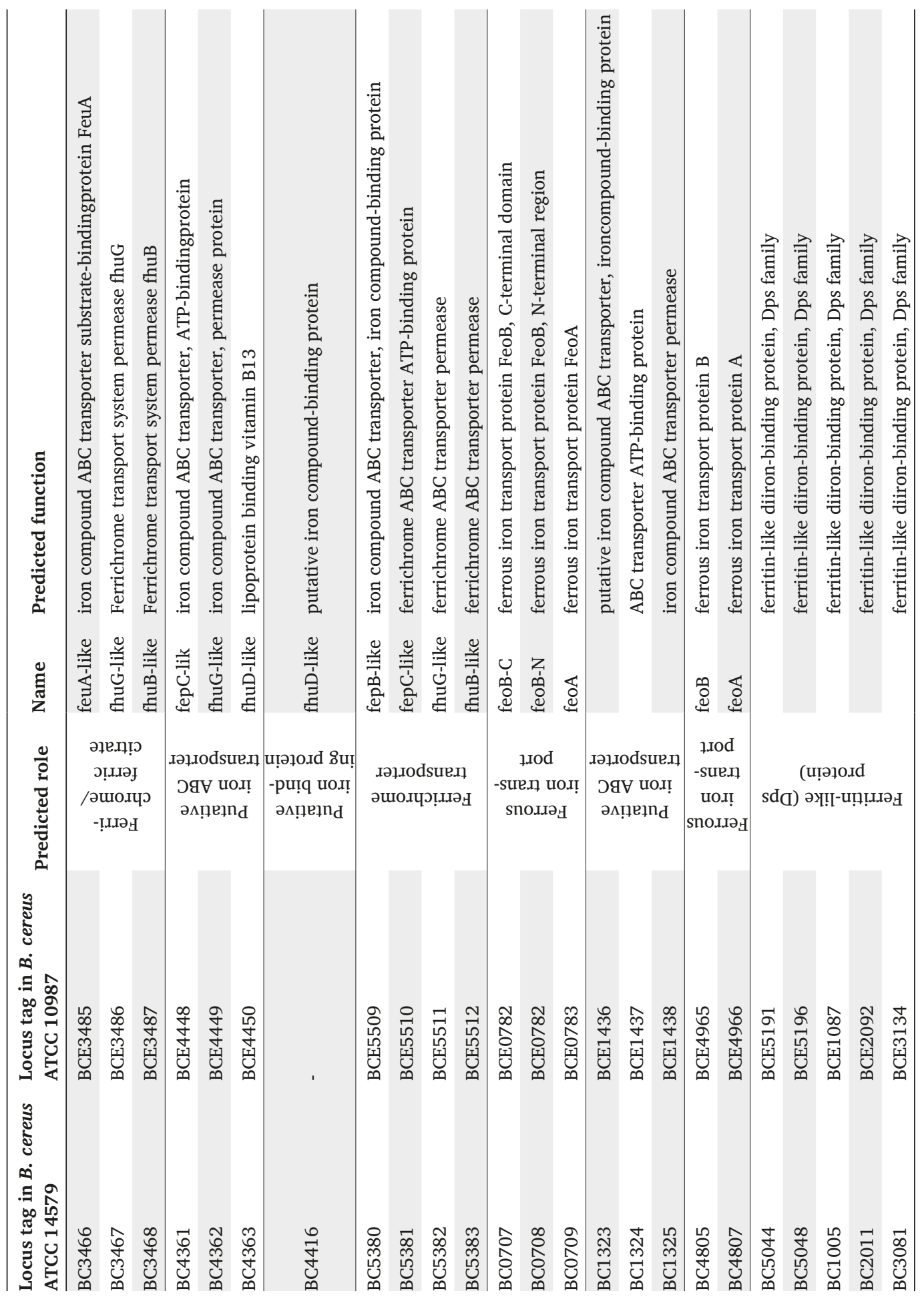


Table 2. Biofilm formation in the presence of different iron sources. The biofilm was formed in polystyrene 96-well plates in LB medium, and LB supplemented with Bip with or without addition of indicated iron sources. The biofilm was measured with CV assay after $24 \mathrm{~h}$ incubation at $30{ }^{\circ} \mathrm{C}$.

\begin{tabular}{|c|c|c|c|c|c|c|c|c|c|}
\hline Strains & $\stackrel{9}{\exists}$ & $\begin{array}{l}. \hat{\oplus} \\
+ \\
0 \\
0\end{array}$ & 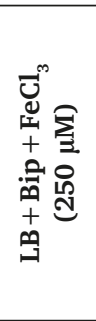 & 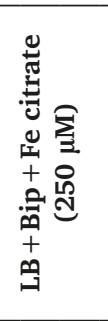 & 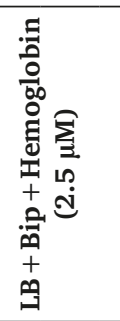 & 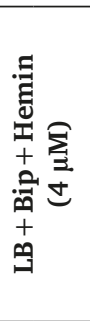 & 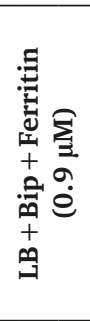 & 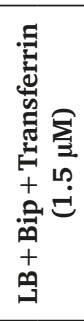 & 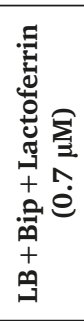 \\
\hline B4078 & + & - & $++*$ & $++*$ & $+*$ & -* & - & - & - \\
\hline B4079 & + & - & $++*$ & $++*$ & + & - & - & - & - \\
\hline B4082 & - & - & $-*$ & $-*$ & $-*$ & -* & $-*$ & $-*$ & $-*$ \\
\hline B4083 & ++ & - & $++*$ & $++*$ & $++*$ & $+*$ & - & $+*$ & - \\
\hline B4086 & + & - & $++*$ & $++*$ & $+*$ & -* & - & - & - \\
\hline B4087 & - & - & $+*$ & $+*$ & $+*$ & -* & - & $-*$ & - \\
\hline B4116 & + & - & $++*$ & $++*$ & $+*$ & -* & - & - & - \\
\hline B4117 & + & - & $+*$ & $t^{*}$ & $+*$ & -* & - & $-*$ & - \\
\hline B4118 & - & - & $-*$ & $-*$ & $-*$ & $-*$ & $-*$ & $-*$ & $-*$ \\
\hline ATCC 14579 & - & - & $-*$ & $-*$ & $+*$ & -* & $-*$ & $+*$ & - \\
\hline ATCC 10987 & - & - & $-*$ & $-*$ & $-*$ & $+*$ & - & - & + \\
\hline B4077 & - & - & $-*$ & $-*$ & $+*$ & - & - & - & + \\
\hline B4080 & - & + & $-*$ & $-*$ & $+*$ & + & + & + & + \\
\hline B4081 & - & - & $-*$ & $-*$ & $+*$ & $-*$ & - & - & - \\
\hline B4084 & - & - & $-*$ & $-*$ & $-*$ & $-*$ & - & - & - \\
\hline B4085 & + & - & $++*$ & $++*$ & $+*$ & -* & - & - & - \\
\hline B4088 & - & - & $-*$ & $-*$ & -* & $+*$ & - & - & - \\
\hline B4120 & - & + & $-*$ & $-*$ & $-*$ & $+*$ & + & + & + \\
\hline B4147 & - & - & $-*$ & $-*$ & $+*$ & -* & - & - & - \\
\hline B4153 & + & - & $++*$ & $++*$ & $+*$ & -* & - & - & - \\
\hline B4155 & + & + & $+^{*}$ & $+*$ & $+*$ & $+*$ & + & + & + \\
\hline B4158 & + & - & $-*$ & $+*$ & $++*$ & $-*$ & - & - & + \\
\hline $\begin{array}{l}\text { total number of } \\
\text { biofilm forming } \\
\text { strains }\end{array}$ & 10 & 3 & 10 & 11 & 16 & 6 & 3 & 5 & 6 \\
\hline
\end{tabular}

+ OD (Crystal violet assay) $>0.1$

++ OD (Crystal violet assay) $>1$

- OD (Crystal violet assay) $<0.1$

* growth was significantly restored compared to LB + Bip 


\section{Discussion}

In this study we present data showing the impact of different iron sources on growth and biofilm formation capacity and type of biofilms formed for 20 Bacillus cereus food isolates and 2 reference strains.

Bacillibactin (BB) and petrobactin (PB) are iron-transporting siderophores produced by Bacillus cereus group members. The relevance of $\mathrm{PB}$ in $B$. anthracis growth and virulence was shown, however for $B$. cereus $B B$ was suggested to be of more importance (Segond et al. 2014). Notably, BB is present in all the strains in this study, while PB is absent in seven strains.

Limitation of free iron impaired the growth of all tested B. cereus strains in LB + Bip but was most prominent for B4079, lacking both PB siderophore and functional IlsA. This also prevented efficient use of $\mathrm{Hb}$ and hemin by this strain, in contrast to strains missing only one of the mentioned systems. Interestingly, strains able to use ferritin or transferrin as iron source encompass the whole repertoire of iron transporters, with only minor exceptions. This is in agreement with the previously suggested cooperation between different systems such as IlsA and petrobactin siderophore in iron uptake from ferritin (Segond et al. 2014).

The ability of $B$. cereus strains to grow on complex iron sources does not always correspond to the presence of relevant genes. For example, B4120 and B4155 contain the full repertoire of iron transporters, however these strains could not use transferrin, ferritin or lactoferrin as iron sources. This may be explained either by differences in regulation of expression of these genes in the selected conditions, presence of transcriptional activators such as specific iron starvation ECF factors (Visca et al. 2002), or factors that affect translation or activity of the synthesised proteins.

Contradictory data have been reported previously concerning the use of transferrin by $B$. cereus. According to one report, $B$. cereus could use human transferrin as an iron source, albeit with lower efficiency compared to Staphylococcus aureus, Escherichia coli and Pseudomonas aeruginosa (Park et al. 2005). Two other studies report inability of $B$. cereus to grow on transferrin (Sato et al. 1998, Daou et al. 2009), or growth inhibition of B. cereus and B. anthracis by human transferrin (Sato et al. 1998) due to iron deprivation (Rooijakkers et al. 2010). Our data show that the ability to use human transferrin is strain and concentration dependent, concentrations exceeding $2 \mathrm{uM}$ displayed a bacteriostatic effect on several strains (not shown), while 1.5 uM transferrin was the optimal concentration that could be used by 6 out of 22 strains. Besides, the source of transferrin seems of importance since the $S$. aureus transferrin receptor was shown to bind preferentially human and rodent transferrin 
but not that of bovine and porcine origin (Modun and Williams 1999). Aerobic or anaerobic growth conditions could also play a role since oxygen availability has for example been shown to affect the relative abundance of petrobactin and bacillibactin in B. anthracis (Lee et al. 2011). Furthermore, all the strains used in this study, with the exception of ATCC 14579 (isolated from air in a cow shed) were food isolates. Systemic infections caused by B. cereus (Bottone 2010, Uchino et al. 2012) are caused by more clinically relevant strains, that likely differ in their ability to use and tolerate high levels of transferrin compared to food isolates. To test this, further studies including clinical isolates should be performed.

Lactoferrin is abundant in milk, but also in blood and secreted fluids such as tears and displays antimicrobial properties (Oram and Reiter 1968, Sato et al. 1999b, Orsi 2004). Lactoferrin can be used as an iron source by Pseudomonas ssp. (Xiao and Kisaalita 1997) and several other microorganisms (Morgenthau et al. 2013), but not by B. cereus as reported previously (Sato et al. 1999b, Daou et al. 2009). The latter study used $1.5 \mathrm{uM}$ of lactoferrin, which in our study also did not restore the growth of any of the 22 strains and inhibited the growth for strain B4086 (not shown). However, a concentration of $0.7 \mathrm{uM}$ lactoferrin slightly restored the growth of two strains (B4082 and B4118), which could also use all other tested iron sources, indicating that these strains were in general better equipped for use of complex iron sources, in line with the full repertoire of iron transporting systems present in these strains. The low number of strains able to use lactoferrin is unexpected given the fact that $B$. cereus is a common contaminant in dairy products.

The capacity to use different complex iron sources could not be linked to the isolation source of the strains. However, clustering of the strains used in this study according to Guinebretière et al. (2008), revealed that all strains lacking petrobactin encoding genes belong to the phylogenetic group III (Warda et al. 2016). A common habitat for strains of group III are dehydrated/starchy foods (Guinebretière et al. 2008). Interestingly, all group IIIstrains in the current study were isolated from a starch or dairy containing food product as reported previously (Hayrapetyan et al. 2015a).

\section{Iron sources and biofilm formation}

Previously, we reported that addition of free iron $\left(\mathrm{FeCl}_{3}\right)$ promoted formation of airliquid interface biofilms by $B$. cereus strains. In this study we show that apart from $\mathrm{FeCl}_{3}$ also Fe citrate promoted biofilm formation. $\mathrm{Hb}$ triggered biofilm formation for a subset of strains for which the growth was also restored and resulting in partial submerged and air-liquid biofilms. Even strain B4079, which did not show significant growth recovery with $\mathrm{Hb}$, was able to form biofilm upon its addition. It showed very limited growth in the presence of $\mathrm{Hb}$ (to $\mathrm{OD}=0.05$, compared to $\mathrm{LB}+\mathrm{Bip} \mathrm{OD}=0.01$, 
Fig. 3), which may have caused stress conceivably linked to biofilm formation as a response. $\mathrm{Hb}$ was previously identified as a component in nasal secretions that promoted colonization by $S$. aureus via repression of the agr quorum sensing system resulting in reduced production of proteases with concomitant reduction in biofilm dispersal (Pynnonen et al. 2011). Interestingly this effect was found to be exerted by the $\mathrm{Hb}$ protein independently of its iron content. The mechanism of $\mathrm{Hb}$-induced biofilm formation in $B$. cereus remains to be elucidated.

Ferritin and transferrin only slightly supported biofilm formation, mostly for strains already able to form biofilm in iron limited conditions (B4080, B4120 and B4155, Table 2). A role for the surface protein IsdC in cell-cell attachment and biofilm formation under iron deplete conditions was shown for Staphylococcus lugdunensis (Missineo et al. 2014). Interestingly, this protein is a homolog of BC4549, encoding a component of the IlsA iron transporting system. Since iron starvation most likely triggers the upregulation of such proteins this may be linked to biofilm-promoting effect of iron depletion for strains B4080 and B4120 (Table 2).

The iron-chelating properties combined with a direct bactericidal effect of lactoferrin has led to its proposed role as potential anti-biofilm compound (Ammons and Copié 2013). In our study, lactoferrin triggered submerged biofilm formation by $B$. cereus strains B4158 and ATCC 10987, even though growth was not restored. The underlying mechanism remains to be elucidated.

This study shows that ferric citrate and $\mathrm{FeCl}_{3}$ could be used by all $B$. cereus strains and were preferred iron sources. Hemoglobin, hemin, transferrin, ferritin and lactoferrin could also act as iron sources but their use appeared to be highly strain-dependent. The ability of $B$. cereus strains to grow on complex iron sources correlated largely with the genome content, but could not always be linked to specific iron transporter genes present. The ability to use complex iron sources seems to be dictated by the combined presence or absence of more than one functional iron transporting system, rather than one single system. Furthermore, biofilm formation was found to be affected by the type of iron source used, including stimulation of biofilms at liquid-air interphase $\left(\mathrm{FeCl}_{3}\right.$ and $\mathrm{Fe}$ citrate) and formation of submerged type biofilms (hemin and lactoferrin). Notably, generation of submerged biofilms was in some cases linked to lack of growth stimulation by the complex iron source tested. To conclude, our results show strain variability in the genome repertoire of iron-transporting systems and differences in efficacy to use complex iron sources for growth and biofilm formation. These features may affect $B$. cereus survival and persistence in specific niches including food processing environments and the human host. 


\section{Acknowledgements}

We thank Jos Boekhorst (NIZO food research) for his assistance with genome database and comparative genomic activities and Michiel Wells (NIZO food research) for the array hybridization design and data normalisation.

The project was funded by TI Food and Nutrition, a public-private partnership on precompetitive research in food and nutrition. The public partners are responsible for the study design, data collection and analysis, decision to publish, and preparation of the manuscript. The private partners have contributed to the project through regular discussion. 


\section{References}

Abergel, R. J., M. K. Wilson, J. E. Arceneaux, T. M. Hoette, R. K. Strong, B. R. Byers and K. N. Raymond (2006). Anthrax pathogen evades the mammalian immune system through stealth siderophore production. Proceedings of the National Academy of Sciences of the United States of America 103(49): 18499-18503.

Abergel, R. J., A. M. Zawadzka and K. N. Raymond (2008). Petrobactin-mediated iron transport in pathogenic bacteria: coordination chemistry of an unusual 3,4-catecholate/citrate siderophore. Journal of the American Chemical Society 130(7): 2124-2125.

Abi-Khalil, E., D. Segond, T. Terpstra, G. André-Leroux, M. Kallassy, D. Lereclus, F. Bou-Abdallah and C. Nielsen-Leroux (2015). Heme interplay between IlsA and IsdC: Two structurally different surface proteins from Bacillus cereus. Biochimica et Biophysica Acta - General Subjects 1850(9): 1930-1941.

Ammons, M. C. and V. Copié (2013). Mini-review: Lactoferrin: a bioinspired, anti-biofilm therapeutic. Biofouling 29(4): 443-455.

Bottone, E. J. (2010). Bacillus cereus, a volatile human pathogen. Clinical Microbiology Reviews 23(2): 382-398.

Brown, J. S. and D. W. Holden (2002). Iron acquisition by Gram-positive bacterial pathogens. Microbes and Infection 4(11): 1149-1156.

Cendrowski, S., W. MacArthur and P. Hanna (2004). Bacillus anthracis requires siderophore biosynthesis for growth in macrophages and mouse virulence. 51(2): 407-417.

Daou, N., C. Buisson, M. Gohar, J. Vidic, H. Bierne, M. Kallassy, D. Lereclus and C. Nielsen-LeRoux (2009). IlsA, a unique surface protein of Bacillus cereus required for iron acquisition from heme, hemoglobin and ferritin. PLoS Pathogens 5(11).

Dixon, S. D., B. K. Janes, A. Bourgis, P. E. Carlson, Jr. and P. C. Hanna (2012). Multiple ABC transporters are involved in the acquisition of petrobactin in Bacillus anthracis. Molecular Microbiology 84(2): 370-382.

Edgar, R. C. (2004). MUSCLE: A multiple sequence alignment method with reduced time and space complexity. BMC Bioinformatics 5 .

Enright, A. J., S. Van Dongen and C. A. Ouzounis (2002). An efficient algorithm for large-scale detection of protein families. Nucleic Acids Research 30(7): 1575-1584.

Federhen, S., R. Rossello-Mora, H.-P. Klenk, B. J. Tindall, K. T. Konstantinidis, W. B. Whitman, D. Brown, D. Labeda, D. Ussery, G. M. Garrity, R. R. Colwell, N. Hasan, J. Graf, A. Parte, P. Yarza, B. Goldberg, H. Sichtig, I. Karsch-Mizrachi, K. Clark, R. McVeigh, K. D. Pruitt, T. Tatusova, R. Falk, S. Turner, T. Madden, P. Kitts, A. Kimchi, W. Klimke, R. Agarwala, M. DiCuccio and J. Ostell (2016). Meeting report: GenBank microbial genomic taxonomy workshop (12-13 May, 2015). Standards in Genomic Sciences 11: 15.

Fukushima, T., A. K. Sia, B. E. Allred, R. Nichiporuk, Z. Zhou, U. N. Andersen and K. N. Raymond (2012). Bacillus cereus iron uptake protein fishes out an unstable ferric citrate trimer. Proceedings of the National Academy of Sciences of the United States of America 109(42): 16829-16834.

Guinebretière, M. H., F. L. Thompson, A. Sorokin, P. Normand, P. Dawyndt, M. Ehling-Schulz, B. Svensson, V. Sanchis, C. Nguyen-The, M. Heyndrickx and P. De Vos (2008). Ecological diversification in the Bacillus cereus Group. Environmental Microbiology 10(4): 851-865.

Hantke, K. (2003). Is the bacterial ferrous iron transporter FeoB a living fossil? Trends in Microbiology 11(5): 192-195.

Harvie, D. R. and D. J. Ellar (2005). A ferric dicitrate uptake system is required for the full virulence of Bacillus cereus. Current Microbiology 50(5): 246-250.

Harvie, D. R., S. Vílchez, J. R. Steggles and D. J. Ellar (2005). Bacillus cereus Fur regulates iron metabolism and is required for full virulence. Microbiology 151(2): 569-577. 
Hayrapetyan, H., L. Muller, M. Tempelaars, T. Abee and M. Nierop Groot (2015a). Comparative analysis of biofilm formation by Bacillus cereus reference strains and undomesticated food isolates and the effect of free iron. International Journal of Food Microbiology 200: 72-79.

Hayrapetyan, H., M. Tempelaars, M. Nierop Groot and T. Abee (2015b). Bacillus cereus ATCC 14579 RpoN (Sigma 54) is a pleiotropic regulator of growth, carbohydrate metabolism, motility, biofilm formation and toxin production. PloS One 10(8): e0134872.

Hotta, K., C. Y. Kim, D. T. Fox and A. T. Koppisch (2010). Siderophore-mediated iron acquisition in Bacillus anthracis and related strains. Microbiology 156(7): 1918-1925.

Kim, H., H. Lee and D. Shin (2012). The FeoA protein is necessary for the FeoB transporter to import ferrous iron. Biochemical and Biophysical Research Communications 423(4): 733-738.

Koppisch, A. T., C. C. Browder, A. L. Moe, J. T. Shelley, B. A. Kinkel, L. E. Hersman, S. Iyer and C. E. Ruggiero (2005). Petrobactin is the primary siderophore synthesized by Bacillus anthracis str. Sterne under conditions of iron starvation. Biometals 18(6): 577-585.

Krawczyk, A. O., A. de Jong, R. T. Eijlander, E. M. Berendsen, S. Holsappel, M. H. Wells-Bennik and O. P. Kuipers (2015). Next-Generation Whole-Genome Sequencing of Eight Strains of Bacillus cereus, Isolated from Food. Genome Announc 3(6): e01480-01415.

Lee, J. Y., K. D. Passalacqua, P. C. Hanna and D. H. Sherman (2011). Regulation of petrobactin and bacillibactin biosynthesis in Bacillus anthracis under iron and oxygen variation. PloS One 6(6): e20777.

Missineo, A., A. D. Poto, J. A. Geoghegan, S. Rindi, S. Heilbronner, V. Gianotti, C. R. Arciola, T. J. Foster, P. Speziale and G. Pietrocola (2014). IsdC from Staphylococcus lugdunensis induces biofilm formation under low-iron growth conditions. Infection and Immunity 82(6): 2448-2459.

Modun, B. and P. Williams (1999). The staphylococcal transferrin-binding protein is a cell wall glyceraldehyde-3-phosphate dehydrogenase. Infection and Immunity 67(3): 1086-1092.

Mols, M., H. Mastwijk, M. Nierop Groot and T. Abee (2013). Physiological and transcriptional response of Bacillus cereus treated with low-temperature nitrogen gas plasma. Journal of Applied Microbiology 115(3): 689-702.

Mols, M., R. van Kranenburg, C. C. J. van Melis, R. Moezelaar and T. Abee (2010). Analysis of acidstressed Bacillus cereus reveals a major oxidative response and inactivation-associated radical formation. Environmental Microbiology 12(4): 873-885.

Morgenthau, A., A. Pogoutse, P. Adamiak, T. F. Moraes and A. B. Schryvers (2013). Bacterial receptors for host transferrin and lactoferrin: Molecular mechanisms and role in host-microbe interactions. Future Microbiology 8(12): 1575-1585.

Oram, J. D. and B. Reiter (1968). Inhibition of bacteria by lactoferrin and other iron-chelating agents. BBA - General Subjects 170(2): 351-365.

Orsi, N. (2004). The antimicrobial activity of lactoferrin: Current status and perspectives. Biometals 17(3): 189-196.

Park, R. Y., M. H. Choi, H. Y. Sun and S. H. Shin (2005). Production of catechol-siderophore and utilization of transferrin-bound iron in Bacillus cereus. Biological and Pharmaceutical Bulletin 28(6): 1132-1135.

Porcheron, G. and C. M. Dozois (2015). Interplay between iron homeostasis and virulence: Fur and RyhB as major regulators of bacterial pathogenicity. Veterinary Microbiology 179(1-2): 2-14.

Pynnonen, M., R. E. Stephenson, K. Schwartz, M. Hernandez and B. R. Boles (2011). Hemoglobin promotes Staphylococcus aureus nasal colonization. PLoS Pathogens 7(7).

Ratledge, C. and L. G. Dover (2000). Iron metabolism in pathogenic bacteria. Annual Review of Microbiology. 54: 881-941.

Rooijakkers, S. H. M., S. L. Rasmussen, S. M. McGillivray, T. B. Bartnikas, A. B. Mason, A. M. Friedlander and V. Nizet (2010). Human transferrin confers serum resistance against Bacillus anthracis. Journal of Biological Chemistry 285(36): 27609-27613. 
Sato, N., S. Ikeda, T. Mikami and T. Matsumoto (1999a). Bacillus cereus dissociates hemoglobin and uses released heme as an iron source. Biological and Pharmaceutical Bulletin 22(10): 1118-1121.

Sato, N., H. Kurotaki, S. Ikeda, R. Daio, N. Nishinome, T. Mikami and T. Matsumoto (1999b). Lactoferrin inhibits Bacillus cereus growth and heme analogs recover its growth. Biological and Pharmaceutical Bulletin 22(2): 197-199.

Sato, N., H. Kurotaki, T. Watanabe, T. Mikami and T. Matsumoto (1998). Use of hemoglobin as an iron source by Bacillus cereus. Biological and Pharmaceutical Bulletin 21(4): 311-314.

Segond, D., E. Abi Khalil, C. Buisson, N. Daou, M. Kallassy, D. Lereclus, P. Arosio, F. Bou-Abdallah and C. Nielsen Le Roux (2014). Iron acquisition in Bacillus cereus: the roles of IlsA and bacillibactin in exogenous ferritin iron mobilization. 10(2).

Stauff, D. L. and E. P. Skaar (2009). Bacillus anthracis HssRS signalling to HrtAB regulates haem resistance during infection. Molecular Microbiology 72(3): 763-778.

Sturn, A., J. Quackenbush and Z. Trajanoski (2002). Genesis: Cluster analysis of microarray data. Bioinformatics 18(1): 207-208.

Tu, W. Y., S. Pohl, J. Gray, N. J. Robinson, C. R. Harwood and K. J. Waldron (2012). Cellular iron distribution in Bacillus anthracis. Journal of Bacteriology 194(5): 932-940.

Uchino, Y., N. Iriyama, K. Matsumoto, Y. Hirabayashi, K. Miura, D. Kurita, Y. Kobayashi, M. Yagi, H. Kodaira, A. Hojo, S. Kobayashi, Y. Hatta and J. Takeuchi (2012). A case series of Bacillus cereus septicemia in patients with hematological disease. Internal Medicine 51(19): 2733-2738.

Visca, P., L. Leoni, M. J. Wilson and I. L. Lamont (2002). Iron transport and regulation, cell signalling and genomics: Lessons from Escherichia coli and Pseudomonas. Molecular Microbiology 45(5): 1177-1190.

Warda, A. K., R. J. Siezen, J. Boekhorst, M. H. J. Wells-Bennik, A. De Jong, O. P. Kuipers, M. N. Nierop Groot and T. Abee (2016). Linking Bacillus cereus genotypes and carbohydrate utilization capacity. PloS One In press.

Wilson, M. K., R. J. Abergel, K. N. Raymond, J. E. Arceneaux and B. R. Byers (2006). Siderophores of Bacillus anthracis, Bacillus cereus, and Bacillus thuringiensis. Biochemical and Biophysical Research Communications 348(1): 320-325.

Xiao, R. and W. S. Kisaalita (1997). Iron acquisition from transferrin and lactoferrin by Pseudomonas aeruginosa pyoverdin. Microbiology 143(7): 2509-2515.

Zawadzka, A. M., R. J. Abergel, R. Nichiporuk, U. N. Andersen and K. N. Raymond (2009). Siderophore-mediated iron acquisition systems in Bacillus cereus: Identification of receptors for anthrax virulence-associated petrobactin. Biochemistry 48(16): 3645-3657. 


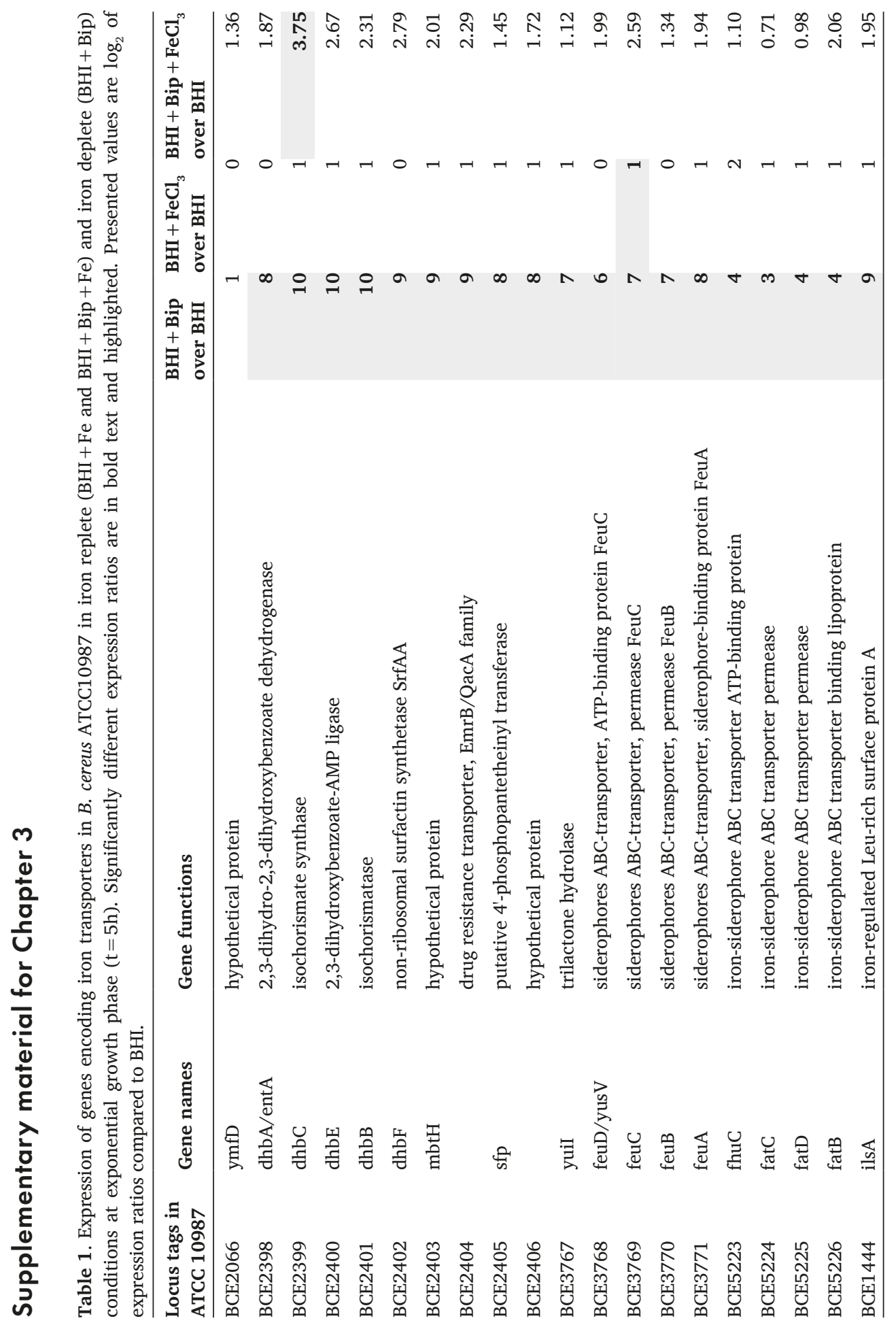




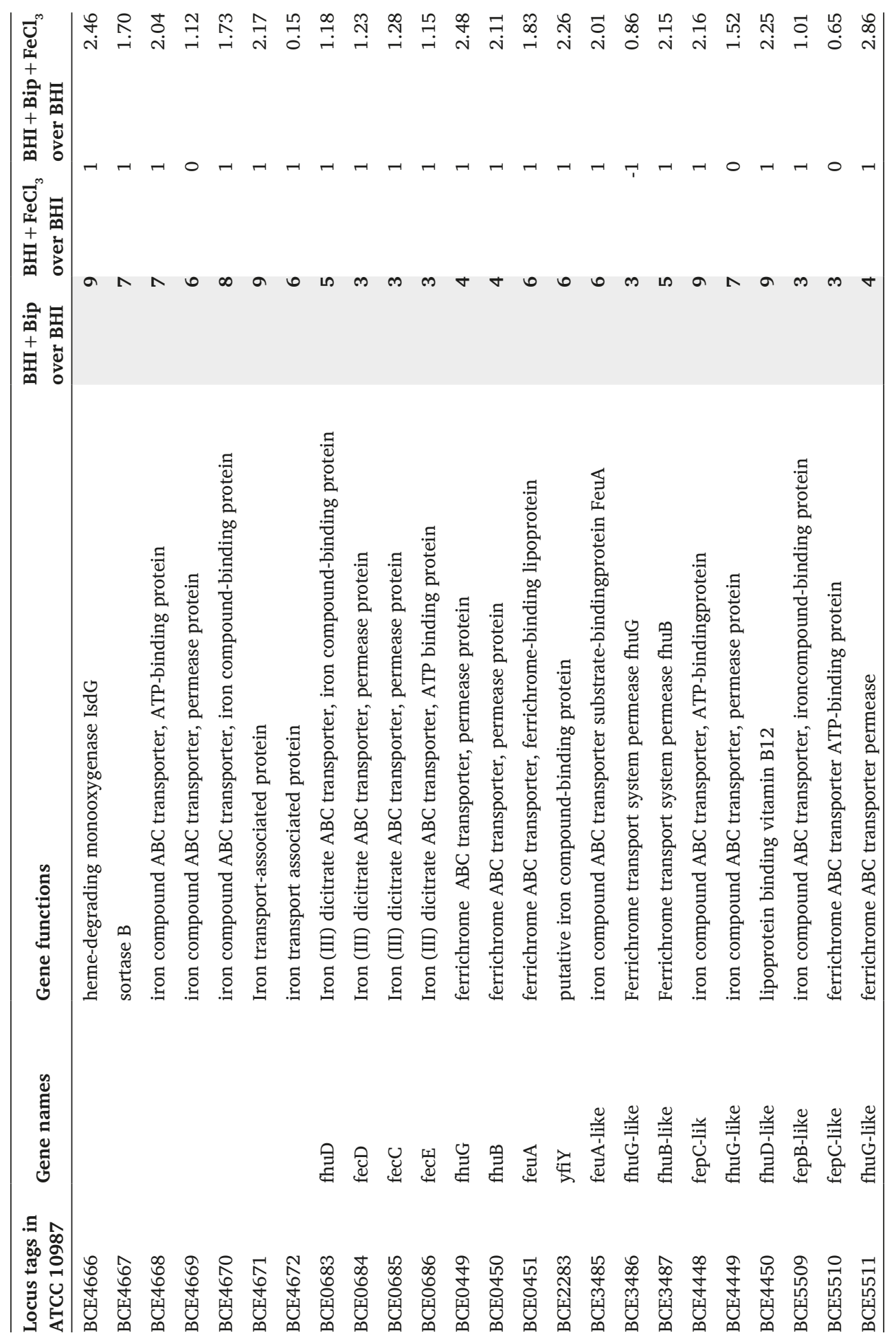




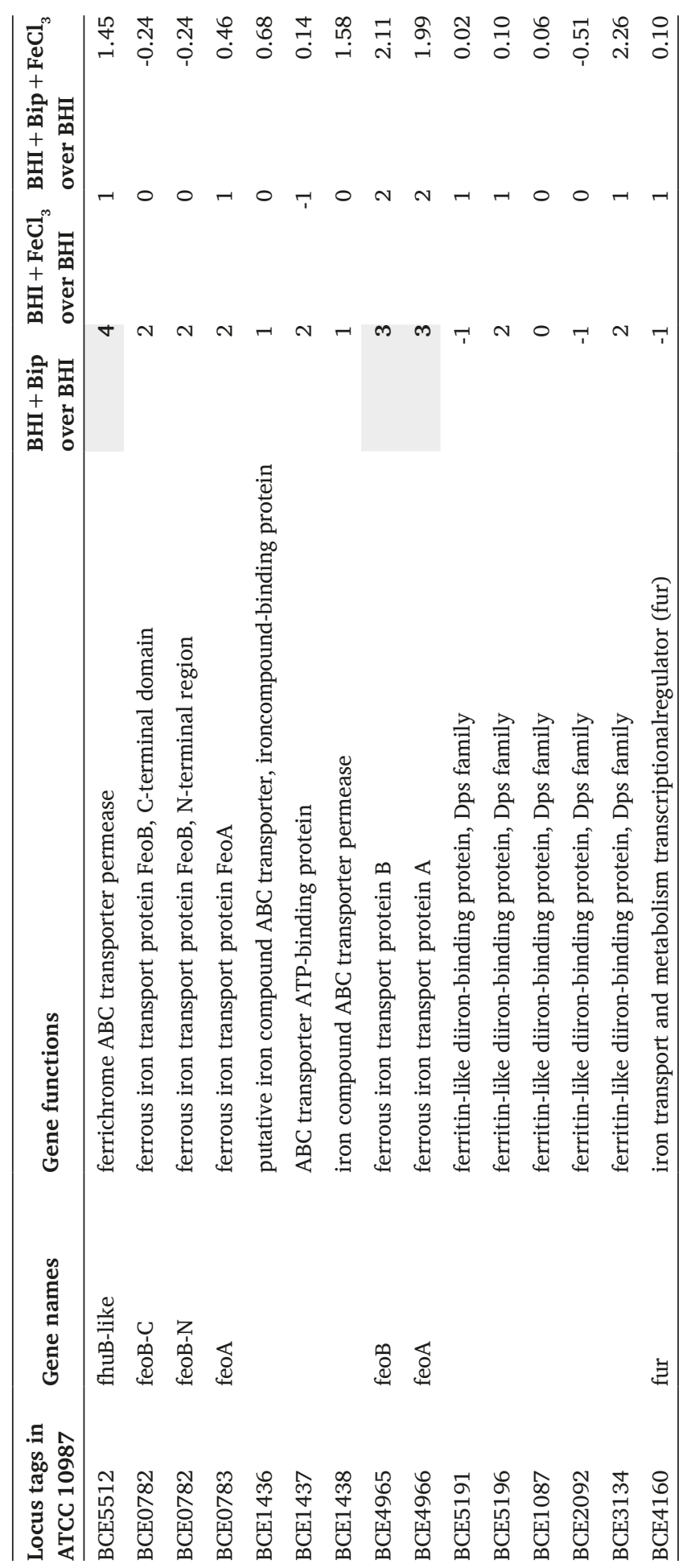




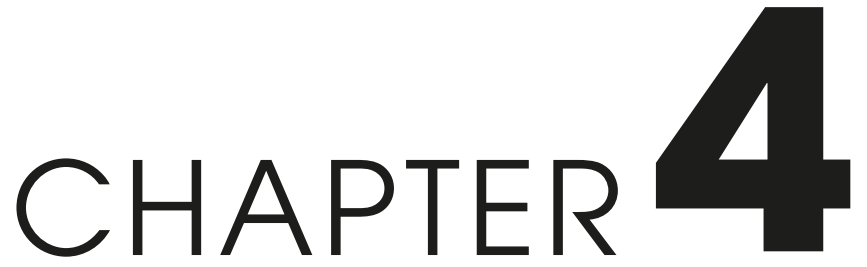

Sporulation dynamics and spore heat resistance in wet and dry biofilms of Bacillus cereus

Hasmik Hayrapetyan

Tjakko Abee

Masja Nierop Groot

Published in Food Control (2015) 60: 493-499 


\begin{abstract}
Environmental conditions and growth history can affect the sporulation process as well as subsequent properties of formed spores. The sporulation dynamics was studied in wet and air-dried biofilms formed on stainless steel (SS) and polystyrene (PS) for B. cereus ATCC 10987 and the undomesticated food isolate B. cereus NIZO 4080. After harvesting and maturation, the wet heat resistance of spores obtained from these biofilms was tested and compared to planktonic and agar plate-derived spores. Drying / air exposure of the preformed $24 \mathrm{~h}$ old biofilms accelerated spore formation for both strains and resulted in higher final spore percentages. Prolonged dry incubation of more than three days triggered germination of spores in the biofilms of ATCC 10987. Spores harvested from wet biofilms on SS displayed the highest heat resistance compared to liquid, agar plate and PS biofilm derived spores. The $\mathrm{D}_{95^{\circ} \mathrm{C}}$ values for these spores were 17 and 22 minutes for NIZO 4080 and ATCC 10987, respectively, which was 2 and 1.2 fold higher compared to planktonic spores of these strains. Spores obtained from dried biofilms of ATCC 10987 displayed reduced heat resistance compared to wet biofilm spores. The results indicate that environmental conditions encountered by biofilms affect sporulation dynamics and spore heat resistance, thus affecting subsequent quality issues and safety risks related to these biofilms.
\end{abstract}




\section{Introduction}

Bacillus cereus is a food spoilage and pathogenic microorganism which uses several strategies to cope with unfavourable conditions in the environment. The main strategy for $B$. cereus to survive harsh conditions is the formation of spores. The spores of this microorganism can survive pasteurisation and end up in the final product, with the potential to cause spoilage and food poisoning, especially since pasteurisation eliminates most of the competitor vegetative cells (Andersson et al. 1995). B. cereus can also form spores in biofilms (Faille et al. 2014, Hayrapetyan et al. 2015), which can sometimes reach up to $90 \%$ of the total viable counts in the biofilm (Wijman et al. 2007). The sporulation process and resulting spore properties are affected by environmental conditions (Ryu and Beuchat 2005, Nguyen Thi Minh et al. 2011, Sella et al. 2014). Environmental parameters described to influence spore heat resistance include medium composition (Mazas et al. 1995, Guizelini et al. 2012), mineral availability (Bender and Marquis 1985), water activity of the medium (Nguyen Thi Minh et al. 2008), sporulation temperature (Baril et al. 2011, Marshall et al. 2015), oxygen availability and spatial distribution, such as in liquid culture versus agar surface (Veening et al. 2006, Rose et al. 2007). For example, spores derived from biofilms of $B$. cereus emetic toxin producing strains grown in polystyrene 96-wells displayed a higher heat resistance compared to spores derived from liquid cultures (van der Voort and Abee 2013). This triggers the question how the biofilm environment affects spore formation and heat resistance characteristics, and whether the biofilm contact surface influences spore properties.

To study this, we mimicked conditions conceivably encountered by biofilm producing bacterial spore-formers in a food processing line or in the environment with interchanging wet (submerged) and dry (exposed to air) conditions.

Biofilm formation of B. cereus reference strain ATCC 10987 and the undomesticated food isolate NIZO 4080 was studied in a chemically defined sporulation supporting medium on stainless steel (SS) and polystyrene (PS) as contact surface materials. Sporulation efficiency on these surfaces in wet and dry biofilms was monitored by both plate counting and phase contrast microscopy. Subsequently, the wet heat resistance of spores harvested from these biofilms was measured and compared to spores derived from parallel incubations in liquid and agar-based media. 


\section{Materials and methods}

\section{Strains and culturing conditions}

The reference strain ATCC 10987 and an undomesticated food isolate NIZO 4080 of Bacillus cereus (previously isolated from dried onion, NIZO culture collection) were used in this study. Strains were streaked on BHI (Brain Heart Infusion, Becton Dickinson) agar plates from stocks stored at $-80{ }^{\circ} \mathrm{C}$ and incubated for $24 \mathrm{~h}$ at $30{ }^{\circ} \mathrm{C}$ to obtain single colonies. A single colony was used to inoculate BHI broth to obtain apre-culture of $18 \mathrm{~h}$ at $30^{\circ} \mathrm{C}$. For sporulation and biofilm formation the chemically defined medium Y1 described previously (De Vries et al. 2004) was used, with the following modified composition: D-glucose $(10 \mathrm{mM})$, L-glutamic acid (20 $\mathrm{mM})$, L-leucine $(1.2 \mathrm{mM})$, L-valine $(0.52 \mathrm{mM})$, L-threonine $(0.28 \mathrm{mM})$, L-methionine $(0.1 \mathrm{mM})$, L-histidine $(0.06 \mathrm{mM})$, sodium-DL-lactate $(5 \mathrm{mM})$, acetic acid $(1 \mathrm{mM})$, $\mathrm{FeCl}_{3}(50 \mu \mathrm{M}), \mathrm{CuCl}_{2}(2.5 \mu \mathrm{M}), \mathrm{ZnCl}_{2}(12.5 \mu \mathrm{M}), \mathrm{MnSO}_{4}(66 \mu \mathrm{M}), \mathrm{MgCl}_{2}(1 \mathrm{mM})$, $\left(\mathrm{NH}_{4}\right)_{2} \mathrm{SO}_{4}(5 \mathrm{mM}), \mathrm{Na}_{2} \mathrm{MoO}_{4}(2.5 \mu \mathrm{M}), \mathrm{CoCl}_{2}(2.5 \mu \mathrm{M})$, and $\mathrm{Ca}\left(\mathrm{NO}_{3}\right)_{2}(1 \mathrm{mM})$. The $\mathrm{pH}$ was adjusted to 7.4 with $100 \mathrm{mM}$ potassium phosphate buffer.

\section{Biofilm formation and spore quantification}

Biofilms were grown on stainless steel (SS, AISI 304, surface finish 2B) and polystyrene (PS) coupons (W:H=22:18 mm) vertically placed in 12-well plates (Cellstar, suspension culture plate, Greiner bio-one) which were half filled with $3 \mathrm{ml}$ broth and inoculated with $1.5 \%$ pre-culture. Coupons were washed and sterilized prior to use as described in (Castelijn et al. 2013). Plates with coupons were incubated at $30{ }^{\circ} \mathrm{C}$ for 1 to 5 days. For "dry biofilm" conditions, the coupons with formed biofilm were removed from the medium after $24 \mathrm{~h}$ and placed into empty 12-well plates, which were further incubated at $30{ }^{\circ} \mathrm{C}$ and relative humidity $73+4 \%$ (monitored over 24 hours with ESCORT RH-meter) in a humid chamber.

Biofilms on the coupons were quantified using the crystal violet (CV) assay (Merritt et al. 2011) with modifications as described in (Hayrapetyan et al. 2015). Sporulation efficiency in biofilms was determined by plate counting as the ratio of spore counts to total viable counts. For total counts the re-suspended biofilm was plated without heating while for spore counts it was heated at $80^{\circ} \mathrm{C}$ for 10 minutes before plating. The details of the procedure are described in (Hayrapetyan et al. 2015). 


\section{Preparation of spores for heat resistance measurement}

The spores of B. cereus ATCC 10987 and NIZO 4080 were harvested from six growth conditions, namely planktonic growth, growth on agar plates, and four biofilm growth modes consisting of biofilms on SS and PS exposed to wet and dry conditions. Planktonic spores were derived from a $500 \mathrm{ml}$ flask filled with $100 \mathrm{ml}$ broth inoculated with $1 \%$ pre-culture and grown with aeration at $200 \mathrm{rpm}$. Agar plates were prepared by addition of $1.5 \%$ agar to the Y1 broth. The agar surface was spread-inoculated with exponentially growing cells obtained from a pre-culture in $\mathrm{Y} 1$.

Formation of spores was monitored by phase contrast microscopy and spores were harvested when $>95 \%$ (or $>60 \%$ for some biofilms) of the culture consisted of free spores. This was typically between $2-5$ days depending on the condition and the strain. Spores were harvested in Sodium phosphate buffer $(100 \mathrm{mM}, \mathrm{pH}=7.4)$ containing $0.1 \%$ Tween 80 to prevent clumping of spores, as described previously (van Melis et al. 2011). Subsequently the crops were washed every day by centrifugation and the concentration of Tween 80 was reduced gradually reaching $0.01 \%$ on day 7 . Washing of spores continued until 14 days, after which they were stored at $4{ }^{\circ} \mathrm{C}$ and within one week used for heat treatment experiments.

\section{Spore heat resistance}

To determine heat resistance properties of the different spores, $50 \mu \mathrm{l}$ of pure spore crops with $10^{7}-10^{8} \mathrm{CFU} / \mathrm{ml}$ in phosphate buffer with $0.01 \%$ Tween 80 were filled in PCR tubes and heated at $95{ }^{\circ} \mathrm{C}$ for regular intervals from 3 to 30 minutes in a thermo-cycler (Applied Biosystems 2720). A separate sample was heated at $80{ }^{\circ} \mathrm{C}$ for $10 \mathrm{~min}$ as a control and the counts of this sample were taken as initial spore counts, which were for all spore crops close to the counts of untreated samples. Serial 10 fold dilutions of the heated suspensions were spread-plated on BHI and incubated at $30{ }^{\circ} \mathrm{C}$ for up to four days. Two or three independent spore crops were obtained for each condition and for each spore crop heat treatments were performed in three independent experiments. Decimal reduction times $\left(\mathrm{D}_{95^{\circ} \mathrm{C}}\right)$ were obtained by fitting inactivation data of three repetitions with log-linear model with GInaFiT (Version 1.6) tool as an add-in in Excel (Geeraerd et al. 2005). The goodness of fit was judged based on criteria described in (Den Besten et al. 2006). All the curves were statistically acceptable. Presented D values are averages of at least two separate biologicals with standard deviation. 


\section{Statistics}

Biofilm formation and sporulation experiments were repeated on three independent occasions each time including 3 coupons. Presented values are the averages with standard deviations. D value calculation is explained in Spore heat resistance section. Observed differences were considered statistically significant when the following two criteria were met: 1) significance according to a one-sided student t-test with the cut-off value of $\mathrm{p}<0.05,2$ ) cell count differences should be at least 0.5 Log or higher for biofilm total CFU and spore counts.

\section{Results}

\section{Biofilm formation on SS and PS and sporulation efficiency in wet (submerged) and dry (exposed to air) conditions}

The total biomass of the wet biofilms formed by B. cereus NIZO 4080 and ATCC 10987 was quantified on SS and PS coupons from day 1 to 5 (Fig. 1). Biofilms were formed at the air-liquid interface, characteristic for this microorganism (Wijman et al. 2007, Hayrapetyan et al. 2015). The two strains followed different biofilm formation dynamics. The biofilm formed by strain NIZO 4080 reached a maximum after 1 and 2 days on SS and PS, respectively, followed by a decline due to partial release of the biofilm into the medium. The biofilm of ATCC 10987 was formed at a slower rate reaching its maximum amount on day 3 and subsequent release on day 5 .

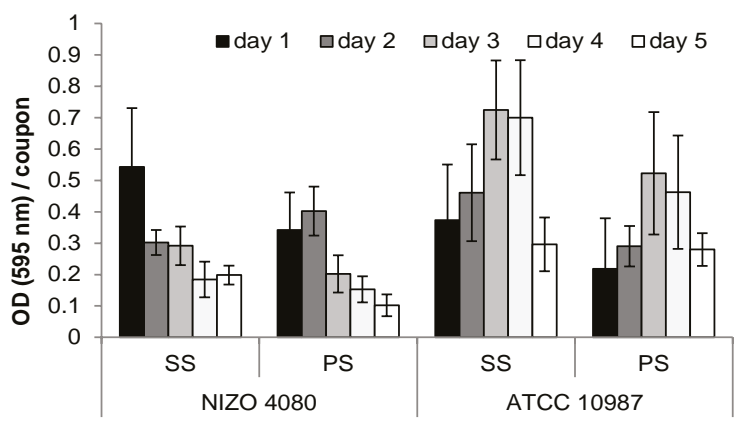

Figure 1. Biofilm biomass. Biofilm formation (crystal violet assay) of $B$. cereus NIZO 4080 and ATCC 10987 on SS and PS surfaces in chemically defined medium from day 1 to 5 at $30{ }^{\circ} \mathrm{C}$.

Total CFUs in the wet biofilm of NIZO 4080 on SS and PS reached the maximum at day 1 and decreased significantly on day 3 (Fig. 2a and b). For strain ATCC 10987, the total CFU counts in the wet biofilm reached maximum values on day 2 and declined significantly on day 3 on both surfaces (Fig. $2 c$ and d), whereas the total biomass reached a maximum on day 3 (Fig.1), possibly resulting from accumulation of dead cells and an increase in biofilm matrix components such as extracellular DNA (eDNA) (Vilain et al. 2009, Jakubovics et al. 2013). 

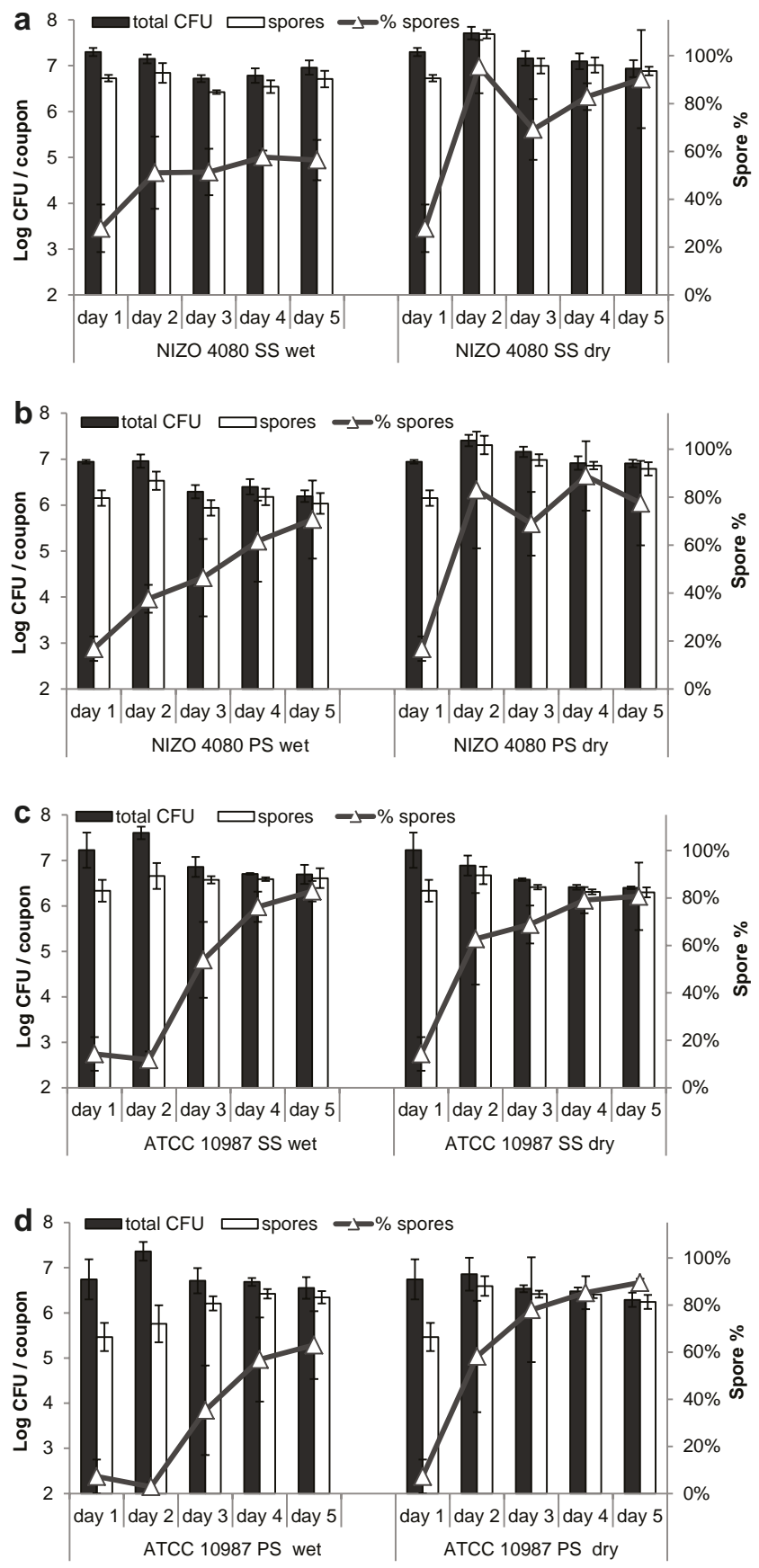

Figure 2. Biofilm cell counts and sporulation dynamics. Spore (white columns) and total CFU counts (black columns) inside wet and dry biofilms of $B$. cereus NIZO 4080 on SS (a) and PS (b), and of B. cereus ATCC 10987 on SS (c) and PS (d). Spore percentages were determined as average ratio of spore counts to total $\mathrm{CFU}$ counts and are presented by triangles. Presented values are the averages of at least 9 replicates performed on three independent occasions with standard deviation. Indications for significant differences $(\mathrm{p}<0.05$ and $\log$ difference $>$ 0.5 Log CFU) can be found in the Supplementary file 1.

The sporulation dynamics in the biofilms in wet and dry conditions was followed using plate counting (Fig. 2) and phase contrast microscopy (Fig. 3 and 4). The sporulation efficiency was expressed as the ratio of spore counts over total CFUs (Fig. 2). Strain NIZO 4080 formed 28 and $17 \%$ spores in the 1 day wet biofilms 
on SS and PS respectively. Air exposure of the 1 day old biofilms significantly accelerated sporulation leading to 95 and $83 \%$ spores at day 2 in biofilms on SS and PS, respectively, corresponding to spore counts of 7.7 and $7.3 \log$ CFU/ coupon. For comparison, wet biofilms at day 2 contained significantly lower amount of spores reaching 6.8 (51\%) and 6.5 (38\%) log spores per SS and PS coupon, respectively. During further incubation of wet biofilms the \% of spores increased gradually and reached the maximum of 56 and $70 \%$ on SS and PS, respectively on day 5, with significantly higher spore counts on SS (6.7 log CFU coupon) compared to PS (6 Log CFUs) (Fig. 2a and b). When comparing dry and wet conditions, dry incubation up to day 5 resulted in significantly higher final spore numbers of $6.8 \log$ CFU on PS as compared to $6 \log$ CFUs for the wet biofilm on PS (Fig. 2b).

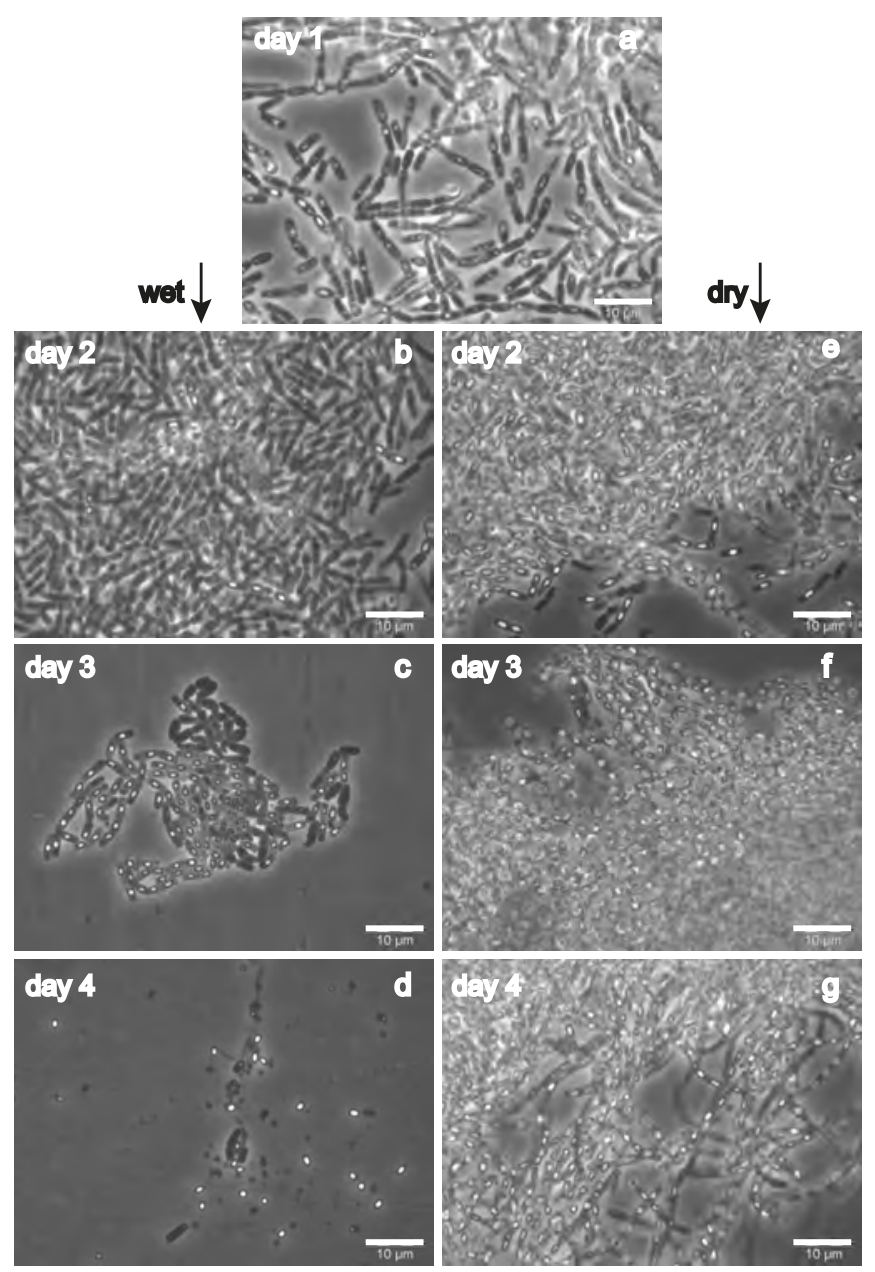

Figure 3. Sporulation followed by microscopy, B. cereus NIZO 4080. B. cereus NIZO 4080 sporulation in wet (b, c, d) and dry (e, f, g) biofilms formed on PS followed by phase contrast microscopy by taking samples from day 1 to 4 . Drying of the biofilm was initiated after day1 on already formed $24 \mathrm{~h}$ old biofilms (a). Dry condition accelerated the formation and release of spores compared to the wet biofilm. 


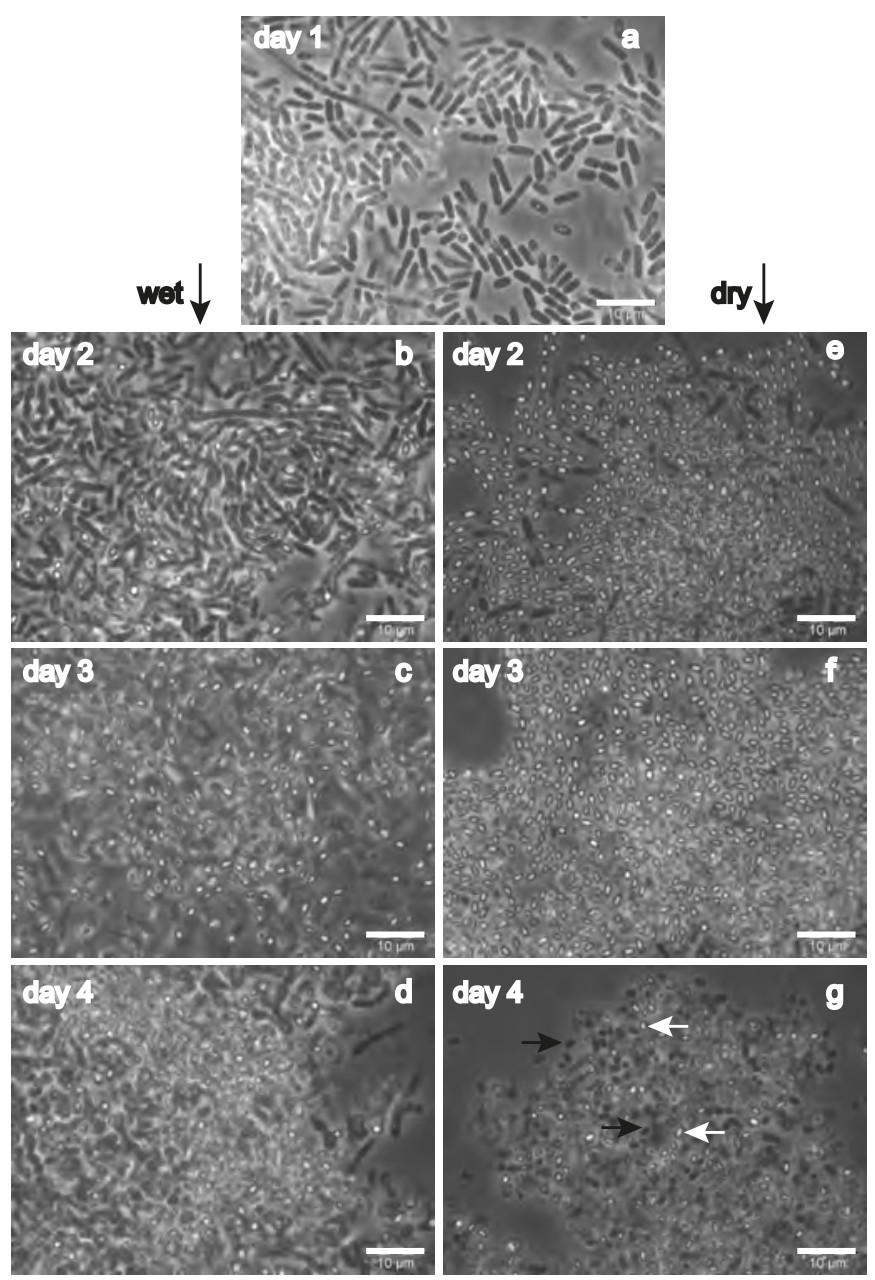

Figure 4. Sporulation followed by microscopy, B. cereus ATCC 10987. B. cereus ATCC 10987 sporulation in wet (b, c, d) and dry (e, f, g) biofilms formed on PS followed by phase contrast microscopy by taking samples from day 1 to 4 . Drying of the biofilm was initiated after day 1 on already formed 24 $\mathrm{h}$ old biofilms (a). Dry condition accelerated the formation and release of spores compared to the wet biofilm. During prolonged incubations of more than 3 days in dry biofilms germinating phase dark spores (black arrows) could be distinguished from still dormant phase bright spores (white arrows). 
B. cereus ATCC 10987 wet biofilms of day 1 contained significantly higher number of spores on SS (6.3 log, 14\%) as compared to PS (5.5 log, 7\%) (Fig. 2c and d). Further incubation of these biofilms in the medium (wet biofilm) slightly increased the total CFUs at day 2 and insignificantly decreased the relative spore content to 13 and $3 \%$ on SS and PS, respectively. By contrast, transfer of the 1 day old biofilms from the medium to dry conditions quickly increased the relative spore content of these dry biofilms to 63 and $58 \%$ on SS and PS, respectively on day 2. Drying resulted in significantly higher spore numbers in biofilms on PS (6.6 log per coupon) at day 2 compared to wet biofilm on PS (5.8 log per coupon). Prolonged incubation of wet biofilms gradually increased the relative spore content due to increase of spore counts on PS and decrease of total CFUs on SS and PS, most likely due to death of non-sporulating vegetative cells. Spore counts did not further increase from day 2 onwards for dry biofilms but death of vegetative cells resulted in a further increase in relative spore content.

The sporulation process was followed with phase contrast microscopy (Fig. 3 and 4) which revealed that the spores in the dry biofilms of both strains reached higher densities faster compared to wet biofilms. The spores in dry biofilms were also generally faster released from the mother cells. Interestingly, the dry biofilm spores of ATCC 10987 showed germination both on SS and PS coupons usually after two to three days of incubation (Fig. $4 \mathrm{f}$ and $\mathrm{g}$ ).

\section{Heat resistance of spores derived from wet and dry biofilms on SS and PS, agar plate and liquid culture}

Spores harvested from wet and dry biofilms on SS and PS, agar plate and liquid culture were maturated during 14 days to obtain stable crops before they were tested for wet heat resistance at $95{ }^{\circ} \mathrm{C}$.(Den Besten et al. 2006) For liquid derived spores of the two strains, spores from strain ATCC $10987\left(\mathrm{D}_{95^{\circ} \mathrm{C}}=19 \mathrm{~min}\right)$ showed higher heat resistance compared to NIZO $4080\left(D_{95^{\circ} \mathrm{C}}=9 \mathrm{~min}\right)$. For both strains, the heat resistance of spores from wet biofilm on PS was not significantly different from liquid spores. Heat resistance of agar plate-derived spores of NIZO 4080 was not significantly different from liquid spores, while heat resistance of such spores from ATCC 10987 was lower compared to that of liquid spores.

For both B. cereus NIZO 4080 and ATCC 10987, the spores derived from wet biofilm on SS were among the most resistant spores, with $\mathrm{D}_{95^{\circ} \mathrm{C}}$ of 17 and 22 minutes, respectively. PS wet biofilm spores of NIZO 4080 displayed a similar D value $\left(D_{95^{\circ} \mathrm{C}}\right.$ $=17 \mathrm{~min}$ ) as that for SS wet biofilm spores, however inactivation experiments showed a higher variation between replicate samples and therefore it was not significantly 
different. The spores of NIZO 4080 from dry biofilm on SS showed similar heat resistance $\left(D_{95^{\circ} \mathrm{C}}=16 \mathrm{~min}\right)$ to that of wet biofilm on SS, while NIZO 4080 spores from liquid and agar displayed significantly lower D values. Interestingly, spores from dry biofilms displayed a decreased heat resistance compared to those of wet conditions, this was most pronounced for strain ATCC 10987, for which the $\mathrm{D}_{95^{\circ} \mathrm{C}}$ of spores formed in SS biofilms was $14 \mathrm{~min}$ for dry conditions compared to $22 \mathrm{~min}$ for wet biofilm-derived spores.

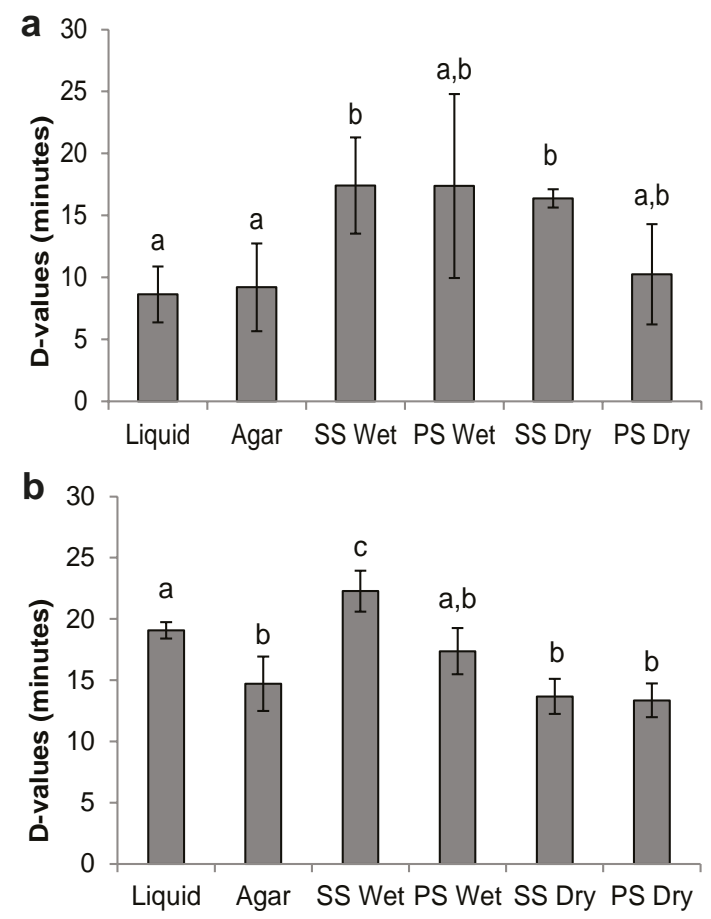

Figure 5. Spore heat resistance. Heat resistance of B. cereus NIZO 4080 (a) and ATCC 10987 (b) spores derived from 6 different conditions, at $95{ }^{\circ} \mathrm{C}$ presented in the form of D-values derived from linear inactivation curves (fitted by GinaFit in Excel). Presented values are averages of at least two independent biologicals with standard deviations. Significant differences are indicated by different letters $(p<0.05$, t-test). 


\section{Discussion}

Biofilms of $B$. cereus in industrial settings can become a source of post-pasteurisation contamination with heat resistant spores. We studied biofilm formation by $B$. cereus in a defined sporulation medium and analysed sporulation efficiency in those biofilms. Depending on the industrial process, environmental conditions encountered by biofilms cells in processing lines fluctuate in terms of nutrients or oxygen availability and humidity. It is conceivable that biofilms encounter transient wet (submerged) and dry (air exposed) conditions for example in empty or halffilled transport pipes and on food processing surfaces. These are the conditions we tried to mimic in our study on B. cereus biofilm formation and maturation with a special focus on sporulation and spore characteristics.

We show that removal of the biofilm from the medium and exposure to air accelerated spore formation and spore release from the mother cell. To check whether this effect could be linked to nutrient deprivation we transferred submerged wet biofilm into Phosphate Buffered Saline (PBS) solution devoid of any nutrients and observed similar accelerated sporulation (not shown). Ryu and Beuchat (2005) exposed biofilms of $B$. cereus formed in TSB to air which resulted in increased spore formation at $22{ }^{\circ} \mathrm{C}$ and high relative humidity of 97 and $100 \%$, whereas exposure to air with low humidity (85\%) did not affect sporulation but resulted in death of vegetative cells. Baweja et al. (2008) transferred planktonic early stationary culture of Bacillus anthracis into PBS and observed significantly increased sporulation efficiency up to $50 \%$ compared to $5 \%$ for the control within $8 \mathrm{~h}$, confirming the sporulation promoting effect of nutrient deprivation.

Lindsay et al. (2006) showed that B. cereus spores initially attached to a surface were able to germinate and grow out in a nutrient-rich but not in nutrient-poor medium. In our study the spores of strain ATCC 10987 inside dry biofilms readily germinated when incubated for more than 3 days. It can be anticipated that the biofilm environment provides nutrients to trigger germination most likely originating from the matrix components and lysed cells. This effect was more pronounced in the dry biofilms compared to wet biofilms, for which spore germination was not observed until incubation up to at least 7 days (not shown). At a later stage after appearance of germinating phase dark spores in the dry biofilm we also observed a large fraction of lysing phase dark spores, suggesting that conditions were not favourable to support full outgrowth of these germinated spores into vegetative cells (not shown). However, for biofilms in food processing environments, release of germinated spores can result in post-pasteurisation contamination which, without further heat treatment, may lead to rapid outgrowth causing spoilage and/or safety issues. 
In this study we compared the heat resistance of spores harvested from liquid culture, agar surface and wet and dry biofilms on SS and PS surfaces. Harvested spores were allowed to mature for 14 days before heat treatment to conserve only intrinsic and stable differences. The spores formed in wet biofilms on SS showed highest heat resistance, whereas dry biofilm spores conceivably produced at lower water activity $\left(\mathrm{a}_{\mathrm{w}}\right)$ showed reduced heat resistance compared to wet biofilms, with NIZO 4080 SS-dry spores as an exception. This is in line with previous observations on reduced heat resistance of $B$. subtilis spores derived from cultures grown at lower water activity ( $\mathrm{a}_{\mathrm{w}}=0.95$ vs. 0.99 ), and it was suggested that this phenomenon was related to changes in protein content of the spores and/or rapid rehydration when suspended in distilled water which could induce a mechanical weakening of the cortex (Nguyen Thi Minh et al. 2008)2h.

A range of spore components has been described to play a role in heat resistance including dipicolinic acid (DPA) (Paidhungat et al. 2000) and mineral content (Cazemier et al. 2001). Similar to our findings, spores of $B$. anthracis developed in nutrient deprived conditions submerged in PBS, displayed lower resistance properties against wet heat and several chemical denaturants, such as acidic or alkali $\mathrm{pH}$ and hydrogen peroxide. These spores contained the same level of DPA as the spores from the control culture but may have an altered composition due to lack of precursors for synthesis of different spore components (Baweja et al. 2008). Similarly, in our study there was no correlation found between the heat resistance of spores derived from different conditions and their DPA content measured according to (Kort et al. 2005) (not shown).

Contrary to our findings, B. subtilis agar plate derived spores were previously reported to be more heat resistant (at $90^{\circ} \mathrm{C}$ ) compared to liquid spores. Interestingly, this was not related to differences in core water, DPA or SASP contents, but was conceivably due to differences in the fatty acid composition of the inner membrane of spores (Rose et al. 2007).

Increased heat resistance of spores from biofilms on SS could be related to enhanced metal availability during sporulation, especially iron ( $>70 \%$ of SS composition) and manganese ( $1 \%$ of SS composition), possibly caused by corrosion (Bragadeeswaran et al. 2011, Rajasekar and Ting 2011). Other metals present in the SS material are chromium (18\%) and nickel (8\%). Previously, a positive correlation was found between high manganese content and wet heat resistance (at $85{ }^{\circ} \mathrm{C}$ ) of Bacillus megaterium spores (Ghosh et al. 2011). Notably, a high iron content was linked to reduced resistance of Clostridium botulinum spores when heated at $95-110{ }^{\circ} \mathrm{C}$ (Kihm et al. 1990). 
The $\mathrm{D}_{95^{\circ} \mathrm{C}}$ values reported in this study for agar-based media derived spores of $B$. cereus NIZO 4080 and ATCC 10987 (9 and $15 \mathrm{~min}$ ) are just within the range of $\mathrm{D}_{95^{\circ} \mathrm{C}}$ values $(2-15 \mathrm{~min}$ ) reported for agar derived spores of $B$. cereus belonging to different ecological groups (Luu-Thi et al. 2014) with the exclusion of one outlier with high resistance (30 min after extrapolation) and psychrotolerant strains with very low heat resistance. This comparison shows that spores of $B$. cereus ATCC 10987 are amongst the most heat resistant $B$. cereus strains tested. The fact that NIZO 4080 and ATCC 10987 spores from biofilms on SS show even higher D values $\left(\mathrm{D}_{95^{\circ} \mathrm{C}}\right.$ of 17 and $22 \mathrm{~min}$ ) indicates the impact of biofilm sporulation history on spore resistance.

In conclusion, we showed that sporulation dynamics in biofilms can be influenced by environmental conditions. Air exposure of the biofilms drastically accelerated spore formation for both B. cereus ATCC 10987 and NIZO 4080 strains on both SS and PS surface materials. Biofilms formed on stainless steel yielded spores with significantly higher heat resistance compared to liquid spores for both strains. In contrast, drying of biofilms by air-exposure may have a negative effect on spore heat resistance and stability, as reflected in increased germination of spores in the biofilm upon prolonged incubation in dry conditions. Data presented in this study provide insight in sporulation dynamics and characteristics of spores produced in biofilms that may be helpful in design of cleaning strategies against $B$. cereus biofilms.

\section{Acknowledgements}

We thank Cindy Cruz Ponton and Jorge Duran Barragan for their input in initial stages of this research in defining the optimum conditions of experiments and selection of medium and strains to test. We also thank Heidy den Besten for her help in estimating the goodness of fit for heat inactivation curves.

The project is funded by TI Food and Nutrition, a public-private partnership on precompetitive research in food and nutrition. The public partners are responsible for the study design, data collection and analysis, decision to publish, and preparation of the manuscript. The private partners have contributed to the project through regular discussion. 


\section{References}

Andersson, A., U. Rönner and P. E. Granum (1995). What problems does the food industry have with the spore-forming pathogens Bacillus cereus and Clostridium perfringens? International Journal of Food Microbiology 28(2): 145-155.

Baril, E., L. Coroller, F. Postollec, I. Leguerinel, C. Boulais, F. Carlin and P. Mafart (2011). The wetheat resistance of Bacillus weihenstephanensis KBAB4 spores produced in a two-step sporulation process depends on sporulation temperature but not on previous cell history. International Journal of Food Microbiology 146(1): 57-62.

Baweja, R. B., M. S. Zaman, A. R. Mattoo, K. Sharma, V. Tripathi, A. Aggarwal, G. P. Dubey, R. K. Kurupati, M. Ganguli, N. K. Chaudhury, S. Sen, T. K. Das, W. N. Gade and Y. Singh (2008). Properties of Bacillus anthracis spores prepared under various environmental conditions. Archives of Microbiology 189(1): 71-79.

Bender, G. R. and R. E. Marquis (1985). Spore heat resistance and specific mineralization. Applied and Environmental Microbiology 50(6): 1414-1421.

Bragadeeswaran, S., R. Jeevapriya, K. Prabhu, S. S. Rani, S. Priyadharsini and T. Balasubramanian (2011). Exopolysaccharide production by Bacillus cereus GU812900, a fouling marine bacterium. African Journal of Microbiology Research 5(24): 4124-4132.

Castelijn, G. A., J. A. Parabirsing, M. H. Zwietering, R. Moezelaar and T. Abee (2013). Surface behaviour of S. Typhimurium, S. Derby, S. Brandenburg and S. Infantis. Veterinary Microbiology 161(3-4): 305-314.

Cazemier, A. E., S. F. M. Wagenaars and P. F. Ter Steeg (2001). Effect of sporulation and recovery medium on the heat resistance and amount of injury of spores from spoilage Bacilli. Journal of Applied Microbiology 90(5): 761-770.

De Vries, Y. P., L. M. Hornstra, W. M. De Vos and T. Abee (2004). Growth and Sporulation of Bacillus cereus ATCC 14579 under Defined Conditions: Temporal Expression of Genes for Key Sigma Factors. Applied and Environmental Microbiology 70(4): 2514-2519.

Den Besten, H. M. W., M. Mataragas, R. Moezelaar, T. Abee and M. H. Zwietering (2006). Quantification of the effects of salt stress and physiological state on thermotolerance of Bacillus cereus ATCC 10987 and ATCC 14579. Applied and Environmental Microbiology 72(9): 5884-5894.

Faille, C., T. Bénézech, G. Midelet-Bourdin, Y. Lequette, M. Clarisse, G. Ronse, A. Ronse and C. Slomianny (2014). Sporulation of Bacillus spp. within biofilms: A potential source of contamination in food processing environments. Food Microbiology 40: 64-74.

Geeraerd, A. H., V. P. Valdramidis and J. F. Van Impe (2005). GInaFiT, a freeware tool to assess nonlog-linear microbial survivor curves. International Journal of Food Microbiology 102(1): 95-105.

Ghosh, S., A. Ramirez-Peralta, E. Gaidamakova, P. Zhang, Y. Q. Li, M. J. Daly and P. Setlow (2011). Effects of Mn levels on resistance of Bacillus megaterium spores to heat, radiation and hydrogen peroxide. Journal of Applied Microbiology 111(3): 663-670.

Guizelini, B. P., L. P. S. Vandenberghe, S. R. B. R. Sella and C. R. Soccol (2012). Study of the influence of sporulation conditions on heat resistance of Geobacillus stearothermophilus used in the development of biological indicators for steam sterilization. Archives of Microbiology 194(12): 991-999.

Hayrapetyan, H., L. Muller, M. Tempelaars, T. Abee and M. Nierop Groot (2015). Comparative analysis of biofilm formation by Bacillus cereus reference strains and undomesticated food isolates and the effect of free iron. International Journal of Food Microbiology 200: 72-79.

Jakubovics, N. S., R. C. Shields, N. Rajarajan and J. G. Burgess (2013). Life after death: The critical role of extracellular DNA in microbial biofilms. Letters in Applied Microbiology 57(6): 467-475.

Kihm, D. J., M. T. Hutton, J. H. Hanlin and E. A. Johnson (1990). Influence of transition metals added during sporulation on heat resistance of Clostridium botulinum 113B spores. Applied and Environmental Microbiology 56(3): 681-685. 
Kort, R., A. C. O'Brien, I. H. M. Van Stokkum, S. J. C. M. Oomes, W. Crielaard, K. J. Hellingwerf and S. Brul (2005). Assessment of heat resistance of bacterial spores from food product isolates by fluorescence monitoring of dipicolinic acid release. Applied and Environmental Microbiology 71(7): 3556-3564.

Lindsay, D., V. S. Brözel and A. Von Holy (2006). Biofilm-spore response in Bacillus cereus and Bacillus subtilis during nutrient limitation. Journal of Food Protection 69(5): 1168-1172.

Luu-Thi, H., D. B. Khadka and C. W. Michiels (2014). Thermal inactivation parameters of spores from different phylogenetic groups of Bacillus cereus. International Journal of Food Microbiology 189: 183-188.

Marshall, K. M., L. Nowaczyk, II, T. R. Morrissey, V. Loeza, L. A. Halik, G. E. Skinner, N. R. Reddy, G. J. Fleischman and J. W. Larkin (2015). Effect of sporulation temperature on the resistance of Clostridium botulinum type A spores to thermal and high pressure processing. Journal of Food Protection 78(1): 146-150.

Mazas, M., I. Gonzalez, M. Lopez, J. Gonzalez and R. M. Sarmiento (1995). Effects of sporulation media and strain on thermal resistance of Bacillus cereus spores. International Journal of Food Science \& Technology 30(1): 71-78.

Merritt, J. H., D. E. Kadouri and G. A. O'Toole (2011). Growing and analyzing static biofilms. Current protocols in microbiology(SUPPL. 22).

Nguyen Thi Minh, H., A. Durand, P. Loison, J. M. Perrier-Cornet and P. Gervais (2011). Effect of sporulation conditions on the resistance of Bacillus subtilis spores to heat and high pressure. Applied Microbiology and Biotechnology 90(4): 1409-1417.

Nguyen Thi Minh, H., S. Guyot, J. M. Perrier-Cornet and P. Gervais (2008). Effect of the osmotic conditions during sporulation on the subsequent resistance of bacterial spores. Applied Microbiology and Biotechnology 80(1): 107-114.

Paidhungat, M., B. Setlow, A. Driks and P. Setlow (2000). Characterization of spores of Bacillus subtilis which lack dipicolinic acid. Journal of Bacterioloby 182(19): 5505-5512.

Rajasekar, A. and Y. P. Ting (2011). Role of inorganic and organic medium in the corrosion behavior of Bacillus megaterium and Pseudomonas sp. in stainless steel SS 304. Industrial and Engineering Chemistry Research 50(22): 12534-12541.

Rose, R., B. Setlow, A. Monroe, M. Mallozzi, A. Driks and P. Setlow (2007). Comparison of the properties of Bacillus subtilis spores made in liquid or on agar plates. Journal of Applied Microbiology 103(3): 691-699.

Ryu, J. H. and L. R. Beuchat (2005). Biofilm formation and sporulation by Bacillus cereus on a stainless steel surface and subsequent resistance of vegetative cells and spores to chlorine, chlorine dioxide, and a peroxyacetic acid-based sanitizer. Journal of Food Protection 68(12): 2614-2622.

Sella, S. R. B. R., L. P. S. Vandenberghe and C. R. Soccol (2014). Life cycle and spore resistance of sporeforming Bacillus atrophaeus. Microbiological Research 169(12): 931-939.

van der Voort, M. and T. Abee (2013). Sporulation environment of emetic toxin-producing Bacillus cereus strains determines spore size, heat resistance and germination capacity. Journal of Applied Microbiology 114(4): 1201-1210.

van Melis, C. C. J., M. N. Nierop Groot, M. H. Tempelaars, R. Moezelaar and T. Abee (2011). Characterization of germination and outgrowth of sorbic acid-stressed Bacillus cereus ATCC 14579 spores: Phenotype and transcriptome analysis. Food Microbiology 28(2): 275-283.

Veening, J. W., O. P. Kuipers, S. Brul, K. J. Hellingwerf and R. Kort (2006). Effects of phosphorelay perturbations on architecture, sporulation, and spore resistance in biofilms of Bacillus subtilis. Journal of Bacteriology 188(8): 3099-3109.

Vilain, S., J. M. Pretorius, J. Theron and V. S. Brözel (2009). DNA as an adhesin: Bacillus cereus requires extracellular DNA to form biofilms. Applied and Environmental Microbiology 75(9): 2861-2868.

Wijman, J. G. E., P. P. L. A. De Leeuw, R. Moezelaar, M. H. Zwietering and T. Abee (2007). Airliquid interface biofilms of Bacillus cereus: Formation, sporulation, and dispersion. Applied and Environmental Microbiology 73(5): 1481-1488. 
Supplementary material can be found in the online version of the article. 



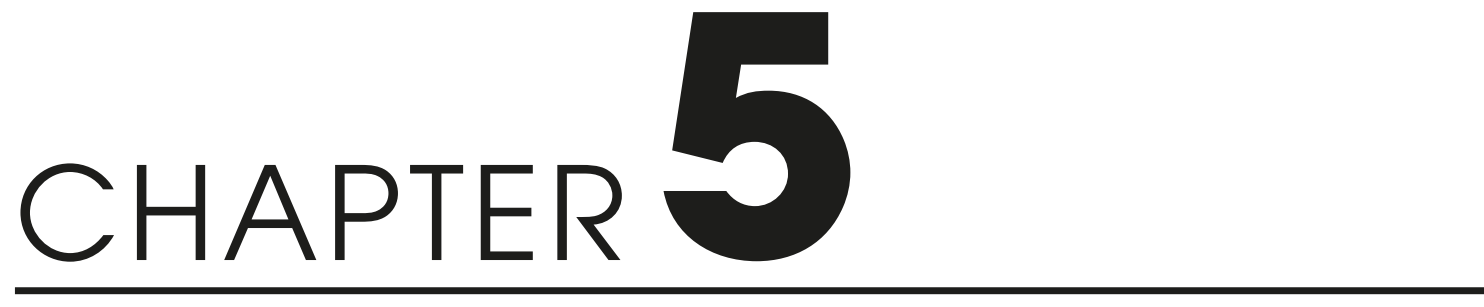

Bacillus cereus ATCC 14579 RpoN (Sigma 54) is a pleiotropic regulator of growth, carbohydrate metabolism, motility, biofilm formation and toxin production

Hasmik Hayrapetyan

Marcel Tempelaars

Masja Nierop Groot

Tjakko Abee 


\section{Abstract}

Sigma 54 is a transcriptional regulator predicted to play a role in physical interaction of bacteria with their environment, including virulence and biofilm formation. In order to study the role of Sigma 54 in Bacillus cereus, a comparative transcriptome and phenotypic study was performed using $B$. cereus ATCC 14579 WT, a markerless rpoN deletion mutant, and its complemented strain. The mutant was impaired in many different cellular functions including low temperature and anaerobic growth, carbohydrate metabolism, sporulation and toxin production. Additionally, the mutant showed lack of motility and biofilm formation at air-liquid interphase, and this correlated with absence of flagella, as flagella staining showed only WT and complemented strain to be highly flagellated. Comparative transcriptome analysis of cells harvested at selected time points during growth in aerated and static conditions in BHI revealed large differences in gene expression associated with loss of phenotypes, including significant down regulation of genes in the mutant encoding enzymes involved in degradation of branched chain amino acids, carbohydrate transport and metabolism, flagella synthesis and virulence factors. Our study provides evidence for a pleiotropic role of Sigma 54 in B. cereus supporting its adaptive response and survival in a range of conditions and environments. 


\section{Introduction}

Microorganisms may encounter many different environments during their lifecycle and rapid adaptation to these specific conditions requires tailored regulatory mechanisms. As part of such a mechanism, alternative sigma factors regulate the onset and expression level of a subset of genes at a given physiological state of the cell. There are different types of sigma factors in bacteria, each of them regulating a specific response, such as Sigma B regulating gene expression in response to a range of stresses including heat, low temperature and acid in Bacillus subtilis and related species (Van Schaik et al. 2004, Hecker et al. 2007) and for example Sigma 32 that supports heat shock survival in Escherichia coli (Arsène et al. 2000). The majority of these sigma factors belong to the Sigma 70 family, with Sigma 54 as an exception, and as the only known representative of this class (Merrick 1993). Sigma 54, encoded by the rpoN gene in B. cereus, also referred to as SigL in B. subtilis (Debarbouille et al. 1991) and RpoN in E. coli (Jones et al. 1994), is unique among all sigma factors in its structure and the mechanism of action since it needs specific activator proteins called Enhancer Binding Proteins (EBPs) and ATP hydrolysis in order to initiate transcription (Buck et al. 2000). Specificity and activity of Sigma 54 dependent transcription is modulated by EBPs which bind to specific enhancer binding sequences and are triggered by different environmental cues (Studholme and Dixon 2003).

The Sigma 54-controlled functions described for bacterial species are diverse and include nitrogen metabolism (Debarbouille et al. 1991, Reitzer and Schneider 2001), motility (Wolfe et al. 2004, Dong et al. 2011), biofilm formation (Iyer and Hancock 2012), stress tolerance and resistance to antimicrobials (Dalet et al. 2001, Hwang et al. 2011), carbohydrate uptake and metabolism (Stevens et al. 2010), and virulence (Hao et al. 2013). In B. subtilis Sigma 54 (SigL) is known to be involved in regulation of cold shock adaptation (Wiegeshoff et al. 2006), degradation of the branched chain amino acids isoleucine and valine (Debarbouille et al. 1999) and acetoin catabolic pathway (Ali et al. 2001), whereas in Bacillus thuringiensis regulation of the gab gene cluster, involved in $\gamma$-aminobutyric acid (GABA) shunt which can channel glutamate into the tricarboxylic acid (TCA) cycle has been reported (Zhu et al. 2010, Peng et al. 2014). A recent study showed a role of Sigma 54 in nitrogen utilisation in $B$. thuringiensis and proposed putative regulon members for this sigma factor (Peng et al. 2015).

A cross-phylum in silico analysis by Franke et al. (2011) aiming for prediction of Sigma 54 functions based on its genetic context, associated EBP-activators and promoters, and reported phenotypes, revealed a role for Sigma 54 as a modulator of bacterial cell exterior as a unifying theme. This control is executed by regulating 
the transport and biosynthesis of components involved in the interaction of the cell with its environment, such as the cell wall, flagella, extracellular polysaccharides and proteins. For pathogens such as for example Bacillus cereus, this may imply a role of this sigma factor in host colonization and biofilm formation (Francke et al. 2011, Ceuppens et al. 2013).

Bacillus cereus is a foodborne pathogen that is ubiquitously present in the environment showing high capacity to adapt to different environmental niches. Soil is the main reservoir of $B$. cereus spores and food can serve as a vehicle to transfer them to the host. Apart from food spoilage, this species may cause food poisoning due to production of toxins. The spores of $B$. cereus survive many stresses applied by food producing industries such as heat and disinfectant treatments, making them hard to eliminate as contaminants. Surviving $B$. cereus spores germinate and grow out into vegetative cells, which can also cope with unfavourable conditions, such as anaerobic environment (Rosenfeld et al. 2005, Van Der Voort and Abee 2009), acidic environments (Mols and Abee 2011) or low temperature (Guinebretière et al. 2008).

The aim of this study was to assess the role of Sigma 54 in B. cereus by a comparative transcriptomic and phenotype analysis, using B. cereus ATCC 14579 wild type, its marker-less rpoN deletion mutant, and a complemented strain under different growth conditions.

Presented data shows that the $B$. cereus rpoN mutant was impaired in many different cellular functions which were correlated with differences in gene expression. This provides evidence for a pleiotropic role of Sigma factor 54 in B. cereus supporting adaptive responses and performance of this foodborne pathogen in a range of conditions and environments.

\section{Materials and Methods}

\section{Strains and culture conditions}

Bacillus cereus ATCC 14579 wild type (WT), its rpoN mutant derivative ( $\Delta$ rpoN) and complemented strain ( $\Delta$ rpoN-comp) stocks from $-80{ }^{\circ} \mathrm{C}$ were streaked on $\mathrm{BHI}$ (Brain Heart Infusion, Becton Dickinson) plates and incubated for $24 \mathrm{~h}$ at $30{ }^{\circ} \mathrm{C}$. Single colonies were inoculated into BHI broth and cultivated for $18 \mathrm{~h}$ at $30{ }^{\circ} \mathrm{C}$ with aeration (200rpm). Erythromycin $(10 \mathrm{ug} / \mathrm{ml}$ ) was added for the $r p o N$-comp strain to agar plates and overnight culture broth. 
Occasionally, after prolonged static incubations ( $>48 \mathrm{~h}$ ) a spontaneous secondary mutant with a more widespread and round colony appeared. To avoid interference of this secondary mutant, incubation times were kept within $48 \mathrm{~h}$ and routinely, cultures were screened on plate to confirm presence of a single colony morphology. Interestingly, a similar phenomenon has been described previously for a Pseudomonas fluorescence rpoN mutant (Jones et al. 2007).

\section{Growth, sporulation and diarrhoeal enterotoxin production}

Aerated $(200 \mathrm{rpm})$ and static growth of the strains was monitored at $30{ }^{\circ} \mathrm{C}$ in 250 $\mathrm{ml}$ erlenmeyer flasks filled with $50 \mathrm{ml}$ BHI. Anaerobic cultivation was performed in rubber sealed serum bottles which were flushed with nitrogen for $2 \mathrm{~h}$ before inoculation. Nitrogen flushing was repeated for $20 \mathrm{sec}$. after each sampling point to ensure anaerobic conditions after sampling. Anaerobic cultures were incubated at $200 \mathrm{rpm}$. At regular time points between 0 and $48 \mathrm{~h}$, samples were taken and the $\mathrm{OD}$ at $600 \mathrm{~nm}$ was measured.

The number of spores in the aerated culture was determined by plating the samples after heating for $10 \mathrm{~min}$ at $80^{\circ} \mathrm{C}$ on BHI agar plates. Unheated samples were plated for total number of CFUs (spores and vegetative cells).

The diarrhoeal non-haemolytic enterotoxin production was measured using the Bacillus Diarrhoeal Enterotoxin Visual Immunoassay kit (TECRA International Pty) following the instructions of the manufacturer. The amount of the toxin was measured in supernatants of the samples taken for RNA isolation for the microarray.

The growth at $12{ }^{\circ} \mathrm{C}$ was monitored in two different ways, by cultivation in aerated conditions (similar to $30^{\circ} \mathrm{C}$ ) described above and by streaking overnight cultures on a BHI agar plate and incubating at $12{ }^{\circ} \mathrm{C}$ for up to 12 days.

\section{Biofilm formation}

The biofilm formation by the WT, the rpoN mutant and the complemented strain was tested on stainless steel coupons (AISI 304, surface finish 2B) with the size of 22:18 $\mathrm{mm}$, placed vertically in a 12-well plate (Cellstar, suspension culture plate, Greiner). The wells were half filled with $3 \mathrm{ml}$ BHI broth and inoculated with $1.5 \%$ overnight culture. Coupons were washed and sterilized in advance as described previously (Castelijn et al. 2013). Biofilms formed on the coupons were visualized by staining in $0.1 \%$ crystal violet for $30 \mathrm{~min}$ and subsequently washing in demineralized water to remove the excess stain. 


\section{Motility assay and flagella staining}

Swimming motility was tested on BHI plates supplemented with $0.3 \%$ agar on which $5 \mu \mathrm{l}$ of overnight culture was spotted in the centre and incubated for $48 \mathrm{~h}$ at $30{ }^{\circ} \mathrm{C}$.

For flagella staining the procedure described previously (Harshey and Matsuyama 1994) was followed. The cells used for flagella staining were taken from the edges of the colonies formed on the above described swimming plates.

\section{DNA manipulation techniques}

Chromosomal DNA was isolated from B. cereus using the Wizard Genomic DNA Purification kit (Promega) for sequencing reactions and using InstaGene Matrix (Biorad) for fast colony PCR screening. Plasmid DNA was extracted using QiaPrep spin miniprep columns (Qiagen). Oligonucleotide primers (Table 1) were synthesized by Sigma. PCR amplification for cloning and sequencing was performed using KAPA HiFi Hotstart DNA Polymerase (Kapa Biosystems, Inc. Wilmington) whereas DreamTaq DNA polymerase (Fisher Scientific) was used for control PCR reactions. Restriction enzymes, T4 DNA ligase and FastAP Termosensitive Alkaline Phosphatase were obtained from Fisher Scientific and used according to manufacturer's instructions. Plasmid constructs and B. cereus deletion and complementation clones were confirmed by DNA sequencing (Baseclear, Leiden, The Netherlands).

\section{Deletion mutant construction and complementation}

To elucidate the role of $r p o N$ in B. cereus ATCC14579 an antibiotic marker-free deletion mutant, designated FM145143, was constructed using the temperaturesensitive suicide plasmid pAUL-A (Chakraborty et al. 1992). Flanking regions of this gene were amplified from $B$. cereus chromosomal DNA using primers rpoN-1 to rpoN-4 (Table 1) and purified using the MiniElute PCR purification Kit (Qiagen). The PCR products were digested and purified using a MiniElute Reaction Cleanup Kit (Qiagen). The temperature-sensitive suicide plasmid pAUL-A was digested with EcoRI and SalI followed by alkaline dephosphorylation. The treated plasmid was purified using Phenol chloroform extraction and the resulting plasmid backbone ligated with the digested flanking regions, fused in frame by introduction of a NotI site. The ligation mix was introduced into MAX Efficiency E.coli DH5 $\alpha$ competent cells (Invitrogen) as described by the manufacturer, plated on LB containing $250 \mu \mathrm{g} /$ $\mathrm{ml}$ erythromycin and obtained transformants were checked by PCR and sequencing. The resulting plasmid pAUL- $\Delta r p o N$ was transformed into B. cereus ATCC 14579 by

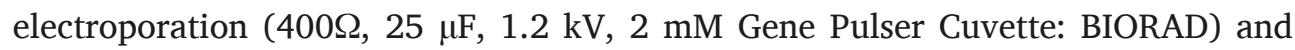


plated on BHI and grown at $30{ }^{\circ} \mathrm{C}$ in the presence of $10 \mu \mathrm{g} / \mathrm{ml}$ erythromycin (E10). pAUL- $\Delta r p o N$ integration was achieved by growing the plasmid carrying strain, while shaking, for 16 hours at $42{ }^{\circ} \mathrm{C}$ in a $250 \mathrm{ml}$ shaking flask containing $50 \mathrm{ml} \mathrm{BHI}$ in the presence of E10. A volume of $500 \mu \mathrm{l}$ of this overnight culture was transferred into a new shaking flask containing $50 \mathrm{ml}$ BHI without antibiotics and grown overnight at $30{ }^{\circ} \mathrm{C}$, to induce double crossover events. This overnight culture was diluted and subsequently plated on BHI and grown at $37^{\circ} \mathrm{C}$. Single colonies were replica plated on BHI with and without E10. PCR analyses and DNA sequencing of E10 sensitive colonies confirmed the correct $1296 \mathrm{bp}$ internal in-frame deletion of rpoN.

Sequencing also revealed a point mutation in the $\operatorname{cggR}$ gene (BC5141) flanking the $r p o N$. The $\operatorname{cggR}$ gene encodes a repressor of five glycolytic genes downstream of cggR (Doan and Aymerich 2003). Four of those glycolytic genes (BC5135-5138) were repressed in the mutant compared to the WT during static growth and were unaffected during shaking growth. This effect was relieved in the complemented mutant and suggests that the observed phenotypes could not be ascribed to the point mutation or potential polar effect in flanking genes or other regulatory elements.

Complementation of the $\Delta r p o N$ deletion strain was performed by a low copy number plasmid (approximately 15 copies per cell (Arantes and Lereclus 1991)) carrying the full length rpoN gene including $300 \mathrm{bp}$ of its upstream region. This fragment was amplified from chromosomal DNA of the WT strain using primers BC5143compl_F and BC5143compl_R (Table 1) that included a tag with recognition sites for PstI and XbaI restriction enzymes. The plasmid pHT315 (Arantes and Lereclus 1991, Song et al. 2012) and the insert were digested with PstI and XbaI and ligated resulting in complementation vector PHT315_BC5143compl. This complementation vector was introduced into the $r p o N$ deletion strain by electroporation as described above. To maintain the plasmid, the complemented strain was pre-cultured in the presence of E10. During the experiments no antibiotic pressure was used in order to prevent secondary growth effects. Total Viable Count (TVC) plating with and without E10 did not show loss of the complementation vector. The maintenance of pBClin15 in B. cereus ATCC14579 and its derivatives was checked using plasmid specific primers BCp0019_F and BCp0019_R (Table 1). 
Table 1. Primers used for rpoN mutant construction and complementation, in 5' to 3' orientation. Restriction sites are in bold.

\begin{tabular}{ll}
\hline rpoN-1 & AATCTGAATTCACTGCTGTGCTTTTTAT \\
rpoN-2 & TGCAGCGGCCGCCTTCAAACTAATCTCCCCCTT \\
rpoN-3 & TCTAGCGGCCGCATAGGTGAAGAAGATGAAAGTTG \\
rpoN-4 & GGCAGTCGACTCGCTACTAACATGGTCTGGAACA \\
BC5143compl_F & GCATTCTAGAATCCCTCTGGGCGCGTCAAAAA \\
BC5143compl_R & CATCCTGCAGAGTACAACTTTCATCTTCTTCACCTAT \\
BCp0019_F & GAAGGCGATGTTGTAAGAAATGTT \\
BCp0019_R & TCCGGTGCGTAGCGTGTT \\
\hline
\end{tabular}

\section{RNA isolation, cDNA synthesis and labelling}

RNA was isolated from liquid cultures of the WT, the $\Delta r p o N$ and $\Delta$ rpoN-comp strains in BHI grown with aeration and statically. Aerated cultures were sampled at two time points, upon reaching OD $(600 \mathrm{~nm}$ ) values of 0.2 (shaking t1) and 1 (shaking t2), which corresponded to mid-exponential and end-exponential growth phases, respectively. Statically grown cultures were sampled at $\mathrm{OD}=0.2(600$ $\mathrm{nm}$ ) corresponding to mid-exponential growth (static). Cultures were centrifuged in $50 \mathrm{ml}$ Falcon tubes for $1 \mathrm{~min}$ at room temperature (11.000 x g). Immediately after centrifugation the pellet was re-suspended in $1 \mathrm{ml}$ TRI reagent (Ambion) by vortexing, snap frozen in liquid nitrogen and stored at $-80{ }^{\circ} \mathrm{C}$ until use. RNA was extracted according to the RNAwiz (Ambion) protocol. Residual DNA was enzymatically removed using the TURBO DNA-free (Ambion) kit following the instructions of the manufacturer. The quality of the extracted RNA was checked by using the Bioanalyzer (Agilent) with the Agilent RNA 6000 Nano kit, according to manufacturer's instructions. Complementary DNA (cDNA) with amino-allyllabelled dUTP (Ambion) was synthesized from RNA by using Superscript III reverse transcriptase (Invitrogen). Labelling and hybridization were performed as described elsewhere (Mols et al. 2013). Two independent biological replicates were hybridized on the arrays with either 2 (WT) or 3 ( $\Delta$ rpon and $\Delta r p o N$-comp) technical replicates for each biological replicate, which were labelled with the swapped dyes (Cy3 and Cy5). 


\section{Microarray design and data analysis}

Custom-made array design for $B$. cereus ATCC 14579 was based on the 8 x 15K platform of Agilent Technologies (GEO accession number GPL9493, $3^{\text {rd }}$ design) and the genome sequence of $B$. cereus ATCC 14579 (NCBI accession number NC_004722). Microarrays were scanned with an Agilent G2505C scanner with two different intensities from which the optimal version was used. Image analysis and processing were performed with the Agilent Feature Extraction software (version 10.7.3.1). Transcriptome profiles were normalized using LOWESS normalization (Yang et al. 2002) as implemented in MicroPreP (van Hijum et al. 2003). The data were corrected for inter-slide differences on the basis of total signal intensity per slide using Postprep (van Hijum et al. 2003) and median intensity of the different probes per gene was selected as the gene expression intensity. CyberT software was used to compare the different transcriptomes (Baldi and Long 2001), resulting in gene expression ratios and false discovery rates (FDR) for each gene. The gene was considered significantly differentially expressed when FDR-adjusted p-value was $<0.01$ and expression fold change was higher than $3(\log 2$ ratio $>1.58$ for up regulation, and $<-1.58$ for down regulation). To study the effect of the rpoN gene deletion in $B$. cereus the transcription profiles of the deletion mutant were compared to the WT. In order to see the effect of complementation, the complemented strain was compared to the WT. The expression of a certain gene was considered to be restored close to the WT level if the expression ratio rpoN-comp over WT was smaller than 3 fold and had a non-significant fdr $>0.01$ value. The subsets of significantly affected genes were analysed for overrepresented KEGG metabolic pathways with the web-based tool for functional analysis of genes FIVA (Blom et al. 2007). Microarray raw and processed data is deposited in the GEO database (http:// www.ncbi.nlm.gov/geo/) under accession number GSE65894.

\section{Statistical analysis}

All described experiments were performed in independent biological triplicates, unless stated otherwise. Presented data in the graphs are the averages of the replicates \pm the standard deviation. Differences were considered statistically significant if the p value from student t-test (MS Excel2010) for two samples with equal variance was $\mathrm{p}<0.05$. For the microarray gene expression ratios were considered relevant when the $\mathrm{fdr}<0.01$. 


\section{Results}

Deletion of rpoN affects the colony morphotype and cell morphology of $B$. cereus ATCC 14579

B. cereus ATCC 14579, its rpoN mutant and complemented strain were routinely streaked on BHI plates with $1.5 \%$ agar. On this medium the $r p o N$ mutant displayed characteristic dendritic (branched) colony morphology (Fig. 1) in contrast to the round shaped and wide-spread colonies of the wild type strain (WT). The colony morphotype was partially restored in the complemented rpoN mutant albeit that the colony size remained reduced compared to the WT. Images of the rpoN mutant and WT cells from aerated overnight cultures obtained by Scanning Electron Microscopy (SEM) revealed differences in the morphology of single cells (Fig. 2), with the mutant population displaying relatively more curved cells ( $\sim 7 \%$ versus $<0.7 \%$ for the WT) with a less smooth cell surface compared to the WT.

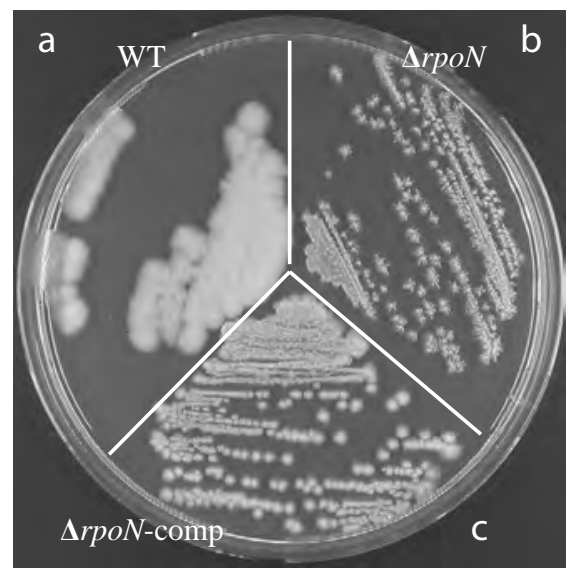

Figure 1. Colony morphotypes. Colonies of B. cereus ATCC 14579 WT (a), its $\Delta r p o N$ mutant derivative (b) and the complemented mutant ( $\Delta r p o N$-comp) (c) cultivated on BHI plates for $24 \mathrm{~h}$ at $30^{\circ} \mathrm{C}$.
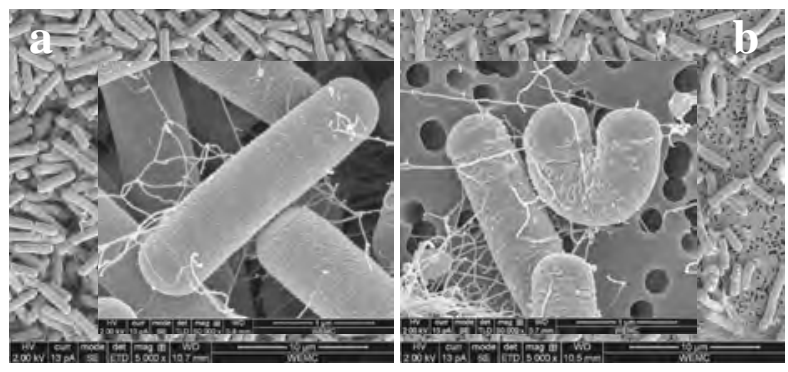

Figure 2. Cells of the WT and its $\triangle$ rpoN mutant. SEM images of aerobically grown overnight cultures of $B$. cereus ATCC 14579 WT (a) and its $\triangle r p o N$ mutant derivative (b) in BHI at $30{ }^{\circ} \mathrm{C}$. 
The rpoN gene is essential for growth under oxygen limitation and at low temperature

The growth of the WT, its rpoN mutant derivative $(\Delta r p o N)$ and complemented rpoN mutant (rpoN-comp) was measured under aerated (with shaking), static and anaerobic conditions (with shaking). The static and anaerobic growth of the mutant was drastically impaired compared to the WT as determined by measurement of optical density at $600 \mathrm{~nm}$ (Fig. 3). The aerobic growth was affected to a lesser extent. For all conditions tested, the phenotype of the rpoN mutant was restored to WT behaviour upon complementation with a plasmid-encoded copy of the rpoN gene. In addition, spore numbers in BHI after $48 \mathrm{~h}$ of aerated growth were significantly reduced for the rpoN mutant in comparison with the WT and the complemented strain (Fig. 4).
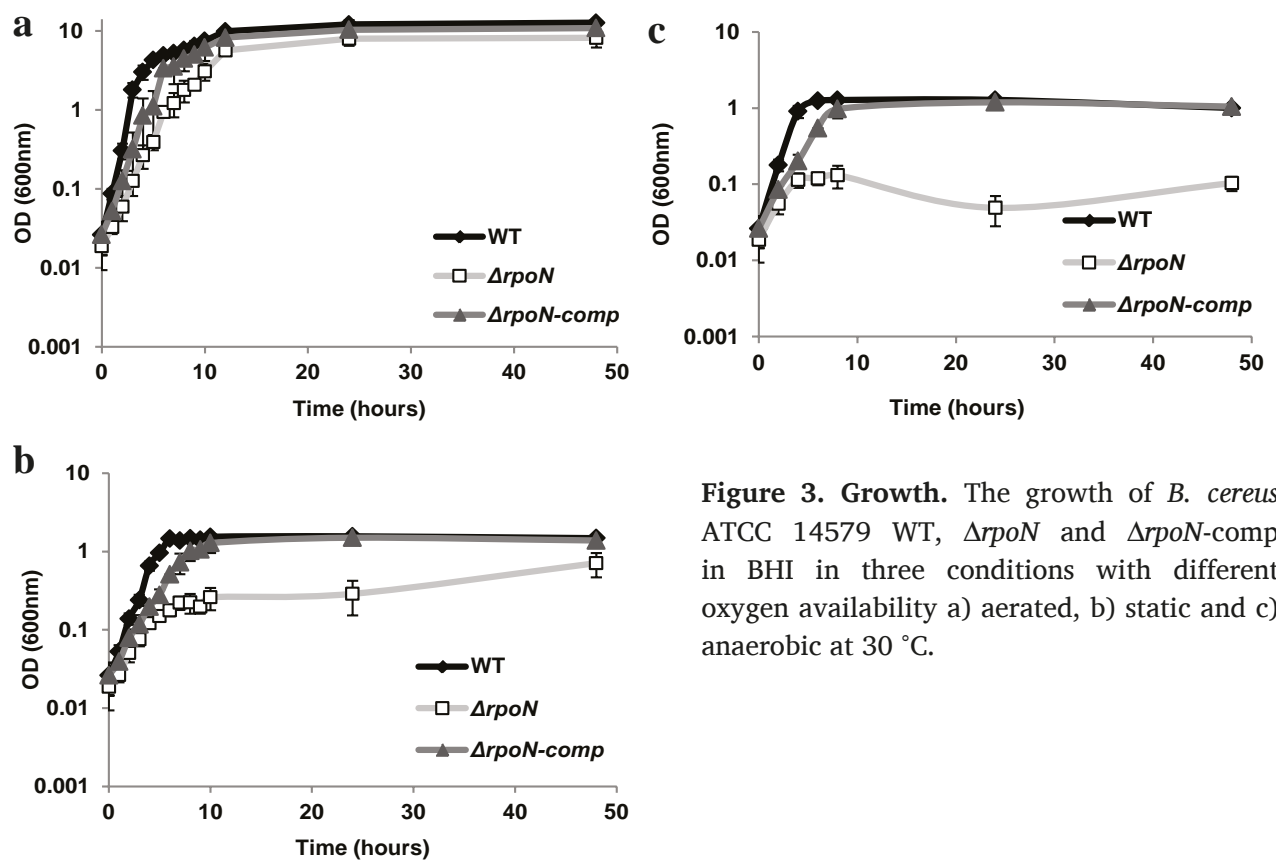

Figure 3. Growth. The growth of $B$. cereus ATCC 14579 WT, $\Delta r p o N$ and $\Delta r p o N$-comp in BHI in three conditions with different oxygen availability a) aerated, b) static and c) anaerobic at $30{ }^{\circ} \mathrm{C}$. 


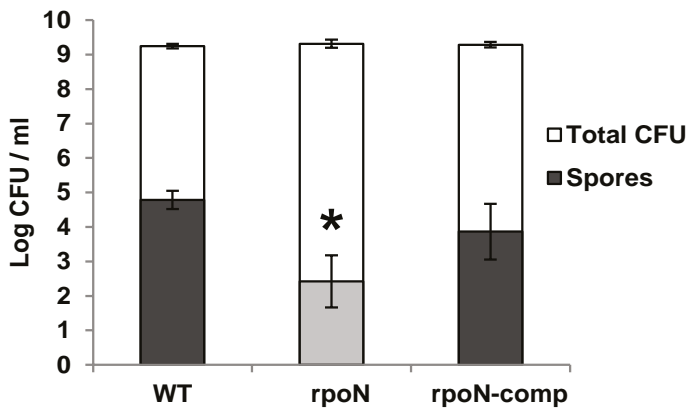

Figure 4. Spore formation. Number of spores and total viable counts in BHI formed by B. cereus ATCC 14579 WT, $\Delta r p o N$ and $\triangle r p o N$-comp in BHI following aerated growth at $30{ }^{\circ} \mathrm{C}$ for $48 \mathrm{~h}$. The asterisk indicates significant difference (student's t test, $\mathrm{p}<0.05$ ) of the $\Delta r p o N$ compared to both the WT and $\Delta r p o N$ comp.

The rpoN mutant was unable to grow at $12{ }^{\circ} \mathrm{C}$ with aeration in $\mathrm{BHI}$ broth over a period of 4 days during which the OD at $600 \mathrm{~nm}$ was measured (Fig. 5a). Upon prolonged incubation on BHI agar plates the colonies of the mutant were smaller and almost invisible compared to the WT and complemented strain when grown for up to 12 days at $12{ }^{\circ} \mathrm{C}$ (Fig. $5 \mathrm{~b}$ ).

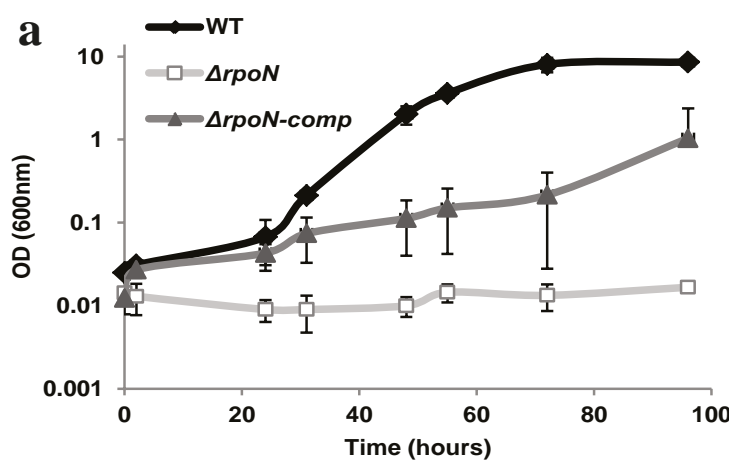

b

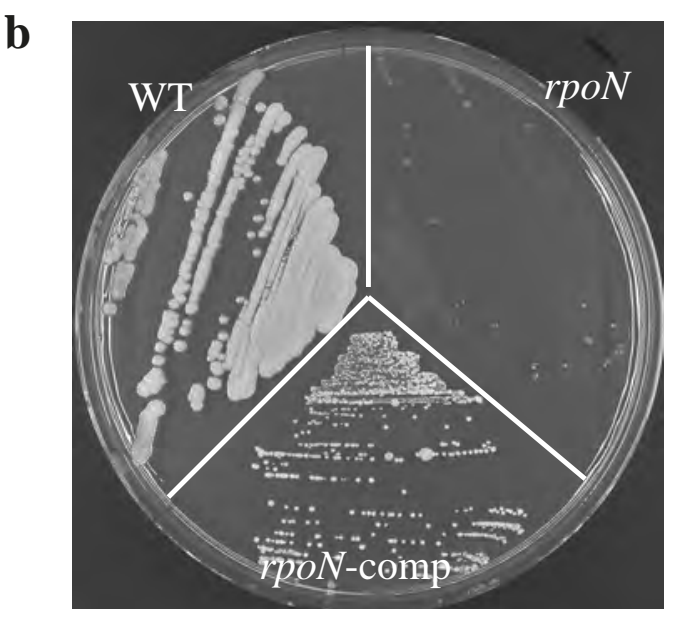

Figure 5. Growth at low temperature. Growth of B. cereus ATCC 14579 WT, $\Delta r p o N$ and $\Delta r p o N$-comp at $12{ }^{\circ} \mathrm{C}$. a) Aerated growth in BHI monitored up to $96 \mathrm{~h}, \mathrm{~b})$ growth on $\mathrm{BHI}$ agar plate, picture was taken on day 12 . 


\section{Carbohydrate metabolism}

The ability of the WT, rpoN mutant and its complemented counterpart to ferment different carbohydrates was studied using the API CH50 test (BioMerieux). The rpoN mutant was able to ferment most of the sugars that were metabolized by the parental strain, with the exception of arbutin, esculin and cellobiose. These carbohydrates share a common structure, the first two are glucosides, and cellobiose is a disaccharide of glucose. All three carbohydrates share the same structural features as the building blocks of chitobiose, which is a glucosamine dimer.

\section{Sigma 54 is essential for flagella biosynthesis and affects biofilm formation and toxin production}

The swimming motility of the WT, rpoN mutant and the complemented strain was tested on BHI plates with $0.3 \%$ agar (Fig. 6a, b and c) and showed that the rpoN mutant was severely impaired in motility (Fig. 6a). Further support for the lack of motility of the rpoN mutant was obtained by flagella staining (Fig. 6d, e and f). Notably, flagella could not be visualized for the mutant cells taken from the colony on swimming agar surface (Fig. 6e), in contrast to the hyperflagellated cells of the WT and rpoN-comp (Fig. 6d and f).
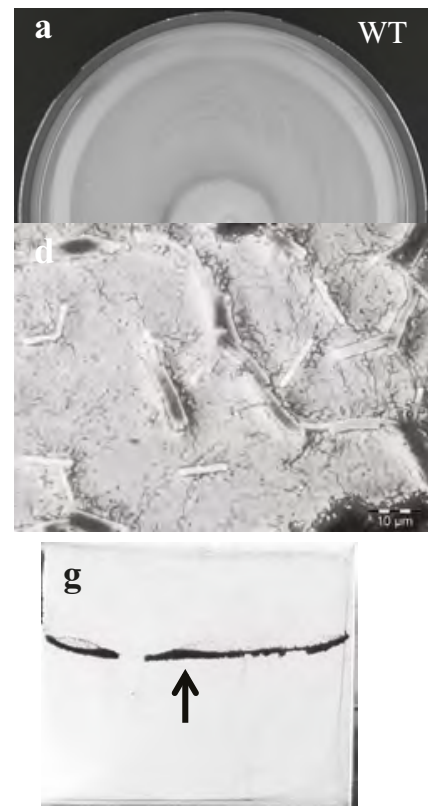
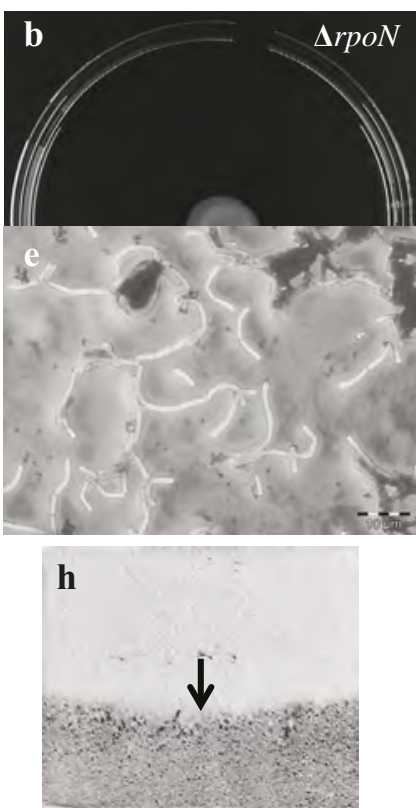
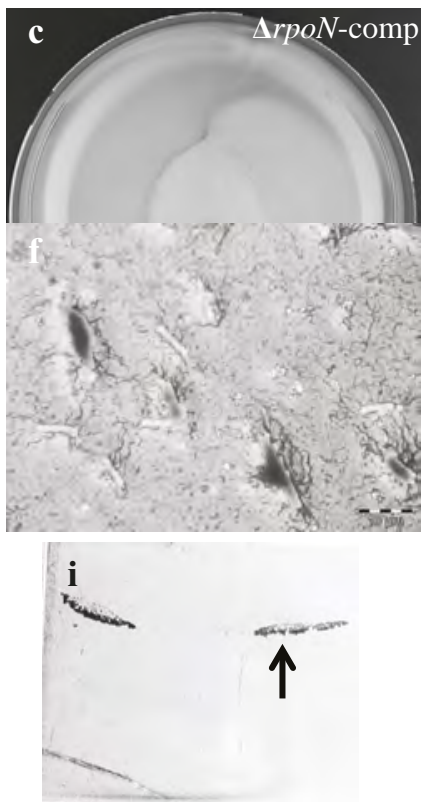

Figure 6. Motility and biofilm formation. Motility, presence of flagella and biofilm formation by $B$. cereus ATCC 14579 WT, $\Delta r p o N$ and $\Delta r p o N$-comp. (a-c) Motility on swimming BHI plates with $0.3 \%$ agar after 48 h, (d-f) flagella staining of cells taken from the swimming plate, (g-i) Static biofilm formation on stainless steel coupons partly submerged in BHI after $48 \mathrm{~h}$ at $30{ }^{\circ} \mathrm{C}$. Biofilms were stained with crystal violet. 
B. cereus, including strain ATCC 14579 typically forms biofilms attached to polystyrene or stainless steel surfaces at the air-liquid interface (Wijman et al. 2007, Hayrapetyan et al. 2015). The rpoN mutant lost the ability to form robust biofilms of this type, but instead formed a submerged biofilm on the surface of the stainless steel coupons with lower intensity of staining (Fig. 6h).

Production of non-haemolytic enterotoxin lytic component L2 (NheA) was measured in aerated (mid-exponential and end-exponential) and static (mid-exponential) growing conditions. Toxin levels for the $r p o N$ mutant were significantly lower compared to the WT, with ratios of WT/ $\Delta r p o N$ levels varying between 2.9 and 4 depending on the condition tested (Fig. 7). The toxin level was partially restored to that of the WT for the complemented mutant strain.

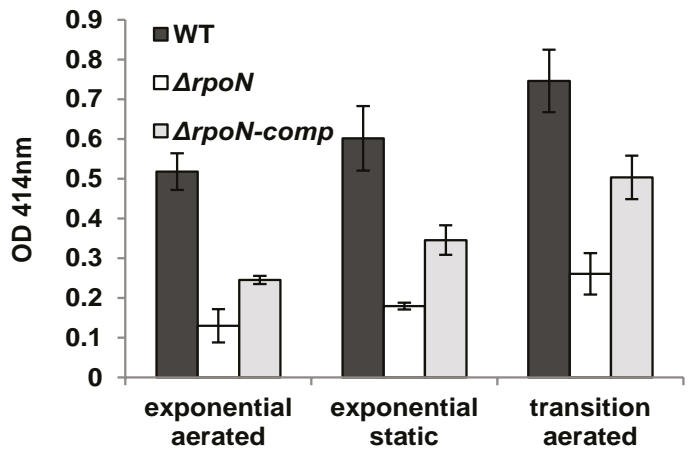

Figure 7. Toxin production. Production of non-hemolytic toxin (NheA) measured in $\mathrm{BHI}$ at $30{ }^{\circ} \mathrm{C}$ with aeration at midexponential (OD $600 \mathrm{~nm}=0.2$ ) and endexponential (OD $600 \mathrm{~nm}=1$ ) growth phases, and at mid-exponential (OD 600 $\mathrm{nm}=0.2$ ) phase during static growth.

\section{Altered gene expression profile upon deletion of the rpoN gene}

Gene expression profiles of the WT, the $r p o N$ mutant and the complemented mutant were investigated for aerobically grown cultures at mid-exponential and endexponential growth phases, and for static cultures at mid-exponential phase. The profiles of the WT and $\Delta$ rpoN-comp clustered together and separately from $\Delta$ rpoN (supplement Fig. S1). This confirms that the observed effects of $r p o N$ deletion on gene expression result mainly from deletion of the target gene and not from possible polar effects on neighbouring genes or regulatory elements.

The number of genes significantly affected in the rpoN mutant was the lowest in mid-exponentially (shaking t1) growing cells with aeration (598, from which 118 were down and 480 up regulated in the mutant). $39 \%$ of the affected genes were restored to WT level by complementation. In the end-exponential phase (shaking t2) with aeration 993 genes were altered in the mutant, of which 320 were down and 673 up regulated. Static growth affected the rpoN mutant most dramatically, with 1535 (854 up and 681 down regulated) gene expressions significantly changed compared to the WT. In the complemented mutant, gene expression was restored to WT levels by $48 \%$ (shaking t2) and 78\% (static). 
For the transcriptome data analysis our initial focus was on functions lost in the rpoN mutant but restored to near WT levels by complementation. The KEGG Metabolic pathways were analysed for functionalities down regulated and overrepresented in the mutant (Fig. 8). Most dominant categories identified refer to flagellar assembly, two component systems, aminoacid metabolism, carbohydrate metabolism and phosphotransferase systems (PTS). The affected cellular processes in the rpoN mutant are schematically presented in Fig. 9 a, b and c for mid-exponential aerated, end-exponential aerated and exponential static growth phases respectively.

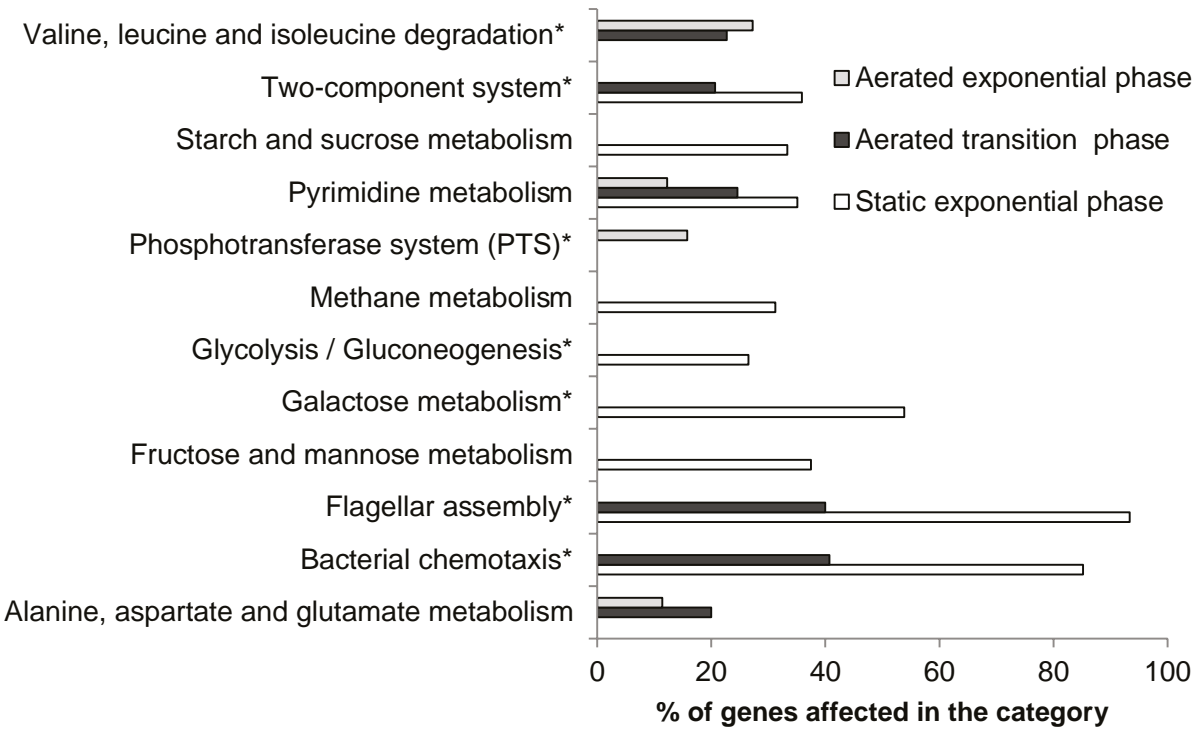

Figure 8. Affected metabolic pathways. Overrepresented metabolic pathways significantly down regulated in $\Delta r p o N$. Outcome of FIVA analysis of significantly affected genes. Categories with asterisk (*) were restored to close to WT condition by complementation.

\section{Transcriptome responses linked to phenotypes and prediction of the Sigma 54 regulon}

Specific transcriptome responses showed good agreement with the observed phenotypes such as cell wall biogenesis, carbohydrate metabolism, toxin production, motility and biofilm formation. In relation to cell surface morphology, transcriptome analysis showed several (14 in aerated condition at end-exponential phase, 36 under static condition) membrane and cell wall biogenesis related genes down regulated in the mutant (S1 Table). As support for observed phenotypes related to carbohydrate utilisation (APICH50 test) in the rpoN mutant, BC0807 encoding a component of the diacetylchitobiose-specific sugar transporting PTS system was downregulated in the mutant, along with BC5211 encoding lichenan oligosaccharide 
specific PTS component in shaking t1 and static conditions (S2 Table). The latter belongs to the orthologous group of cellobiose-specific PTS systems. A Sigma 54 promoter binding site was identified upstream BC5211 as a result of an in silico search using the -12 -24 consensus promoter region by Francke et al. (Francke et al. 2011) (S3 Table, previously unpublished). Furthermore the gene encoding for the EBP levR (BC5205) is located in proximity, which suggests that this PTS system is most likely regulated by Sigma 54. In addition, several genes enconding enzymes, such as chitooligosaccharide deacetylase (BC0171) and 6-phospho-beta-glucosidase (BC5209), involved in initial stages of utilisation of the above mentioned carbon sources were also down regulated in the mutant (S2 Table).

The role of Sigma 54 in cold shock survival of $B$. subtilis has been linked previously to synthesis of branched chain fatty acids which can be formed by degradation of branched amino acids, such as isoleucine (Wiegeshoff et al. 2006). Enzymes encoded by the $b k d$ operon are involved in this conversion. Similar to B. subtilis (Debarbouille et al. 1999), the gene encoding the BkdR regulator (BC4165) is located in the flanking region of the $B$. cereus bkd operon (BC4163-4157) which was down regulated in the rpoN mutant in all three conditions tested (S4 Table). Furthermore, a Sigma 54 promoter binding site was identified upstream of BC4163 (S3 Table), which suggests that the $b k d$ operon is regulated by Sigma factor 54 in $B$. cereus. Reduced expression of the $b k d$ operon could explain the impaired growth of the rpoN mutant observed at low temperature.

Loss of motility was accompanied by lower expression levels of genes involved in flagellar biosynthesis and chemotaxis, including the gene that encodes FlhF, a putative transcriptional regulator (Salvetti et al. 2007), in the mutant compared to the WT at shaking t2 (12 genes) and especially in static conditions (42 genes) (S5 Table).

The transcriptome data revealed up regulation of SinR, a known negative regulator of biofilm formation in B. subtilis (Kearns et al. 2005), in the rpoN mutant in shaking $\mathrm{t} 1$ and static conditions, which was restored by complementation in static condition. Interestingly, even though SinI, the antagonist of SinR, was also up regulated in the mutant in all conditions (S6 Table), sipW encoding a signal peptidase, which processes the EPS component TasA and is important for B. subtilis and B. cereus biofilm formation (Gao et al. 2015), was down regulated in static condition. Furthermore, genes involved in putative capsular polysaccharide (CPS) biosynthesis (BC5263-BC5278 (Ivanova et al. 2003)) were down regulated in the mutant and reverted to WT levels in static (16 genes) and shaking t2 (13 genes) conditions upon complementation (S6 Table). 
The gab gene cluster, involved in $\gamma$-aminobutyric acid (GABA) shunt, as well as the lysine-2,3-aminomutase gene are regulated by Sigma 54 in $B$. thuringiensis (Zhu et al. 2010, Peng et al. 2014, Zhang et al. 2014). GabT (BC0355) and Lysine 2.3-aminomutase (BC2251) were predicted to be in the regulon of Sigma 54 in $B$. cereus (this study, S3 Table). Both of these genes are located in the proximity of Sigma 54 EBPs (BC0356 and BC2250 respectively, for the full list of EBPs refer to supplement 2 in (Francke et al. 2011)). However, the expression of these two genes was not affected in the rpoN mutant.

Lower non-haemolytic enterotoxin (NHE) production by the rpoN mutant was supported by lower expression of the NHE-lytic component L2 gene (BC1809, S7 Table). The expression of several other predicted or confirmed virulence factors (Gohar et al. 2008), including the virulence regulator PlcR were also down regulated in the mutant, for the affected genes ( 6 in shaking t1, 10 in shaking t2, 18 in static) see S7 Table.

Differential expression of sporulation related genes such as AbrB (BC0042) and Stage V sporulation protein S (BC2142) (S9 Table) was observed in end-exponential phase cells, which may have affected sporulation efficiency in the mutant, but more studies are required to support a direct role for Sigma 54 in sporulation control. 


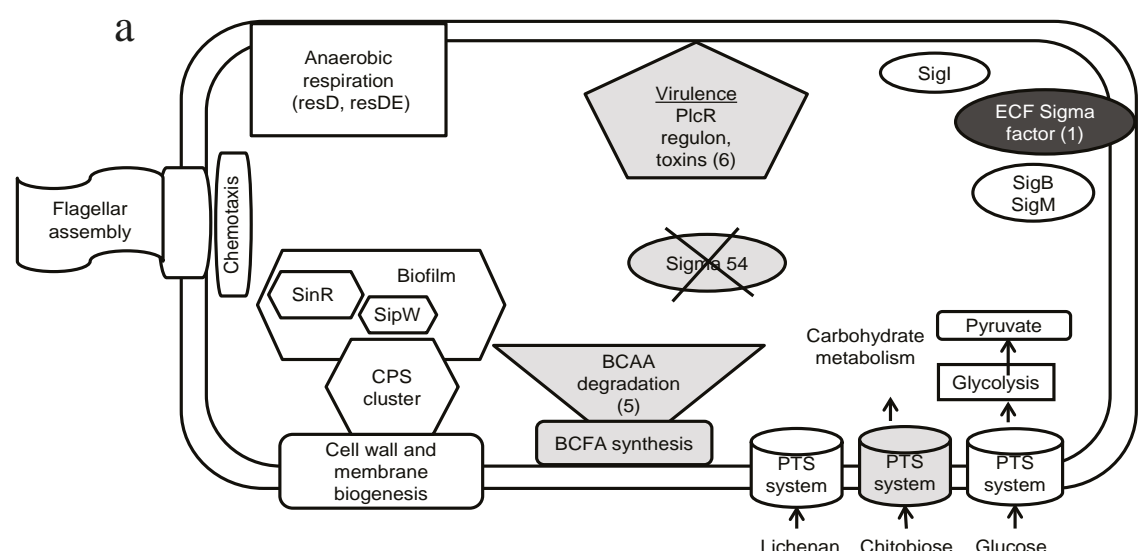

(2)
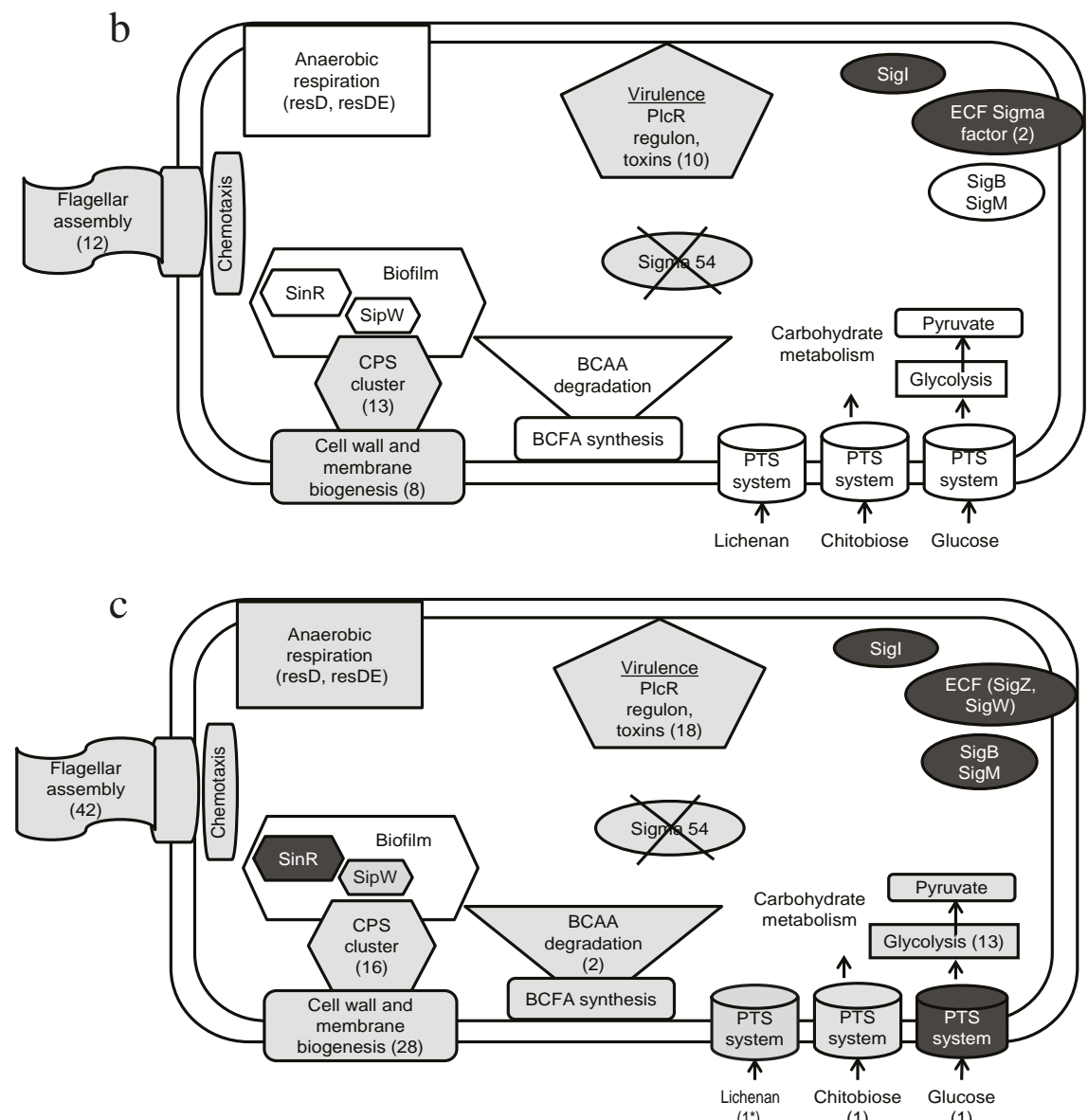

Down regulated Not affected Up regulated 
Figure 9. Affected processes in the cell. Schematic model of cellular processes, based on observed phenotypes combined with affected and complemented genes in the rpoN mutant. a) Aerated growth mid-exponential phase, b) aerated growth end-exponential phase, c) static growth mid-exponential phase. The numbers in (brackets) are the number of genes affected in the given category. Asterisk (*) means the gene was not complemented.

\section{Discussion}

Even though deletion of the rpoN gene was not lethal to B. cereus ATCC 14579, a wide range of cellular functions was affected as reflected both in phenotypic response and in gene expression patterns of the rpoN mutant compared to the WT. Phenotypes that were affected in the rpoN mutant included growth under anaerobic conditions and at low temperature, biofilm formation and motility, sporulation and toxin production. Most of these functions are part of survival strategies of $B$. cereus, in line with described roles of Sigma 54 in adaptation to unfavourable environmental conditions for Listeria monocytogenes and Escherichia coli (Reitzer and Schneider 2001, Mattila et al. 2012). A common theme for Sigma 54 among different species can be found in regulation of processes related to flagellar biosynthesis and motility. Its role in motility has been previously reported for different microorganisms, such as Campylobacter jejuni (Hwang et al. 2010), L. monocytogenes (Mattila et al. 2012), Vibrio fischeri (Wolfe et al. 2004), E. coli (Dong et al. 2011) and Pseudomonas fluorescens (Jones et al. 2007). In addition, a multispecies in silico study pointed at a strong positive correlation between the presence of the Sigma 54 encoding gene and the ability of the species to form flagella (Francke et al. 2011). However, motility of a B. subtilis rpoN mutant was not affected (Debarbouille et al. 1991). In our study the ability to synthesize flagella was lost in the rpoN mutant of B. cereus ATCC 14579, shown both by phenotypes and flagellar gene expression, thus supporting the role of Sigma 54 in motility in this species.

The role of Sigma 54 in motility in literature is often intertwined with its role in biofilm formation (Wolfe et al. 2004, Saldías et al. 2008, Hao et al. 2013), which is not surprising since for a wide range of microorganisms, motility was found to be a prerequisite for biofilm formation (Karatan and Watnick 2009, Houry et al. 2010). Biofilm formation was reduced upon deletion of the gene encoding Sigma 54 for various species, including Vibrio anguillarum (Hao et al. 2013) and Burkholderia cenocepacia (Saldías et al. 2008). By contrast, the rpoN mutant of Enterococcus faecalis was resistant to autolysis and formed more robust biofilms conceivably due to altered relative composition of extracellular components (Iyer and Hancock 2012). V. fischeri produced a more widespread biofilm with less intense CV staining compared to the WT upon deletion of the rpoN gene. This effect could not be ascribed 
to the loss of motility since a flagella-less mutant of $V$. fischeri could still form WTlike biofilms (Wolfe et al. 2004). In our study, motility loss could be responsible for the appearance of a submerged biofilm of the B. cereus rpoN mutant, while both the WT and complemented mutant strain formed only air-liquid biofilms. This is in line with another study showing importance of motility for formation of airliquid interface biofilms (Houry et al. 2010). In addition to motility loss, other factors may have contributed to reduced biofilm formation in the rpoN mutant, including downregulation of sipW and the putative CPS cluster encoding capsular polysaccharide biosynthesis genes (S6 Table), and slower growth in static conditions.

The rpoN mutant formed very distinctive dendritic colonies on BHI plates (Fig. 1). This type of colony morphology has been described previously for a PlcR deletion mutant of $B$. cereus ATCC 14579 albeit on nutrient poor swarming agar. This phenotype was caused by overproduction of a biosurfactant leading to sliding behaviour of the non-flagellated mutant (Hsueh et al. 2007). It was suggested that the production of the biosurfactant is negatively regulated by PlcR. Notably, the expression of PlcR and its regulon members was downregulated in the rpoN mutant (S7 Table), but it remains to be determined whether the dendritic colony formation is caused by altered surfactant production.

PTS systems are an important part of carbon metabolism in bacteria since they catalyse the transport of sugars and their derivatives. Some PTS systems have been shown to be under the control of Sigma 54 in different microorganisms (Héchard et al. 2001, Arous et al. 2004, Stevens et al. 2010). Around 3\% of all predicted EBPs involved in Sigma 54 mediated regulation have been found to be directly linked to signalling via PTS systems (Francke et al. 2011). In addition to mediating nutrient uptake, PTS systems play a regulatory role in metabolism (Arous et al. 2004, Pflüger-Grau and Görke 2010) and a role in biofilm formation by B. cereus (Xu et al. 2014) has been described. In our study the expression of diacetylchitobiosespecific and sucrose-specific PTS systems was down regulated in the rpoN mutant (S2 Table) showing the positive regulation of those PTS systems by Sigma 54 .

The growth of the rpoN mutant was significantly impaired in static and anaerobic conditions, which indicates that the role of Sigma 54 is more pronounced in environments with oxygen limitation. Similarly, a Campylobacter jejuni rpoN mutant showed survival defects in static cultures compared to those grown with aeration (Hwang et al. 2011). A possible link for impaired static growth of the rpoN mutant of $B$. cereus could be down-regulation of the two component regulatory genes res $D$ and resE required for anaerobic respiration in B. subtilis (Nakano et al. 1996) and respiratory nitrate (nar) and nitrite (nas) reductase operons (Van Der Voort and Abee 2009) (S8 Table). On the other hand, B. cereus is able to switch to fermentative 
metabolism under anaerobic conditions, however for this pyruvate availability is important (Rosenfeld et al. 2005), and this intermediate is produced via glycolysis in the cell, a pathway which was downregulated in the rpoN mutant during static growth.

An in silico search by Francke et al. (Francke et al. 2011) (data presented in S3 Table, previously unpublished) based on the conserved promoter binding sites of Sigma 54 found putative binding sites in proximity of 32 genes in $B$. cereus ATCC 14579 (S3 Table). A similar search by Peng et al. (2015) in B. thuringiensis revealed 16 positions, from which 9 gene functions are overlapping with our predicted regulon. In our transcriptome study, 16 out of those 32 genes were significantly affected ( $\mathrm{fdr}<0.01$, without using any cut off for expression) in the rpoN mutant at least in one of the conditions. Seven of those genes were under positive regulation by Sigma 54, and included genes involved in cell metabolism such as phosphate butyryltransferase (BC4163), PTS system lichenan-specific IIC component (BC5211), methionine aminopeptidase (BC0153), undecaprenyl pyrophosphate phosphatase (BC0677) and 6-phosphogluconate dehydrogenase-like protein (BC2225). However, several of the other predicted regulon members were significantly upregulated in the rpoN mutant, such as MarR family transcriptional regulator (BC2434) and PhaR protein (BC1316), suggesting the existence of additional regulatory networks or indirect regulation. The other 16 genes were not significantly affected, which may be due to specificity of growth conditions required for expression of these genes.

Several phenotypes such as the toxin production and low temperature growth were only partly restored, which could be due to the fact that the re-introduction of the rpoN gene on a plasmid is not identical to the WT situation. Such incomplete complementation of the rpoN has been reported previously for L. monocytogenes (Okada et al. 2006) and E. faecalis (Iyer and Hancock 2012).

In all conditions the number of genes up regulated in the rpoN deletion mutant exceeded the number of down regulated genes. Sigma 54 is known to act as an activator and not a repressor of gene expression (Sana et al. 2013), which seems in contradiction with our data. However, it may suggest that up regulation of genes in the rpoN mutant results from indirect effects of $r p o N$ deletion, for example via other affected regulators. Indeed, regulators such as several extra-cytoplasmic function (ECF) sigma factors and Sigma B (in static growth) were affected in the rpoN mutant (S9 Table), or $\operatorname{cod} Y$ (Lindbäck et al. 2012) which was down regulated in static growth. Furthermore, due to the link of Sigma 54 to metabolism and environmental response, the effects of $r p o N$ deletion can also be medium or temperature dependent, which was already shown for motility of an E. coli rpoN mutant (Dong et al. 2011). 
To conclude, this study provides experimental evidence that in B. cereus Sigma 54 is involved either directly or indirectly in a large range of cellular processes such as growth at low temperature and in anaerobic conditions, motility and biofilm formation and toxin production. All observed phenotypes indicate that Sigma 54 of $B$. cereus regulates metabolic rearrangements as a survival strategy to adapt to different environmental niches, ranging from soil, via food processing environments and foods, to human.

\section{Acknowledgements}

We thank Jos Boekhorst (NIZO food research) for designing the array hybridization scheme and subsequently normalizing obtained transcriptomic data, Hans Heilig (Wageningen University) for array slides image analysis with Agilent Feature Extraction software and Julien Brillard (INRA, Avignon) for kindly providing us with the plasmid (pHT 315) for complementation. We also thank Christof Francke (CMBI, Radboud University) for the predicted Sigma 54 regulon members in Bacillus cereus ATCC 14579. 


\section{References}

Ali, N. O., J. Bignon, G. Rapoport and M. Debarbouille (2001). Regulation of the acetoin catabolic pathway is controlled by sigma L in Bacillus subtilis. Journal of Bacteriology 183(8): 2497-2504.

Arantes, O. and D. Lereclus (1991). Construction of cloning vectors for Bacillus thuringiensis. Gene 108(1): 115-119.

Arous, S., C. Buchrieser, P. Folio, P. Glaser, A. Namane, M. Hébraud and Y. Héchard (2004). Global analysis of gene expression in an rpoN mutant of Listeria monocytogenes. Microbiology 150(5): 1581-1590.

Arsène, F., T. Tomoyasu and B. Bukau (2000). The heat shock response of Escherichia coli. International Journal of Food Microbiology 55(1-3): 3-9.

Baldi, P. and A. D. Long (2001). A Bayesian framework for the analysis of microarray expression data: regularized t -test and statistical inferences of gene changes. Bioinformatics (Oxford, England) 17(6): 509-519.

Blom, E. J., D. W. J. Bosman, S. A. F. T. van Hijum, R. Breitling, L. Tijsma, R. Silvis, J. B. T. M. Roerdink and O. P. Kuipers (2007). FIVA: Functional Information Viewer and Analyzer extracting biological knowledge from transcriptome data of prokaryotes. Bioinformatics (Oxford, England) 23(9): 1161-1163.

Buck, M., M. T. Gallegos, D. J. Studholme, Y. Guo and J. D. Gralla (2000). The bacterial enhancerdependent $\sigma 54(\sigma(\mathrm{N}))$ transcription factor. Journal of Bacteriology 182(15): 4129-4136.

Castelijn, G. A., J. A. Parabirsing, M. H. Zwietering, R. Moezelaar and T. Abee (2013). Surface behaviour of S. Typhimurium, S. Derby, S. Brandenburg and S. Infantis. Veterinary Microbiology 161(3-4): 305-314.

Ceuppens, S., N. Boon and M. Uyttendaele (2013). Diversity of Bacillus cereus group strains is reflected in their broad range of pathogenicity and diverse ecological lifestyles. FEMS Microbiology Ecology 84(3): 433-450.

Chakraborty, T., M. Leimeister-Wachter, E. Domann, M. Hartl, W. Goebel, T. Nichterlein and S. Notermans (1992). Coordinate regulation of virulence genes in Listeria monocytogenes requires the product of the prfA gene. Journal of Bacteriology 174(2): 568-574.

Dalet, K., Y. Cenatiempo, P. Cossart, P. Glaser, A. Amend, F. Baquero-Mochales, P. Berche, et al., (2001). A o54-dependent PTS permease of the mannose family is responsible for sensitivity of Listeria monocytogenes to mesentericin Y105. Microbiology 147(12): 3263-3269.

Debarbouille, M., R. Gardan, M. Arnaud and G. Rapoport (1999). Role of bkdR, a transcriptional activator of the SigL-dependent isoleucine and valine degradation pathway in Bacillus subtilis. Journal of Bacteriology 181(7): 2059-2066.

Debarbouille, M., I. Martin-Verstraete, F. Kunst and G. Rapoport (1991). The Bacillus subtilis sigL gene encodes an equivalent of sigma 54 from gram-negative bacteria. Proceedings of the National Academy of Sciences of the United States of America 88(20): 9092-9096.

Doan, T. and S. Aymerich (2003). Regulation of the central glycolytic genes in Bacillus subtilis: binding of the repressor CggR to its single DNA target sequence is modulated by fructose-1,6-bisphosphate. Molecular Microbiology 47(6): 1709-1721.

Dong, T., R. Yu and H. Schellhorn (2011). Antagonistic regulation of motility and transcriptome expression by RpoN and RpoS in Escherichia coli. Molecular Microbiology 79(2): 375-386.

Francke, C., T. Groot Kormelink, Y. Hagemeijer, L. Overmars, V. Sluijter, R. Moezelaar and R. J. Siezen (2011). Comparative analyses imply that the enigmatic sigma factor 54 is a central controller of the bacterial exterior. BMC Genomics 12.

Gao, T., L. Foulston, Y. Chai, Q. Wang and R. Losick (2015). Alternative modes of biofilm formation by plant-associated Bacillus cereus. MicrobiologyOpen.

Gohar, M., K. Faegri, S. Perchat, S. Ravnum, O. A. Økstad, M. Gominet, A. B. Kolstø and D. Lereclus (2008). The PlcR virulence regulon of Bacillus cereus. PloS One 3(7). 
Guinebretière, M. H., F. L. Thompson, A. Sorokin, P. Normand, P. Dawyndt, M. Ehling-Schulz, B. Svensson, V. Sanchis, C. Nguyen-The, M. Heyndrickx and P. De Vos (2008). Ecological diversification in the Bacillus cereus Group. Environmental Microbiology 10(4): 851-865.

Hao, B., Z. L. Mo, P. Xiao, H. J. Pan, X. Lan and G. Y. Li (2013). Role of alternative sigma factor 54 (RpoN) from Vibrio anguillarum M3 in protease secretion, exopolysaccharide production, biofilm formation, and virulence. Applied Microbiology and Biotechnology 97(6): 2575-2585.

Harshey, R. M. and T. Matsuyama (1994). Dimorphic transition in Escherichia coli and Salmonella typhimurium: Surface-induced differentiation into hyperflagellate swarmer cells. Proceedings of the National Academy of Sciences of the United States of America 91(18): 8631-8635.

Hayrapetyan, H., L. Muller, M. Tempelaars, T. Abee and M. Nierop Groot (2015). Comparative analysis of biofilm formation by Bacillus cereus reference strains and undomesticated food isolates and the effect of free iron. International Journal of Food Microbiology 200: 72-79.

Héchard, Y., C. Pelletier, Y. Cenatiempo and J. Frére (2001). Analysis of o54-dependent genes in Enterococcus faecalis: A mannose PTS permease (EIIMan) is involved in sensitivity to a bacteriocin, mesentericin Y105. Microbiology 147(6): 1575-1580.

Hecker, M., J. Pane-Farre and U. Volker (2007). SigB-dependent general stress response in Bacillus subtilis and related gram-positive bacteria. Annual Review of Microbiology 61: 215-236.

Houry, A., R. Briandet, S. Aymerlch and M. Gohar (2010). Involvement of motility and flagella in Bacillus cereus biofilm formation. Microbiology 156(4): 1009-1018.

Hsueh, Y. H., E. B. Somers, D. Lereclus, E. Ghelardi and A. C. L. Wong (2007). Biosurfactant production and surface translocation are regulated by PlcR in Bacillus cereus ATCC 14579 under low-nutrient conditions. Applied and Environmental Microbiology 73(22): 7225-7231.

Hwang, J. K., M. J. Chae, J. W. Kim, B. K. Ku and Y. J. Lee (2010). Role of flagella-related $r P o N$ and fliA genes in Campylobacter jejuni. Journal of Animal and Veterinary Advances 9(24): 3034-3038.

Hwang, S., B. Jeon, J. Yun and S. Ryu (2011). Roles of RpoN in the resistance of Campylobacter jejuni under various stress conditions. BMC Microbiology 11.

Ivanova, N., A. Sorokin, I. Anderson, N. Galleron, B. Candelon, V. Kapatral, A. Bhattacharyya, G. Reznik, N. Mikhailova, A. Lapidus, L. Chu, M. Mazur, E. Goltsman, N. Larsen, M. D'Souza, T. Walunas, Y. Grechkin, G. Pusch, R. Haselkorn, M. Fonstein, S. D. Ehrlich, R. Overbeek and N. Kyrpides (2003). Genome sequence of Bacillus cereus and comparative analysis with Bacillus anthracis. Nature 423(6935): 87-91.

Iyer, V. S. and L. E. Hancock (2012). Deletion of $054(r p o N)$ alters the rate of autolysis and biofilm formation in Enterococcus faecalis. Journal of Bacteriology 194(2): 368-375.

Jones, D. H. A., F. C. H. Franklin and C. M. Thomas (1994). Molecular analysis of the operon which encodes the RNA polymerase sigma factor o54 of Escherichia coli. Microbiology 140(5): 10351043.

Jones, J., D. J. Studholme, C. G. Knight and G. M. Preston (2007). Integrated bioinformatic and phenotypic analysis of RpoN-dependent traits in the plant growth-promoting bacterium Pseudomonas fluorescens SBW25. Environmental Microbiology 9(12): 3046-3064.

Karatan, E. and P. Watnick (2009). Signals, regulatory networks, and materials that build and break bacterial biofilms. Microbiology and Molecular Biology Reviews 73(2): 310-347.

Kearns, D. B., F. Chu, S. S. Branda, R. Kolter and R. Losick (2005). A master regulator for biofilm formation by Bacillus subtilis. Molecular Microbiology 55(3): 739-749.

Lindbäck, T., M. Mols, C. Basset, P. E. Granum, O. P. Kuipers and A. T. Kovács (2012). CodY, a pleiotropic regulator, influences multicellular behaviour and efficient production of virulence factors in Bacillus cereus. Environmental Microbiology 14(8): 2233-2246.

Mattila, M., P. Somervuo, T. Rattei, H. Korkeala, R. Stephan and T. Tasara (2012). Phenotypic and transcriptomic analyses of Sigma L-dependent characteristics in Listeria monocytogenes EGD-e. Food Microbiology 32(1): 152-164.

Merrick, M. J. (1993). In a class of its own - The RNA polymerase sigma factor $\sigma 54(\sigma(\mathrm{N}))$. Molecular Microbiology 10(5): 903-909. 
Mols, M. and T. Abee (2011). Bacillus cereus responses to acid stress. Environmental Microbiology 13(11): 2835-2843.

Mols, M., H. Mastwijk, M. Nierop Groot and T. Abee (2013). Physiological and transcriptional response of Bacillus cereus treated with low-temperature nitrogen gas plasma. Journal of Applied Microbiology 115(3): 689-702.

Nakano, M. M., P. Zuber, P. Glaser, A. Danchin and F. M. Hulett (1996). Two-component regulatory proteins ResD-ResE are required for transcriptional activation of fnr upon oxygen limitation in Bacillus subtilis. Journal of Bacteriology 178(13): 3796-3802.

Okada, Y., N. Okada, S.-i. Makino, H. Asakura, S. Yamamoto and S. Igimi (2006). The sigma factor RpoN (o54) is involved in osmotolerance in Listeria monocytogenes. FEMS Microbiology Letters 263(1): 54-60.

Peng, Q., G. Wang, G. Liu, J. Zhang and F. Song (2015). Identification of metabolism pathways directly regulated by Sigma54 factor in Bacillus thuringiensis. Name: Frontiers in Microbiology 6: 407.

Peng, Q., M. Yang, W. Wang, L. Han, G. Wang, P. Wang, J. Zhang and F. Song (2014). Activation of gab cluster transcription in Bacillus thuringiensis by inverted question mark-aminobutyric acid or succinic semialdehyde is mediated by the Sigma 54-dependent transcriptional activator GabR. BMC Microbiology 14(1): 306.

Pflüger-Grau, K. and B. Görke (2010). Regulatory roles of the bacterial nitrogen-related phosphotransferase system. Trends in Microbiology 18(5): 205-214.

Reitzer, L. and B. L. Schneider (2001). Metabolic context and possible physiological themes of o54dependent genes in Escherichia coli. Microbiology and Molecular Biology Reviews 65(3): 422444.

Rosenfeld, E., C. Duport, A. Zigha and P. Schmitt (2005). Characterization of aerobic and anaerobic vegetative growth of the food-borne pathogen Bacillus cereus F4430/73 strain. Canadian Journal of Microbiology 51(2): 149-158.

Saldías, M. S., J. Lamothe, R. Wu and M. A. Valvano (2008). Burkholderia cenocepacia requires the RpoN sigma factor for biofilm formation and intracellular trafficking within macrophages. Infection and Immunity 76(3): 1059-1067.

Salvetti, S., E. Ghelardi, F. Celandroni, M. Ceragioli, F. Giannessi and S. Senesi (2007). FlhF, a signal recognition particle-like GTPase, is involved in the regulation of flagellar arrangement, motility behaviour and protein secretion in Bacillus cereus. Microbiology 153(8): 2541-2552.

Sana, T. G., C. Soscia, C. M. Tonglet, S. Garvis and S. Bleves (2013). Divergent control of two type VI secretion systems by RpoN in Pseudomonas aeruginosa. PloS One 8(10).

Song, F., Q. Peng, J. Brillard, C. Buisson, M. De Been, T. Abee, V. Broussolle, D. Huang, J. Zhang, D. Lereclus and C. Nielsen-LeRoux (2012). A multicomponent sugar phosphate sensor system specifically induced in Bacillus cereus during infection of the insect gut. FASEB Journal 26(8): 3336-3350.

Stevens, M. J. A., D. Molenaar, A. De Jong, W. M. De Vos and M. Kleerebezem (2010). б54mediated control of the mannose phosphotransferase sytem in Lactobacillus plantarum impacts on carbohydrate metabolism. Microbiology 156(3): 695-707.

Studholme, D. J. and R. Dixon (2003). Domain architectures of o54-dependent transcriptional activators. Journal of Bacteriology 185(6): 1757-1767.

Van Der Voort, M. and T. Abee (2009). Transcriptional regulation of metabolic pathways, alternative respiration and enterotoxin genes in anaerobic growth of Bacillus cereus ATCC 14579. Journal of Applied Microbiology 107(3): 795-804.

van Hijum, S. A., J. García de la Nava, O. Trelles, J. Kok and O. P. Kuipers (2003). MicroPreP: a cDNA microarray data pre-processing framework. Appl Bioinformatics 2(4): 241-244.

Van Schaik, W., M. H. Tempelaars, J. A. Wouters, W. M. De Vos and T. Abee (2004). The alternative sigma factor $\sigma \mathrm{B}$ of Bacillus cereus: response to stress and role in heat adaptation. Journal of Bacteriology 186(2): 316-325. 
Wiegeshoff, F., C. L. Beckering, M. Debarbouille and M. A. Marahiel (2006). Sigma L is important for cold shock adaptation of Bacillus subtilis. Journal of Bacteriology 188(8): 3130-3133.

Wijman, J. G. E., P. P. L. A. De Leeuw, R. Moezelaar, M. H. Zwietering and T. Abee (2007). Airliquid interface biofilms of Bacillus cereus: Formation, sporulation, and dispersion. Applied and Environmental Microbiology 73(5): 1481-1488.

Wolfe, A. J., D. S. Millikan, J. M. Campbell and K. L. Visick (2004). Vibrio fischeri o54 controls motility, biofilm formation, luminescence and colonization. Applied and Environmental Microbiology 70(4): 2520-2524.

Xu, Y. B., M. Chen, Y. Zhang, M. Wang, Y. Wang, Q. b. Huang, X. Wang and G. Wang (2014). The phosphotransferase system gene ptsI in the endophytic bacterium Bacillus cereus is required for biofilm formation, colonization, and biocontrol against wheat sharp eyespot. FEMS Microbiology Letters 354(2): 142-152.

Yang, Y. H., S. Dudoit, P. Luu, D. M. Lin, V. Peng, J. Ngai and T. P. Speed (2002). Normalization for cDNA microarray data: a robust composite method addressing single and multiple slide systematic variation. Nucleic Acids Research 30(4): e15.

Zhang, Z., M. Yang, Q. Peng, G. Wang, Q. Zheng, J. Zhang and F. Song (2014). Transcription of the lysine-2,3-aminomutase Gene in the kam locus of Bacillus thuringiensis subsp. Kurstaki HD73 is controlled by both o54 and oK Factors. Journal of Bacteriology 196(16): 2934-2943.

Zhu, L., Q. Peng, F. Song, Y. Jiang, C. Sun, J. Zhang and D. Huang (2010). Structure and regulation of the gab gene cluster, involved in the $\gamma$-aminobutyric acid shunt, are controlled by a 054 factor in Bacillus thuringiensis. Journal of Bacteriology 192(1): 346-355. 


\section{Supplementary material for Chapter 5}

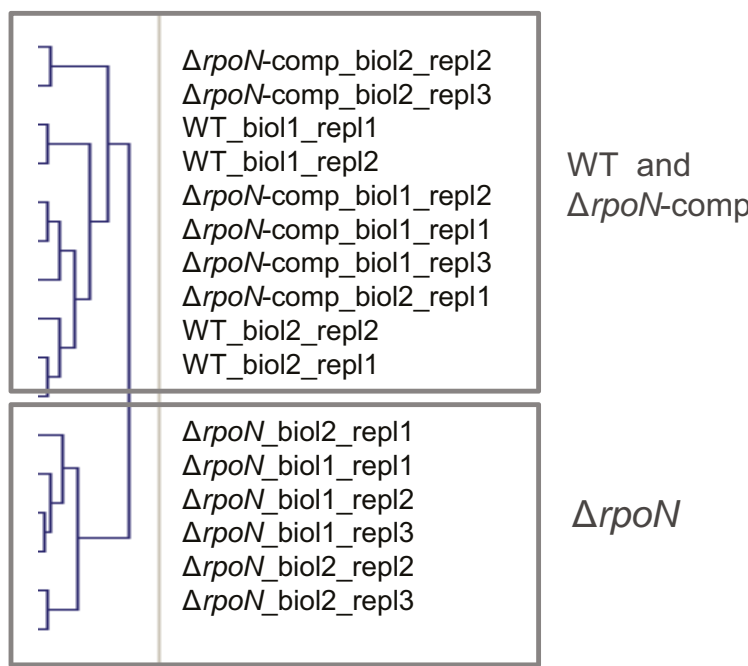

S1 Figure. Clustering of WT, $\Delta r p o N$ mutant and $\Delta r p o N$-comp. Clustering of array samples based on expression patterns (example on aerated end-exponential phase). Data was normalized per gene and per row and clustered using UPGMA \& pearson correlation in Genesis (Sturn et al.,2002. Genesis: cluster analysis of microarray data. Bioinformatics, 18(1):207-208). 
S1 Table. Cell wall and membrane biogenesis. Genes related to cell wall and membrane biogenesis significantly down regulated in the rpoN mutant $(\mathrm{p}<0.01$, ratio $>3)$. Genes that are also a part of the CPS cluster in Biofilm related table are not included here.

\begin{tabular}{|c|c|c|c|c|c|c|c|}
\hline \multirow[b]{2}{*}{ 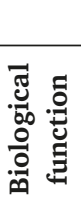 } & \multirow[b]{2}{*}{ Gene } & \multirow[b]{2}{*}{ COG } & \multirow[b]{2}{*}{ Name } & \multirow[b]{2}{*}{ Annotation } & \multicolumn{3}{|c|}{$\log 2 \Delta r p o N / W T$} \\
\hline & & & & & 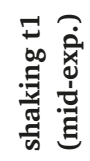 & 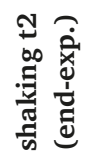 & 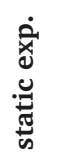 \\
\hline \multirow{24}{*}{ 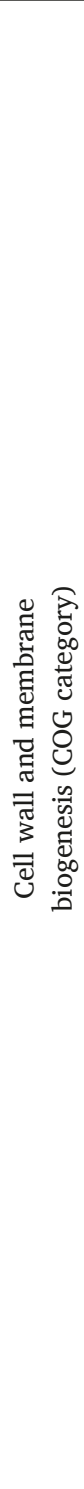 } & BC0054 & M & gcaD & Glucosamine-1-phosphate acetyltransferase & - & - & -2.13 \\
\hline & BC0190 & M & $\operatorname{glmS}$ & $\begin{array}{l}\text { Glucosamine--fructose-6-phosphate } \\
\text { aminotransferase [isomerizing] }\end{array}$ & - & - & -1.78 \\
\hline & ВС0258 & M & murF & $\begin{array}{l}\text { UDP-N-acetylmuramoylalanyl-D-glutamyl-2,6- } \\
\text { diaminopimelate--D-alanyl-D- alanyl ligase }\end{array}$ & - & - & -1.73 \\
\hline & BC0740 & $\mathrm{M}, \mathrm{T}$ & & Cell wall endopeptidase, family M23/M37 & - & - & -1.70 \\
\hline & ВС0887 & M & & Collagen adhesion protein & - & - & -3.89 \\
\hline & BC0888 & M & $\mathrm{cwlH}$ & $\mathrm{N}$-acetylmuramoyl-L-alanine amidase & - & -2.76 & -4.07 \\
\hline & BC0902 & M & & $\begin{array}{l}\text { S-layer protein / N-acetylmuramoyl-L-alanine } \\
\text { amidase }\end{array}$ & -1.98 & -4.43 & -4.69 \\
\hline & BC0966 & M & & Fimbria associated protein & -2.21 & -2.36 & -3.63 \\
\hline & BC1067 & M & $\mathrm{pbpF}$ & $\begin{array}{l}\text { Multimodular transpeptidase-transglycosylase } \\
\text { PBP 2C }\end{array}$ & - & - & -2.12 \\
\hline & BC1277 & M & & D-alanyl-D-alanine carboxypeptidase & - & - & -1.88 \\
\hline & BC1535 & M & урјН & Glycosyltransferase & - & - & -1.67 \\
\hline & BC1660 & M & yjbJ & Soluble lytic murein transglycosylase & - & - & -2.47 \\
\hline & BC2850 & MR & ykfB & $\begin{array}{l}\text { Mandelate racemase/muconate lactonizing } \\
\text { enzyme family protein }\end{array}$ & - & -1.80 & -2.61 \\
\hline & BC3090 & M & yvdQ & hypothetical protein & - & - & -1.61 \\
\hline & BC3257 & $\mathrm{T}, \mathrm{M}$ & & $\mathrm{N}$-acetylmuramoyl-L-alanine amidase & - & - & -1.97 \\
\hline & BC3307 & M & & D-alanyl-D-alanine carboxypeptidase & - & - & -2.05 \\
\hline & ВС3308 & M & & Capsule biosynthesis protein capA & - & - & -2.10 \\
\hline & BC3909 & M & murB & UDP-N-acetylenolpyruvoylglucosamine reductase & - & - & -1.63 \\
\hline & BC3912 & M & murD & $\begin{array}{l}\text { UDP-N-acetylmuramoylalanine--D-glutamate } \\
\text { ligase }\end{array}$ & - & - & -1.82 \\
\hline & BC3913 & M & mraY & $\begin{array}{l}\text { Phospho-N-acetylmuramoyl-pentapeptide- } \\
\text { transferase }\end{array}$ & - & - & -2.17 \\
\hline & BC3914 & M & murE & $\begin{array}{l}\text { UDP-N-acetylmuramoylalanyl-D-glutamate--2,6- } \\
\text { diaminopimelate ligase }\end{array}$ & - & - & -2.05 \\
\hline & BC4669 & M & mscL & Large-conductance mechanosensitive channel & - & - & -1.69 \\
\hline & BC4897 & M & & IG hypothetical 16740 & - & - & -3.68 \\
\hline & BC5005 & M & & D-alanyl-D-alanine carboxypeptidase & - & -2.39 & - \\
\hline
\end{tabular}




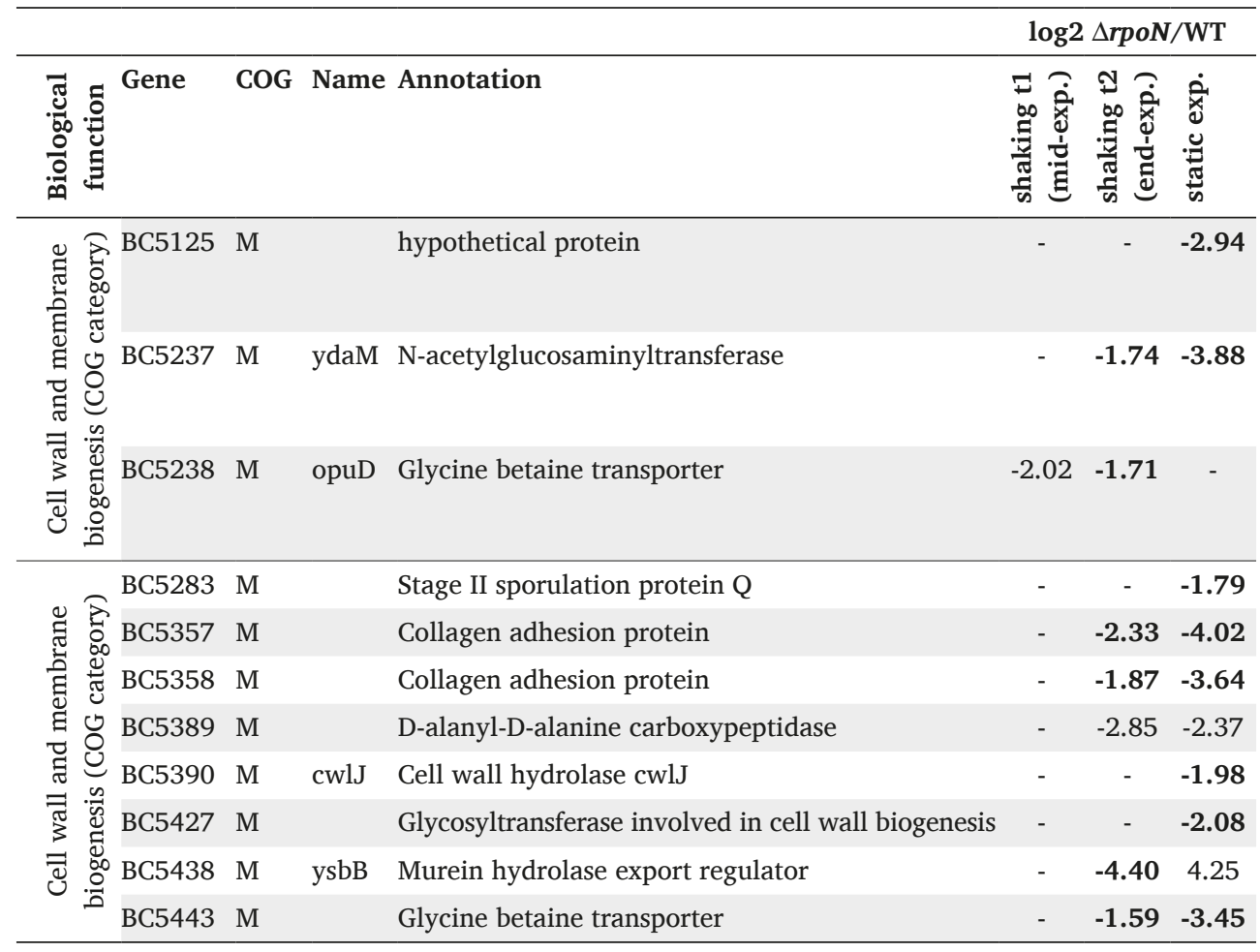

(-) means the gene was not significantly and highly affected in the given condition.

Genes with ratios in bold were restored to close to WT levels by complementation. 
S2 Table. Carbohydrate metabolism. Genes related to carbohydrate metabolism significantly down regulated in the rpoN mutant $(\mathrm{p}<0.01$, ratio $>3)$.

\begin{tabular}{|c|c|c|c|c|c|c|c|}
\hline \multirow[b]{2}{*}{ 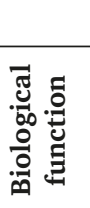 } & \multirow[b]{2}{*}{ Gene } & \multirow[b]{2}{*}{ COG } & \multirow[b]{2}{*}{ Name } & \multirow[b]{2}{*}{ Annotation } & \multicolumn{3}{|c|}{$\log 2 \Delta r p o N / W T$} \\
\hline & & & & & 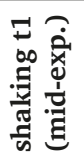 & 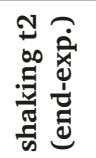 & 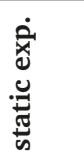 \\
\hline \multirow{29}{*}{ 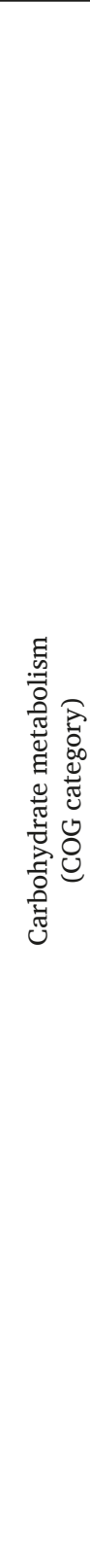 } & BC0171 & G & ybaN & Chitooligosaccharide deacetylase & - & -3.12 & -3.57 \\
\hline & BC0202 & GEPR & yitZ & Multidrug resistance protein B & - & -1.84 & -3.50 \\
\hline & BC0219 & G & & Glucose uptake protein homolog & - & -2.73 & -2.80 \\
\hline & BC0398 & GEPR & & Benzoate transport protein & - & - & -2.95 \\
\hline & BC0413 & G & yugT & Exo-alpha-1,4-glucosidase & - & - & -2.78 \\
\hline & BC0569 & $\mathrm{G}$ & yesQ & $\begin{array}{l}\text { SN-glycerol-3-phosphate transport system } \\
\text { permease protein ugpE }\end{array}$ & - & - & -1.95 \\
\hline & ВС0660 & G & rbsK & Ribokinase & - & - & -1.86 \\
\hline & BC0757 & GEPR & yvmA & Bicyclomycin resistance protein & - & - & -3.39 \\
\hline & ВC0773 & G & ydjE & Fructokinase & - & - & -2.15 \\
\hline & BC0774 & $\mathrm{G}$ & sacA & Sucrose-6-phosphate hydrolase & - & - & -3.17 \\
\hline & BC0775 & G, G & sacP & PTS system, sucrose-specific IIBC component & - & -4.18 & -3.79 \\
\hline & BC0807 & $\mathrm{G}$ & & $\begin{array}{l}\text { PTS system, diacetylchitobiose-specific IIA } \\
\text { component }\end{array}$ & -2.23 & - & -1.68 \\
\hline & BC0896 & G & & $\begin{array}{l}\text { S-layer protein / Peptidoglycan endo-beta-N- } \\
\text { acetylglucosaminidase }\end{array}$ & - & -2.78 & -4.51 \\
\hline & BC0962 & GEPR & $\operatorname{lmrB}$ & Lincomycin resistance protein & -1.67 & - & - \\
\hline & BC0981 & G & & Dihydroxyacetone kinase & -2.61 & - & -1.99 \\
\hline & BC1598 & G & & LACX protein & - & - & -2.26 \\
\hline & BC1759 & GEPR & ydeG & Tetracycline resistance protein & - & - & -1.70 \\
\hline & BC2104 & G & & hypothetical protein & - & - & -2.07 \\
\hline & BC2300 & GEPR & & Oxalate/formate antiporter & - & -2.21 & 3.39 \\
\hline & BC2325 & GEPR & ykuC & Macrolide-efflux protein & - & -1.83 & -4.65 \\
\hline & BC2393 & G & & $\begin{array}{l}\text { PTS system, diacetylchitobiose-specific IIB } \\
\text { component }\end{array}$ & -2.36 & - & - \\
\hline & BC2464 & G & & $\begin{array}{l}\text { S-layer protein / Peptidoglycan endo-beta-N- } \\
\text { acetylglucosaminidase }\end{array}$ & - & - & -2.14 \\
\hline & BC3682 & G & & Transketolase & - & - & -1.67 \\
\hline & BC3718 & $\mathrm{G}, \mathrm{G}, \mathrm{G}$ & TfruA & PTS system, fructose-specific IIABC component & -2.13 & - & - \\
\hline & BC3719 & G & fruK & 1-phosphofructokinase & -2.70 & - & -2.35 \\
\hline & BC3720 & KG & fruR & Fructose repressor & - & - & -3.28 \\
\hline & BC3804 & G & ylxY & Chitooligosaccharide deacetylase & - & -2.23 & -3.05 \\
\hline & BC4271 & GEPR & yqgE & Transporter, MFS superfamily & - & - & -2.03 \\
\hline & BC4507 & G & & Aquaporin & - & -2.15 & -3.47 \\
\hline
\end{tabular}




\begin{tabular}{|c|c|c|c|c|c|c|c|}
\hline \multirow[b]{2}{*}{ 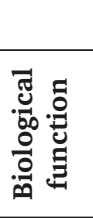 } & \multirow[b]{2}{*}{ Gene } & \multirow[b]{2}{*}{ COG } & \multirow[b]{2}{*}{ Name } & \multirow[b]{2}{*}{ Annotation } & \multicolumn{3}{|c|}{$\log 2 \Delta r p o N / W T$} \\
\hline & & & & & 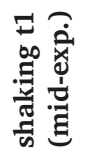 & 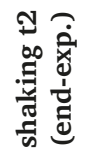 & 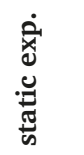 \\
\hline \multirow{16}{*}{ 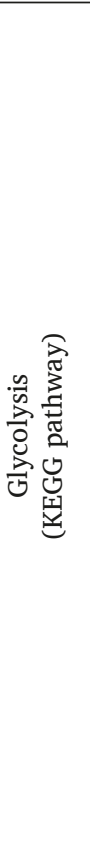 } & BC4707 & GEPR & & Multidrug resistance protein $\mathrm{B}$ & - & - & -1.78 \\
\hline & BC4716 & G & glcU & Glucose uptake protein & - & - & -2.12 \\
\hline & BC4738 & GEPR & $\mathrm{yttB}$ & Multidrug resistance protein $B$ & - & - & -3.43 \\
\hline & BC4959 & G & yutF & 4-nitrophenylphosphatase & - & -1.77 & -2.66 \\
\hline & BC5012 & G & ydhL & Chloramphenicol resistance protein & - & -3.39 & - \\
\hline & BC5030 & GER & & Transporter, Drug/Metabolite Exporter family & - & - & -1.83 \\
\hline & BC5058 & G & & chloramphenicol resistance protein & - & - & -1.75 \\
\hline & BC5114 & G & & hypothetical protein & -2.02 & -3.07 & -1.71 \\
\hline & BC5209 & G & licH & 6-phospho-beta-glucosidase & -1.60 & - & -1.83 \\
\hline & BC5211 & G & & $\begin{array}{l}\text { PTS system, lichenan oligosaccharide-specific } \\
\text { IIC component }\end{array}$ & - & - & -3.69 \\
\hline & BC5258 & G & & Phosphoglycerate transporter protein & - & -2.28 & - \\
\hline & BC5271 & MG & & UDP-N-acetylglucosamine 4-epimerase & - & -1.89 & -4.19 \\
\hline & BC5274 & MG & yveM & UDP-N-acetylglucosamine 4,6-dehydratase & - & -1.59 & -4.39 \\
\hline & BC5276 & GM & ywqE & $\begin{array}{l}\text { Phosphotyrosine-protein phosphatase } \\
\text { (capsular polysaccharide biosynthesis) }\end{array}$ & - & - & -4.84 \\
\hline & BC5442 & GEPR & & Transporter, MFS superfamily & - & - & -1.64 \\
\hline & BC1691 & G & & Phosphoglycerate mutase & - & - & -2.61 \\
\hline \multirow{10}{*}{ 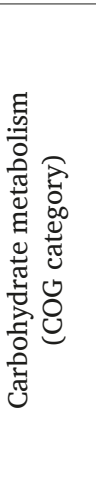 } & BC4260 & KG & glcK & Glucokinase & - & - & -1.68 \\
\hline & BC4365 & $\mathrm{C}, \mathrm{C}$ & & Alcohol dehydrogenase & - & - & -4.33 \\
\hline & BC4599 & $\mathrm{G}, \mathrm{T}$ & & Pyruvate kinase & - & - & -2.26 \\
\hline & BC4600 & G & pfkA & 6-phosphofructokinase & - & - & -1.81 \\
\hline & BC4898 & G & & Glucose-6-phosphate isomerase & - & - & -2.34 \\
\hline & BC4919 & G & yhxB & Phosphoglucomutase & - & - & -2.01 \\
\hline & BC4962 & G & & Fructose-1,6-bisphosphatase & - & - & -2.04 \\
\hline & BC4996 & $\mathrm{C}$ & ldh & L-lactate dehydrogenase & - & -2.05 & -2.02 \\
\hline & BC5135 & G & eno & Enolase & - & - & -1.78 \\
\hline & BC5136 & G & pgm & Phosphoglycerate mutase & - & - & -1.85 \\
\hline \multirow{2}{*}{ 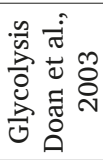 } & BC5137 & - & tpiA & & - & - & -1.78 \\
\hline & BC5138 & - & $\mathrm{pgk}$ & & - & - & -1.50 \\
\hline
\end{tabular}

(-) means the gene was not significantly and highly affected in the given condition. Genes with ratios in bold were restored to close to WT levels by complementation. 


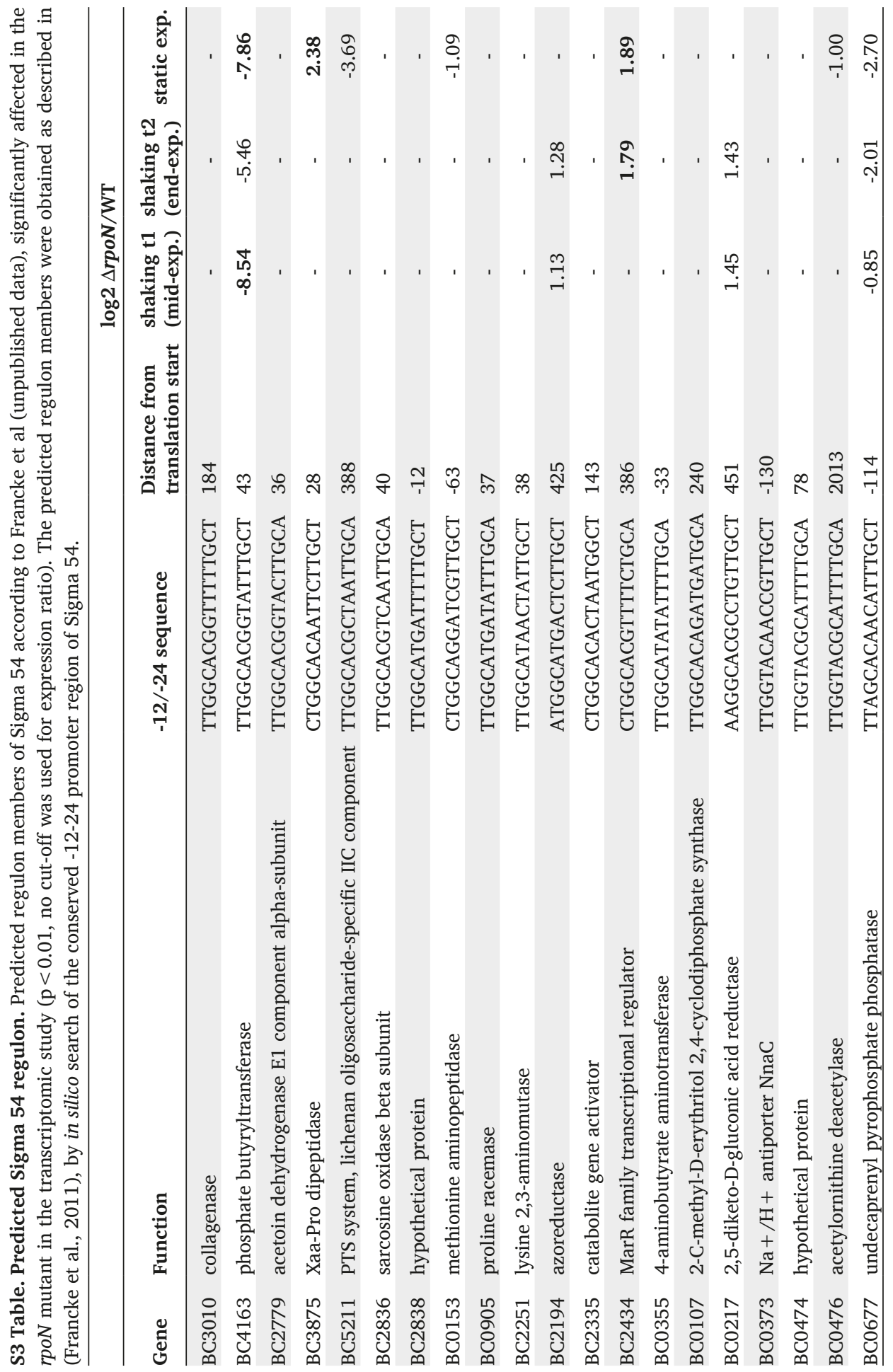




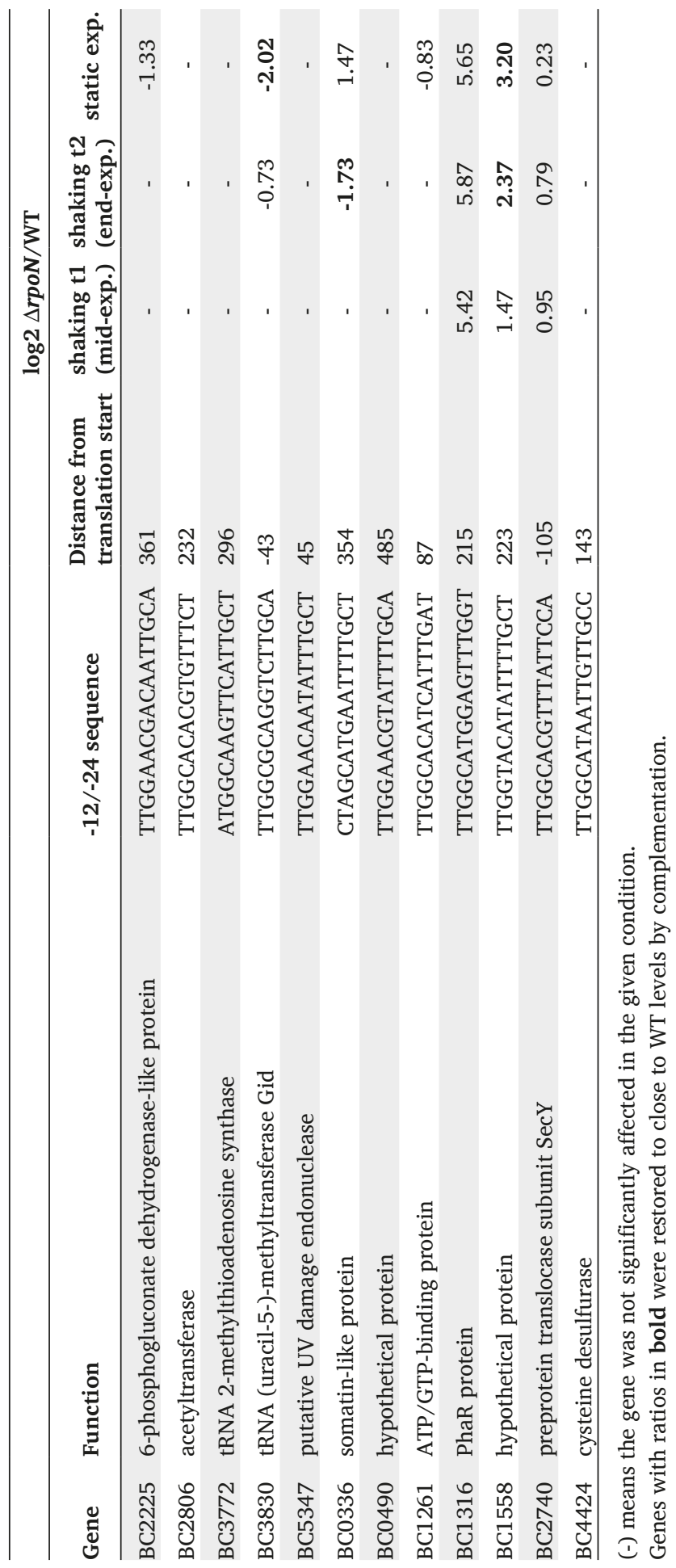


S4 Table. Amino acid metabolism. Genes involved in Valine, leucine and Isoleucine degradation significantly down regulated in the rpoN mutant $(\mathrm{p}<0.01$, ratio $>3)$.

\begin{tabular}{|c|c|c|c|c|c|c|c|}
\hline \multirow[b]{2}{*}{ 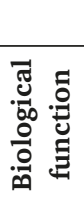 } & \multirow[b]{2}{*}{ Gene } & \multirow[b]{2}{*}{ COG } & \multirow[b]{2}{*}{ Name } & \multirow[b]{2}{*}{ Annotation } & \multicolumn{3}{|c|}{$\log 2 \Delta r p o N / W T$} \\
\hline & & & & & 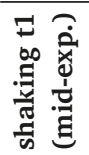 & 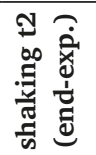 & 它 \\
\hline \multirow{7}{*}{ 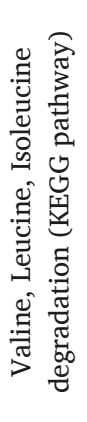 } & BC4157 & $\mathrm{C}$ & bkdB & $\begin{array}{l}\text { Lipoamide acyltransferase component of } \\
\text { branched-chain alpha-keto acid dehydrogenase } \\
\text { complex }\end{array}$ & -7.05 & -4.64 & -6.52 \\
\hline & BC4158 & $\mathrm{C}$ & & 2-oxoisovalerate dehydrogenase beta subunit & -7.29 & -3.93 & -5.99 \\
\hline & BC4159 & $\mathrm{C}$ & & 2-oxoisovalerate dehydrogenase alpha subunit & -7.86 & -4.03 & -6.74 \\
\hline & BC4160 & $\mathrm{C}$ & lpdV & Dihydrolipoamide dehydrogenase & -8.48 & -5.33 & -7.57 \\
\hline & BC4161 & $\mathrm{C}$ & & Branched-chain-fatty-acid kinase & -8.34 & -5.11 & -6.84 \\
\hline & BC4162 & $\mathrm{E}$ & & Leucine dehydrogenase & -5.69 & -3.09 & -5.34 \\
\hline & BC4163 & C & & Phosphate butyryltransferase & -8.54 & -5.46 & -7.86 \\
\hline
\end{tabular}

(-) means the gene was not significantly and highly affected in the given condition.

Genes with ratios in bold were restored to close to WT levels by complementation. 
S5 Table. Motility. Genes related to motility significantly down regulated in the $r p o N$ mutant $(\mathrm{p}<0.01$, ratio $>3$ ).

\begin{tabular}{|c|c|c|c|c|c|c|c|}
\hline \multirow[b]{2}{*}{ 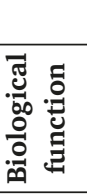 } & \multirow[b]{2}{*}{ Gene } & \multirow[b]{2}{*}{ COG } & \multirow[b]{2}{*}{ Name } & \multirow[b]{2}{*}{ Annotation } & \multicolumn{3}{|c|}{$\log 2 \Delta r p o N / W T$} \\
\hline & & & & & 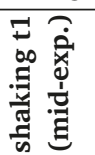 & 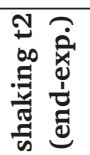 & 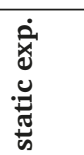 \\
\hline \multirow{32}{*}{ 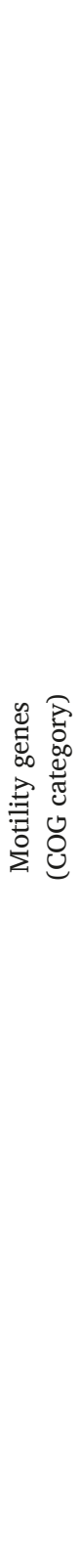 } & ВС0404 & NT & & Methyl-accepting chemotaxis protein & - & - & -2.13 \\
\hline & BC0422 & NT & & Methyl-accepting chemotaxis protein & - & -3.88 & -5.48 \\
\hline & ВC0559 & NT & & Methyl-accepting chemotaxis protein & - & -3.12 & -3.74 \\
\hline & ВС0576 & NT & & Methyl-accepting chemotaxis protein & -1.83 & -2.90 & -3.00 \\
\hline & ВС0678 & NT & & Methyl-accepting chemotaxis protein & - & -2.98 & -3.57 \\
\hline & BC1124 & NT & & Methyl-accepting chemotaxis protein & - & - & -2.66 \\
\hline & BC1625 & $\mathrm{N}$ & & Chemotaxis motA protein & - & -3.01 & -5.09 \\
\hline & BC1626 & $\mathrm{N}$ & ytxE & Chemotaxis motB protein & - & -1.71 & -2.49 \\
\hline & BC1628 & NT & cheA & Chemotaxis protein cheA & - & -2.26 & -4.94 \\
\hline & BC1629 & NT, NU & fliY & Chemotaxis protein cheC & - & - & -3.02 \\
\hline & BC1632 & NT & cheR & Chemotaxis protein methyltransferase & - & - & -1.72 \\
\hline & BC1636 & $\mathrm{N}$ & & Flagellar hook-associated protein 1 & - & -1.80 & -3.54 \\
\hline & BC1637 & $\mathrm{N}$ & & Flagellar hook-associated protein 3 & - & -1.61 & -3.09 \\
\hline & BC1638 & $\mathrm{N}$ & & Flagellar hook-associated protein 2 & - & - & -3.27 \\
\hline & BC1639 & NUO & & Flagellar protein flis & - & - & -2.85 \\
\hline & BC1641 & $\mathrm{N}$ & & Flagellar basal-body rod protein flgB & - & -1.87 & -3.72 \\
\hline & BC1642 & $\mathrm{N}$ & flgC & Flagellar basal-body rod protein flgC & - & -1.89 & -3.72 \\
\hline & BC1643 & NU & & $\begin{array}{l}\text { Flagellar hook-basal body complex } \\
\text { protein fliE }\end{array}$ & - & -2.10 & -4.10 \\
\hline & BC1644 & NU & & Flagellar M-ring protein fliF & - & - & -3.59 \\
\hline & BC1645 & $\mathrm{N}$ & fliG & Flagellar motor switch protein fliG & - & - & -3.46 \\
\hline & BC1647 & NU & & Flagellum-specific ATP synthase & - & - & -4.05 \\
\hline & BC1650 & $\mathrm{N}$ & & Basal-body rod modification protein flgD & - & - & -3.05 \\
\hline & BC1651 & $\mathrm{N}$ & & Flagellar hook protein flgE & - & - & -3.46 \\
\hline & BC1654 & $\mathrm{T}, \mathrm{NT}$ & cheV & Chemotaxis protein cheV & - & - & -3.66 \\
\hline & BC1656 & $\mathrm{N}$ & & Flagellin & - & - & -4.97 \\
\hline & BC1658 & $\mathrm{N}$ & yvzB & Flagellin & - & -2.19 & -4.91 \\
\hline & BC1661 & NU & & Flagellar motor switch protein fliN & - & - & -2.64 \\
\hline & BC1662 & $\mathrm{N}$ & flim & Flagellar motor switch protein fliM & - & - & -2.89 \\
\hline & BC1663 & NU & & Flagellar motor switch protein fliN & - & - & -2.45 \\
\hline & BC1665 & NU & flip & Flagellar biosynthetic protein flip & - & - & -3.25 \\
\hline & BC1666 & NU & & Flagellar biosynthetic protein fliQ & - & - & -3.06 \\
\hline & BC1667 & NU & fliR & Flagellar biosynthetic protein fliR & - & - & -2.97 \\
\hline
\end{tabular}




\begin{tabular}{|c|c|c|c|c|c|c|c|}
\hline \multirow[b]{2}{*}{ 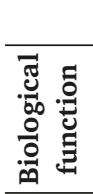 } & \multirow[b]{2}{*}{ Gene } & \multirow[b]{2}{*}{ COG } & \multirow[b]{2}{*}{ Name } & \multirow[b]{2}{*}{ Annotation } & \multicolumn{3}{|c|}{$\log 2 \Delta r p o N / W T$} \\
\hline & & & & & 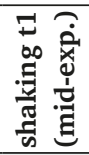 & 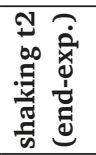 & 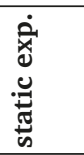 \\
\hline \multirow{10}{*}{ 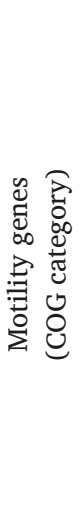 } & BC1668 & NU & flhB & Flagellar biosynthetic protein flhB & - & - & -2.71 \\
\hline & BC1671 & $\mathrm{N}$ & flhA & Flagellar basal-body rod protein flgG & - & -1.88 & -3.77 \\
\hline & BC2006 & NT & tlpA & Methyl-accepting chemotaxis protein & - & - & -3.41 \\
\hline & BC3101 & NT & & $\begin{array}{l}\text { Hemolysin BL binding component } \\
\text { precursor }\end{array}$ & -1.89 & -3.15 & -1.60 \\
\hline & BC3520 & NT & & Methyl-accepting chemotaxis protein & - & - & -2.82 \\
\hline & BC4512 & $\mathrm{N}$ & $\operatorname{motB}$ & Chemotaxis motB protein & - & -2.96 & -4.44 \\
\hline & BC4513 & $\mathrm{N}$ & motA & Chemotaxis motA protein & - & -2.12 & -2.80 \\
\hline & BC5034 & NT & уоан & Methyl-accepting chemotaxis protein & - & -3.50 & -4.26 \\
\hline & BC5065 & NT & & Methyl-accepting chemotaxis protein & - & - & -1.87 \\
\hline & BC5424 & NT & & Methyl-accepting chemotaxis protein & - & - & -1.85 \\
\hline
\end{tabular}

(-) means the gene was not significantly and highly affected in the given condition.

Genes with ratios in bold were restored to close to WT levels by complementation. 
S6 Table. Biofilm formation. Genes related to biofilm formation significantly affected in the rpoN mutant $(\mathrm{p}<0.01$, ratio $>3)$.

\begin{tabular}{|c|c|c|c|c|c|c|c|}
\hline \multirow[b]{2}{*}{ 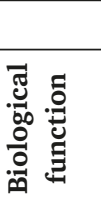 } & \multirow[b]{2}{*}{ Gene } & \multirow[b]{2}{*}{ COG } & \multirow[b]{2}{*}{ Name } & \multirow[b]{2}{*}{ Annotation } & \multicolumn{3}{|c|}{$\log 2 \Delta r p o N / W T$} \\
\hline & & & & & 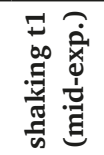 & 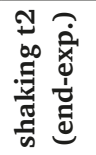 & 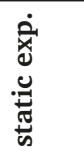 \\
\hline \multirow{17}{*}{ 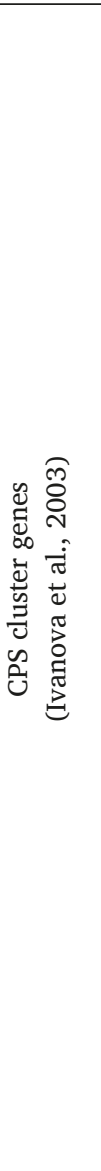 } & BC5263 & M & & UDP-glucose 4-epimerase & - & -2.53 & -3.60 \\
\hline & BC5264 & & & EPSX protein & - & -2.52 & -3.65 \\
\hline & BC5265 & $\mathrm{K}$ & lytR & Transcriptional regulator, LytR family & - & -1.84 & -1.75 \\
\hline & BC5266 & $\mathrm{R}$ & & $\begin{array}{l}\text { Heteropolysaccharide repeat unit } \\
\text { export protein }\end{array}$ & - & -2.23 & -3.05 \\
\hline & BC5267 & M & yveT & Glycosyltransferase & - & -1.68 & -2.52 \\
\hline & BC5268 & & & Secreted polysaccharide polymerase & - & -1.84 & -2.98 \\
\hline & BC5269 & M & & Amylovoran biosynthesis AmsK & - & -2.42 & -3.97 \\
\hline & BC5270 & M & yvfC & $\begin{array}{l}\text { Undecaprenyl-phosphate } \\
\text { galactosephosphotransferase }\end{array}$ & - & -2.21 & -4.32 \\
\hline & BC5271 & MG & & UDP-N-acetylglucosamine 4-epimerase & - & -1.89 & -4.19 \\
\hline & BC5272 & & & $\begin{array}{l}\text { Carbamoyl-phosphate synthase small } \\
\text { chain }\end{array}$ & - & - & -3.86 \\
\hline & BC5273 & M & spsC & UDP-bacillosamine synthetase & - & -1.82 & -4.89 \\
\hline & BC5274 & MG & yveM & $\begin{array}{l}\text { UDP-N-acetylglucosamine } \\
\text { 4,6-dehydratase }\end{array}$ & - & -1.59 & -4.39 \\
\hline & BC5275 & M & & $\begin{array}{l}\text { UTP--glucose-1-phosphate } \\
\text { uridylyltransferase }\end{array}$ & - & - & -2.65 \\
\hline & BC5276 & GM & ywqE & $\begin{array}{l}\text { Phosphotyrosine-protein phosphatase } \\
\text { (capsular polysaccharide biosynthesis) }\end{array}$ & - & - & -4.84 \\
\hline & BC5277 & $\mathrm{D}$ & ywqD & $\begin{array}{l}\text { Tyrosine-protein kinase (capsular } \\
\text { polysaccharide biosynthesis) }\end{array}$ & - & -2.47 & -5.53 \\
\hline & BC5278 & M & ywqC & $\begin{array}{l}\text { Chain length regulator (capsular } \\
\text { polysaccharide biosynthesis) }\end{array}$ & - & -2.40 & -5.71 \\
\hline & BC5279 & $\mathrm{D}$ & & $\begin{array}{l}\text { Tyrosine-protein kinase (capsular } \\
\text { polysaccharide biosynthesis) }\end{array}$ & - & 3.44 & 3.07 \\
\hline \multirow{2}{*}{ 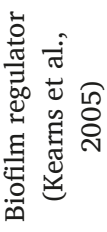 } & BC1282 & $\mathrm{K}$ & $\sin R$ & SinR protein & 1.63 & - & 2.59 \\
\hline & BC1283 & & $\sin I$ & SinI protein & 1.83 & 1.95 & 5.04 \\
\hline \multicolumn{2}{|c|}{ 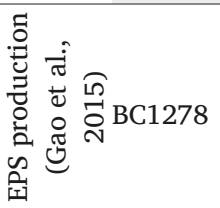 } & $\mathrm{U}$ & sipW & Signal peptidase I & - & - & -1.6 \\
\hline
\end{tabular}

(-) means the gene was not significantly and highly affected in the given condition.

Genes with ratios in bold were restored to close to WT levels by complementation. 
S7 Table. Virulence. Genes related to virulence significantly affected in the rpoN mutant $(\mathrm{p}<0.01$, ratio $>3)$.

\begin{tabular}{|c|c|c|c|c|c|c|c|}
\hline \multirow[b]{2}{*}{ 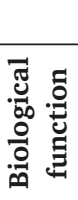 } & \multirow[b]{2}{*}{ Gene } & \multirow[b]{2}{*}{ COG } & \multirow[b]{2}{*}{ Name } & \multirow[b]{2}{*}{ Annotation } & \multicolumn{3}{|c|}{$\log 2 \Delta r p o N / W T$} \\
\hline & & & & & 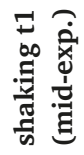 & 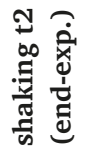 & 㐫 \\
\hline & BC1809 & - & nheA & $\begin{array}{l}\text { Non-hemolytic enterotoxin lytic } \\
\text { component L2 }\end{array}$ & -2.33 & -4.53 & -1.97 \\
\hline & BC1810 & - & nheB & $\begin{array}{l}\text { Non-hemolytic enterotoxin lytic } \\
\text { component L1 }\end{array}$ & -2.71 & -4.46 & -1.79 \\
\hline & BC1811 & $\mathrm{D}$ & nheC & Non-expressed Enterotoxin C & -2.35 & -2.56 & - \\
\hline & BC3102 & - & hblB & $\begin{array}{l}\text { Hemolysin BL binding component } \\
\text { precursor }\end{array}$ & -1.62 & -2.25 & -1.96 \\
\hline & ВС3103 & - & hblL1 & Hemolysin BL lytic component L1 & -1.90 & -2.57 & -2.18 \\
\hline & BC3104 & - & hblL2 & Hemolysin BL lytic component L2 & -1.74 & -2.14 & -1.79 \\
\hline & BC5101 & - & clo & Perfringolysin O precursor & -2.31 & -4.00 & - \\
\hline & BC1110 & - & cytK & Cytotoxin $\mathrm{K}$ & - & -5.30 & -2.33 \\
\hline & BC3761 & - & plcA & $\begin{array}{l}\text { 1-phosphatidylinositol phosphodiesterase } \\
\text { precursor }\end{array}$ & - & -3.59 & - \\
\hline & ВC0670 & - & plcB & Phospholipase C & -2.30 & -4.87 & -2.49 \\
\hline & BC0671 & - & smase & Sphingomyelin phosphodiesterase & - & -4.38 & -1.72 \\
\hline & BC2735 & $\mathrm{E}$ & nprP2 & Bacillolysin & - & - & - \\
\hline & BC3383 & $\mathrm{E}$ & nprC & Bacillolysin & - & -1.74 & -1.70 \\
\hline & BC5351 & $\mathrm{E}$ & nprB & Bacillolysin & - & -3.68 & 1.84 \\
\hline$\hat{\tilde{E}}$ & ВC0556 & $\mathrm{R}$ & colC & Microbial collagenase & - & -1.65 & - \\
\hline 0 & BC3161 & $\mathrm{R}$ & colA & Microbial collagenase & -2.37 & - & - \\
\hline$\simeq$ & BC3384 & - & $\mathrm{mpbE}$ & Enhancin & - & - & - \\
\hline & BC3762 & $\mathrm{O}$ & $\operatorname{sfp}$ & Microbial collagenase & -2.02 & -4.10 & -3.45 \\
\hline & BC5101 & - & sppc1 & Perfringolysin $\mathrm{O}$ precursor & -2.31 & -4.00 & - \\
\hline & BC2463 & & sppc2 & Peptide with anti-bacterial activity & - & - & - \\
\hline & BC3185 & - & sppc3 & hypothetical protein & - & - & - \\
\hline & BC5349 & - & papR & PapR protein & - & -1.81 & - \\
\hline & ВC0576 & NT & mcpA & Methyl-accepting chemotaxis protein & -1.83 & -2.90 & -3.00 \\
\hline & BC3385 & NT & tlpA & Methyl-accepting chemotaxis protein & - & - & - \\
\hline & ВС0577 & $\mathrm{T}$ & yufL & Two-component sensor kinase yufL & - & - & - \\
\hline & BC3747 & $\mathrm{T}, \mathrm{T}$ & & Sensory box/GGDEF family protein & - & -2.27 & - \\
\hline & BC4509 & $\mathrm{CP}$ & yhaP & Sodium export permease protein & - & -2.07 & -2.03 \\
\hline & BC4510 & $\mathrm{R}$ & yhaQ & Sodium export ATP-binding protein & - & -2.13 & -1.86 \\
\hline & BC2411 & GEPR & & Macrolide-efflux protein & - & - & - \\
\hline & BC3763 & - & cwh & Cell wall hydrolase & - & -2.01 & -3.08 \\
\hline
\end{tabular}




\begin{tabular}{|c|c|c|c|c|c|c|c|}
\hline \multirow[b]{2}{*}{ 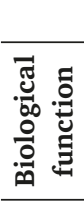 } & \multirow[b]{2}{*}{ Gene } & \multirow[b]{2}{*}{ COG } & \multirow[b]{2}{*}{ Name } & \multirow[b]{2}{*}{ Annotation } & \multicolumn{3}{|c|}{$\log 2 \Delta r p o N / W T$} \\
\hline & & & & & 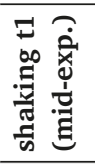 & 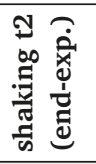 & 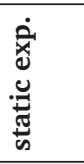 \\
\hline \multirow{15}{*}{ 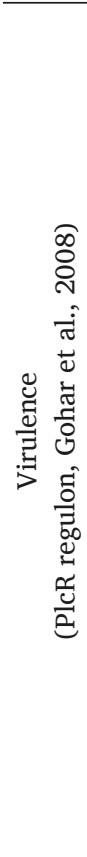 } & ВС0991 & $\mathrm{D}$ & slpA & $\begin{array}{l}\text { S-layer homology domain / putative } \\
\text { murein endopeptidase }\end{array}$ & -2.26 & -5.53 & -5.50 \\
\hline & BC3746 & $\mathrm{R}$ & Predicte & $\begin{array}{l}\text { d2-hydroxy-6-oxo-6-phenylhexa-2,4- } \\
\text { dienoate hydrolase }\end{array}$ & - & - & - \\
\hline & BC0666 & $S$ & inhA2 & Immune inhibitor A precursor & - & - & - \\
\hline & BC4999 & $\mathrm{R}$ & & CAAX amino terminal protease family & - & -2.54 & -2.25 \\
\hline & BC4511 & $\mathrm{R}$ & lppC & Acid phosphatase & -1.89 & -5.31 & -3.65 \\
\hline & BC2552 & - & & hypothetical protein & - & -2.09 & -3.39 \\
\hline & BC1713 & - & & hypothetical Membrane Spanning Protein & -1.71 & -2.79 & - \\
\hline & BC3527 & - & & hypothetical protein & - & -2.06 & 1.77 \\
\hline & вС0361 & G & yxkH & Polysaccharide deacetylase & - & - & - \\
\hline & BC0362 & - & & hypothetical protein & - & - & - \\
\hline & ВC0578 & KT & yufM & Two-component response regulator yufM & - & - & - \\
\hline & BC2410 & $\mathrm{K}$ & tetR & Transcriptional regulator, TetR family & - & - & - \\
\hline & BC1082 & $\mathrm{KR}$ & & $\begin{array}{l}\text { Ribosomal-protein-alanine } \\
\text { acetyltransferase }\end{array}$ & - & - & - \\
\hline & BC5350 & $\mathrm{R}, \mathrm{K}$ & plcR & Transcriptional activator plcR & - & -2.94 & -2.22 \\
\hline & BC1081 & - & prp2 & PlcR-regulated protein PRP2 & - & -3.67 & -2.51 \\
\hline
\end{tabular}

(-) means the gene was not significantly and highly affected in the given condition.

Genes with ratios in bold were restored to close to WT levels by complementation. 
S8 Table. Anaerobic respiration. Genes relevant for anaerobic respiration significantly down regulated in the rpoN mutant $(\mathrm{p}<0.01$, ratio $>3)$.

\begin{tabular}{|c|c|c|c|c|c|c|c|}
\hline \multirow[b]{2}{*}{ 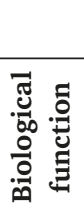 } & \multirow[b]{2}{*}{ Gene } & \multirow[b]{2}{*}{ COG } & \multirow[b]{2}{*}{ Name } & \multirow[b]{2}{*}{ Annotation } & \multicolumn{3}{|c|}{$\log 2 \Delta r p o N / W T$} \\
\hline & & & & & 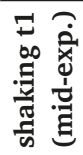 & 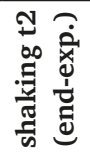 & 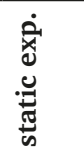 \\
\hline \multirow{10}{*}{ 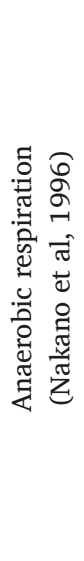 } & BC1477 & TK & resD & Transcriptional regulatory protein resD & - & - & -2.30 \\
\hline & BC1478 & $\mathrm{T}$ & resE & Sensor protein resE & - & - & -2.28 \\
\hline & BC2118 & $\mathrm{C}$ & narG & Respiratory nitrate reductase alpha chain & - & - & -3.74 \\
\hline & BC2119 & $\mathrm{C}$ & narH & Respiratory nitrate reductase beta chain & - & - & -5.98 \\
\hline & BC2120 & $\mathrm{C}$ & narJ & Respiratory nitrate reductase delta chain & - & - & -5.33 \\
\hline & BC2121 & $\mathrm{C}$ & narI & Respiratory nitrate reductase gamma chain & - & - & -5.54 \\
\hline & BC2122 & $\mathrm{T}$ & fnr & Transcription regulator, Crp family & - & - & - \\
\hline & BC2128 & $\mathrm{P}$ & nark & Nitrite extrusion protein & - & - & -7.64 \\
\hline & BC2135 & PR & nasE & Nitrite reductase $[\mathrm{NAD}(\mathrm{P}) \mathrm{H}]$ small subunit & - & - & -6.23 \\
\hline & BC2136 & $\mathrm{C}$ & nasD & Nitrite reductase $[\mathrm{NAD}(\mathrm{P}) \mathrm{H}]$ large subunit & -2.37 & - & -5.52 \\
\hline
\end{tabular}

(-) means the gene was not significantly and highly affected in the given condition.

Genes with ratios in bold were restored to close to WT levels by complementation. 
S9 Table. Regulators and sporulation related genes. Sigma factors significantly affected in the rpoN mutant $(\mathrm{p}<0.01$, ratio $>3)$.

\begin{tabular}{|c|c|c|c|c|c|c|c|}
\hline \multirow[b]{2}{*}{ 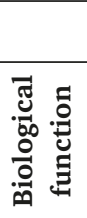 } & \multirow[b]{2}{*}{ Gene } & \multirow[b]{2}{*}{ COG } & \multirow[b]{2}{*}{ Name } & \multirow[b]{2}{*}{ Annotation } & \multicolumn{3}{|c|}{$\log 2 \Delta r p o N / \mathrm{WT}$} \\
\hline & & & & & 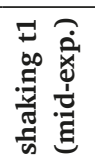 & 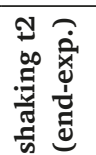 & 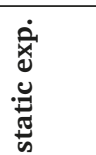 \\
\hline \multirow{10}{*}{ 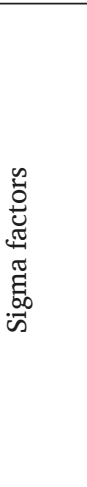 } & ВC0647 & $\mathrm{K}$ & & RNA polymerase ECF-type sigma factor & 3.51 & 3.30 & - \\
\hline & BC1002 & $\mathrm{T}$ & rsbV & Anti-sigma B factor antagonist & - & - & 2.38 \\
\hline & BC1003 & $\mathrm{T}$ & rsbW & Anti-sigma B factor & - & - & 3.00 \\
\hline & BC1004 & $\mathrm{K}$ & $\operatorname{sigB}$ & RNA polymerase sigma-B factor & - & - & 1.94 \\
\hline & BC1114 & $\mathrm{K}$ & sigM & RNA polymerase sigma factor sigM & - & - & 1.97 \\
\hline & BC2108 & $\mathrm{K}$ & $\operatorname{sigZ}$ & RNA polymerase ECF-type sigma factor & - & - & 2.51 \\
\hline & BC2386 & $\mathrm{K}$ & & RNA polymerase ECF-type sigma factor & 3.97 & 2.67 & 2.10 \\
\hline & BC3426 & $\mathrm{K}$ & sigI & RNA polymerase sigma-I factor & 4.81 & 1.98 & 2.07 \\
\hline & BC5143 & $\mathrm{K}$ & $\operatorname{sigL}$ & RNA polymerase sigma- 54 factor rpoN & $-6.04 *$ & $-3.7^{*}$ & $-4.85^{*}$ \\
\hline & BC5363 & $\mathrm{K}$ & sigW & RNA polymerase ECF-type sigma factor & - & - & 3.73 \\
\hline \multirow{2}{*}{ 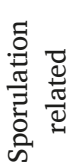 } & BC0042 & $\mathrm{K}$ & abrB & Transcription state regulatory protein abrB & - & -2.4 & - \\
\hline & BC2142 & S & & Stage V sporulation protein $S$ & 3.5 & 3.6 & 4.3 \\
\hline
\end{tabular}

* Expression of the rpoN gene was restored in the complemented mutant, but in shaking t1 (mid-exp.) and static exp. it was higher than in the WT, and in shaking t2 (end-exp.) it was closer to WT but still significantly different from it.

(-) means the gene was not significantly and highly affected in the given condition.

Genes with ratios in bold were restored to close to WT levels by complementation. 



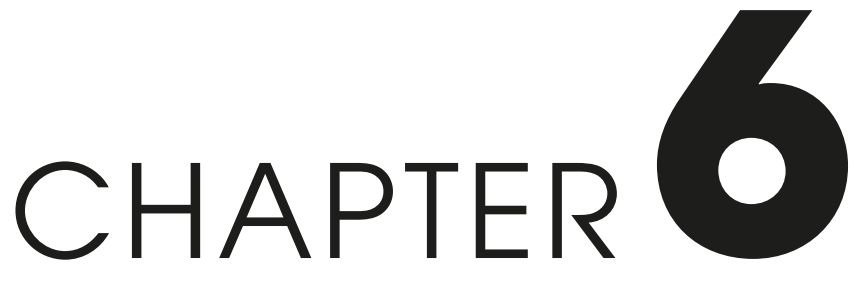

General discussion 



\section{Introduction}

The best strategy to eradicate biofilms in a food production environment is to prevent surface colonisation by microorganisms. Good hygiene and manufacturing practices, hygienic design of the equipment, effective cleaning in place procedures and short production cycles are key factors in prevention of biofilm formation. Despite above mentioned preventive practices, biofilms are still encountered by industry and can cause economic loss and food quality and safety issues. Biofilms can be established in processing lines and tanks, typically in hard to clean places such as dead ends or valves and gaskets, and for example on dairy processing membranes(Austin and Bergeron 1995, Sharma and Anand 2002). Once established, biofilms can cause equipment failure or corrosion of the contact surface, resulting in downtime of the production line during cleaning and disinfection practices, or pose a risk of post-pasteurization contamination which may result in product spoilage or even food poisoning. Furthermore, some chronic diseases in humans are associated with microbial biofilms. Taken together, biofilms are highly relevant, not only affecting food quality and safety, but also in the medical field. Therefore, biofilms have received intensive research efforts. Understanding conditions promoting or preventing biofilm formation and underlying mechanisms are a prerequisite to develop effective intervention strategies.

The work described in this thesis aimed at providing more insight in biofilm formation by the spore forming microorganism Bacillus cereus, a soil dweller and a common contaminant in many food products, as for example dairy, dry cereals, rice and other foods rich in proteins and starch. B. cereus can cause food spoilage and two types of food poisoning, diarrheal and emetic. Since it is able to form biofilms, the risk of food contamination with this pathogen at the level of food processing in the production chain should be minimized by reducing the chance of colonisation and further dispersal. Therefore, research topics described in this thesis concern different phases and aspects of the biofilm lifecycle of B. cereus. The work described in this thesis starts with a study on the initial attachment of $B$. cereus and the influence of contact surface material on biofilm formation, in the next step, abiotic factors contributing to surface colonisation including mechanisms underlying the process of biofilm formation were identified, and finally the heat resistance properties of $B$. cereus spores dispersed from mature biofilms and possible impact on recontamination of foods was discussed. No single strain can represent the characteristics of the whole species (Fux et al. 2005), therefore, besides the frequently studied B. cereus model strains (ATCC 14579 and ATCC 10987) the work described in this thesis included also 20 food isolates (BC1 to BC20). 
Interestingly, all B. cereus strains formed higher biofilm on stainless steel, a material typically applied in food processing environments compared to polystyrene (Chapter 2). Furthermore different types of iron sources were shown to influence biofilm formation in a strain dependent way; for example by promoting the formation of air-liquid interface or submerged biofilms (Chapter 3). The capacity to use complex iron sources for growth was investigated for $22 \mathrm{~B}$. cereus strains and linked to predicted capacity based on the genome content of the strains (Chapter 3). In Chapter 4, sporulation in the biofilms and heat resistance of these spores was studied. In Chapter 5, the role of a specific transcriptional regulator, the alternative Sigma factor 54 (Sigma 54, RpoN), which was previously implicated in regulation of processes influencing cell surface characteristics and biofilm formation (Francke et al. 2011) was studied. Comparative analysis of $B$. cereus ATCC 14579 wild type and its Sigma 54 deletion mutant provided novel insights in the role of this sigma factor in this foodborne human pathogen. Finally, this chapter (Chapter 6) provides a general discussion of the research findings and implications for food industry.

\section{Impact of strain diversity and environmental factors on biofilm formation: lessons learnt}

Biofilm formation can be studied by several different methods, such as total biomass staining using crystal violet (CV), cell enumeration or microscopy. Findings in this thesis highlight the importance of combining different methods for comprehensive characterisation of biofilms. CV staining is a quick and simple method allowing for high throughput studies of total biofilm formation. However, the correlation between $\mathrm{CV}$ values and culturable cells is influenced by conditions and type of species used or even varies with the strains used in selected experiments. A correlation between $\mathrm{CV}$ values and culturable cell numbers was identified in the current study of $B$. cereus, and revealed that significant CV staining was only observed at around 6 $\log \mathrm{CFU} /$ coupon or higher. For Salmonella, significant CV staining was observed at around $7 \log \mathrm{CFU} /$ well or higher in 96-well plates (Castelijn et al. 2012). Analysis of surface colonisation resulted in case of the poorest biofilm former on polystyrene (B. cereus ATCC 14579) at around 5 log culturable cells attached per coupon. As a consequence, relatively low numbers of cells attached to a surface, that may not be considered a biofilm based on the definition of microbial biofilms and fall below the detection limit of biochemical staining methods, may still pose a risk for contamination. Obviously, dense biofilms that are multi-layered, with cells embedded in a matrix containing extracellular polymeric compounds including protective polysaccharides and/or DNA, may pose higher safety or spoilage risks 
since the cells in these biofilms are physically more protected from disinfectant treatments which may finally lead to higher (re)contamination efficacy.

Biofilm formation by $B$. cereus was shown to be highly affected by the contact material. All 23 strains tested in this thesis formed visible biofilm on stainless steel (SS), significantly higher compared to those formed on polystyrene (PS) after $24 \mathrm{~h}$ (Chapter 2). All the strains originated from food, except for one reference strain isolated from the air in a cow shed (ATCC 14579). The capacity to form biofilms can be a strategy to adapt to the natural habitat. Stainless steel is typically encountered as food contact surface in food production environments, although the route of contamination is unknown, high biofilm formation on this material appears a general feature of the tested B. cereus food isolates. Around $50 \%$ of soil and diarrheal disease associated isolates of $B$. cereus in another study were positive for biofilm formation on polyvinyl chloride (PVC) whereas none of the emetic strains or oral disease isolates formed a biofilm on this material (Auger et al. 2009). This reduced biofilm formation capacity of periodontal strains may be related to the fact that they act as secondary species in dental plaque and not as main colonisers (Auger et al. 2009). For emetic strains, conditions and surface material (PVC) used in the same study (Auger et al. 2009) may not be optimal for their biofilm formation, since these are often found in association with plant roots and tubers (Ehling-Schulz et al. 2015) where biofilm formation may play a role, even though an endophytic lifestyle has been proposed for these strains (Ehling-Schulz et al. 2015). In another study, including non-pathogenic food isolates, diarrheal and clinical strains of B. cereus, no link was observed between biofilm formation on PVC and strain origin (Kamar et al. 2013). Wijman et al. (2007) used a range of environmental conditions to study biofilm formation and showed that almost all $56 \mathrm{~B}$. cereus strains of different origins produced a biofilm in at least one of the tested growth condition. This suggests that optimal conditions for biofilm formation can differ for selected isolates. It would be interesting to study the biofilm formation of strains of different origins, including food isolates and pathogenic isolates with distinct groups formed by diarrheal and emetic strains, as well as periodontal B. cereus strains on stainless steel, since it seems that the latter two groups show distinct biofilm forming capacities. For Salmonella, a link between biofilm formation capacity and pathogenic potential of selected strains was found, with disease and outbreak-related strains showing higher biofilm formation capacity in static conditions compared to industrial or retail isolates (Castelijn et al. 2012). Similarly, animal isolates of $S$. aureus showed higher static biofilm formation capacity than plant isolates (Kim et al. 2016) which may be explained by differences in optimal conditions of biofilm formation for each group of isolates including the surface, temperature and the medium used. 
The observed preference of $B$. cereus for SS as surface to form biofilms is species specific since for other microorganisms, such as different serotypes of Salmonella (Castelijn et al. 2013) and Lactobacillus plantarum (Fernández Ramírez 2016), biofilm formation on SS was comparable to that on PS. For L. plantarum this may be explained by the fact that this species is non motile and initial attachment depends on sedimentation processes rather than active movement to a surface. Salmonella is motile, nevertheless, the surface type did not influence biofilm formation. Therefore, biofilm formation investigated on PS surfaces may give a good indication of performance in practice for static biofilm formation by L. plantarum and Salmonella. For $B$. cereus, performance on PS may underestimate performance in practice since SS, which showed higher biofilms for this species, is more likely to be encountered in industrial environments.

Iron is the main component of SS which triggered us to investigate the impact of this metal ion on biofilm formation. Addition of free iron promoted air-liquid interface biofilm formation (Chapters 2 and 3) both for surface attached biofilm, and surface floating (pellicle type) biofilms for B. cereus strain ATCC 10987 in case of prolonged incubations of more than 3 days (not shown). Addition of iron also triggered pellicle formation by Bacillus subtilis 168 in LB medium, a medium that normally does not support pellicle biofilm formation by this species (data not shown). Notably, in LB $+\mathrm{Fe}$ the medium below the pellicle was almost transparent, showing that the majority of cells in the suspension floated to the surface where they formed a pellicle, whereas in LB without supplementation no pellicle was observed and the suspension was turbid. Since stainless steel is a very common surface used throughout food processing lines it may higher the probability of $B$. cereus establishment on those surfaces leading to a contamination risk.

It remains to be established whether the corrosive capacity of the $B$. cereus strains can be linked to high biofilm formation on SS. Passive release of metal ions from SS into the medium was low $(<1 \mu \mathrm{M})$ as measured by ICP-MS (Chapter 2), however it cannot be excluded that $B$. cereus can actively take up metals from SS during growth resulting in corrosion of SS. Other unreported observations suggest that the SS coupon may serve as a source of iron. For example in defined medium (MO(Mols et al. 2007)) devoid of iron, the strain ATCC 14579 grew and formed pellicle only in the wells that contained the SS coupon and not the PS coupon. Similar to addition of iron, the presence of a SS coupon in BHI also promoted pellicle formation by the other reference strain ATCC 10987 after $72 \mathrm{~h}$ of incubation (Fig. 1). 


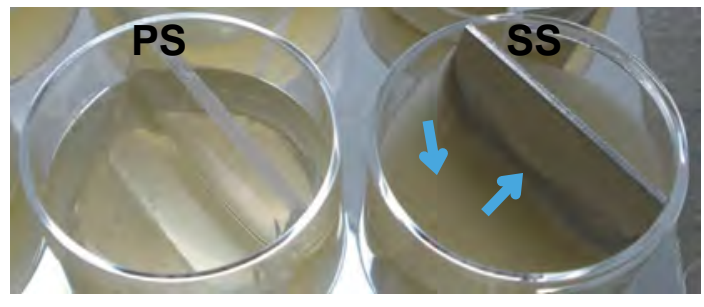

Figure 1. Pellicle formation by B. cereus ATCC 10987 in wells containing PS (left) or SS (right) coupons $\left(\mathrm{BHI} / 30^{\circ} \mathrm{C} / 72 \mathrm{~h}\right)$. PS, negative result; SS, positive result. The arrows indicate the high air-liquid interface biofilm and pellicle formed in the presence of SS coupon. Own unpublished results.

Besides iron, other metals present in SS (nickel $8 \%$, manganese $1 \%$ and chromium $18 \%$ ) were tested but showed no effect on biofilm formation. However, it cannot be excluded that adhesion and biofilm formation of $B$. cereus on SS is affected by a combination of metals, as well as surface characteristics of the SS material compared to PS, thus further studies are required.

\section{Adaptation of $B$. cereus to different environmental niches}

\section{The role of iron}

Most microorganisms depend on iron for their basic biological activities. However, this metal is not readily available in the environment. For the uptake of iron from the environment, bacteria rely on highly efficient acquisition systems.

A comparative genome analysis of $22 \mathrm{~B}$. cereus isolates (Chapter 3 ) revealed the presence of two major siderophores for iron uptake in most of the tested strains: bacillibactin (BB) and petrobactin ( $\mathrm{PB})$. Interestingly, the siderophore $\mathrm{BB}$ was present in all strains, while the stealth siderophore PB (Abergel et al. 2006), which is not sensed by the mammal immune system and is important for virulence in $B$. anthracis (Cendrowski et al. 2004), was present in 15 of the 22 tested strains. The observed in vitro utilisation of different iron sources by $B$. cereus strains suggests that they encounter these sources in their natural environment. It may be expected that virulent strains have the ability to utilise host iron sources such as heme and hemoglobin, and spend resources on maintenance of the transport systems required. Notably, genome analysis of non-pathogenic B. subtilis revealed absence of genes/ gene clusters encoding biosynthesis of either petrobactin siderophore or IlsA hemophore (our data not shown)(Ollinger et al. 2006), but this bacterium produces a transporter for import of petrobactin from the environment (Zawadzka et al. 2009). Similarly, the B. cereus group member Bacillus thuringiensis, which is used as an insecticide, also lacks the petrobactin biosynthesis genes. Notably, for $B$. cereus the capacity to produce the PB siderophore was present in both pathogenic and non-pathogenic strains (Koppisch et al. 2008). This means that mere presence of PB 
biosynthesis genes does not necessarily imply pathogenicity, however its absence conceivably reduces the ability of $B$. cereus species to survive in a vertebrate host (Wilson et al. 2006, Koppisch et al. 2008).

Further studies should clarify whether the virulence capacity of the tested $B$. cereus isolates correlates with the presence of siderophore genes. A possible link between virulence and PB biosynthesis might be suggested by the fact that 7 out of 22 tested B. cereus strains missing PB siderophore genes also lack genes encoding for hemolysin BL lytic components (genes BC3103 and BC3104 in ATCC 14579), whereas of the remaining 15 PB siderophore-positive strains, 13 also carry the hemolysin genes. Interestingly, all PB-negative strains belonged to the phylogenetic group III (Guinebretière et al. 2008) and some of these strains also showed a restricted carbohydrate utilisation capacity (Warda et al. 2016). Notably, the identified strains appeared to originate from starchy foods, which most likely provide a narrow spectrum of growth substrates and thus may have selected for the latter type of strains. Whether the narrow carbohydrate utilisation capacity and reduced iron acquisition capacity correlate remains to be elucidated.

Since ability to use host iron sources is an important determinant of virulence, siderophore biosynthesis and transport can serve as targets for antimicrobial strategies such as antibiotics or vaccines (Brown et al. 2001, Tripathi et al. 2014).

\section{Sigma factor 54 plays a role in survival strategies of B. cereus including biofilm formation}

Sigma 54 is a unique transcriptional regulator among other sigma regulators, since its structure and mechanism of action differ from other prokaryotic sigma factors and its mechanism has common features with transcription in eukaryotes. To initiate transcription it requires Enhancer Binding Proteins (EBPs). These activators are each specific to different cellular functions (Martin et al. 1989, Studholme and Dixon 2003). Interestingly, $43 \%$ of all the known EBPs are related to the transduction of extracellular signals via a histidine kinase two-component system (Francke et al. 2011), which supports the idea that this sigma factor is important in adaptation to different environments. In agreement with this, two-component systems were among the most affected categories in our gene expression study of the rpoN deletion mutant of $B$. cereus. B. cereus group members have 7 or 8 EBPs, B. subtilis has $4, L$. plantarum only 1, whereas in Pseudomonas aeruginosa or Pseudomonas putida even up to 22 and 24 EBPs are present, respectively (supplement 2 in (Francke et al. 2011)). This may be related to ability to adapt to different environments and could also explain differences in the magnitude of the impact of rpoN deletion in these 
microorganisms (Jones et al. 2007, Stevens et al. 2010). In accordance with this, the predicted regulon of Sigma 54 in B. subtilis consists of 13 genes, in L. plantarum only 7 whereas in P. putida up to 54 genes are included (supplement 4 in (Francke et al. 2011)).

Sigma 54 regulated transcription also depends on ATP hydrolysis catalysed by EBPs (Bush and Dixon 2012). The functions related to this alternative sigma factor such as survival of nitrogen starvation, alternative carbon utilisation, motility or cold shock adaptation, appear non-essential for basic viability of bacteria (Morett and Segovia 1993) under non-stress conditions. Moreover, the ATP dependency of the system indicates that the cell should have enough energy reserves to be able to execute functions related to Sigma 54.

The role of Sigma 54 becomes important in suboptimal environments, for example under nutrient limitation (Reitzer and Schneider 2001), cold temperature or anaerobic conditions (Wiegeshoff et al. 2006)(Chapter 5). Sigma 54 may also play a role in regulation of virulence since it influences the expression of the virulence regulator PlcR (Chapter 5). Due to the pleiotropic role of this sigma factor in control of several cell functionalities, including pathogenicity, targeting its expression and/ or activity could offer a way to modify bacterial behaviour or to inhibit growth. An example of specifically targeting a transcription factor has been provided previously for another sigma factor, Sigma B, activity of which could be blocked by using a sulfonamide derivative compound (Palmer et al. 2011). Sigma 54 was proposed as a specific target for antibacterial treatments due to its involvement in bacterial defences (Yang et al. 2015) and stress responses (Feklístov et al. 2014). Although a challenging idea, complexity of the roles that different sigma factors play and their interconnection with other sigma factors and transcriptional regulators can make the effect of such an approach unpredictable and therefore unreliable. A comprehensive understanding of the function, mode of action and interaction of sigma factors is important before undertaking any attempt to apply this knowledge in practice.

\section{Sporulation within biofilms and spore properties}

\section{Formation of spores in a biofilm in wet and dry conditions}

Sporulation is a process generally known to be induced by reduced amounts of nutrients in the environment (Driks 2002, Piggot and Hilbert 2004). Sporulation and biofilm formation mechanisms are extensively studied in $B$. subtilis, which shares many of the regulatory pathways with $B$. cereus group members (Fagerlund et al. 2014, Majed et al. 2016). Whether the cells will sporulate or initiate biofilm 
formation depends on the phosphorylation degree of Spo0A, which is a regulator involved in both of these processes (Hamon and Lazazzera 2001). Intermediate levels of phosphorylated Spo0A (Spo0A-P) trigger matrix synthesis and biofilm formation, whereas higher concentrations induce sporulation genes (Fujita et al. 2005), finally resulting in the formation of spores inside the biofilm (Vlamakis et al. 2013). Possibly, the environmental conditions in the biofilm, especially limitation of nutrients (Piggot and Hilbert 2004, El-Khoury et al. 2016), may affect the phosphorylation cascade leading to higher Spo0A-P levels resulting in early onset of sporulation (Fujita et al. 2005, Fujita and Losick 2005) in biofilm cells compared to their planktonic counterparts. Additionally, in certain conditions this may also result in higher total numbers of spores eventually formed in the biofilms compared to the surrounding planktonic phase, as observed in Chapter 2. The onset of sporulation in the ring of an air-liquid interface biofilm of $B$. thuringiensis was also shown to precede the sporulation in the pellicle type biofilm in the same setting, presumably linked to the earlier nutrient limitation experienced in the ring compared to the pellicle (El-Khoury et al. 2016).

Due to heterogeneity and labour division, not all cells perform the same functions in biofilms (van Gestel et al. 2015). In B. thuringiensis biofilms, only a subpopulation of cells forms spores (Verplaetse et al. 2015, Verplaetse et al. 2016). In a colony biofilm or in an insect host, these cells originate from necrotrophic cells which are distinct from virulent cells (Verplaetse et al. 2015). Whereas in the air-liquid biofilm formed in a sporulation promoting medium necrotrophism was not the only pathway leading to sporulating cells (Verplaetse et al. 2016) and virulent cells were absent. Furthermore, the percentage of spores in the latter biofilm was higher. Similarly $B$. cereus biofilms formed in a rich medium such as BHI (Chapter 2) contained lower amount of spores compared to the biofilm formed in a poor sporulation promoting medium (Chapter 4).

A remarkable aspect of $B$. cereus biofilms formed on SS surface was the higher spore content compared to that of biofilms formed on PS as observed both in BHI medium (Chapter 2) and in defined Y1 medium (Chapter 4). As previously reported, iron and especially manganese have been shown to increase sporulation efficiency for B. subtilis in liquid cultures, though this effect was not significant for B. cereus (Curran and Evans 1954). For Bacillus megaterium removal of manganese, and not iron, resulted in loss of sporulation (Kolodziej and Slepecky 1964). Obviously, the possible influence of metals released from stainless steel on B. cereus biofilm formation and sporulation deserves further attention and extended study.

Most biofilm studies are performed in nutritive medium, either liquid or agar based. Dry conditions may also evoke biofilm formation as a survival strategy since the 
EPS produced by biofilm formers may provide protection against desiccation, as shown for Salmonella (Iibuchi et al. 2010) and Acinetobacter baumannii (Espinal et al. 2012). Extended survival up to 175 days for the cells of biofilm forming strains of Salmonella has been reported (Iibuchi et al. 2010). In practice, wet, nutrient rich conditions, and dry conditions may alternate and affect biofilm formation. The influence of such wet to dry transition was studied on sporulation in B. cereus air-liquid interface biofilms and was shown to significantly increase sporulation efficiency (Chapter 4). This approach mimics conditions in food industry, where wet and dry conditions constantly interchange between production and cleaning cycles, which will have consequences for the risks related to biofilms. The formed spores and biofilm parts can be released into the surrounding liquid. Spores may be released into food product stream and persist in the final product if no further heating steps are applied. Furthermore, these dispersed spores can attach to new surfaces. Adhered spores have higher chances of surviving certain disinfectants and heat treatment compared to their planktonic counterparts (Faille et al. 2001, Simmonds et al. 2003, Ryu and Beuchat 2005, Shaheen et al. 2010). These spores can germinate and outgrowing cells attached to the surface can start forming a new biofilm.

\section{Heat resistance of biofilm spores}

Sporulation conditions are known to affect spore properties (Carlin 2011, Planchon et al. 2011). Heat resistance properties of spores are of key importance to their survival of food processing and the impact on quality and safety issues. Extrinsic factors such as medium composition, sporulation temperature and water activity may influence spore properties (Gaillard et al. 1998, González et al. 1999, Palop et al. 1999). The sporulation response to environmental conditions is species and strain specific (Mazas et al. 1995, González et al. 1999), sometimes even displaying opposite responses for the same factor, as reported for spores of different Bacillus species formed in rich and poor sporulation media (Baril et al. 2012).

In this thesis we studied the influence of the biofilm growth mode on heat resistance of the formed spores (Chapter 4). These biofilms were grown on SS and PS as surface material and in wet or dry conditions. Spores from the wet biofilms on stainless steel were 1.2 and 2 times more resistant compared to liquid spores, which was within the range previously reported for the biofilm spores of $B$. cereus (1.7 and 3.4) (van der Voort and Abee 2013). This influence of biofilm growth mode is relevant in food production as spores detached from the biofilms, especially biofilms on SS may pose a higher contamination risk than planktonic spores. This impact may be higher for other sporulating bacteria with higher heat resistance properties, such as the 
thermophilic contaminants typical for dairy products Anoxybacillus flavithermus and Geobacillus spp. (Burgess et al. 2009, Burgess et al. 2010, Zhao et al. 2013), which are able to form spores within biofilms.

Intrinsic factors encoded by genotypic differences can have a large impact on spore heat resistance, such as a recently discovered mobile genetic element (Tn1546like), causing 130 fold higher $\mathrm{D}_{120^{\circ} \mathrm{C}}$ values for $B$. subtilis strains (Berendsen et al. 2015, Berendsen et al. 2016). The functions of genes carried on this transposon (SpoVAC, SpoVAD, SpoVAEb and four other unknown genes) are not completely known but the presence of the transposon results in about $50 \%$ higher dipicolinic acid (DPA) content (Berendsen et al. 2016). B. cereus strains belonging to various phylogenetic groups displayed lower variability in their heat resistance, having $\mathrm{D}_{95^{\circ} \mathrm{C}}$ values between 2 and 30 min, excluding psychrotolerant strains with low heat resistance (Luu-Thi et al. 2014). Extrinsic factors such as sporulation conditions affect spore properties to a lesser degree. Sporulation temperature has a large effect on spore heat resistance of $B$. cereus with a 10 fold difference in decimal reduction time $\left(\mathrm{D}_{100^{\circ} \mathrm{C}}\right)$ for spores formed at 20 compared to $45^{\circ} \mathrm{C}$ (González et al. 1999). Most studies show lower impact of different factors such as sporulation medium, level of nutrients or $\mathrm{pH}$ on spore heat resistance, reporting between 1.3 to 6 fold changes in decimal reduction values (D-values) (Mazas et al. 1995, Baweja et al. 2008, Baril et al. 2012).

The different biofilm scenarios investigated in Chapter 4 represent different contamination routes that may be encountered in practice. Both vegetative cells and spores dispersed from the biofilm can be of concern and are undesired contaminants in heat treated products. The release of cells and spores can be a rapid process. For example, within one hour an $8 \log \mathrm{CFU} /$ coupon biofilm of B. cereus (formed in BHI) released $5 \log \mathrm{CFU} / \mathrm{ml}$ cells into the standing phosphate buffer surrounding it (not shown). The number of spores in the biofilm (El-Khoury et al. 2016) and their heat resistance is influenced by the phase of the biofilm development and environmental parameters encountered such as dry or wet conditions (summarised in Fig. 2). For example the biofilms that were allowed to dry showed higher sporulation rate, however, the dry conditions negatively affected the heat resistance of the spores for one of the strains (Chapter 4). Thus the history of the biofilm may affect the resistance of the released spores and thereby the risk of their survival in the final food product. 


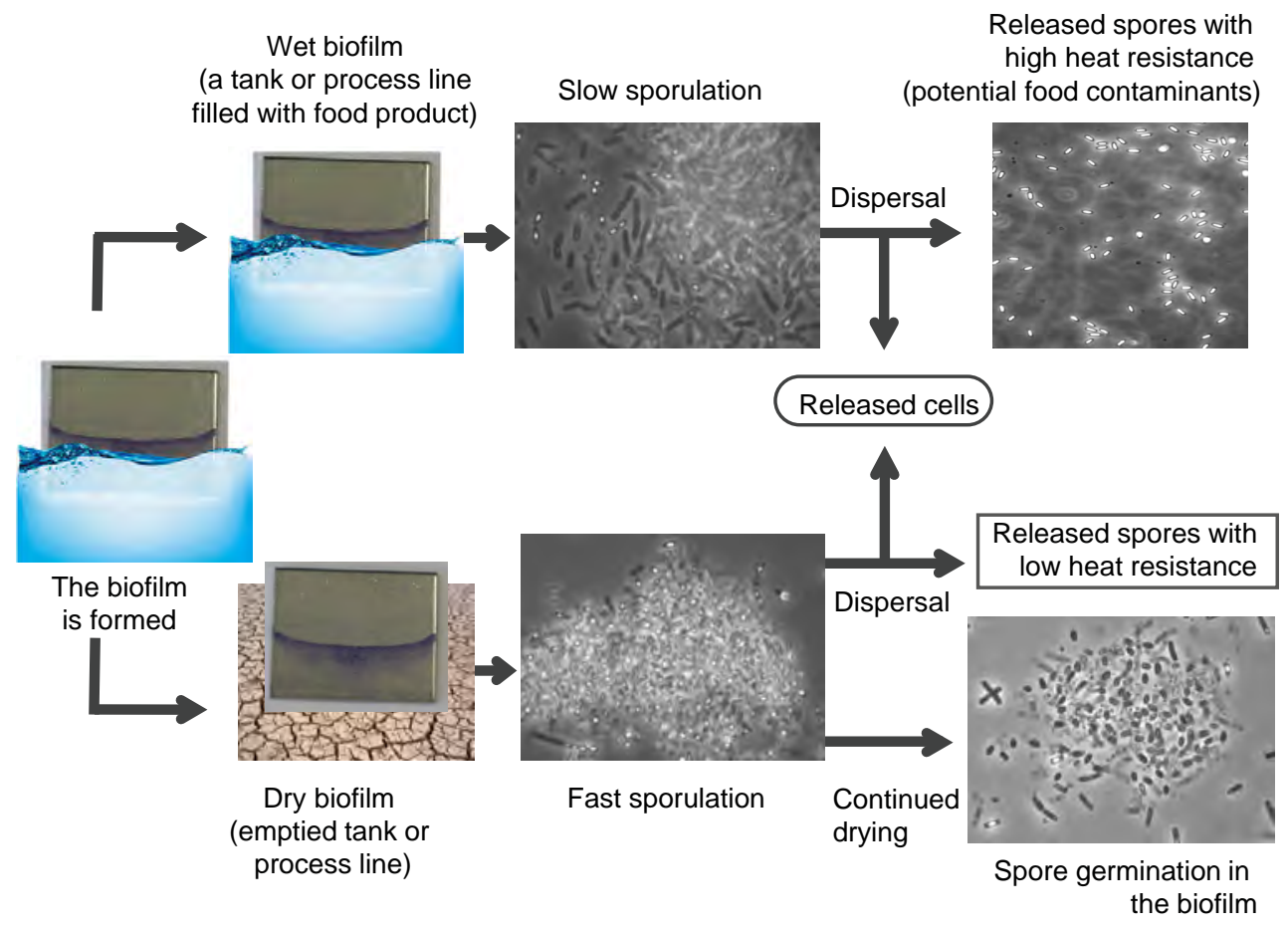

Figure 2. Possible scenarios for practical implications of $B$. cereus biofilm growth in a food processing line and its exposure to dry and wet conditions.

How sporulation conditions affect heat resistance properties of $B$. cereus remains to be elucidated. The DPA content, known to affect the spore heat resistance (Setlow et al. 2006) was not significantly different for spores derived from biofilms and planktonic cultures in our study. DPA content also did not explain the higher heat resistance of biofilm derived spores of emetic B. cereus strains (van der Voort and Abee 2013) or colony biofilm derived spores of B. subtilis (Veening et al. 2006). Other components, such as calcium, manganese and magnesium were shown to influence spore heat resistance (Beaman et al. 1982, Bender and Marquis 1985, Beaman and Gerhardt 1986). In B. subtilis the spore manganese content was proposed as a biomarker for high heat resistance (Rebelo Lima 2012). High levels of manganese in the medium resulted in $B$. megaterium spores with much higher resistance towards several inactivating treatments, including wet and dry heat (Ghosh et al. 2011). Even though the main component of SS material is iron ( $>70$ $\%)$, it also contains manganese ( $1 \%$ ). The exact mechanism how manganese affects spore heat resistance is unknown, but it was suggested that it decreased the spore core water content by increasing the amount of Mn-DPA complex (Setlow 2006). The Mn in the Mn-DPA complex may also provide protection of spore molecules, such as restriction enzymes against reactive oxygen species such as generated 
during irradiation or dry heat (Granger et al. 2011). For Clostridium spores on the other hand, a high iron concentration in the spore seems to be an indicator for low heat resistance (Kihm et al. 1990). To develop full resistance properties, the spores need to incorporate optimal concentrations of all the components. Since exposure to dry conditions accelerated spore formation, this may have affected the optimal process of the sporulation and maturation resulting in lower heat resistance of dry biofilm spores.

In order to understand the reasons behind the differential heat resistance of biofilm spores it would be interesting to study other resistance properties of these spores, for instance against dry heat, UV light or chemical disinfectants, which have other mechanisms of spore inactivation (Setlow 2006). Measurements of differences in chemical composition and core water content, as well as the structure of outer layers of spores may provide more information on their resistance mechanisms.

\section{Mechanisms of biofilm formation}

Different approaches undertaken in this study to elucidate biofilm formation mechanisms in $B$. cereus included a gene expression study in the presence and absence of free iron, characterisation of the rpoN knockout mutant and gene-trait matching (schematically represented in Fig. 3). A more detailed discussion on these approaches is provided below.

\section{Iron sources and biofilm}

Iron is not only essential for bacterial survival. Its source and availability also affects biofilm formation (Chapters 2 and 3 ) of B. cereus. Interestingly both the amount and type of biofilm depended on the supplied iron source. The air-liquid interface biofilm typical for $B$. cereus was formed when free iron or iron citrate was available. While in iron depleted conditions, caused by addition of the iron scavenger Bipyridine, most of the strains did not form a biofilm. For a few strains that did form a biofilm under these conditions, even though their growth was inhibited, the biofilm was of a submerged type. Submerged types of biofilms were also promoted in the presence of hemin and lactoferrin. The latter is surprising in relation to previous reports of inhibition and even disruption of Pseudomonas biofilms by lactoferrin (Singh et al. 2002, Kamiya et al. 2012). The anti-biofilm effect of lactoferrin was apparently not simply due to iron removal since increasing concentrations of iron in the presence of lactoferrin increased its anti-biofilm activity (O'May et al. 2009). 
Formation of different types of biofilms points at different mechanisms of biofilm formation triggered in iron deplete and replete conditions or in the presence of certain iron sources. Biofilm formation could be one of the defence mechanisms under unfavourable conditions as a response to stress. Biofilm formed under suboptimal growth conditions may consist of high numbers of dead cells. Although these biofilms may contain low number of viable cells, from a contamination perspective, this could still be relevant as cells within the biofilm are protected against disinfectants by the biomass of dead cells. In $P$. aeruginosa cell aggregation, either via growth in a colony or by means of exopolysaccharide (EPS) production, has been shown to trigger the production of the siderophore pyoverdine and other virulence factors (Visaggio et al. 2015). In Staphylococcus lugdunensis, the cell wall bound IsdC protein involved in iron transport promoted cell aggregation in iron depleted condition (Missineo et al. 2014). Such mechanisms of linking iron transport with biofilm formation may also be present in $B$. cereus and require further study.

In general, based on the observations and results presented in this thesis, it can be concluded that in iron rich conditions, B. cereus cells tend to form biofilms at the air liquid interface, where there is more oxygen available, either attached to the surface or as floating pellicles. Iron depletion has an opposite effect inhibiting both types of surface biofilms and in some strains triggering submerged type of biofilm formation. This seems counterintuitive since iron is known to cause oxidative stress by triggering formation of highly reactive oxygen species via the Fenton reaction (Andrews et al. 2003) and this effect would be enhanced by elevated oxygen concentrations at the surface. However, air-liquid interface also provides advantageous conditions for aerobic microorganisms due to high oxygen availability and respiration activity in the electron transfer chains, with iron playing a key role in the active site of components involved (Anraku 1988).

In another study, transcriptome analysis of $P$. aeruginosa pellicle cells showed that the cells were in aerobic but presumably iron depleted conditions, since the expression of genes encoding iron transporting siderophores was up regulated (Yamamoto et al.). This means that pellicle cells gathered at the surface may be experiencing iron shortage which could be due to low solubility of iron in aerobic conditions (Yamamoto et al.) or due to the high demand and competition for this essential element in the crowded pellicle biofilm.

The inhibitory effect of iron limitation on biofilm formation and its underlying mechanism is widely studied for $P$. aeruginosa (Musk et al. 2005, Banin et al. 2006, Patriquin et al. 2008). The effect of iron was confirmed with a mutant defective in pyoverdine mediated iron transport (Patriquin et al. 2008, Ponraj et al. 2012). The intracellular iron concentration serves as a signal for $P$. aeruginosa biofilm 
development (Banin et al. 2005). The reduced biofilm in iron limited condition was related to increased twitching motility of $P$. aeruginosa and Quorum Sensing (QS) (Singh et al. 2002, Patriquin et al. 2008, Cai et al. 2010). Modulation of QS and eDNA release by iron was another proposed underlying mechanism for the biofilm promotion by iron (Yang et al. 2007). Iron chelating agents inhibited initial attachment and biofilm formation of $S$. aureus via reduction of a polysaccharide synthesis, shown to be important in intercellular adhesion (Lin et al. 2012).

\section{Iron dependent expression of genes in B. cereus relevant for biofilm formation}

To study the effect of iron on biofilm formation in more detail a microarray study was performed on planktonic cells of B. cereus ATCC 10987 in BHI either depleted or supplemented with free iron. The microarray experiment is described in Chapter 3 while the genes affected in relation to biofilm formation are discussed below. Two candidate genes were identified, namely the $\mathrm{ABC}$ transporter oligopeptide binding protein (BCE1000, Opp), and the Twin-arginine translocation (Tat, BCE2272-2273) system.

The expression of Opp was significantly upregulated in the presence of excess iron at the beginning of the stationary growth phase (time $=12$ hours). Interestingly, this was the only gene significantly affected at this timepoint. The Opp protein was previously isolated from the biofilm EPS of this same B. cereus (ATCC 10987) strain (Karunakaran and Biggs 2011). In B. subtilis it is membrane lipid anchored in exponential phase but is released into medium in stationary phase (Perego et al. 1991). The B. cereus opp gene is homologous to spoOK of $B$. subtilis and is required for sporulation and competence (Rudner et al. 1991) as well as eDNA production (Zafra et al. 2012). Even though the opp mutant of B. subtilis deficient in eDNA production formed wild-type like pellicle and wrinkled colony biofilms, eDNA is required for B. cereus biofilm formation (Vilain et al. 2009). In contradiction to our hypothesis, the oppA knockout mutant of Vibrio fluvialis produced more biofilm than the wildtype (Lee et al. 2004). However, for some other microorganisms it was suggested to be involved in adhesion to epithelial cells, which seems to be in agreement with our hypothesis of improved cell-cell interaction. Opp mutants of Streptococcus pneumoniae failed to recognise glycoconjugate receptors on the surface of epithelial cells and attach to them (Cundell et al. 1995). Additionally, an oligopeptide binding protein was shown to be directly involved in adhesion of Bifidobacterium bifidum to Caco-2 cells (Guglielmetti et al. 2008). Opp could also be involved in quorum sensing via transporting signalling peptides which may trigger EPS production thus affecting the biofilm formation indirectly, as was suggested 
for colony and pellicle cells of $B$. subtilis overexpressing the Opp, along with an extracellular serine protease (Vpr) (Morikawa et al. 2006).

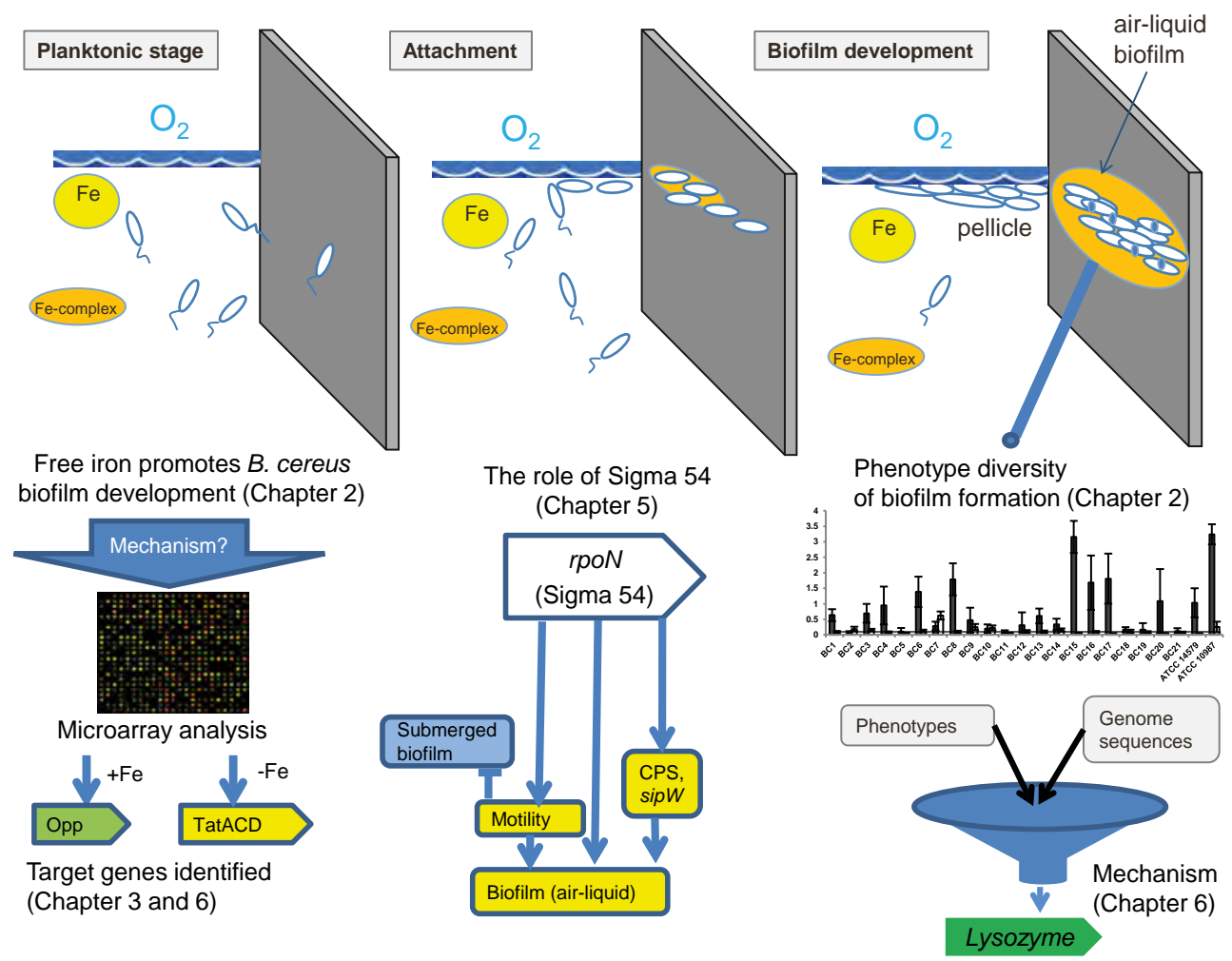

Figure 3. Approaches used to identify mechanisms of biofilm formation in B. cereus.

The Twin-arginine translocation (Tat) system (BCE2272-2273) was the second possible link to biofilm formation. This system was down regulated in response to iron starvation in B. cereus. Several previously reported observations point to a possible role of the Tat system in biofilm formation. Tat pathway transports folded proteins across the membrane (De Buck et al. 2008) and a range of cellular processes was shown to be affected by the Tat system including motility, virulence, biofilm formation and iron acquisition in $E$. coli, $P$. aeruginosa and several other gramnegative species, as reviewed in (De Buck et al. 2008). The role in iron acquisition is manifested via import of siderophores through the cell membrane. A B. subtilis Tat mutant displayed a delayed pellicle-biofilm formation (Goosens et al. 2013). Mutations in Tat system genes in Legionella pneumophila (De Buck et al. 2005) and Vibrio cholerae led to decreased biofilm formation (Zhang et al. 2009). 
The roles of the two candidate genes remain to be confirmed since the strain ATCC 10987 is genetically inaccessible due to presence of restriction modification systems directed against any foreign non-methylated DNA (Xu et al. 2012). Our attempts to use in vitro methylated DNA for transformation, previously used to overcome the restriction modification barrier in other B. cereus strains (Nierop Groot et al. 2008) was not successful in strain ATCC 10987.

\section{Transcriptional regulators and biofilm formation: Sigma 54}

The regulatory network of biofilm formation is complex and includes both direct and indirect effects of regulators involved. Examples of direct regulators are Spo0A, AbrB and SinI/SinR (Fagerlund et al. 2014, Majed et al. 2016). SinR and its antagonist SinI influence biofilm formation by regulating the production of EPS components and motility (Vlamakis et al. 2013, Majed et al. 2016). The signalling molecule dinucleotide derivative cyclic-di-GMP has also been shown to positively affect $B$. cereus biofilm formation (Fagerlund et al. 2016). Other regulators, including sigma factors can affect biofilm formation also indirectly, either via a second regulator or affecting physiological processes in the cell with consequences for biofilm formation (Vlamakis et al. 2013, Majed et al. 2016). Sigma factor 54 was predicted to have a central role in the biosynthesis of components involved in the interaction of the cell with its environment, which includes biofilm formation and interaction with the host (Francke et al. 2011). In Chapter 5 we show that several factors, such as cell membrane biogenesis, biofilm regulator SinR expression and capsular polysaccharide production were affected in the rpoN mutant, which may affect biofilm formation. However it seems that the most dramatic influence on biofilm is indirect, mediated via motility and flagella loss, which are important for static biofilm formation at the liquid-air interphase (Pratt and Kolter 1999, Houry et al. 2010). Even though motility and flagella loss is a common phenotype of Sigma 54 mutants (Wolfe et al. 2004, Dong et al. 2011), and both phenotypic and transcriptomic data of the RpoN mutant of $B$. cereus ATCC 14579 show this, it seems to be affected indirectly since motility related genes were not a part of the predicted regulon of this strain (Chapter 5).

\section{The potential of comparative genomics: gene-trait matching}

Nowadays, large amounts of omics data can be readily obtained with available tools. Different bioinformatics tools can be used to extract new leads for microbial behaviour out of omics data (Bayjanov et al. 2012). Phenolink is one of such tools applied for gene-trait matching. It can be used to correlate phenotypes with gene presence/absence data, and to predict possible gene functions, as demonstrated for 
L. plantarum and Lactococcus lactis strains in relation to phenotypes such as sugar utilisation, metal resistance and arginine metabolism (Bayjanov et al. 2012, Bayjanov et al. 2013). This approach was shown preciously successful in identification of a mobile genetic element responsible for high heat resistance of $B$. subtilis spores (Berendsen et al. 2016). We applied gene-trait matching to predict genes involved in biofilm formation of $B$. cereus. For this, the sequenced strains were grouped into high and low biofilm formers and the Phenolink software was exploited to search for possible links in the grouped genomes. The most promising result emerged from a comparative analysis of biofilm forming capacity on PS surface of $15 \mathrm{~B}$. cereus strains, that indicated the lysozyme encoding gene (BC3441) to be absent in 8 strains able to form a biofilm on PS surface and present in the other 7 strains, including the reference strain ATCC 14579, that are not able to form biofilms on this material. This predicts a preventive role for the self-produced lysozyme in biofilm formation on PS. Lysozyme is a glycosidase enzyme which can change the structure of polysaccharides in peptidoglycan layer of the cell wall and cause cell lysis. Lysozyme coatings can be applied on different surfaces to prevent microbial attachment and growth (Conte et al. 2006, Caro et al. 2009, Al Meslmani et al. 2016). It is possible that the self-produced lysozyme modifies the cell wall structure of $B$. cereus in a way that binding to polystyrene is prevented, while it does not negatively affect binding to stainless steel. For experimental validation of this prediction we attempted to construct a deletion mutant of this gene in ATCC 14579 strain, which did not form biofilm on PS. Deletion of this gene would theoretically turn this strain into a biofilm former on this material. However the mutant construction was unsuccessful, since the integration of the construct carrying the deletion into the chromosome of this strain was not possible, which could be due to importance of the neighbouring regions of the gene. Phenotypic verification of the function prediction in some cases remains to be a limiting factor for genomic studies, which may be resolved in near future due to improved methodologies enabling genetic manipulations in B. cereus.

\section{Conclusions and future perspectives}

The data presented in this study improved our understanding of how biofilms by $B$. cereus are formed and which (a)biotic parameters are involved. The study included both two model strains and a set of 20 food isolates which allowed identification of not only generic factors in B. cereus biofilm formation but also strain specific features. One important determinant in B. cereus biofilm formation was the surface material. Stainless steel (SS) as a contact surface provided more favourable conditions for biofilm formation compared to polystyrene, which could serve as an 
additional selection criterion for food contact material in equipment design. The availability and sources of iron appeared to have a large impact on $B$. cereus growth and/or biofilm formation, with free iron strongly promoting $B$. cereus biofilm formation. Complex iron sources also affected biofilm formation with Haemoglobin, a component widely present in meat processing environments, supporting growth and in specific strains promoting biofilm formation, while for example ferritin and transferrin for most of the strains did not promote the growth and neither biofilm formation.

The transcriptional regulator Sigma 54 was identified as an important regulator affecting $B$. cereus fitness, adaptive response and survival in different environments including its biofilm formation capacity. This sigma factor, which is found in a wide range of gram-negative and gram-positive bacteria, may therefore be an interesting, but challenging target for control strategies, as interference in its functioning may affect $B$. cereus growth and survival capacity in a range of niches.

In the biofilm on SS, the relative spore content was higher compared to PS. SS biofilm also yielded spores with higher heat resistance compared to liquid spores. Collectively, these results suggest that current industrial environment with SS as one of the widely used contact surfaces creates favourable conditions for $B$. cereus biofilms to thrive and release heat resistant spores posing a risk of food contamination. Within 24 hours, B. cereus biofilms can maturate and be partly released, which implies that dispersal of cells and/or spores from biofilms during a food production run is a realistic scenario for food contamination leading to spoilage and safety concerns. This emphasizes the importance of the frequency of cleaning cycles in between production times, which is commonly about every 24 $\mathrm{h}$, however special care should be taken in cases when a delay in the cleaning and disinfection routine takes place. All of the above suggests that for a better biofilm control studies on new surface materials or anti-biofilm coatings for industrial use should be encouraged. Since in iron depleted conditions only a minority of strains formed a biofilm and only in low amounts, modulating iron availability seems to be a promising strategy to prevent the biofilm formation by this microorganism. Metal chelating agents could also be used in combination with cleaning and disinfection to increase the effectiveness of cleaning, as shown for EDTA, which made it easier to remove the organic matter from nanofiltration membranes (Hong and Elimelech 1997), or lactoferrin which was able to disrupt preformed Pseudomonas biofilms (Kamiya et al. 2012). In case of B. cereus biofilms this strategy would most likely have a preventive role rather than cause disruption of a biofilm. Another strategy could be to eliminate the air inside the production lines thereby reducing the airliquid interfaces where $B$. cereus preferentially forms its biofilms. 
In conclusion, this study has provided novel insights in the biofilm formation capacity and underlying mechanisms by $B$. cereus, using a collection of genome sequenced reference strains and food isolates. Additionally, insights have been obtained in conditions that promote biofilm formation and sporulation inside biofilms, in combination with a comparative analysis of spore heat resistance. All this information may further support the identification and quantification of risk factors for food contamination and safety issues related to B. cereus biofilms and may provide clues to design novel (combination) approaches to prevent the formation and/or eradication of biofilms in food processing environments. 


\section{References}

Abergel, R. J., M. K. Wilson, J. E. Arceneaux, T. M. Hoette, R. K. Strong, B. R. Byers and K. N. Raymond (2006). Anthrax pathogen evades the mammalian immune system through stealth siderophore production. Proceedings of the National Academy of Sciences of the United States of America 103(49): 18499-18503.

Al Meslmani, B. M., G. F. Mahmoud, T. Leichtweiss, B. Strehlow, F. O. Sommer, M. D. Lohoff and U. Bakowsky (2016). Covalent immobilization of lysozyme onto woven and knitted crimped polyethylene terephthalate grafts to minimize the adhesion of broad spectrum pathogens. Materials Science \& Engineering. C: Materials for Biological Applications 58: 78-87.

Andrews, S. C., A. K. Robinson and F. Rodríguez-Quiñones (2003). Bacterial iron homeostasis. FEMS Microbiology Reviews 27(2-3): 215-237.

Anraku, Y. (1988). Bacterial electron transport chains. Annual Review of Biochemistry 57: 101-132.

Auger, S., N. Ramarao, C. Faille, A. Fouet, S. Aymerich and M. Gohar (2009). Biofilm formation and cell surface properties among pathogenic and nonpathogenic strains of the Bacillus cereus group. Applied and Environmental Microbiology 75(20): 6616-6618.

Austin, J. W. and G. Bergeron (1995). Development of bacterial biofilms in dairy processing lines. Journal of Dairy Research 62(3): 509-519.

Banin, E., K. M. Brady and E. P. Greenberg (2006). Chelator-induced dispersal and killing of Pseudomonas aeruginosa cells in a biofilm. Applied and Environmental Microbiology 72(3): 20642069.

Banin, E., M. L. Vasil and E. P. Greenberg (2005). Iron and Pseudomonas aeruginosa biofilm formation. Proceedings of the National Academy of Sciences of the United States of America 102(31): 11076-11081.

Baril, E., L. Coroller, O. Couvert, I. Leguérinel, F. Postollec, C. Boulais, F. Carlin and P. Mafart (2012). Modeling heat resistance of Bacillus weihenstephanensis and Bacillus licheniformis spores as function of sporulation temperature and pH. Food Microbiology 30(1): 29-36.

Baweja, R. B., M. S. Zaman, A. R. Mattoo, K. Sharma, V. Tripathi, A. Aggarwal, G. P. Dubey, R. K. Kurupati, M. Ganguli, N. K. Chaudhury, S. Sen, T. K. Das, W. N. Gade and Y. Singh (2008). Properties of Bacillus anthracis spores prepared under various environmental conditions. Archives of Microbiology 189(1): 71-79.

Bayjanov, J. R., D. Molenaar, V. Tzeneva, R. J. Siezen and S. A. F. T. van Hijum (2012). PhenoLink a web-tool for linking phenotype to $\sim$ omics data for bacteria: Application to gene-trait matching for Lactobacillus plantarum strains. BMC Genomics 13(1).

Bayjanov, J. R., M. J. Starrenburg, M. R. Van Der Sijde, R. J. Siezen and S. A. Van Hijum (2013). Genotype-phenotype matching analysis of 38 Lactococcus lactis strains using random forest methods. BMC Microbiology 13(1).

Beaman, T. C. and P. Gerhardt (1986). Heat resistance of bacterial spores correlated with protoplast dehydration, mineralization, and thermal adaptation. Applied and Environmental Microbiology 52(6): 1242-1246.

Beaman, T. C., J. T. Greenamyre, T. R. Corner, H. S. Pankratz and P. Gerhardt (1982). Bacterial spore heat resistance correlated with water content, wet density, and protoplast/sporoplast volume ratio. Journal of Bacteriology 150(2): 870-877.

Bender, G. R. and R. E. Marquis (1985). Spore heat resistance and specific mineralization. Applied and Environmental Microbiology 50(6): 1414-1421.

Berendsen, E. M., J. Boekhorst, O. P. Kuipers and M. H. J. Wells-Bennik (2016). A mobile genetic element profoundly increases heat resistance of bacterial spores. ISME J.

Berendsen, E. M., M. H. Zwietering, O. P. Kuipers and M. H. J. Wells-Bennik (2015). Two distinct groups within the Bacillus Subtilis group display significantly different spore heat resistance properties. Food Microbiology 45(PA): 18-25. 
Brown, J. S., A. D. Ogunniyi, M. C. Woodrow, D. W. Holden and J. C. Paton (2001). Immunization with components of two iron uptake $\mathrm{ABC}$ transporters protects mice against systemic Streptococcus pneumoniae infection. Infection and Immunity 69(11): 6702-6706.

Burgess, S. A., J. D. Brooks, J. Rakonjac, K. M. Walker and S. H. Flint (2009). The formation of spores in biofilms of Anoxybacillus flavithermus. Journal of Applied Microbiology 107(3): 10121018.

Burgess, S. A., D. Lindsay and S. H. Flint (2010). Thermophilic bacilli and their importance in dairy processing. International Journal of Food Microbiology 144(2): 215-225.

Bush, M. and R. Dixon (2012). The role of bacterial enhancer binding proteins as specialized activators of o54-dependent transcription. Microbiology and Molecular Biology Reviews 76(3): 497-529.

Cai, Y., R. Wang, M. M. An and B. B. Liang (2010). Iron-depletion prevents biofilm formation in Pseudomonas aeruginosa through twitching motility and quorum sensing. Brazilian Journal of Microbiology 41(1): 37-41.

Carlin, F. (2011). Origin of bacterial spores contaminating foods. Food Microbiology 28(2): 177-182.

Caro, A., V. Humblot, C. Méthivier, M. Minier, M. Salmain and C.-M. Pradier (2009). Grafting of lysozyme and/or poly(ethylene glycol) to prevent biofilm growth on stainless steel surfaces. The Journal of Physical Chemistry B 113(7): 2101-2109.

Castelijn, G. A., J. A. Parabirsing, M. H. Zwietering, R. Moezelaar and T. Abee (2013). Surface behaviour of S. Typhimurium, S. Derby, S. Brandenburg and S. Infantis. Veterinary Microbiology 161(3-4): 305-314.

Castelijn, G. A. A., S. van der Veen, M. H. Zwietering, R. Moezelaar and T. Abee (2012). Diversity in biofilm formation and production of curli fimbriae and cellulose of Salmonella Typhimurium strains of different origin in high and low nutrient medium. Biofouling 28(1): 51-63.

Cendrowski, S., W. MacArthur and P. Hanna (2004). Bacillus anthracis requires siderophore biosynthesis for growth in macrophages and mouse virulence. 51(2): 407-417.

Conte, A., G. G. Buonocore, A. Bevilacqua, M. Sinigaglia and M. A. Del Nobile (2006). Immobilization of lysozyme on polyvinylalcohol films for active packaging applications. Journal of Food Protection 69(4): 866-870.

Cundell, D. R., B. J. Pearce, J. Sandros, A. M. Naughton and H. R. Masure (1995). Peptide permeases from Streptococcus pneumoniae affect adherence to eucaryotic cells. Infection and Immunity 63(7): 2493-2498.

Curran, H. R. and F. R. Evans (1954). The influence of iron or manganese upon the formation of spores by mesophilic aerobes in fluid organic media. Journal of Bacteriology 67(4): 489-497.

De Buck, E., E. Lammertyn and J. Anné (2008). The importance of the twin-arginine translocation pathway for bacterial virulence. Trends in Microbiology 16(9): 442-453.

De Buck, E., L. Maes, E. Meyen, L. Van Mellaert, N. Geukens, J. Anné and E. Lammertyn (2005). Legionella pneumophila Philadelphia-1 tatB and tatC affect intracellular replication and biofilm formation. Biochemical and Biophysical Research Communications 331(4): 1413-1420.

Dong, T., R. Yu and H. Schellhorn (2011). Antagonistic regulation of motility and transcriptome expression by RpoN and RpoS in Escherichia coli. Molecular Microbiology 79(2): 375-386.

Driks, A. (2002). Overview: Development in bacteria: spore formation in Bacillus subtilis. Cellular and Molecular Life Sciences 59(3): 389-391.

Ehling-Schulz, M., E. Frenzel and M. Gohar (2015). Food-bacteria interplay: pathometabolism of emetic Bacillus cereus. Front Microbiol 6: 704.

El-Khoury, N., R. Majed, S. Perchat, M. Kallassy, D. Lereclus and M. Gohar (2016). Spatio-temporal evolution of sporulation in Bacillus thuringiensis biofilm. Frontiers in Microbiology 7: 1222.

Espinal, P., S. Martí and J. Vila (2012). Effect of biofilm formation on the survival of Acinetobacter baumannii on dry surfaces. Journal of Hospital Infection 80(1): 56-60.

Fagerlund, A., T. Dubois, O. A. Økstad, E. Verplaetse, N. Gilois, I. Bennaceur, S. Perchat, M. Gominet, S. Aymerich, A. B. Kolstø, D. Lereclus and M. Gohar (2014). SinR controls enterotoxin expression in Bacillus thuringiensis biofilms. 9(1). 
Fagerlund, A., V. Smith, Å. K. Røhr, T. Lindbäck, M. P. Parmer, K. K. Andersson, L. Reubsaet and O. A. Økstad (2016). Cyclic diguanylate regulation of Bacillus cereus group biofilm formation. Molecular Microbiology 101(3): 471-494.

Faille, C., F. Fontaine and T. Bénézech (2001). Potential occurrence of adhering living Bacillus spores in milk product processing lines. Journal of Applied Microbiology 90(6): 892-900.

Feklístov, A., B. D. Sharon, S. A. Darst and C. A. Gross (2014). Bacterial sigma factors: A historical, structural, and genomic perspective. Annual Review of Microbiology. 68: 357-376.

Fernández Ramírez, M. D. (2016). Characterisation of Lactobacillus plantarum single and multi-strain biofilms. PhD thesis Wageningen.

Francke, C., T. Groot Kormelink, Y. Hagemeijer, L. Overmars, V. Sluijter, R. Moezelaar and R. J. Siezen (2011). Comparative analyses imply that the enigmatic sigma factor 54 is a central controller of the bacterial exterior. BMC Genomics 12.

Fujita, M., J. E. González-Pastor and R. Losick (2005). High- and low-threshold genes in the Spo0A regulon of Bacillus subtilis. Journal of Bacteriology 187(4): 1357-1368.

Fujita, M. and R. Losick (2005). Evidence that entry into sporulation in Bacillus subtilis is governed by a gradual increase in the level and activity of the master regulator Spo0A. Genes and Development 19(18): 2236-2244.

Fux, C. A., M. Shirtliff, P. Stoodley and J. W. Costerton (2005). Can laboratory reference strains mirror 'real-world' pathogenesis? Trends in Microbiology 13(2): 58-63.

Gaillard, S., I. Leguerinel and P. Mafart (1998). Model for combined effects of temperature, $\mathrm{pH}$ and water activity on thermal inactivation of Bacillus cereus spores. Journal of Food Science 63(5): 887-889.

Ghosh, S., A. Ramirez-Peralta, E. Gaidamakova, P. Zhang, Y. Q. Li, M. J. Daly and P. Setlow (2011). Effects of Mn levels on resistance of Bacillus megaterium spores to heat, radiation and hydrogen peroxide. Journal of Applied Microbiology 111(3): 663-670.

González, I., M. López, S. Martínez, A. Bernardo and J. González (1999). Thermal inactivation of Bacillus cereus spores formed at different temperatures. International Journal of Food Microbiology 51(1): 81-84.

Goosens, V. J., A. Otto, C. Glasner, C. C. Monteferrante, R. Van Der Ploeg, M. Hecker, D. Becher and J. M. Van Dijl (2013). Novel twin-arginine translocation pathway-dependent phenotypes of Bacillus subtilis unveiled by quantitative proteomics. Journal of Proteome Research 12(2): 796-807.

Granger, A. C., E. K. Gaidamakova, V. Y. Matrosova, M. J. Daly and P. Setlow (2011). Effects of $\mathrm{Mn}$ and Fe levels on Bacillus subtilis spore resistance and effects of $\mathrm{Mn} 2+$, other divalent cations, orthophosphate, and dipicolinic acid on protein resistance to ionizing radiation. Applied and Environmental Microbiology 77(1): 32-40.

Guglielmetti, S., I. Tamagnini, D. Mora, M. Minuzzo, A. Scarafoni, S. Arioli, J. Hellman, M. Karp and C. Parini (2008). Implication of an outer surface lipoprotein in adhesion of Bifidobacterium bifidum to Caco-2 cells. Applied and Environmental Microbiology 74(15): 4695-4702.

Guinebretière, M. H., F. L. Thompson, A. Sorokin, P. Normand, P. Dawyndt, M. Ehling-Schulz, B. Svensson, V. Sanchis, C. Nguyen-The, M. Heyndrickx and P. De Vos (2008). Ecological diversification in the Bacillus cereus Group. Environmental Microbiology 10(4): 851-865.

Hamon, M. A. and B. A. Lazazzera (2001). The sporulation transcription factor Spo0A is required for biofilm development in Bacillus subtilis. Molecular Microbiology 42(5): 1199-1209.

Hong, S. and M. Elimelech (1997). Chemical and physical aspects of natural organic matter (NOM) fouling of nanofiltration membranes. Journal of Membrane Science 132(2): 159-181.

Houry, A., R. Briandet, S. Aymerlch and M. Gohar (2010). Involvement of motility and flagella in Bacillus cereus biofilm formation. Microbiology 156(4): 1009-1018.

Iibuchi, R., Y. Hara-Kudo, A. Hasegawa and S. Kumagai (2010). Survival of Salmonella on a polypropylene surface under dry conditions in relation to biofilm-formation capability. Journal of Food Protection 73(8): 1506-1510. 
Jones, J., D. J. Studholme, C. G. Knight and G. M. Preston (2007). Integrated bioinformatic and phenotypic analysis of RpoN-dependent traits in the plant growth-promoting bacterium Pseudomonas fluorescens SBW25. Environmental Microbiology 9(12): 3046-3064.

Kamar, R., M. Gohar, I. Jehanno, A. Rejasse, M. Kallassy, D. Lereclus, V. Sanchis and N. Ramarao (2013). Pathogenic potential of Bacillus cereus strains as revealed by phenotypic analysis. Journal of Clinical Microbiology 51(1): 320-323.

Kamiya, H., T. Ehara and T. Matsumoto (2012). Inhibitory effects of lactoferrin on biofilm formation in clinical isolates of Pseudomonas aeruginosa. Journal of Infection and Chemotherapy 18(1): 47-52.

Karunakaran, E. and C. A. Biggs (2011). Mechanisms of Bacillus cereus biofilm formation: An investigation of the physicochemical characteristics of cell surfaces and extracellular proteins. Applied Microbiology and Biotechnology 89(4): 1161-1175.

Kihm, D. J., M. T. Hutton, J. H. Hanlin and E. A. Johnson (1990). Influence of transition metals added during sporulation on heat resistance of Clostridium botulinum 113B spores. Applied and Environmental Microbiology 56(3): 681-685.

Kim, B. R., Y. M. Bae, J. H. Hwang and S. Y. Lee (2016). Biofilm formation and cell surface properties of Staphylococcus aureus isolates from various sources. Food Science and Biotechnology 25(2): 643-648.

Kolodziej, B. J. and R. A. Slepecky (1964). Trace metal requirements for sporulation of Bacillus megaterium. Journal of Bacteriology 88(4): 821-830.

Koppisch, A. T., S. Dhungana, K. K. Hill, H. Boukhalfa, H. S. Heine, L. A. Colip, R. B. Romero, Y. Shou, L. O. Ticknor, B. L. Marrone, L. E. Hersman, S. Iyer and C. E. Ruggiero (2008). Petrobactin is produced by both pathogenic and non-pathogenic isolates of the Bacillus cereus group of bacteria. Biometals 21(5): 581-589.

Lee, E. M., S. H. Ahn, J. H. Park, J. H. Lee, S. C. Ahn and I. S. Kong (2004). Identification of oligopeptide permease (opp) gene cluster in Vibrio fluvialis and characterization of biofilm production by oppA knockout mutation. FEMS Microbiology Letters 240(1): 21-30.

Lin, M. H., J. C. Shu, H. Y. Huang and Y. C. Cheng (2012). Involvement of iron in biofilm formation by Staphylococcus aureus. PloS One 7(3).

Luu-Thi, H., D. B. Khadka and C. W. Michiels (2014). Thermal inactivation parameters of spores from different phylogenetic groups of Bacillus cereus. International Journal of Food Microbiology 189: 183-188.

Majed, R., C. Faille, M. Kallassy and M. Gohar (2016). Bacillus cereus biofilms - same, only different. Frontiers in Microbiology 7.

Martin, I., M. Debarbouille, A. Klier and G. Rapoport (1989). Induction and metabolite regulation of levanase synthesis in Bacillus subtilis. Journal of Bacteriology 171(4): 1885-1892.

Mazas, M., I. Gonzalez, M. Lopez, J. Gonzalez and R. M. Sarmiento (1995). Effects of sporulation media and strain on thermal resistance of Bacillus cereus spores. International Journal of Food Science \& Technology 30(1): 71-78.

Missineo, A., A. D. Poto, J. A. Geoghegan, S. Rindi, S. Heilbronner, V. Gianotti, C. R. Arciola, T. J. Foster, P. Speziale and G. Pietrocola (2014). IsdC from Staphylococcus lugdunensis induces biofilm formation under low-iron growth conditions. Infection and Immunity 82(6): 2448-2459.

Mols, M., M. De Been, M. H. Zwietering, R. Moezelaar and T. Abee (2007). Metabolic capacity of Bacillus cereus strains ATCC 14579 and ATCC 10987 interlinked with comparative genomics. Environmental Microbiology 9(12): 2933-2944.

Morett, E. and L. Segovia (1993). The sigma 54 bacterial enhancer-binding protein family: mechanism of action and phylogenetic relationship of their functional domains. Journal of Bacteriology 175(19): 6067-6074.

Morikawa, M., S. Kagihiro, M. Haruki, K. Takano, S. Branda, R. Kolter and S. Kanaya (2006). Biofilm formation by a Bacillus subtilis strain that produces $\gamma$-polyglutamate. Microbiology 152(9): 2801-2807. 
Musk, D. J., D. A. Banko and P. J. Hergenrother (2005). Iron salts perturb biofilm formation and disrupt existing biofilms of Pseudomonas aeruginosa. Chemistry and Biology 12(7): 789-796.

Nierop Groot, M., F. Nieboer and T. Abee (2008). Enhanced transformation efficiency of recalcitrant Bacillus cereus and Bacillus weihenstephanensis isolates upon in vitro methylation of plasmid DNA. Applied and Environmental Microbiology 74(24): 7817-7820.

O'May, C. Y., K. Sanderson, L. F. Roddam, S. M. Kirov and D. W. Reid (2009). Iron-binding compounds impair Pseudomonas aeruginosa biofilm formation, especially under anaerobic conditions. Journal of Medical Microbiology 58(6): 765-773.

Ollinger, J., K. B. Song, H. Antelmann, M. Hecker and J. D. Helmann (2006). Role of the Fur regulon in iron transport in Bacillus subtilis. Journal of Bacteriology 188(10): 3664-3673.

Palmer, M. E., S. Chaturongakul, M. Wiedmann and K. J. Boor (2011). The Listeria monocytogenes $\sigma(B)$ regulon and its virulence-associated functions are inhibited by a small molecule. mBio 2(6): e00241-00211.

Palop, A., P. Mañas and S. Condón (1999). Sporulation temperature and heat resistance of Bacillus spores: A review. Journal of Food Safety 19(1): 57-72.

Patriquin, G. M., E. Banin, C. Gilmour, R. Tuchman, E. P. Greenberg and K. Poole (2008). Influence of quorum sensing and iron on twitching motility and biofilm formation in Pseudomonas aeruginosa. Journal of Bacteriology 190(2): 662-671.

Perego, M., C. F. Higgins, S. R. Pearce, M. P. Gallagher and J. A. Hoch (1991). The oligopeptide transport system of Bacillus subtilis plays a role in the initiation of sporulation. Molecular Microbiology 5(1): 173-185.

Piggot, P. J. and D. W. Hilbert (2004). Sporulation of Bacillus subtilis. Current Opinion in Microbiology 7(6): 579-586.

Planchon, S., C. Dargaignaratz, C. Levy, C. Ginies, V. Broussolle and F. Carlin (2011). Spores of Bacillus cereus strain $\mathrm{KBAB} 4$ produced at $10^{\circ} \mathrm{C}$ and $30^{\circ} \mathrm{C}$ display variations in their properties. Food Microbiology 28(2): 291-297.

Ponraj, P., M. Shankar, D. Ilakkiam and P. Gunasekaran (2012). Influence of siderophore pyoverdine synthesis and ironuptake on abiotic and biotic surface colonization of Pseudomonas putida S11. Biometals 25(6): 1113-1128.

Pratt, L. A. and R. Kolter (1999). Genetic analyses of bacterial biofilm formation. Current Opinion in Microbiology 2(6): 598-603.

Rebelo Lima, L. J. (2012). Microbial ecology of the cocoa chain : quality aspects and insight into heatresistant bacterial spores. $\mathrm{PhD}$ thesis Wageningen.

Reitzer, L. and B. L. Schneider (2001). Metabolic context and possible physiological themes of o54dependent genes in Escherichia coli. Microbiology and Molecular Biology Reviews 65(3): 422444.

Rudner, D. Z., J. R. LeDeaux, K. Ireton and A. D. Grossman (1991). The spo0K locus of Bacillus subtilis is homologous to the oligopeptide permease locus and is required for sporulation and competence. Journal of Bacteriology 173(4): 1388-1398.

Ryu, J. H. and L. R. Beuchat (2005). Biofilm formation and sporulation by Bacillus cereus on a stainless steel surface and subsequent resistance of vegetative cells and spores to chlorine, chlorine dioxide, and a peroxyacetic acid-based sanitizer. Journal of Food Protection 68(12): 2614-2622.

Setlow, B., S. Atluri, R. Kitchel, K. Koziol-Dube and P. Setlow (2006). Role of dipicolinic acid in resistance and stability of spores of Bacillus subtilis with or without DNA-protective $\alpha / \beta$-type small acid-soluble proteins. Journal of Bacteriology 188(11): 3740-3747.

Setlow, P. (2006). Spores of Bacillus subtilis: Their resistance to and killing by radiation, heat and chemicals. Journal of Applied Microbiology 101(3): 514-525.

Shaheen, R., B. Svensson, M. A. Andersson, A. Christiansson and M. Salkinoja-Salonen (2010). Persistence strategies of Bacillus cereus spores isolated from dairy silo tanks. Food Microbiology 27(3): 347-355. 
Sharma, M. and S. K. Anand (2002). Biofilms evaluation as an essential component of HACCP for food/ dairy processing industry - A case. Food Control 13(6-7): 469-477.

Simmonds, P., B. L. Mossel, T. Intaraphan and H. C. Deeth (2003). Heat resistance of Bacillus spores when adhered to stainless steel and its relationship to spore hydrophobicity. Journal of Food Protection 66(11): 2070-2075.

Singh, P. K., M. R. Parsek, E. P. Greenberg and M. J. Welsh (2002). A component of innate immunity prevents bacterial biofilm development. Nature 417(6888): 552-555.

Stevens, M. J. A., D. Molenaar, A. De Jong, W. M. De Vos and M. Kleerebezem (2010). Involvement of the mannose phosphotransferase system of Lactobacillus plantarum WCFS1 in peroxide stress tolerance. Applied and Environmental Microbiology 76(11): 3748-3752.

Studholme, D. J. and R. Dixon (2003). Domain architectures of o54-dependent transcriptional activators. Journal of Bacteriology 185(6): 1757-1767.

Tripathi, A., M. M. Schofield, G. E. Chlipala, P. J. Schultz, I. Yim, S. A. Newmister, T. D. Nusca, J. B. Scaglione, P. C. Hanna, G. Tamayo-Castillo and D. H. Sherman (2014). Baulamycins $\mathrm{A}$ and $\mathrm{B}$, broad-spectrum antibiotics identified as inhibitors of siderophore biosynthesis in Staphylococcus aureus and Bacillus anthracis. Journal of the American Chemical Society 136(4): 1579-1586.

van der Voort, M. and T. Abee (2013). Sporulation environment of emetic toxin-producing Bacillus cereus strains determines spore size, heat resistance and germination capacity. Journal of Applied Microbiology 114(4): 1201-1210.

van Gestel, J., H. Vlamakis and R. Kolter (2015). Division of Labor in Biofilms: the Ecology of Cell Differentiation. Microbiology Spectrum 3(2).

Veening, J. W., O. P. Kuipers, S. Brul, K. J. Hellingwerf and R. Kort (2006). Effects of phosphorelay perturbations on architecture, sporulation, and spore resistance in biofilms of Bacillus subtilis. Journal of Bacteriology 188(8): 3099-3109.

Verplaetse, E., L. Slamti, M. Gohar and D. Lereclus (2015). Cell differentiation in a Bacillus thuringiensis population during planktonic growth, biofilm formation, and host infection. mBio 6(3).

Verplaetse, E., L. Slamti, M. Gohar and D. Lereclus (2016). Two distinct pathways lead Bacillus thuringiensis to commit to sporulation in biofilm. Research in Microbiology.

Vilain, S., J. M. Pretorius, J. Theron and V. S. Brözel (2009). DNA as an adhesin: Bacillus cereus requires extracellular DNA to form biofilms. Applied and Environmental Microbiology 75(9): 2861-2868.

Visaggio, D., M. Pasqua, C. Bonchi, V. Kaever, P. Visca and F. Imperi (2015). Cell aggregation promotes pyoverdine-dependent iron uptake and virulence in Pseudomonas aeruginosa. Frontiers in Microbiology 6(AUG).

Vlamakis, H., Y. Chai, P. Beauregard, R. Losick and R. Kolter (2013). Sticking together: building a biofilm the Bacillus subtilis way. Nature Reviews Microbiology 11(3): 157-168.

Warda, A. K., R. J. Siezen, J. Boekhorst, M. H. J. Wells-Bennik, A. De Jong, O. P. Kuipers, M. N. Nierop Groot and T. Abee (2016). Linking Bacillus cereus genotypes and carbohydrate utilization capacity. PloS One 11(6): e0156796.

Wiegeshoff, F., C. L. Beckering, M. Debarbouille and M. A. Marahiel (2006). Sigma L is important for cold shock adaptation of Bacillus subtilis. Journal of Bacteriology 188(8): 3130-3133.

Wilson, M. K., R. J. Abergel, K. N. Raymond, J. E. Arceneaux and B. R. Byers (2006). Siderophores of Bacillus anthracis, Bacillus cereus, and Bacillus thuringiensis. Biochemical and Biophysical Research Communications 348(1): 320-325.

Wolfe, A. J., D. S. Millikan, J. M. Campbell and K. L. Visick (2004). Vibrio fischeri o54 controls motility, biofilm formation, luminescence and colonization. Applied and Environmental Microbiology 70(4): 2520-2524. 
Xu, S. Y., R. L. Nugent, J. Ksmkttil, A. Fomenkov, Y. Gupta, A. Aggarwal, X. Wang, Z. Li, Y. Zheng and R. Morgan (2012). Characterization of type II and III restriction-modification systems from Bacillus cereus strains ATCC 10987 and ATCC 14579. Journal of Bacteriology 194(1): 49-60.

Yamamoto, K., H. Arai, M. Ishii and Y. Igarashi (2011). Trade-off between oxygen and iron acquisition in bacterial cells at the air-liquid interface. FEMS Microbiology Ecology 77: 83-94.

Yang, L., K. B. Barken, M. E. Skindersoe, A. B. Christensen, M. Givskov and T. Tolker-Nielsen (2007). Effects of iron on DNA release and biofilm development by Pseudomonas aeruginosa. Microbiology 153(5): 1318-1328.

Yang, Y., V. C. Darbari, N. Zhang, D. Lu, R. Glyde, Y. P. Wang, J. T. Winkelman, R. L. Gourse, K. S. Murakami, M. Buck and X. Zhang (2015). TRANSCRIPTION. Structures of the RNA polymerase-sigma54 reveal new and conserved regulatory strategies. Science 349(6250): 882885.

Zafra, O., M. Lamprecht-Grandío, C. G. de Figueras and J. E. González-Pastor (2012). Extracellular DNA release by undomesticated Bacillus subtilis is regulated by early competence. PloS One 7(11).

Zawadzka, A. M., Y. Kim, N. Maltseva, R. Nichiporuk, Y. Fan, A. Joachimiak and K. N. Raymond (2009). Characterization of a Bacillus subtilis transporter for petrobactin, an anthrax stealth siderophore. Proceedings of the National Academy of Sciences of the United States of America 106(51): 21854-21859.

Zhang, L., Z. Zhu, H. Jing, J. Zhang, Y. Xiong, M. Yan, S. Gao, L. F. Wu, J. Xu and B. Kan (2009). Pleiotropic effects of the twin-arginine translocation system on biofilm formation, colonization, and virulence in Vibrio cholerae. BMC Microbiology 9.

Zhao, Y., M. P. M. Caspers, K. I. Metselaar, P. de Boer, G. Roeselers, R. Moezelaar, M. Nierop Groot, R. C. Montijn, T. Abee and R. Kort (2013). Abiotic and microbiotic factors controlling biofilm formation by thermophilic sporeformers. Applied and Environmental Microbiology 79(18): 5652-5660. 
Summary

Acknowledgements

About the author

List of publications

Overview of training activities 



\section{Summary}

The biofilm growth mode is a common multicellular lifestyle of single cell microorganisms. This way of growth provides several advantages, such as efficient task division, protection against harsh conditions and disinfectants. In this way microorganisms including food-borne pathogens, can persist in environments such as food production plants, hospital premises or the human host, where their presence is not desirable. B. cereus is a spore-forming gram positive pathogen able to form such biofilms. It is notorious for causing spoilage of dairy products and two types of foodborne illness: emetic and diarrheal. In rare cases it can also cause more serious systemic infections.

Different aspects of $B$. cereus biofilm formation were studied in this thesis. In order to prevent formation of $B$. cereus biofilms it is important to improve our understanding of its biofilm life cycle including (a)biotic factors that affect this process. Notably, specific surface materials such as stainless steel that is commonly present in industrial environments were found to promote biofilm formation of $B$. cereus. Strain diversity in biofilm formation on stainless steel and polystyrene was studied by inclusion of two reference strains and 20 undomesticated food isolates. Strikingly, all strains tested showed highest biofilm formation capacity on stainless steel suggesting that this capacity may contribute to persistence in food processing environments. Since stainless steel is composed of metals including iron, the impact of the latter compound on B. cereus growth and biofilm formation was also studied.

The presence/absence of genes encoding iron transporters was analysed in 22 different $B$. cereus strains. For around $70 \%$ of the strains, the iron transport potential predicted based on the gene content corresponded to the ability to grow on different (complex) iron sources. Most preferred complex iron sources for growth were ferric citrate, hemoglobin and hemin, and the least preferred sources were transferrin, ferritin and lactoferrin. These sources differently affected biofilm formation of the strains. For example, ferric citrate promoted the air-liquid interface biofilm formation, while compounds like hemin and lactoferrin triggered submerged biofilm formation, pointing at different mechanisms involved. Different sources of available iron may play a role in growth and survival of $B$. cereus and for example other foodborne pathogens in food processing environments and the human host.

Another highly relevant aspect is the capacity of B. cereus to form spores inside biofilms. Environmental conditions are known to influence spore properties. Similarly, a biofilm environment, especially on stainless steel triggered production of $B$. cereus spores with higher heat resistance compared to planktonic spores. Drying of the biofilms by exposure to air accelerated spore formation resulting in some cases in spores with lower heat resistance. 
Biofilm formation is a multistep process which is directly and indirectly regulated by several factors and among these, Sigma factor 54 was predicted to play a central role in the modulation of the cell exterior affecting interactions with the extracellular environment including biofilm formation. To understand mechanisms of this involvement and in general the role of Sigma 54 in B. cereus a deletion mutant was constructed and studied in detail for a range of functionalities. This analysis revealed a pleiotropic role for this sigma factor in processes important for adaptation in different environments, such as motility and biofilm formation, growth with low oxygen availability or at low temperature, as well as carbohydrate utilisation. These roles were identified based on a combination of phenotypic data and gene expression data using DNA microarrays obtained for the WT and the mutant, as well as an in silico inventory of putative genes under control of this sigma factor (based on the so-called Sigma 54 binding box) in the genome of $B$. cereus ATCC 14579.

In conclusion, this thesis provides more insight in factors influencing biofilm formation by $B$. cereus, a foodborne pathogen commonly present in the environment. Furthermore, factors affecting sporulation and biofilm-derived spore properties are discussed. The obtained knowledge may be useful in preventing or eradicating biofilm-supported domestication of this microorganism in production environments and associated contamination of foods resulting in lower food spoilage and safety risks. 


\section{Acknowledgements}

There have been several periods in my life, which upon ending made me wonder whether it was not the best one? The PhD was certainly one of those phases. I greatly enjoyed it and grew both professionally and personally. This was also thanks to the people surrounding me.

First of all it wouldn't be possible without my promotor and co-promotor, Tjakko and Masja. Thank you for your trust in me as a PhD student. Thank you for your commitment and guidance, for your knowledge and support. I learnt a lot from you. Thank you for your sharp eye, from which no mistake in the manuscript could ever escape. Thank you Tjakko for your creativity and interesting ideas. Thank you Masja for your patience too look at the $1^{\text {st }}$ versions of all my presentations and drafts. Thanks to both of you for your efforts to develop my "helicopter view", I am sorry I might have disappointed you in this. I hope to achieve this learning goal at my new job with your help Masja, since we will continue to work together, for which I am very happy.

I express my sincere gratitude to my Committee members: Prof. Dr Michiel Kleerebezem, Prof. Dr Remco Kort, Dr Emilia Ghelardi and Prof. Dr Ole A.L. Økstad. Thank you for all your time and effort for reviewing my thesis and for being present at my defence.

Dear colleagues from the Laboratory of Food Microbiology (FHM), thank you all for being there and for creating such a good atmosphere.

My dear officemates Monica, Karin and Alicja (Alicja you "disturbed" us so often that I have a feeling that you were also in the same office, for which I am very happy). To the three of you I want to thank particularly, for your friendship and support during the PhD and beyond. I will cherish all the time spent with you either in the lab, or at breaks, in The Netherlands and outside, all the places we went together. All these experiences we also shared with Maciek and Diah (the kindest person in the world). I hope that we will keep our connection for long and good. Special thanks to Karin and Monica also for being my paranimphs.

Dear Greetje, Irma, Ioanna, Paula, Judith, Gerda and Ingrid, you were all a part of the biofilm we created at the Food Microbiology, with your specific roles in it. Each of you was indispensable in your own place. I am happy that you were there.

My students Lisette, Cindy and Jorge, thank you for your hard work and for your trust in me as your supervisor. It was a great experience working with each of you, with your very different personalities and approaches, which also have taught me a lot for becoming a better supervisor. Hopefully we mutually benefited from each 
other. Wish you lots of success in your future career and personal life.

I want to thank all the people at TIFN, particularly the Food Safety and Preservation Theme. I thank all scientific and industrial members for the fruitful discussions during the meetings, and especially Jos and Roland for BioIT support.

My new colleagues at WFBR (Food and Biobased Research), thank you for your warm welcome and your moral support for finishing my thesis.

My dear Armenian "community" friends: Lusine, Gohar and Emma. Thanks for your friendship and for creating a small and cosy environment during all these years, where we could share experiences, have fun and support each other.

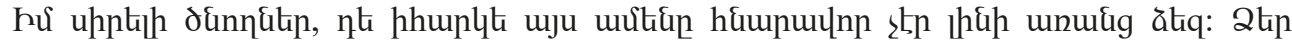

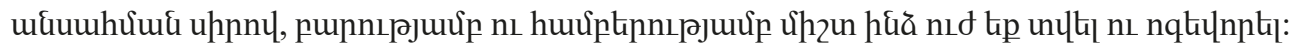

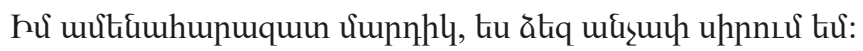

My dear Armen, you have given me unconditional love and support, which helped me immensely during this $\mathrm{PhD}$. Thanks for believing in me and for always being there for me throughout ups and downs of my life.

\section{Hasmik}




\section{About the author}

Hasmik Hayrapetyan was born on $9^{\text {th }}$ of August, 1983 in Yerevan, Armenia. Since high school she was interested in biology and how things work in nature, which is why she went to study at the faculty of Biology at Yerevan State Univerity. For her Master at the same university she shifted her interest into a more applied science, Food Science. After working for some time at a fruit and vegetable processing company she got an opportunity to come to Wageningen to do a Master in Food Safety in 2007. This is when she developed into a typical nerd (even more than before) and graduated it with honour. During the Master she did her thesis at Food Microbiology on the topic of Inhibition on Listeria monocytogenes by pomegranate extract. During her internship at World Health Organisation in Geneva, Switzerland, she learnt how food safety issues are managed on an international level. Another internship as a Food Valley Ambassador followed at the company Corbion in Gorinchem, The Netherlands, where Hasmik was working on applications of bacteriocin based natural antimicrobials. This great experience continued with a few months of employment at the same company after which she started her $\mathrm{PhD}$ program at Wageningen University, Food Microbiology Lab. Her project was entitled "Bacillus cereus biofilms" leaving space for imagination and freedom for discoveries. The results of this work are described in this thesis. Currently Hasmik is working as a scientist at Wageningen Food and Biobased Research institute (WFBR). 


\section{List of publications}

H. Hayrapetyan, L. Muller, M. Tempelaars, T. Abee, M. Nierop Groot. 2015. Comparative analysis of biofilm formation by Bacillus cereus reference strains and undomesticated food isolates and the effect of free iron. International Journal of Food Microbiology, 200: 72-79.

H. Hayrapetyan , R. Siezen, T. Abee, M. Nierop Groot. 2016. Comparative genomics of iron-transporting systems in Bacillus cereus strains and impact of iron sources on growth and biofilm formation. Frontiers in Microbiology, 7:842.

H. Hayrapetyan , T. Abee, M. Nierop Groot. 2015. Sporulation dynamics and spore heat resistance in wet and dry biofilms of Bacillus cereus. Food Control, 60: 493-499.

H. Hayrapetyan, M. Tempelaars, M. Nierop Groot, T. Abee. 2016. Bacillus cereus ATCC 14579 RpoN (Sigma 54) is a pleiotropic regulator of growth, carbohydrate metabolism, motility, biofilm formation and toxin production. PLoS ONE, 10(8): e0134872.

H. Hayrapetyan, J. Boekhorst, A. de Jong, O. P. Kuipers, M. N. Nierop Groot, T. Abee. 2016. Draft whole-genome sequences of 11 Bacillus cereus food isolates. Genome Announcements, 4(3):e00485-16. doi:10.1128/genomeA.00485-16. 


\section{Overview of completed training activities}

Discipline specific activities

\section{Courses}

Management of Microbiological Hazards in Foods

VLAG, Wageningen 2011

Advanced visualisation, integration and

biological interpretation of -omics data

Phenolink introduction

Hand-on BioIT training

Genetics and physiology of food-associated

micro-organisms

Confocal Laser Scanning Microscopy training

VLAG, Wageningen 2011

TIFN/CMBI, Nijmegen 2012

TIFN/CMBI, Nijmegen 2012

VLAG, Wageningen 2013

WUR, Wageningen 2013

\section{Conferences}

Biofilm 6 ASM, poster presentation

Miami, US

2012

IAFP European symposium, oral presentation

Marseille, France

2013

Biofilms 6 Microbiology society, oral

presentation

Vienna, Austria

2014

6th Congress of European Microbiologists,

FEMS, poster presentation

Maastricht, The

Netherlands

2015

\section{General courses}

Information Literacy and EndNote

WUR, Wageningen 2011

Project and Time Management

WGS, Wageningen 2011

PhD week

VLAG, Wageningen 2011

Advanced course guide to scientific artwork

WUR, Wageningen 2012

IP-Intellectual property introduction

TIFN, Wageningen 2012

Basic statistics

PE\&RC, Wageningen 2014

\section{Other activities}

Organisation of PhD trip to Japan

PhD trip to Japan

PhD trip to Ireland

Food Microbiology department seminars

TIFN expert meetings

$\begin{array}{ll}\text { FHM, Wageningen } & 2011 \\ \text { FHM, Wageningen } & 2012 \\ \text { FHM, Wageningen } & 2014 \\ \text { FHM, Wageningen } & 2011-2014 \\ \text { TIFN, Wageningen } & 2011-2014\end{array}$


The studies presented in this thesis were performed within the framework of TI Food and Nutrition.

Financial support from Wageningen University for printing this thesis is gratefully acknowledged.

Cover design: Hasmik Hayrapetyan, Armen Takgyozyan, with licenced material from www.123rf.com, author Baloncici, Stock Photo.

Layout: Iliana Boshoven-Gkini | AgileColor.com

Printing by: Ridderprint, Ridderkerk (NL) | Ridderprint.nl 
